\title{
ALGUNS ASPECTOS DOS EFEITOS DA INTERAÇÃO SOLO - ESTRUTURA EM EDIFÍCIOS DE MÚLTIPLOS ANDARES COM FUNDAÇÃO PROFUNDA
}

\section{Roberto Kunihiro Iwamoto}

Dissertação apresentada à Escola de Engenharia de São Carlos da Universidade de São Paulo, como parte dos requisitos para obtenção do Título de Mestre em Engenharia de Estruturas

ORIENTADORA: Prof ${ }^{\mathrm{a}}$ Dr $^{\mathrm{a}}$ Helena M. C. Carmo Antunes

São Carlos

2000 
Aos meus pais

\section{Hayao e Kazuko}




\section{AGRADECIMENTOS}

À professora Helena M. C. Carmo Antunes pela escolha do tema, a orientação segura e objetiva durante a elaboração deste trabalho.

Ao professor Nelson Aoki pelas preciosas colaborações e amizade.

Aos colegas Carlos H. Martins e Edgard Sousa Junior pelas sugestões importantes durante o desenvolvimento do programa computacional.

Ao Roberto M. Urioste pelo desenvolvimento da interface em Visual Basic.

Aos colegas da turma Gerson M. S. Alva, Valentim C. Netto, Rodrigo A. Neves, Patrícia L. Oliveira, Yuri I. Maggi, Alio E. Kimura, Patrícia D. Garcia, Palmira C. Barbosa, Eduardo A. B. Aguiar, Ana C. Oliveira, Rejane M. Fernandes, George M. Maranhão e Marcelo Greco, pelo convívio, troca de conhecimentos e a amizade.

Aos professores, funcionários e amigos do Departamento de Estruturas da Escola de Engenharia de São Carlos, pela amizade e dos momentos de descontração.

Aos professores e colegas da Fundação Universidade do Amazonas, pelo incentivo.

A todos que, direta ou indiretamente, contribuíram para a realização deste trabalho.

À CAPES - Fundação Coordenação de Aperfeiçoamento de Pessoal de Nível Superior - pela bolsa de estudo concedida. 


\section{SUMÁRIO}

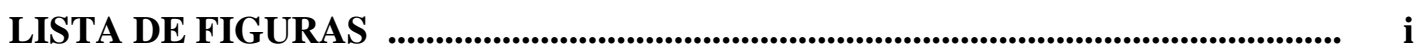

LISTA DE TABELAS .................................................................................................................. iv

LISTA DE ABREVIATURAS E SIGLAS _..................................................................... iv

LISTA DE SÍMBOLOS ….................................................................................... v

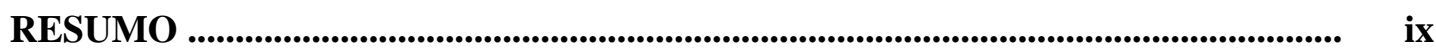

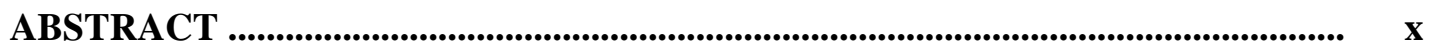

$1 \quad$ INTRODUÇÃ

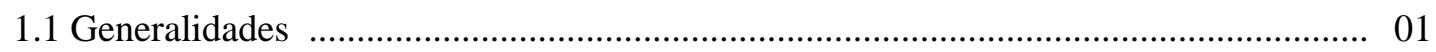

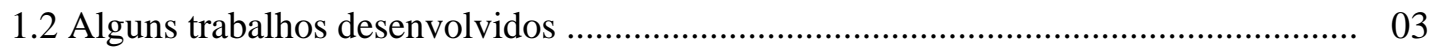

1.2.1 Modelos desenvolvidos ........................................................................ 03

1.2.2 Efeitos da interação solo - estrutura ...................................................... 06

1.2.2.1 Influência do tempo ........................................................................ 06

1.2.2.2 Influência da rigidez da estrutura ………........................................... 07

1.2.2.3 Influência do processo construtivo ................................................. 10

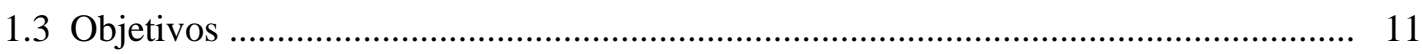

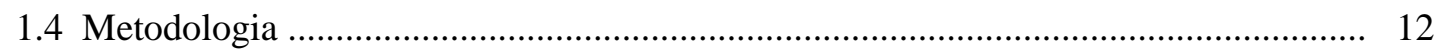

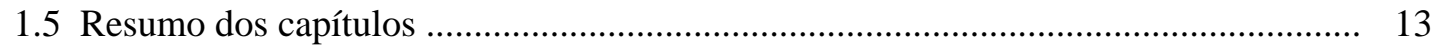

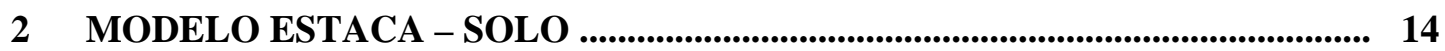

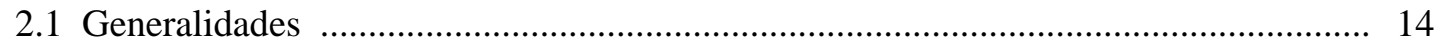

2.2 Métodos de previsão de recalques ....................................................................... 15

2.2.1 Métodos teóricos simplificados ................................................................. 15

2.2.2 Métodos que consideram efeitos da interação solo - estaca ............................. 16

2.2.2.1 Métodos que empregam fatores de interação ....................................... 16 
2.3 Mecanismos de transferência de carga em sistema estaca - solo ............................. 20

2.4 Modelo de estimativa de recalques nas fundações profundas ................................... 23

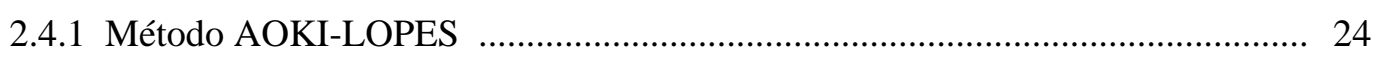

2.4.1.1 Solução de MINDLIN ........................................................................ 26

2.4.1.2 Simplificação de STEINBRENNER ................................................ 28

2.4.1.3 Consideração do contato bloco diretamente no solo .............................. 30

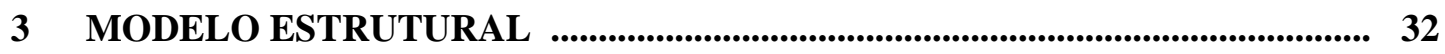

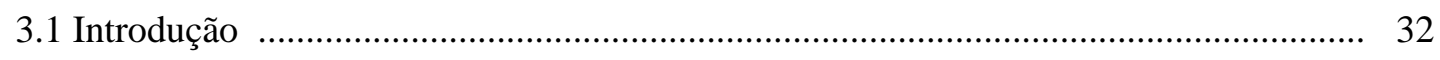

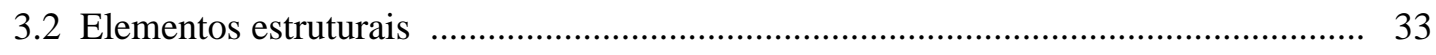

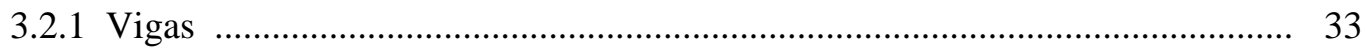

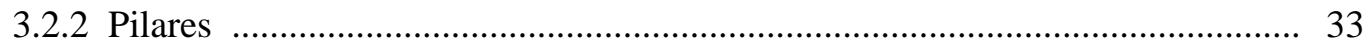

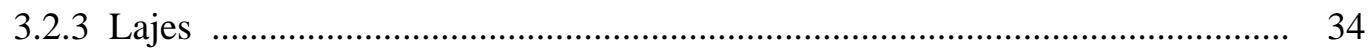

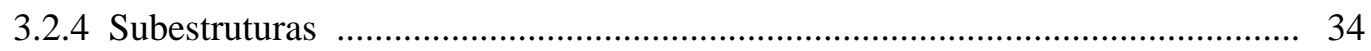

3.3 Sistema de referência …………........................................................................ 35

3.3.1 Sistema de referência global ……............................................................ 35

3.3.2 Sistema de referência local das vigas …….............................................. 35

3.3.3 Sistema de referência das lajes ……………............................................. 36

3.3.4 Sistema de referência dos pilares ………….............................................. 36

3.3.5 Sistema de referência da subestrutura …................................................... 37

3.4 Sistema de coordenadas dos elementos estruturais …........................................... 37

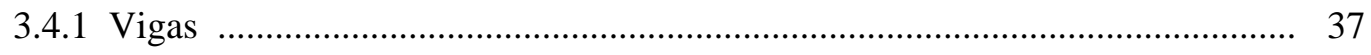

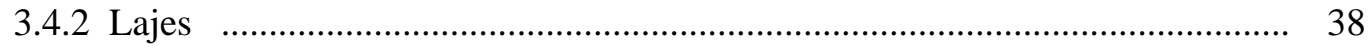

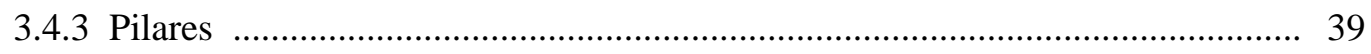




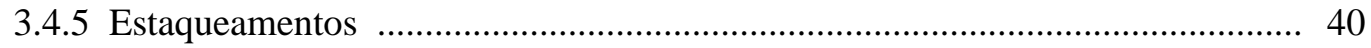

3.5 Obtenção do elemento finito quadrangular a partir dos triangulares ......................... 41

3.6 Contribuição dos pilares à rigidez da subestrutura ................................................. 42

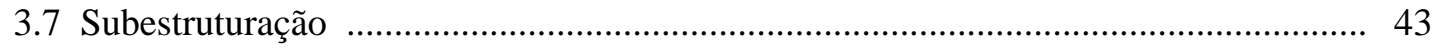

3.7.1 Subestruturação em paralelo ...................................................................... 43

3.7.2 Subestruturação em série ......................................................................... 44

3.8 Esforços solicitantes nos elementos estruturais .................................................... 46

4 INTERAÇÃO SOLO - ESTRUTURA _...............................................................4 47

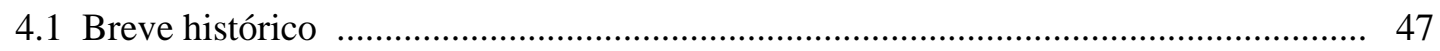

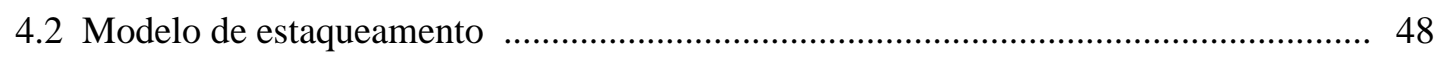

4.3 Consideração da rigidez da estrutura nos recalques .............................................. 53

4.4 Recalques admissíveis ………...................................................................... 55

4.5 Edifícios de múltiplos andares e tipos de fundações …………................................ 58

5 PROGRAMA COMPUTACIONAL _.............................................................60

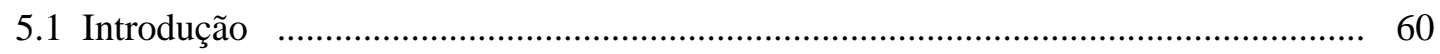

5.2 Modularização do programa computacional ....................................................... 61

5.3 Adaptação do Workspace SERIE .................................................................... 62

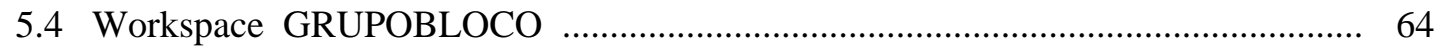

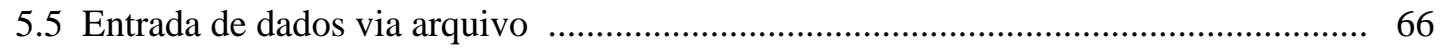

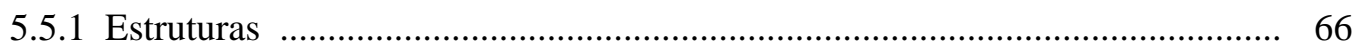

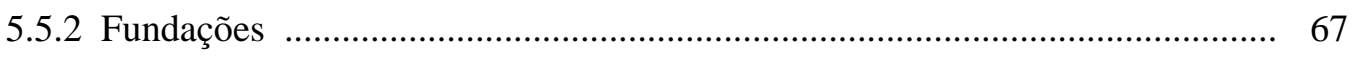

5.5.2.1 Dados de bloco de coroamento .................................................... 67

5.5.2.2 Dados de grupo de estacas ………………..................................... 67 
5.6 Entrada de dados via interface em Visual Basic

5.7 Saída de dados no WordPad .............................................................................. 72

5.7.1 Saída de resultados da estrutura …..................................................... 72

5.7.2 Saída de resultados dos elementos estruturais de fundações ..................... 72

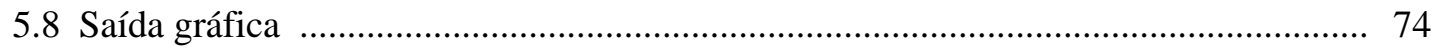

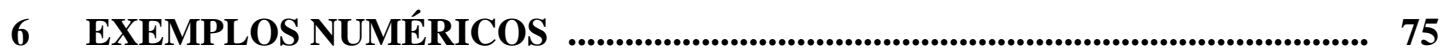

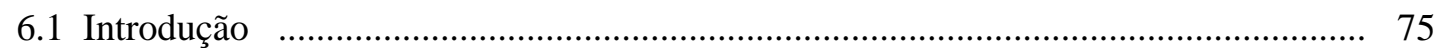

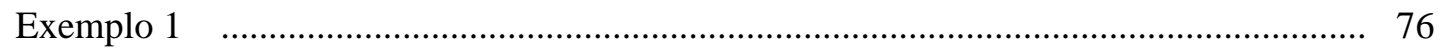

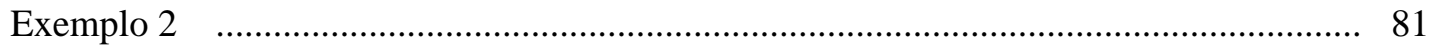

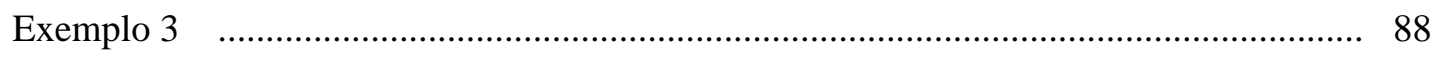

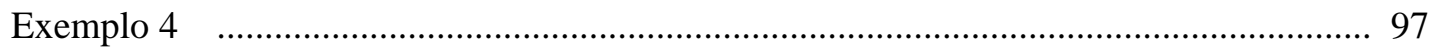

7 CONCLUSÕES

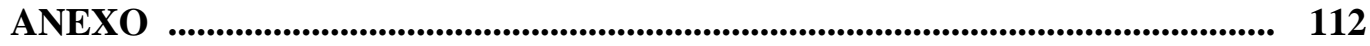

REFERÊNCIAS BIBLIOGRÁFICAS _.................................................................. 127

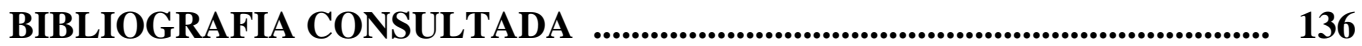




\section{LISTA DE FIGURAS}

Figura 1.1 - Sistema de referência do indeslocável ........................................................ 02

Figura 1.2 - Sistema superestrutura e o sistema elementos de fundações + solo ............... 04

Figura 1.3 - Casos de interação solo - estrutura ........................................................... 06

Figura 1.4 - Analogia da viga - parede …………..................................................... 07

Figura 1.5 - Efeitos de interação ............................................................................... 08

Figura 1.6 - Efeitos da seqüência construtiva _...................................................... 10

Figura 1.7 - Simulação da seqüência construtiva .......................................................... 11

Figura 2.1 - Área plana do grupo de estacas .......................................................... 15

Figura 2.2 - Diagrama de ruptura do contato estaca - solo .......................................... 21

Figura 2.3 - Modelo de transferência de carga ……........................................................ 22

Figura 2.4 - Divisão da base em $\mathrm{n}_{1} \mathrm{x} \mathrm{n}_{2}$ sub-áreas ...................................................... 24

Figura 2.5 - Divisão do fuste da estaca em $\mathrm{n}_{1} \mathrm{x}_{3}$ sub-áreas .......................................... 25

Figura 2.6 - Meio elástico semi - infinito ……............................................................. 26

Figura 2.7 - Sistema estaticamente equivalente de cargas ............................................. 27

Figura 2.8 - Procedimento de Steinnbrenner ……...................................................... 28

Figura 2.9 - Procedimento de Steinnbrenner para estacas .............................................. 29

Figura 2.10 - Contribuição do bloco ..................................................................... 30

Figura 2.11- Seção retangular ................................................................................. 31

Figura 3.1 - Excentricidade da viga i em relação ao C.G do pilar ................................... 33

Figura 3.2 - Excentricidade laje - viga ……….......................................................... 34

Figura 3.3 - Sistema de referência global ………...................................................... 35

Figura 3.4 - Sistema de referência local das vigas ..................................................... . 35

Figura 3.5 - Sistema de referência das lajes ............................................................ 36

Figura 3.6 - Sistema de referência local dos pilares ..................................................... 36

Figura 3.7 - Sistema de referência da subestrutura .................................................... 37

Figura 3.8 - Coordenadas deslocamentos locais de viga ........................................... 37

Figura 3.9 - Coordenadas deslocamentos de corpo rígido no plano horizontal da laje ..... 38

Figura 3.10 - Coordenadas deslocamentos de placa DKT ............................................... 38

Figura 3.11 - Coordenadas deslocamentos locais de pilar ................................................. 39

Figura 3.12 - Coordenadas deslocamentos do nó do pilar na subestrutura ......................... 39

Figura 3.13 - Coordenadas deslocamentos do bloco e estaca $\quad$.......................................... 40

Figura 3.14 - Elemento quadrangular .................................................................. 41 
Figura 3.15 - Subestruturação em paralelo .................................................................. 43

Figura 3.16 - Subestruturação em série ................................................................. 46

Figura 4.1 - Sistema de referência e coordenadas do bloco ............................................. 48

Figura 4.2 - Sistema de referência da estaca i ................................................................ 48

Figura 4.3 - Hipótese do Schiel ............................................................................... 49

Figura 4.4 - Modelo mais realista ………............................................................... 49

Figura 4.5 - Diagrama de transferência de atrito lateral e de ponta ............................... 51

Figura 4.6 - Engastamento perfeito nos apoios ........................................................... 53

Figura 4.7 - Imposição das rigidezes $\mathrm{K}_{\mathrm{i}}$ nos apoios ..................................................... 53

Figura 4.8 - Cargas aplicadas e recalques no bloco ...................................................... 53

Figura 4.9 - Distorção angular limite ..................................................................... 56

Figura 4.10 - Tipo de fundação segundo o porte dos prédios para toda

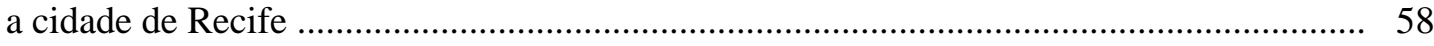

Figura 4.11 - Tipo de fundação segundo a porte dos prédios para o eixo sul da cidade ..... 58

Figura 4.12 - Tipo de fundação segundo o porte dos prédios para o eixo

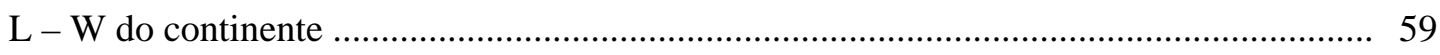

Figura 5.1 - Trapézio do atrito lateral entre a estaca e o solo ........................................ 67

Figura 5.2 - Tela de apresentação .............................................................................. 68

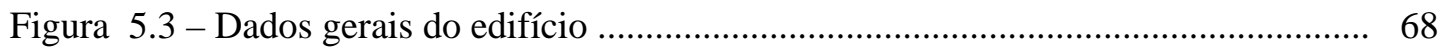

Figura 5.4 - Menu principal de entrada de dados ............................................................ 69

Figura 5.5 - Menu de dados gerais da estrutura ………................................................ 69

Figura 5.6 - Menu opção de entrada de dados ............................................................. 70

Figura 5.7 - Menu características do solo ................................................................. 70

Figura 5.8 - Menu entrada de dados de estaqueamento ............................................... 71

Figura 5.9 - Menu grupo de estacas e atrito lateral máximo ........................................... 71

Figura 5.10 - Menu opção para saída de dados no WordPad ............................................ 72

Figura 5.11 - Saída de dados no WordPad ................................................................. 73

Figura 5.13 - Saída gráfica tridimensional da estrutura ……………............................. 74

Figura 6.1 - Diagrama de ruptura ……………...................................................... 78

Figura 6.2 - Diagrama de ruptura ajustado ………....................................................... 78

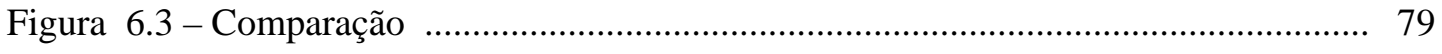

Figura 6.4 - Movimento do bloco rígido ……….................................................... 80

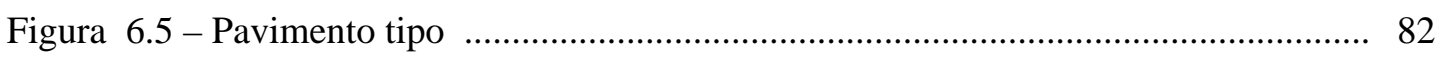

Figura 6.6 - Pavimento base .............................................................................. 82

Figura 6.7 - Diagrama de atrito lateral acumulado e local ............................................. 83 


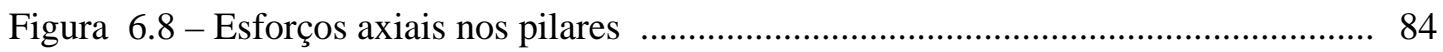

Figura 6.9 - Momentos fletores nos pilares em torno do eixo y ………….................... 85

Figura 6.10 - Esforços nas vigas ………………................................................... 86

Figura 6.11 - Ação do vento no edifício .................................................................... 88

Figura 6.12 - Planta baixa do pavimento tipo ……................................................ 89

Figura 6.13 - Planta baixa do pavimento base ….................................................. 89

Figura 6.14 - Reações verticais nos apoios ............................................................. 90

Figura 6.15 - Momentos fletores nos apoios na direção Y ............................................... 91

Figura 6.16 - Deslocamentos horizontais ..................................................................... 92

Figura 6.17 - Momentos fletores nos pilares .............................................................. 92

Figura 6.18 - Esforços cortantes nas vigas .................................................................. 93

Figura 6.19 - Momentos fletores nas vigas ………........................................................ 94

Figura 6.20 - Esforços axiais nos pilares .................................................................... 95

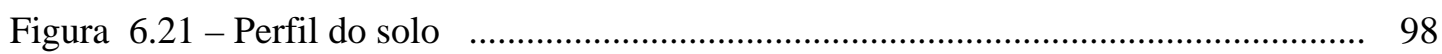

Figura 6.22 - Redução do contato fuste - solo ............................................................ 99

Figura 6.23 - Pavimento tipo ................................................................................. 101

Figura 6.24 - Pavimento tipo discretizado em elementos finitos DKT _.......................... 101

Figura 6.25 - Pavimento térreo ………………......................................................... 102

Figura 6.26 - Primeiro pavimento ........................................................................ 102

Figura 6.27 - Pavimento cobertura ………………................................................. 103

Figura 6.28 - Esquema geral do edifício ...................................................................... 103

Figura 6.29 - Planta baixa dos tubulões $\quad$...................................................................... 104

Figura 6.30 - Deformada dos recalques ................................................................ 105

Figura 6.31 - Deformada dos recalques ................................................................. 106 


\section{LISTA DE TABELAS}

Tabela 2.1 - Características do solo e tipo de estacas ……........................................... 20

Tabela 4.1 - Resumo das soluções de fundações levantadas no Recife ............................ 58

Tabela 6.1 - Características do solo ............................................................................ 76

Tabela 6.2 - Resistência na base e do fuste ............................................................... 77

Tabela 6.3 - Ação horizontal do vento ..................................................................... 81

Tabela 6.4 - Comparação nas reações e recalques ......................................................... 87

Tabela 6.5 - Comparação entre considerar ou não a interação solo - estrutura ................. 95

Tabela 6.6 - Camada de solo ........................................................................................ 99

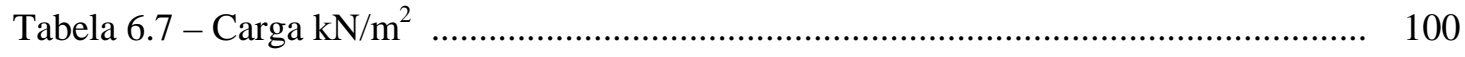

Tabela 6.8 - Dimensões dos pilares e tubulões ............................................................... 104

Tabela 6.9 - Recalques estimados e recalques medidos ................................................ 107

\section{LISTA DE ABREVIATURAS E SIGLAS}

EESC: Escola de Engenharia de São Carlos

C.G .: Centro de gravidade

CPT: Cone Penetration Test (ensaio de penetração de cone)

DKT: Discrete Kirchhoff Theory

SPT: Standart Penetration Test

USP: Universidade de São Paulo 


\section{LISTA DE SÍMBOLOS}

\section{Romanos}

A : Área da seção da estaca

$\mathrm{B}$ : ponto onde se quer calcular o recalque

C : distância entre o nível da base da estaca e a camada indeslocável, antes do carregamento

$\mathrm{c}_{\mathrm{K}}$ : Profundidade onde atua a carga $\mathrm{P}_{\mathrm{i}, \mathrm{k}}$

$\mathrm{D}_{1}$ : Profundidade superior do trecho da estaca em estudo

$\mathrm{D}_{2}$ : Profundidade inferior do trecho da estaca em estudo

E : módulo de elasticidade da estaca

$\mathrm{E}_{\mathrm{yi}}$ : excentricidade da viga i no eixo y

$\mathrm{E}_{\mathrm{zi}}$ : excentricidade da viga i no eixo $\mathrm{z}$

$\mathrm{E}_{\mathrm{s}}$ : módulo de deformabilidade do solo

$\mathrm{f}_{1}$ : Atrito / unidade de comprimento na profundidade $\mathrm{D}_{1}$ do trecho da estaca

$\mathrm{f}_{2}$ : Atrito / unidade de comprimento na profundidade $\mathrm{D}_{2}$ do trecho da estaca

F1 e F2 : Fatores construtivos da estaca

fs : resistência lateral medida na luva de Bengemann do CPT

$\mathrm{H}_{\mathrm{X}}, \mathrm{H}_{\mathrm{Y}}, \mathrm{H}_{\mathrm{Z}}, \mathrm{M}_{\mathrm{X}}, \mathrm{M}_{\mathrm{Y}}, \mathrm{M}_{\mathrm{Z}}$ : Cargas atuantes no bloco de coroamento

$\mathrm{Hx}_{\mathrm{k}}, \mathrm{Hy}_{\mathrm{k}}, \mathrm{Hz}_{\mathrm{k}}, \mathrm{Mx}_{\mathrm{k}}, \mathrm{My}_{\mathrm{k}}, \mathrm{Mz}_{\mathrm{k}}$ : Cargas atuantes no bloco de coroamento $\mathrm{k}$

i , j : índices para indicar a posição de cada sub-área

$\mathrm{K}$ : coeficiente característica do solo em MPa

$\mathrm{k}$ : índice do bloco

L : comprimento da estaca, antes do carregamento

$\mathrm{n}_{1}$ : Número de divisões na circunferência da estaca

$\mathrm{n}_{2}$ : Número de divisões no raio da base da estaca

$\mathrm{n}_{3}$ : Número de divisões no trecho do fuste da estaca, entre as profundidades $\mathrm{D}_{2}-\mathrm{D}_{1}$

$\mathrm{N}_{\mathrm{i}}$ : esforço axial na estaca $\mathrm{i}$

$\mathrm{N}_{\mathrm{o}}(\mathrm{z})$ : Esforço normal na profundidade $\mathrm{z}$ da estaca

$\mathrm{O}_{\mathrm{G}}$ : Origem do sistema de referência dos eixos globais

$\mathrm{O}_{\mathrm{L}}$ : Origem do sistema de referência dos pavimentos

$\mathrm{P}_{\mathrm{b}}$ : Carga atuante na base da estaca

$\mathrm{P}_{\mathrm{i}}$ : Força unitária no eixo da estaca $\mathrm{i}$

$P_{i, j}$ : Força pontual aplicado na sub-área na base da estaca

$P_{i, k}$ : Força pontual aplicado na sub-área no fuste da estaca 
$\mathrm{Pl}$ : Carga lateral de atrito acumulado no fuste da estaca

PL : Carga de ruptura lateral no fuste da estaca - solo

Pp : Carga na base da estaca

PP : Carga de ruptura na base da estaca - solo

PR : Carga de ruptura entre estaca - solo

qc : resistência de ponta no ensaio CPT

$\mathrm{Q}(\mathrm{z})$ : Atrito lateral local ( força / unidade de comprimento )

$\mathrm{r}$ : recalque de uma superfície

r' : recalque de uma massa semi - infinita ao nível da aplicação da carga

r": recalque de uma massa semi - infinita na profundidade onde existe o "indeformável"

$\mathrm{r}_{\mathrm{z}}$ : recalque na profundidade $\mathrm{z}$

$\mathrm{r}_{\ell}$ : resistência do solo no atrito lateral

$r_{p}$ : resistência do solo na base da estaca

$\mathrm{R}_{\mathrm{b}}$ : raio na base da estaca

$\mathrm{R}_{\mathrm{s}}$ : raio no fuste da estaca

$R_{\mathrm{i}}$ : distância projetada entre os pontos de aplicação de carga $P_{i, k}$ e o ponto $B$

$R_{i, j}$ : distância projetada entre os pontos de aplicação de carga $P_{i, j}$ e o ponto $B$

$R_{0}$ : distância projetada entre o centro da base da estaca e o ponto $B$

$R_{1}$ : distância no espaço, entre o ponto de aplicação de carga $P$ e o ponto $B$

$\mathrm{R}_{2}$ : distância no espaço, entre o ponto distante $2 \mathrm{c}$ de aplicação de carga $\mathrm{P}$ e o ponto $\mathrm{B}$

$\mathrm{S}_{\mathrm{i}}$ : rigidez axial da estaca $\mathrm{i}$

U : Perímetro da seção transversal do fuste da estaca

$\mathrm{Vx}_{\mathrm{k}}, \mathrm{Vy}_{\mathrm{k}}, \mathrm{Vz}_{\mathrm{k}}, \mathrm{Va}_{\mathrm{k}}, \mathrm{Vb}_{\mathrm{k}}, \mathrm{Vc}_{\mathrm{k}}$ : deslocamentos do bloco $\mathrm{k}$

$\mathrm{V}_{\mathrm{x}}, \mathrm{M}_{\mathrm{y}}$ e $\mathrm{M}_{\mathrm{z}}$ : Cargas atuantes nos apoios da estrutura

$\mathrm{X}, \mathrm{Y}, \mathrm{Z}$ : Sistema de referência global da estrutura e da subestrutura do pavimento

$\mathrm{X}_{\mathrm{V}}, \mathrm{Y}_{\mathrm{V}}, \mathrm{Z}_{\mathrm{V}}$ : Sistema de referência local das vigas

$\mathrm{X}_{\mathrm{L}}, \mathrm{Y}_{\mathrm{L}}, \mathrm{Z}_{\mathrm{L}}$ : Sistema de referência local das lajes

$X_{P}, Y_{P}, Z_{P}$ : Sistema de referência local dos pilares

$\mathrm{Z}_{\mathrm{A}}$ : profundidade $\mathrm{z}$ no centro da base da estaca .

$\mathrm{Z}_{\mathrm{B}}$ : Profundidade $\mathrm{z}$ onde se quer calcular o recalque 


\section{Gregos}

$\alpha_{i}$ : ângulo de inclinação da estaca i e o eixo x

$\delta$ : distorção angular entre os apoios da estrutura

$\delta \mathrm{o}_{\mathrm{i}}$ : recalque da estaca $\mathrm{i}$

$\delta \mathrm{p}_{\mathrm{i}}$ : deformação elástica da estaca $\mathrm{i}$

$\delta \mathrm{s}_{\mathrm{i}}$ : recalque na base da estaca $\mathrm{i}$

$\delta$ s, : : parcela do recalque na base da estaca $\mathrm{i}$, devido ao conjunto de cargas no fuste da estaca

$\delta s, \mathrm{~b}:$ parcela do recalque na base da estaca $\mathrm{i}$, devido ao conjunto de cargas na base da estaca

$\delta_{\mathrm{x}}, \theta_{\mathrm{y}}$ e $\theta_{\mathrm{z}}$ : coordenadas deslocamentos nos apoios da estrutura

$v$ : coeficiente de Poisson

$\varpi_{\mathrm{i}}$ : ângulo de inclinação da estaca i no plano y - z

\section{Matrizes e vetores}

$\left\{\mathrm{U}_{\mathrm{N}}\right\}$ : vetor deslocamentos do pavimento $\mathrm{N}$, condensado em coordenadas dos pilares

$\left\{\mathrm{U}_{\mathrm{i}}\right\}$ : vetor deslocamentos do pavimento $\mathrm{i}$, condensado em coordenadas dos pilares

$\left\{\mathrm{U}_{0}\right\}$ : vetor deslocamentos do pavimento 0 , condensado em coordenadas dos pilares

[D] : matriz diagonal do Choleski Decomposition

[0] : matriz nula do Choleski Decomposition

$\left\{\mathrm{F}_{\mathrm{N}}\right\}$ : vetor força do pavimento $\mathrm{N}$, condensado em coordenadas dos pilares

$\left\{F_{i}\right\}$ : vetor força do pavimento i, condensado em coordenadas dos pilares

$\left\{\mathrm{F}_{0}\right\}$ : vetor força do pavimento 0 , condensado em coordenadas dos pilares

[I] : matriz identidade do Choleski Decomposition

[L] : matriz triangular inferior com termos unitários na diagonal principal do Choleski

\section{Decomposition}

$[\mathrm{P}]$ : Matriz versor das estacas que compõem o bloco $\mathrm{k}$

$\{\mathrm{F}\}$ : vetor carregamento no bloco $\mathrm{k}$

$\left[\mathrm{R}_{\mathrm{N}, \mathrm{N}}\right]$ : matriz de rigidez do pavimento $\mathrm{N}$, condensado em coordenadas dos pilares

$\left[\mathrm{R}_{\mathrm{i}, \mathrm{i}}\right]$ : matriz de rigidez do pavimento $\mathrm{i}$, condensado em coordenadas dos pilares

$\left[\mathrm{R}_{0,0}\right]$ : matriz de rigidez do pavimento 0 , condensado em coordenadas dos pilares

$\left[\mathrm{R}^{*}{ }_{0,0}\right]$ : matriz de rigidez global da estrutura, condensado em coordenadas dos pilares do pavimento 0

[RT] : matriz retangular do Choleski Decomposition 
[R*] : matriz simétrica condensada do Choleski Decomposition

$[\mathrm{R}]$ : matriz de rigidez do estaqueamento

$\left[\mathrm{R}_{\mathrm{II}}\right]$ : submatriz de rigidez do pavimento em função das coordenadas internas (sem conexão com os pilares)

$\left[\mathrm{R}_{\mathrm{EE}}\right]$ : submatriz de rigidez do pavimento em função das coordenadas externas (em conexão com os pilares)

$\left\{\mathrm{u}_{\mathrm{DKT}}\right\}$ : vetor coordenadas deslocamentos do elemento finito de placa $D K T$

$\left\{\mathrm{u}_{\mathrm{L}}\right\}$ : vetor coordenadas deslocamentos de corpo rígido da laje, no plano horizontal

$\left\{\mathrm{u}_{\mathrm{P}}\right\}$ : vetor coordenadas deslocamentos do pilar

$\left\{\mathrm{u}_{\mathrm{v}}\right\}$ : vetor coordenadas deslocamentos locais de viga

$\{\mathrm{U}\}$ : vetor deslocamento do bloco $\mathrm{k}$ 


\section{RESUMO}

IWAMOTO, R. K. (2000). Alguns aspectos dos efeitos da interação solo - estrutura em edifícios de múltiplos andares com fundação profunda. São Carlos. Dissertação (Mestrado) - Escola de Engenharia de São Carlos, Universidade de São Paulo.

O objetivo do trabalho é mostrar através de um modelo numérico a importância da consideração da interação estrutura - solo na análise global da estrutura.

No modelo de estrutura tridimensional utilizado é considerada a contribuição da rigidez transversal à flexão das lajes, a existência de excentricidades das vigas em relação aos pilares e a hipótese de diafragma rígido no plano horizontal de cada pavimento.

Serão consideradas fundações profundas em estacas verticais submetidos à carga de compressão axial ligadas ao bloco suposto rígido, nas quais o efeito de grupo de estacas imersas no solo é calculado considerando a continuidade do solo. A análise da interação do sistema solo - estrutura será feito através dos ajustes das rigidezes de fundações pelo processo iterativo até que ocorra uma certa convergência nos recalques ou nas reações. Com isso, procura-se mostrar que a análise integrada da estrutura e o solo possibilita uma melhor estimativa dos recalques diferenciais e reações nos apoios, assim como a redistribuição dos esforços nos elementos estruturais com o comportamento mais real da interdependência dos esforços entre a estrutura e o solo.

Palavras - chave: Interação solo - estrutura; edifícios de andares múltiplos; fundações profundas. 


\begin{abstract}
IWAMOTO, R. K. (2000). Some aspects of the effect soil - structure interaction for multistory buildings on deep foundations. Dissertação ( Mestrado ) - Escola de Engenharia de São Carlos, Universidade de São Paulo.
\end{abstract}

The main aim of this work is to use a numerical model for soil - structure interaction and the importance of their consideration in a global structural analysis.

For the structure the model considers the contribution of transverse bending stiffness of slabs, the exccentricy of beams in relation to the pile, and the hypothesis of rigid diaphragms in the plane of the slabs.

Primary attention is placed on vertically loaded pile under rigid pile cap in which the influence of pile groups imerse in the soil is calculated considering the soil continuity. The analysis of soil - structure interaction is done in an iterative process by adjusting the stiffness of the foundation until a certain preestablished convergence of calculated settlements or load reactions are obtained. In this manner it's shown that the integrated analysis of the structure and soil medium leads to better results of differential settlements and load reactions of the supports. In the same manner, this analysis procedure leads to a better estimate of the internal forces in the structural elements, showing a more realistic behaviour of interdependence betwen the strucutre and the soil medium.

Keywords: Soil - structures interaction; Multistory buildings; Deep foundations. 


\subsection{Generalidades}

Nos escritórios de cálculo estrutural, em geral a estrutura é calculada pelo engenheiro de estruturas supondo os apoios indeslocáveis, resultando num conjunto de cargas (reações verticais, horizontais e momentos fletores) que é passado ao engenheiro de fundações que dimensiona as fundações, calcula os recalques comparando-os com os recalques admissíveis. No entanto, estas fundações devido à deformação do solo, solicitam a estrutura, geralmente hiperestáticas, com um fluxo de carregamento diferente da hipótese de apoios indeslocáveis, modificando assim os esforços atuantes na estrutura e as cargas no solo.

Sabe-se que as fundações (ou infraestruturas) não subsistem por si só, são sempre fundações de alguma superestrutura. Aliás, a terminologia diferenciando infra e superestrutura poderia ser revista. Na verdade o que existe é a estrutura e o maciço de solo, sendo que os elementos estruturais que são comumente chamados de "fundações" constituem parte integrante da estrutura e o comportamento desse conjunto inseparável é que denominase interação solo - estrutura.

Uma das principais divergências entre engenheiro de estruturas e geotécnicos começa na escolha do sistema de referência. Enquanto os da estrutura consideram o ponto da base da estrutura como sendo a origem global e sentido para cima, para os geotécnicos esse mesmo referencial tem o sentido para baixo, ou seja, cada um olha o objeto de sua preocupação: para cima a estrutura e para baixo a fundação. Ambas as convenções não fazem sentido pois esse ponto de referência é deslocável. A escolha mais coerente seria num ponto abaixo da superfície do solo na profundidade onde se consideraria a camada indeslocável. 


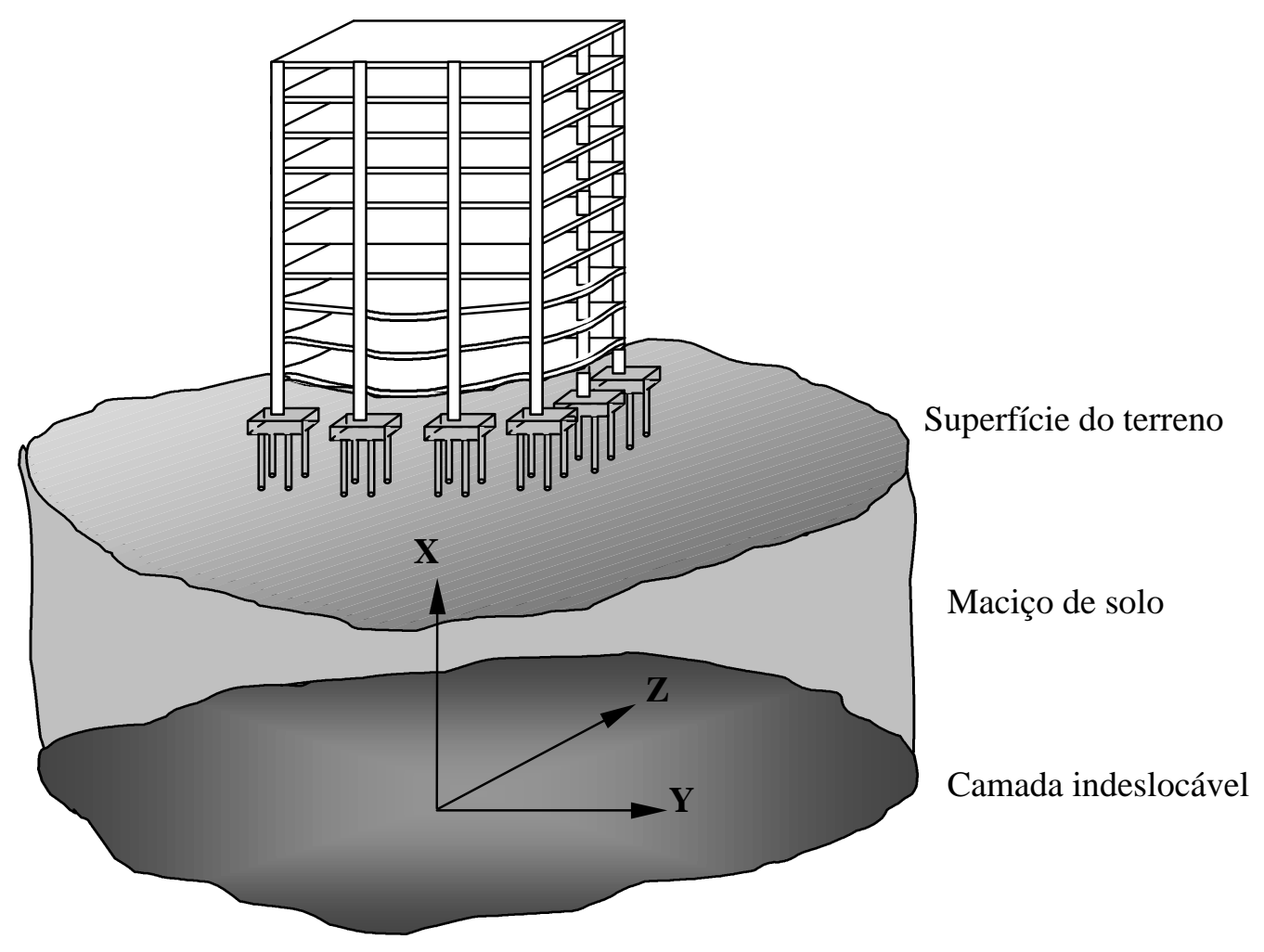

Figura 1.1 - Sistema de referência do indeslocável

O estudo da interação solo - estrutura exige uma visão integrada dos diferentes materiais que compõe um sistema, ou seja, sistemas estruturais mais sistemas geotécnicos ou maciço de solo. Sendo o maciço de solo um conjunto formado por um certo número de elementos de solos ocupando continuamente o espaço físico delineado pela superfície do terreno e a superfície do indeslocável, conforme AOKI\&CINTRA(1996).

Uma das inúmeras vantagens em considerar a interação solo - estrutura é a possibilidade de estimar os efeitos da redistribuição de esforços nos elementos estruturais, a forma e a intensidade dos recalques diferenciais, tornando os projetos mais eficientes e confiáveis. 


\subsection{Alguns trabalhos desenvolvidos}

\subsubsection{Modelos desenvolvidos}

Diversos modelos para análise de interação solo - estrutura têm sido desenvolvidos, no entanto há de se destacar pela vanguarda e originalidade, os trabalhos de Meyerhof e Chamecki.

MEYERHOF (1953) propôs a viga de rigidez à flexão equivalente, para estimar a contribuição da superestrutura. No caso de um edifício com estrutura em pórtico de concreto e painéis de fechamento em alvenaria, tem-se:

$\mathrm{E}_{\mathrm{c}} \mathrm{I}=\Sigma \mathrm{E}_{\mathrm{c}} \mathrm{I}_{\mathrm{v}}+\Sigma \mathrm{E}_{\mathrm{a}} \mathrm{I}_{\mathrm{a}}$

Onde: $E_{c} \mathrm{I}=$ rigidez da viga equivalente

$\Sigma \mathrm{E}_{\mathrm{c}} \mathrm{I}_{\mathrm{v}}=$ somatória da rigidez das vigas da estrutura

$\Sigma \mathrm{E}_{\mathrm{a}} \mathrm{I}_{\mathrm{a}}=$ somatório da rigidez dos painéis de alvenaria

A expressão acima pode ser estendida para incluir a contribuição da rigidez dos pilares mas sem considerarem as deformações axiais das mesmas. No caso de uma fundação combinada, a rigidez da fundação é somada à da viga da estrutura. No caso de um conjunto de fundações isoladas, o cálculo de recalques é feito com as fundações ligadas à viga que representa a estrutura.

CHAMECKI (1956) fez um trabalho pioneiro apresentando o processo iterativo para considerar a rigidez da superestrutura, sem precisar recorrer as simplificações feitas pelo MEYERHOF.

O processo é o seguinte:

1 ) Calcula-se reações Ro nos apoios da estrutura, considerando-os indeslocáveis;

2 ) Determina-se os recalques $\Delta$ o, devido as reações (ações) Ro, sem a consideração da rigidez da estrutura;

3 ) Determina-se a rigidez Q do apoio (ou coeficientes de transferência de carregamento), impondo deslocamentos unitários nas coordenadas dos apoios da estrutura.

Assim, pode-se obter reações em uma determinada coordenada i do apoio em função dos recalques da mesma coordenada i e das outras coordenadas $\mathrm{j}$ :

$$
\mathrm{Ri}=\operatorname{Roi}-\text { Qii } \Delta \mathrm{i}+\sum \text { Qji } \Delta \mathrm{j}(\mathrm{i} \neq \mathrm{j})
$$

4 ) O processo iterativo será realizado até que todos os recalques / ou reações atinjam uma convergência desejada. 
POULOS $^{\mathbf{1}}$ apud GUSMÃO (1991) apresenta uma formulação matricial para estimar os recalques da fundação considerando a interação solo - estrutura.

Para estrutura: $\{\mathrm{V}\}=\left\{\mathrm{V}_{\mathrm{o}}\right\}+[\mathrm{SM}]\{\delta\}$

$\{\mathrm{V}\}=$ vetor de reações na base da estrutura.

$\left\{\mathrm{V}_{0}\right\}=$ vetor de reações na base da estrutura para o apoio indeslocável.

$\{\delta\}=$ vetor de recalques na base da estrutura.

$[\mathrm{SM}]=$ matriz de rigidez, determinado pela imposição de deslocamentos unitários para cada direção dos apoios da estrutura.

Para fundações (maciço de solo + estruturas em contato direto com o solo)

$\{\delta\}=[\mathrm{FM}]\{\mathrm{V}\}$

$[\mathrm{FM}]=$ matriz de flexibilidade da fundação ou matriz de fator de influência do solo.

A [FM] é a matriz de mesma dimensão da [SM], e é determinada de acordo com o tipo de fundações adotadas. Como na realidade, o recalque de um elemento de fundação não depende apenas da carga aplicada diretamente nele, mas também das cargas aplicadas por outros elementos de fundações vizinhas, a modelagem para determinar a matriz [FM] pode ser obtida pela teoria da elasticidade, onde considera-se a continuidade do solo.

Combinando as equações (1.3) e (1.4), tem-se um sistema que leva em conta a rigidez da estrutura e do solo em conjunto : $\quad\{\mathrm{V}\}=\left\{\mathrm{V}_{\mathrm{o}}\right\}+[\mathrm{SM}][\mathrm{FM}]\{\mathrm{V}\}$

$$
\left\{\mathrm{V}_{\mathrm{o}}\right\}=([\mathrm{I}]-[\mathrm{SM}][\mathrm{FM}])\{\mathrm{V}\}
$$

A resolução da equação (1.5) fornecem as incógnitas $\{\mathrm{V}\}$ das reações e com isso pode-se determinar os recalques $\{\delta\}$, pela equação (1.4). Para considerar a não linearidade do material da estrutura ou do solo, será necessário o processo iterativo do sistema (1.5).

Seguindo o modelo do Poulos, MOURA (1995) faz a análise de interação solo estrutura para fundações rasas discretizando o solo em elementos finitos tridimensionais. Utilizou-se a técnica de subestruturação dividindo o conjunto em duas subestruturas:

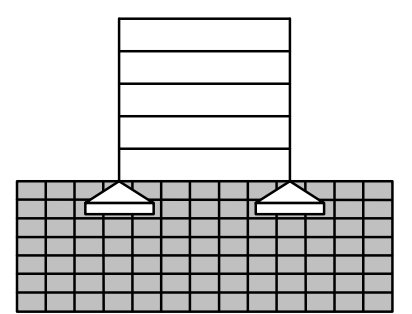

Edificação

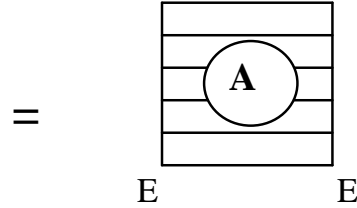

Subestrutura A

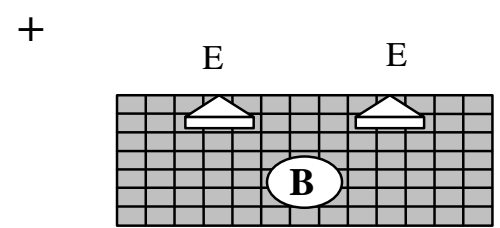

Subestrutura B

Figura 1.2 - O sistema superestrutura e o sistema elementos de fundações + solo.

\footnotetext{
${ }^{1}$ POULOS, H. G. (1975). Settlement analysis of structural foundation systems. In: IV South - East Asian Conference on Soil Engineering, Kuala Lumpur, Malásia, Vol. IV, p.52-62
} 
Desta forma, o sistema de equações considerando como um todo admitindo-se o comportamento elástico linear, pode ser representada na forma particionada a seguir:

$$
\left[\begin{array}{llc}
{\left[\mathrm{S}_{\mathrm{AA}}\right]} & {\left[\mathrm{S}_{\mathrm{AE}}\right]} & {[0]} \\
{\left[\mathrm{S}_{\mathrm{EA}}\right]} & {\left[\mathrm{S}_{\mathrm{EE}}\right]} & {\left[\mathrm{S}_{\mathrm{EB}}\right]} \\
{[0]} & {\left[\mathrm{S}_{\mathrm{BE}}\right]} & {\left[\mathrm{S}_{\mathrm{BB}}\right]}
\end{array}\right]\left\{\begin{array}{l}
\left\{\mathrm{D}_{\mathrm{A}}\right\} \\
\left\{\mathrm{D}_{\mathrm{E}}\right\} \\
\left\{\mathrm{D}_{\mathrm{B}}\right\}
\end{array}\right\}=\left\{\begin{array}{l}
\left\{\mathrm{F}_{\mathrm{A}}\right\} \\
\left\{\mathrm{F}_{\mathrm{E}}\right\} \\
\left\{\mathrm{F}_{\mathrm{B}}\right\}
\end{array}\right\}
$$

Desenvolvendo a equação e expressando as coordenadas em função dos nós comuns a duas subestruturas, obtém-se o sistema reduzido em função da coordenada E:

$$
\left[\mathrm{S}_{\mathrm{EE}}^{*}\right]\left\{\mathrm{D}_{\mathrm{E}}\right\}=\left\{\mathrm{F}_{\mathrm{E}}^{*}\right\}
$$

onde:

$$
\begin{aligned}
& {\left[\mathrm{S}_{\mathrm{EE}}^{*}\right]=\left[\mathrm{S}_{\mathrm{EE}}\right]-\left[\mathrm{S}_{\mathrm{EA}}\right]\left[\mathrm{S}_{\mathrm{AA}}\right]^{-1}\left[\mathrm{~S}_{\mathrm{AE}}\right]-\left[\mathrm{S}_{\mathrm{EB}}\right]\left[\mathrm{S}_{\mathrm{BB}}\right]^{-1}\left[\mathrm{~S}_{\mathrm{BE}}\right]} \\
& \left\{\mathrm{F}_{\mathrm{E}}^{*}\right\}=\left\{\mathrm{F}_{\mathrm{E}}\right\}-\left[\mathrm{S}_{\mathrm{EA}}\right]\left[\mathrm{S}_{\mathrm{AA}}\right]^{-1}\left\{\mathrm{~F}_{\mathrm{A}}\right\}-\left[\mathrm{S}_{\mathrm{EB}}\right]\left[\mathrm{S}_{\mathrm{BB}}\right]^{-1}\left\{\mathrm{~F}_{\mathrm{B}}\right\}
\end{aligned}
$$

SAYEG \& TSUO (1988) apresentam uma formulação matricial tratando a estrutura como elástico linear e o comportamento do sistema estaca - solo como sendo não linear.

Trata-se de processo iterativo, onde a rigidez elástica linear das estacas uma vez determinados serão armazenados na memória do computador e a rigidez geométrica que depende de cargas axiais, será atualizado para cada iteração.

As coordenadas da estrutura serão reduzidas em função do ponto comum entre estrutura e o solo, que são neste caso as extremidades superiores de todas as estacas em conexão com a superestrutura:

$$
\left[\begin{array}{l}
{\left[\mathrm{K}_{11}\right]\left[\mathrm{K}_{12}\right]} \\
{\left[\mathrm{K}_{12}^{\mathrm{T}}\right]\left[\mathrm{K}_{22}\right]}
\end{array}\right]\left\{\begin{array}{l}
\left\{\mathrm{u}_{1}\right\} \\
\left\{\mathrm{u}_{2}\right\}
\end{array}\right\}=\left\{\begin{array}{l}
\left\{\mathrm{F}_{1}\right\} \\
\left\{\mathrm{F}_{2}\right\}
\end{array}\right\} \longrightarrow \longrightarrow K_{22}^{*} \mid\left\{u_{2}\right\}=\left\{F_{2}^{*}\right\}
$$

No sistema solo - estaca, as coordenadas são reduzidas para as extremidades superiores das estacas. Diferente da superestrutura, a matriz de rigidez é não linear, por isso é necessário atualizar a matriz de rigidez tangente e o vetor de força residual.

$\mathrm{Na}$ i - ésima iteração de Newton - Raphson, tem-se:

$$
\left[\mathrm{K}_{22}^{*}\right]_{t}^{i} \Delta\left\{\mathrm{u}_{2}\right\}^{i}=\Delta\left\{\mathrm{F}_{2}^{*}\right\}^{i}
$$

$$
\downarrow \text { Vetor de força residual reduzida }
$$

Matriz de rigidez tangente reduzida 
AOKI (1987) propôs um processo iterativo, como uma das alternativas para se levar em conta as complexas interações entre o solo e a estrutura. Este processo tenta interagir o grupo de estacas com o maciço de solo e o bloco de coroamento e estes com a superestrutura, através de várias iterações até que todas as reações (ou recalques) se igualem com os da iteração imediatamente anterior, dentro de uma tolerância prefixada. Esta técnica, adotado no presente trabalho, será detalhado nos capítulos 2 e 4 .

\subsubsection{Efeitos da interação solo - estrutura}

\subsubsection{Influência do tempo}

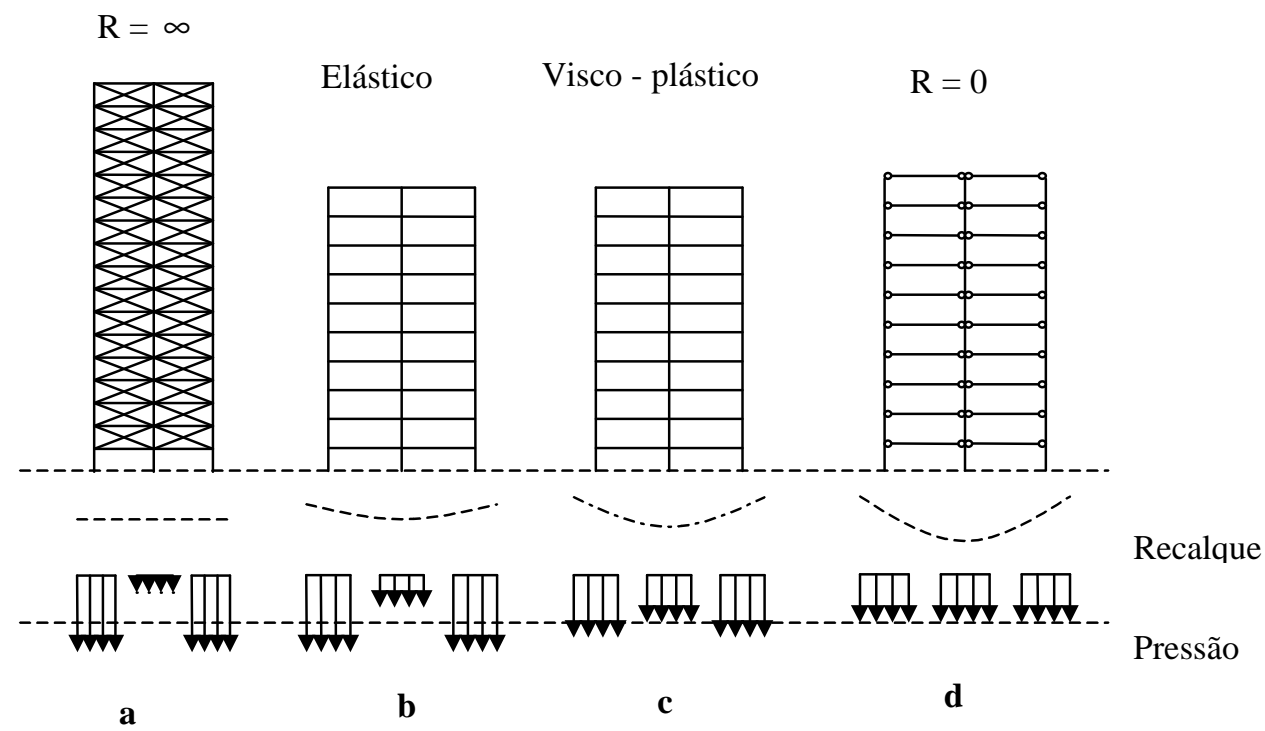

Figura 1.3 - Casos de interação solo - estrutura, CHAMECKI (1969)

CHAMECKI (1969) apresenta os seguintes casos possíveis:

Caso a, estruturas infinitamente rígidas apresentam recalques uniformes. Por causa da tendência do solo deformar mais no centro que as da periferia, devido a continuidade parcial do solo, a distribuição de pressões de contato nos apoios são menores no centro e máximos nos cantos externos. Esta distribuição de pressões assemelham-se ao caso de um corpo infinitamente rígido apoiado em meio elástico. Os edifícios muito altos e com fechamento das paredes resistentes trabalhando em conjunto com a estrutura, podem apresentar comportamento semelhante a este modelo.

O caso oposto do a, é a estrutura que não apresenta rigidez aos recalques diferenciais (caso d). Este tipo de estrutura se adapta perfeitamente às deformações do maciço de solo. A distribuição de pressões de contato não se modifica perante a progressão dos recalques. 
As estruturas isostáticas e edifícios compridos ao longo do eixo horizontal, se aproximam a este tipo de comportamento.

Caso b, uma estrutura perfeitamente elástica possui a rigidez que não depende da velocidade da progressão dos recalques, podendo ser mais rápidos ou lentos, não influindo nos resultados. Os recalques diferenciais obviamente, serão menores que os de rigidez nulo (caso d) e a distribuição de pressões de contato variam muito menos durante o processo de recalque. Estruturas de aço, se assemelham a este comportamento.

Caso c, uma estrutura visco - elástica, como o de concreto armado, apresenta rigidez que depende da velocidade da progressão de recalques diferenciais. Se os recalques acontecem num curto espaço de tempo, a estrutura tem o comportamento elástico (caso b), mas se esta progressão é bastante lenta, a estrutura apresenta um comportamento como um líquido viscoso e tenderá ao caso d. Esta ultima característica acontece graças ao fenômeno de fluência do concreto que faz a redistribuição das tensões nas outras peças de concreto armado menos carregadas, relaxando significativamente as tensões locais.

Neste trabalho, apesar de a análise ser para edifícios altos de concreto armado, como se trata de análise para recalques imediatos e não em função ao longo do tempo, não considerando a reologia do material, a modelagem numérica será elástica, (caso b).

\subsubsection{Influência da rigidez da estrutura}

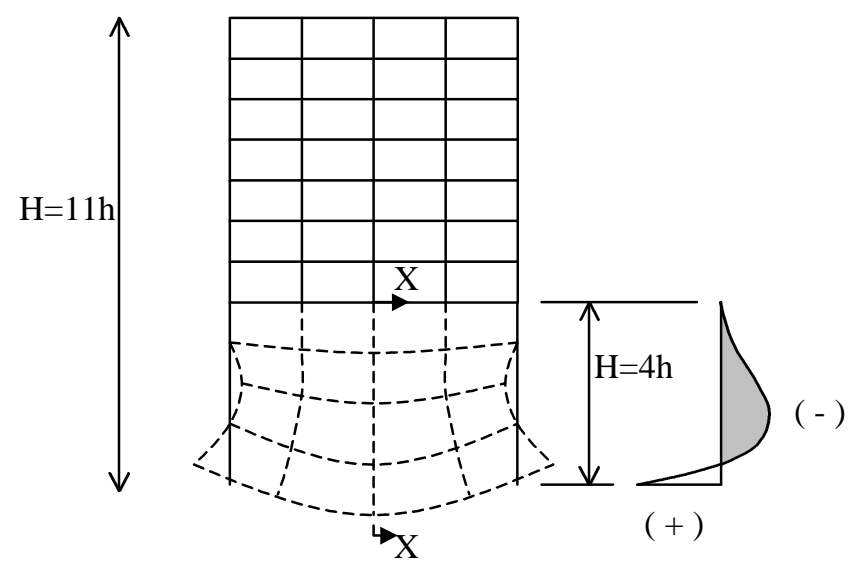

Deformada da estrutura

Distribuição de tensões

Figura 1.4 - Analogia da viga - parede, Goshy (1978)

GUSMÃO (1994) indica que, o número de pavimentos é um dos fatores mais influentes na rigidez da estrutura, quanto maior o número de pavimentos de uma estrutura, 
maior será a sua rigidez. GOSHY (1978) observou a influência maior nos primeiros pavimentos, utilizando a analogia de vigas - parede.

RAMALHO \& CORRÊA (1991) analisaram dois edifícios com fundações em sapatas, um edifício com sistema laje cogumelo e o outro edifício com sistema laje, viga, pilar, fazendo uma comparação entre considerar o solo como totalmente rígido ou elástico.

Os resultados da análise mostram que a influência da consideração da flexibilidade da fundação nos esforços da superestrutura é muito grande. Mesmo com o solo $\mathrm{E}=100.000$ $\mathrm{kN} / \mathrm{m}^{2}$, portanto relativamente rígido, a diferença entre considerar ou não mostrou-se bastante significativa em alguns elementos da estrutura.

Observou-se que nos pilares os esforços normais e momentos fletores tendem a uma redistribuição que torne os seus valores menos díspares, onde os maiores valores tendem a diminuir e os menores a aumentar.

Os edifícios com o sistema estrutural laje cogumelo, mostraram serem mais sensíveis à fundações flexíveis que os do sistema laje, viga, pilar, por terem dimensões de pilares relativamente grandes que tem a tendência de apresentarem elevados valores de momentos fletores na base.

GUSMÃO (1994) apresenta dois parâmetros com fins comparativos entre considerar ou não a interação solo-estrutura:

- Fator de recalque absoluto $\mathrm{AR}=\mathrm{Si} / \mathrm{S}$

- Fator de recalque diferencial $\mathrm{DR}=[\mathrm{Si}-\mathrm{S}] / \mathrm{S}$

$\mathrm{Si}=$ recalque absoluto de apoio $\mathrm{i}$

$\mathrm{S}=$ recalque absoluto médio
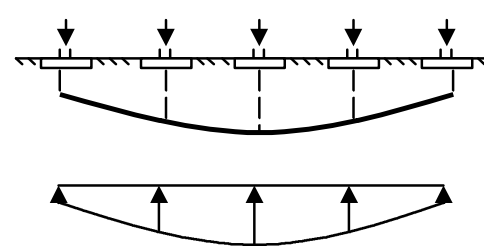

\section{Análise convencional}
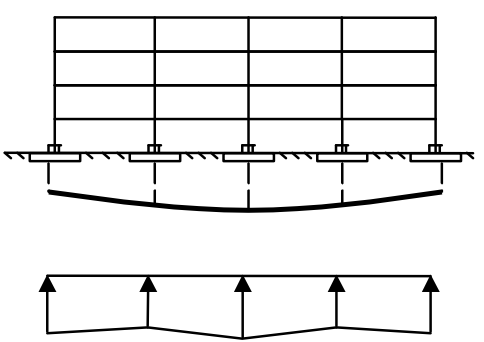

Análise interação solo-estrutura
Deformada de recalques

\section{Reações} na base

\section{Figura 1.5 - Efeitos de interação , GUSMÃO (1994)}

Com o uso destes parâmetros, o autor apresenta três casos reais de edifícios, comparando-os com resultados estimados convencionalmente (sem a consideração da rigidez da estrutura) e com os resultados medidos no campo. Através destas comparações o autor 
prova que o efeito da interação solo-estrutura realmente tende a uniformizar os recalques da edificação.

FERRO \& VENTURINI (1995) apresentam uma formulação que considera a rigidez do meio contínuo infinito para fundações constituídas de grupo de estacas, onde o meio contínuo é equacionado a partir de representações integrais dos elementos de contorno e a estrutura de fundação em estacas é tratada através de elementos finitos, obtendo-se assim um elemento "fundações", cuja rigidez do conjunto meio semi-infinito mais a estrutura de fundações é levada em conta na análise do edifício.

A combinação dos métodos de elementos de contorno e finitos é obtido pela condição de compatibilidade de deslocamentos, sem o deslizamento ao longo das interfaces estacas - meio contínuo.

Foi analisado para uma estrutura de pórticos espaciais com nove pilares, distribuídos em três pórticos simétricos em cada uma das direções em planta e submetido à combinação de ações verticais e horizontais.

As estacas empregadas no projeto de fundações são do tipo pré-moldados e o solo característico da cidade de Bauru-SP, classificado como residual de arenito avermelhado escuro e textura média onde foram estimados a partir de correlações com o SPT obtendo as características do solo como sendo $E_{s}=46000 \mathrm{kN} / \mathrm{m}^{2}$ e $v=0,30$.

Analisaram-se os efeitos de interação solo-estrutura em edifícios com 4,7,10,15,20,25,30 e 40 pavimentos, comparando a fundação rígida e o elemento de fundação desenvolvido pelos autores. Os resultados mostraram que mesmo levando-se em conta apenas os efeitos de primeira ordem da estrutura, este tipo de fundação apresenta deslocamentos superiores aos observados para o caso de fundação rígida, ainda que se inclua os efeitos de segunda ordem da estrutura. Para edifício de 40 pavimentos, obteve-se deslocamento horizontal de $50,8 \mathrm{~cm}$ no topo da estrutura com a fundação proposta, considerando apenas o efeito de primeira ordem. Esse valor, para fundação rígida, mesmo levando-se em conta o efeito de segunda ordem foi de $47,2 \mathrm{~cm}$.

Como era de se esperar, os momentos fletores nas seções de ligação dos pilares com a fundação sofreram redução devido ao movimento da fundação elástica. 


\subsubsection{Influência do Processo Construtivo}

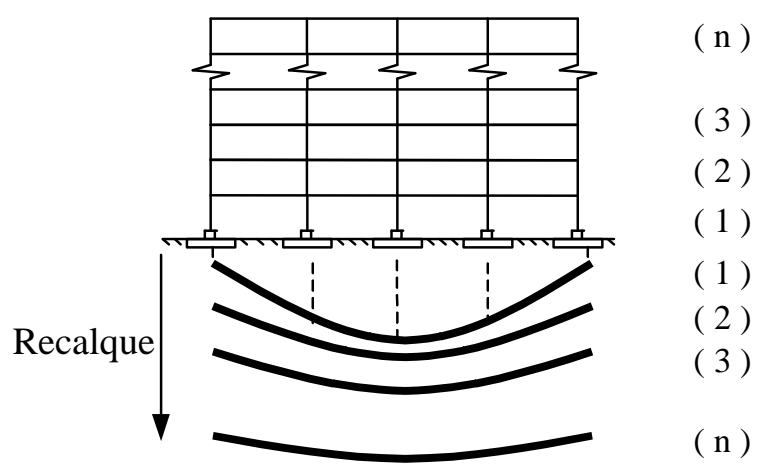

Figura 1.6 - Efeitos da seqüência construtiva , GUSMÃO \& GUSMÃO FILHO (1994)

Segundo GUSMÃO \& GUSMÃO FILHO (1994), durante a construção à medida que vai subindo o pavimento, ocorre uma tendência à uniformização dos recalques devido ao aumento da rigidez da estrutura, sendo que esta rigidez não cresce linearmente com o número de pavimentos.

FONTE et al. (1994a,b) confrontaram os resultados dos recalques de fundações em sapatas medidos na obra de um edifício de quatorze andares com as previsões dos modelos numéricos entre considerar ou não a interação solo - estrutura e efeitos construtivos.

Os resultados indicaram que o modelo que não considera a interação solo - estrutura, superestima a previsão dos recalques diferencias por não considerar a rigidez da estrutura;

O modelo que considera a interação solo - estrutura, mas aplica carregamento instantâneo para a estrutura completa, acaba subestimando a previsão dos recalques, devido a não consideração do carregamento gradual na estrutura e acréscimo de rigidez, o que induz a rigidez da estrutura maior que a real;

Os resultados que mais aproximaram com os medidos no campo, foi o modelo que considera os efeitos da interação solo - estrutura e a aplicação gradual de elementos estruturais que faz com que a rigidez dos elementos sofram constantes modificações para cada seqüência de carregamento.

Para simular numericamente a seqüência construtiva, onde um pavimento em construção não causa esforços solicitantes nos demais elementos superiores que ainda nem foram construídas, HOLANDA JR. (1998) utiliza o processo seqüencial direto. Trata-se de analisar para cada levantamento de pavimento, considerando apenas o carregamento aplicado no ultimo pavimento com todas as barras construídas até aquele momento, prosseguindo até 
que o edifício atinja o seu topo. Como todas as análises realizadas são elásticas e lineares, os esforços finais de cada elemento são determinados com a simples soma dos seus respectivos esforços calculados em todas as etapas. Para considerar que o pavimento é construído nivelado e na sua posição original prevista, os recalques finais da fundação e os deslocamentos verticais de todos os nós do pórtico são obtidas da mesma forma, pela superposição.
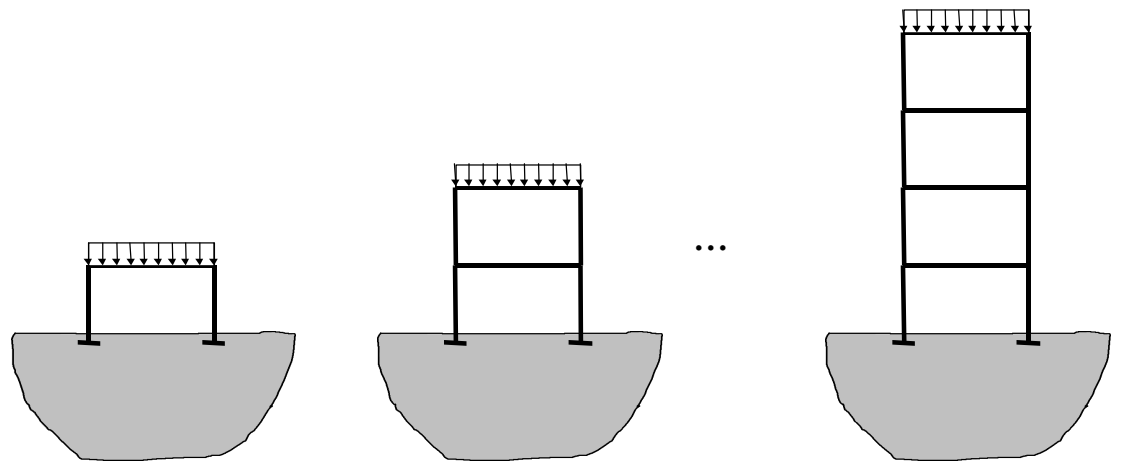

\section{Figura 1.7 - Simulação da seqüência construtiva}

Respeitando a seqüência construtiva, os deslocamentos verticais dos nós de um pavimento não são afetados pelo carregamento dos pavimentos abaixo. Portanto, os deslocamentos diferencias entre os nós de um mesmo pavimento diminuem nos andares superiores, sendo máximos à meia altura do edifício. No topo correspondem a deformação somente do último pavimento. As deformações dos pilares seguem o mesmo raciocínio.

\subsection{Objetivos}

Um dos principais objetivos deste trabalho é como quantificar os esforços secundários na estrutura provocados em decorrência dos recalques diferenciais, que influenciam nos esforços dos pilares, vigas e lajes.

Através da comparação entre considerar ou não a flexibilidade das fundações, tentase responder qual a importância para a estabilidade global da estrutura e os esforços nos elementos. Como um exemplo; duas super-estruturas iguais (geometria, materiais e cargas) construídas em terrenos diferentes, apresentam reações de apoio diferentes, por causa dos recalques, ou seja os procedimentos usuais de cálculo que não consideram a deslocabilidade dos apoios podem conduzir a resultados diferentes dos reais. 
A partir da modelagem numérica e os resultados obtidos, pretende-se no mínimo, sugerir propostas de cálculo no sentido de sensibilizar a importância da sua consideração.

Deve-se ressaltar que este trabalho possibilitará o desenvolvimento de outros programas de interação estrutura - solo e também como um parâmetro preliminar para comparação com os outros modelos numéricos e com os resultados medidos na obra.

\subsection{Metodologia}

O modelo estrutural tem como a base nos trabalhos desenvolvidos em ANTUNES \& MARTINS (1998) e ANTUNES \& BEZERRA (1995) que analisa a contribuição da rigidez transversal das lajes em estruturas de edifícios.

O cálculo de estaqueamento para determinar a força em cada estaca conhecendo a sua rigidez e o movimento do bloco admitindo-se rígido, será utilizado o método idealizado por SCHIEL (1957) e sistematizado por STAMATO (1971).

O diagrama de transferência de carregamento nas estacas serão determinados a partir do conhecimento da carga na estaca e do diagrama de ruptura do método semi-empírico AOKI-VELLOSO (1975) com base nos valores de sondagens do SPT e os coeficientes tabelados para determinados tipos de solo e estacas. O modelo de transferência de carga em estaca será admitido que a carga na base da estaca só é despertada após a total mobilização da capacidade máxima de resistência no contato fuste da estaca - solo, AOKI (1979).

Os recalques do solo imediatamente abaixo na base de uma estaca, considerando o efeito do grupo de estacas, será resolvido pelo método AOKI - LOPES (1975) segundo o qual cargas aplicadas nas estacas serão discretizadas em um sistema estaticamente equivalentes de cargas pontuais, distribuídas de acordo com o diagrama de transferência de carregamento ao longo do fuste e na base da estaca, cujos efeitos são superpostos nos pontos em estudo. O solo é modelado como sendo de material elástico linear com uso de solução de MINDLIN (1936) e procedimento de STEINBRENNER ${ }^{2}$ apud AOKI-LOPES(1975) possibilitam a estimativa dos recalques nas estacas imersas em solos estratificados e a consideração da superfície do indeslocável em uma determinada profundidade.

A interação entre a estrutura e o maciço de solo proposto em AOKI (1987) utiliza o processo iterativo para considerar influência da rigidez da estrutura nos recalques. Com a interação dos efeitos das fundações em grupo de estacas e os da estrutura com as respectivas reações conhecidas na iteração "i”, determinam-se os recalques com o processo que se repete até atingir uma convergência desejada.

\footnotetext{
${ }^{2}$ STEINBRENNER, W. (1934). Tafelun Zur Setzungsberechnung - Die Strasse, Vol.1, p.121
} 


\subsection{Resumo dos capítulos}

No próximo capítulo descrevem-se a revisão da literatura referente à fundações em estacas, destacando alguns trabalhos desenvolvidos. No mesmo capítulo será abordado o modelo de transferência de carga em sistema solo - estaca e o modelo de estimativa de recalques adotado neste trabalho.

No terceiro capítulo, descrevem-se as características dos elementos estruturais que formam o edifício inclusive os elementos de fundações. Também são mostrados o sistema de referência local e as coordenadas de deslocamentos de cada elemento estrutural.

No quarto capítulo, a preocupação é quanto ao modelo de interação solo -grupo de estacas e o edifício, descrevendo-se as rotinas adotadas neste trabalho para a consideração da interação solo - estrutura.

No quinto capítulo, apresenta-se a descrição do programa computacional, com o cuidado de mostrar as implementações feitas a partir dos programas desenvolvidos em BEZERRA (1995) e MARTINS (1998). Também serão listadas as janelas de diálogo do préprocessador elaborado em Visual Basic.

No sexto capítulo serão analisados quatro exemplos numéricos com o objetivo de mostrar o potencial do programa e discutir os resultados.

No último capítulo apresentam-se as conclusões gerais do trabalho, assim como as críticas e sugestões para os trabalhos futuros.

Foi incluído um anexo para mostrar o algoritmo do programa de fundações em estacas ligadas com bloco rígido, desenvolvido e implementado no presente trabalho. 


\section{MODELO ESTACA - SOLO}

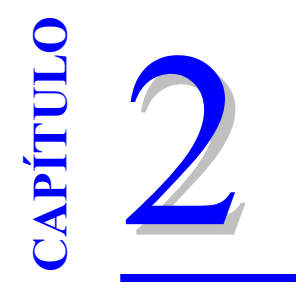

\subsection{Generalidades}

Segundo POULOS (1989), os projetos de fundações durante muitos anos foram baseados numa combinação de empirismo e experiência, havendo uma atitude pessimista com relação às análises teóricas mais refinados. Nos últimos anos tem ocorrido uma mudança gradual nos procedimentos de projeto de estacas, passando-se de métodos essencialmente empíricos para métodos com bases teóricos mais profundos.

Os fatores que estimularam essas mudanças foram:

- O número cada vez maior da utilização de fundações estaqueadas;

- O reconhecimento de que fundações em estacas na realidade recalcam;

- A necessidade cada vez maior de suportarem cargas elevadas nas áreas estreitas, pela tendência do crescimento de quantidade de edifícios altos construídos.

Aliado a isso, tem se notado uma grande revolução da informática, com o desenvolvimento dos computadores menores e mais potentes e o surgimento de técnicas numéricas poderosas como o métodos dos elementos finitos e contorno.

No entanto, algumas incertezas sobre a aplicabilidade destas ferramentas ainda permanecem devido à escassez de casos históricos devidamente documentados, particularmente para o caso de estacas escavadas e escavadas com hélice contínua, POULOS ${ }^{1}$ apud REZENDE (1995).

\footnotetext{
${ }^{1}$ POULOS, H. G. (1993). Settlement prediction for bored pile groups. Proc. $2^{\text {nd }}$ International
} Geotechnical Seminar on Deep Foundations on Bored and Auger Piles. Ghent, 1-4 junho, p.103-117 


\subsection{Métodos de previsão de recalques}

Segundo POULOS ${ }^{1}$ as técnicas de previsão de recalques podem ser classificados em três categorias: empíricas, simplificadas (onde o grupo de estacas é substituído por uma fundação equivalente e mais simples) e métodos analíticos que consideram a interação entre estacas e o solo adjacente.

As primeiras previsões de recalques para grupo de estacas foram os métodos empíricos ou semi-empíricos com base nos resultados de ensaios em modelos reduzidos ou em protótipos. Para areias surgiram as propostas do SKEMPTON (1953), MEYERHOFF (1959), VESIC(1969). Para argilas tem-se WHITAKER (1957) e SOWERS et al. (1961). Estas propostas só consideram a geometria do problema e devem ser utilizadas com cuidado e somente nas condições similares nas quais essas correlações foram baseadas.

\subsubsection{Métodos teóricos simplificados}

Dentre os métodos teóricos simplificados, tem-se a proposta de TERZAGHI\&PECK (1948), para teoria de adensamento para as argilas, substituindo a grupo de estacas por um radier equivalente apoiado a uma profundidade igual a dois terços do comprimento da estaca. SOWERS \& SOWERS (1970) sugeriram um procedimento semelhante mas considerando somente o solo abaixo da estaca. Mais recentemente, TOMLINSON (1986) determina a profundidade do radier equivalente, em função da natureza do perfil do solo, variando de $2 / 3$ do L para estacas de atrito a L para grupos apoiados em rocha. Nesta proposta, o recalque médio é a soma do recalque do radier mais a deformação elástica do fuste das estacas acima do nível do radier equivalente, tratados como colunas livres sem contenções do solo.

POULOS \& DAVIS (1980) sugeriram que o grupo de estacas seja substituído por um tubulão de comprimento e diâmetro equivalente $d_{e}$ e resolvendo como a estaca isolada.

- Estacas predominantemente de atrito $: \mathrm{d}_{\mathrm{e}} \approx 1,27 \sqrt{A_{g}}$

- Estacas predominantemente de ponta $: \mathrm{d}_{\mathrm{e}} \approx 1,13 \sqrt{A_{g}}$

Onde $\mathrm{A}_{\mathrm{g}}$ é a área plana do grupo.

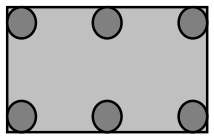

Figura 2.1 - Área plana do grupo de estacas 


$$
E_{e} \cong E_{p} \frac{A_{p}}{A_{g}}+E_{s}\left(1-\frac{A_{p}}{A_{g}}\right)
$$

$\mathrm{E}_{\mathrm{p}}=$ módulo das estacas

$\mathrm{E}_{\mathrm{s}}=$ módulo médio do solo dentro do grupo

$\mathrm{A}_{\mathrm{p}}=$ soma das áreas da seção transversal das estacas que formam o grupo.

RANDOLF(1994) propõe um método na qual o grupo de estacas é substituído por um tubulão equivalente, no entanto, a rigidez do fuste e da base das estacas individuais são ajustadas para levar em conta o efeito de interação total do grupo.

\subsubsection{Métodos que consideram efeitos da interação solo-estaca}

Segundo POULOS ${ }^{1}$, podem ser subdivididos em duas categorias :

- Método que empregam o conceito de fatores de interação;

- Métodos que discretizam o grupo inteiro, fazendo uma análise completa do grupo.

\subsubsection{Métodos que empregam fatores de interação}

Fator de interação é a relação entre o recalque adicional causado em uma estaca devido a uma outra estaca próximo a este que devido a continuidade parcial do solo, arrasta a estaca vizinha, quando ambos estão submetidos à mesma carga. Em geral, os métodos deste tipo são uma extensão dos métodos desenvolvidos para estacas isoladas.

A estaca é dividida em um certo número de elementos uniformemente carregados e efeitos de interação entre duas estacas é avaliado por meio do fator de interação. O efeito do grupo em uma das estacas é dado pela superposição dos efeitos individuais de todas as estacas adjacentes e a solução é obtida impondo-se a compatibilidade entre os deslocamentos da estaca e do solo. Estes deslocamentos, na maioria dos casos, são obtidos usando a equação de MINDLIN (1936) onde o solo é modelado como um semi-espaço infinito homogêneo, isótropo e elástico linear.

Os métodos de POULOS (1968), (1988), POULOS \& DAVIS(1980) segundo POLO \& CLEMENTE (1988) incorporam a hipótese simplificadora com relação à natureza das cargas da ponta e do fuste. 
POLO \& CLEMENTE (1988) apresentam um método em que é admitido que a carga na ponta da estaca não se desenvolve até que seja atingida a resistência lateral do fuste -solo, tornando o método mais apropriado para o caso de estacas flutuantes.

Em AOKI (1979), esse comportamento é simulado mediante uma simplificação (ver item 2.3) que no presente trabalho foi adotado como o modelo de transferência de cargas na estaca.

\subsubsection{Métodos de análise completa}

As características deste tipo de análise são:

- A possibilidade de considerar diferentes comprimentos ou diâmetros de estacas e ou rigidez dentro de um grupo;

- Comportamento não linear da estaca -solo e diferentes resistências do fuste e da base para estacas dentro do grupo.

YAMASHITA et al. (1987) propôs um método com base na solução de MINDLIN (1936) para levar em conta o efeito da não linearidade e da estratificação do solo, além de sugerir uma forma de estimar o módulo de elasticidade a ser empregado na determinação do recalque imediato, a partir dos dados do SPT.

LEE \& POULOS (1990) apresentam um método mais geral, onde se permite considerar um perfil arbitrariamente estratificada com módulos de elasticidade de todas as camadas de solo. Introduziu-se uma expressão semi-empírica simples que relaciona o módulo do solo afetado próximo à estaca ao módulo da massa de solo distante menos afetada, devido a instalação das estacas.

MUQTADIR \& DESAI (1986) apresenta um método de elementos finitos tridimensional, que permite incorporar movimentações relativas de interface e uma grande variedade de modelos de materiais (elástico - linear, elástico - não linear e elasto - plástico) que fornecem resultados satisfatórios quando comparados a modelos de grupos de estacas ensaiados em laboratórios. Apesar de este tipo de análise ser valiosa por conduzir ao melhor entendimento dos detalhes do comportamento da estaca, tem a desvantagem de não ser prático, devido a sua complexidade e o número considerável de parâmetros necessários.

Outro tipo de análise completa, denominado método híbrido, surgiu a partir dos métodos chamados de transferência de carga, para estacas isoladas, que tiveram o início com COYLE \& REESE ${ }^{2}$ apud REZENDE (1995).

\footnotetext{
${ }^{2}$ COYLE, H. M. ; REESE, L. C. (1966). Load trasnfer for axially loaded piles in clay. Jornal of
} Soil Mechanics and Foundations Division, ASCE, Vol 92, No. SM 2, p.1-26. 
Como a função de transferência não leva em conta a interação solo - estaca, esse método não pode ser aplicado diretamente na previsão de recalques de grupo de estacas. Nos métodos híbridos, a análise da transferência de carga é usado para determinar a reação da estaca isolada e a teoria da continuidade é empregada para considerar a influência das estacas vizinhas.

CHOW(1986b) resume este método em seguintes passos:

1- Determinam-se as reações das estacas individuais dentro do grupo, ignorando os efeitos da interação;

2- Com o conhecimento das reações obtidas em 1, determinam-se os deslocamentos adicionais do solo nos nós de outras estacas, por meio da equação de MINDLIN(1936). O efeito de interação entre nós da mesma estaca é ignorado;

3- Ajusta-se a curva de transferência de carga usando os deslocamentos adicionais do solo para levar em conta o efeito de grupo.

Com as curvas de transferência de cargas modificadas repete-se a execução desses três passos, chegando-se a solução por meio de processo iterativo.

CHOW (1985), (1986b) apresenta um refinamento na forma de obtenção da solução para modelo híbrido de O'NEILL et al. (1977), na qual a interação solo - estaca é considerada diretamente. Esse novo procedimento que analisa o efeito do grupo usando a teoria da continuidade elástica, pode ser estendido para o grupo de estacas inclinadas. Este ainda possibilita prever o comportamento carga - recalque até a ruptura, pois considera o efeito da não linearidade do solo, o que resulta numa distribuição mais equilibrada das cargas para estacas individuais dos grupos.

CHOW (1985) utiliza um solo com características médias e a solução de MINDLIN(1936) e posteriormente apresenta um procedimento analítico para obter a solução de uma carga pontual vertical envolvendo elementos isoparamétricos quadrados. Este, permitiu a forma mais rigorosa de tratar a heterogeneidade do solo.

CHOW (1987) apresenta um método numérico para análise tridimensional de grupos de estacas, desconsiderando o contato do bloco com o solo. Nele, as características do modelo de grupo de estacas podem incluir estacas cravadas, de dimensões diferentes, seções de estacas não uniformes, não linearidade do solo, não homogeneidade e interação estaca solo - estaca. 
PAIVA (1993) apresenta uma formulação do método dos elementos de contorno (MEC) para fundações enrijecidas por estacas rígidas levando em conta a simultaneidade de todas as interações presentes no sistema radier - estaca - solo. Os recalques são obtidos a partir da solução fundamental de MINDLIN (1936) admitindo o solo como elástico linear, isótropo, homogêneo e semi - infinito. A partir da teoria clássica de placas, equações integrais são escritas para o radier flexível; cada estaca é representada por um único elemento de contorno onde as tensões cisalhantes ao longo do fuste são interpoladas por um polinômio de segundo grau. Na extremidade inferior da estaca, as tensões normais são admitidas uniformes e portanto, um nó funcional adicional é definido naquela região. Neste modelo, é admitida a compatibilidade entre a superfície de contato estaca - solo. A interface da interação radier - solo é dividida em elementos de contorno triangulares com um nó funcional em cada vértice; a força de superfície de contato é admitida variar linearmente ao longo do elemento. É admitido que os efeitos das cargas aplicadas no meio semi - infinito não seja perturbado pela presença das estacas, ou seja como se fosse contínuo, desprezando o espaço preenchido pelas estacas. Em MENDONÇA (1997), o problema anterior é estendido para análise com estacas flexíveis, no entanto o radier é modelado pelo método dos elementos finitos de placa DKT e HSM. Já em MENDONÇA \& PAIVA (2000), as abordagens descritas em PAIVA (1993) e MENDONÇA (1997) são estendidas para problemas modelados pelo MEC em que todos os componentes do sistema formado pelos elementos estruturais e o maciço de solos são admitidos flexíveis. 


\subsection{Mecanismo de transferência de carga em sistema estaca-solo}

Um grupo de estacas forma uma complexa estrutura por ser formado pelo conjunto de estacas muito próximas entre si interagindo com o solo, além de ser ligado no topo pelo bloco rígido que normalmente está em contato com o solo. Em quaisquer casos a transferência de cargas ocorre através das complexas interações de estacas, superestruturas (blocos de coroamento e estruturas aporticadas) e os solos adjacentes. O comportamento é afetado pela tensão-deformação-tempo e eventuais falhas em um dos elementos que formam o sistema (superestruturas, fundações ou solos adjacentes), assim como as variações nas propriedades do solo provocado pela ordem de execução das estacas.

Os mecanismos envolvidos na transferência de carga dependem do modo como a estaca for carregada, ou seja, por esforço axial, lateral, de torção ou pela combinação destes. Estes serão mais complexos quanto mais complicado for o sistema de carregamento.

Neste trabalho serão consideradas apenas as estacas verticais carregadas axialmente, especificamente as submetidas a esforços de compressão.

A transferência da carga de compressão $\mathrm{N}_{\mathrm{i}}$ recebida pela estaca i para o solo, se dá basicamente em duas parcelas:

- Ao longo do fuste, devido ao pequeno movimento relativo entre a estaca e o solo, em função do carregamento aplicado, o qual provoca o surgimento de tensões de cisalhamento que dão origem a força $\mathrm{Pl}$;

- Na ponta da estaca devido a pressão de contato com o solo, que também depende do movimento vertical da estaca, o qual provoca o surgimento de tensões que dão origem a força Pp.

O método AOKI \& VELLOSO (1975) com base nos resultados semi-empíricos, estima o diagrama de ruptura do sistema estaca - solo e pode ser utilizado como uma ferramenta para a obtenção do diagrama de transferência de carga, como será mostrado nas páginas seguintes:

$$
\begin{array}{ll}
\mathrm{PR}=\mathrm{PL}+\mathrm{PP} & \text { Carga na ruptura do solo que dá suporte à estaca } \\
\mathrm{PL}=\mathrm{U} \cdot \Delta \ell \cdot r_{\ell} & \text { Carga de ruptura lateral ao longo do fuste da estaca } \\
\mathrm{PP}=\mathrm{A} \cdot \mathrm{r}_{\mathrm{p}} & \text { Carga de ruptura na base da estaca } \\
\mathrm{U}=\text { perímetro da seção transversal do fuste da estaca } \\
\mathrm{A}=\text { área da projeção da ponta da estaca } \\
\Delta \ell=\text { trecho onde se admite } \mathrm{r} \ell \text { constante }
\end{array}
$$



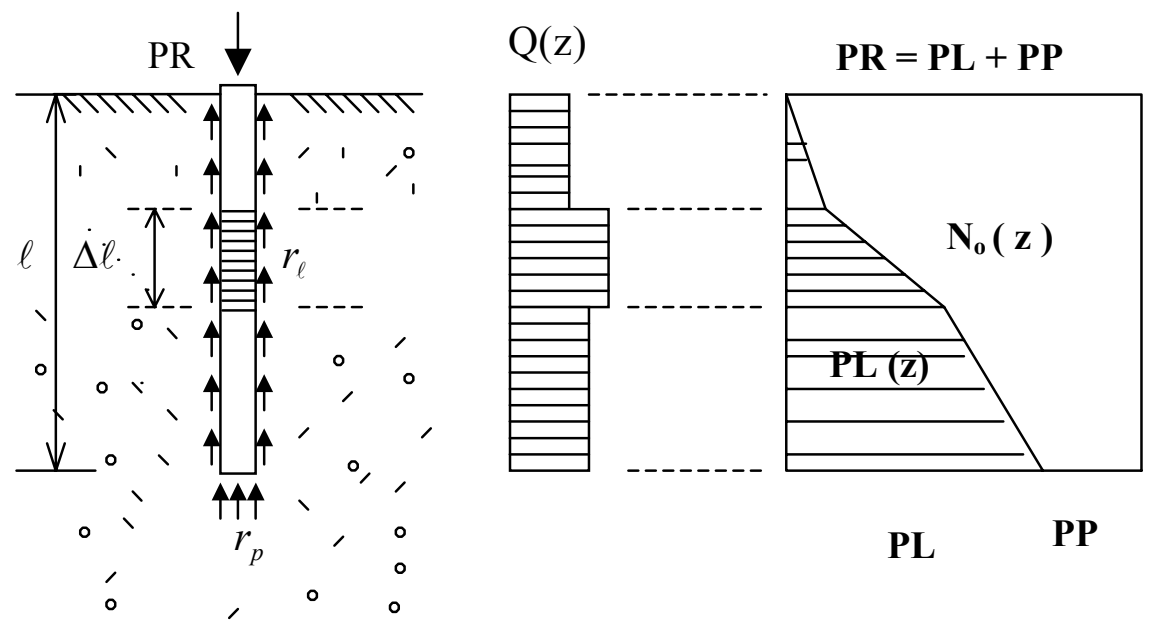

Figura 2.2 - Diagrama de ruptura do contato estaca - solo

$\mathrm{N}_{\mathrm{o}}(\mathrm{z})$ é o diagrama de esforço normal na profundidade $\mathrm{z}$ no fuste da estaca.

Segundo AOKI \& VELLOSO (1975):

$$
\begin{aligned}
& r_{p}=\frac{\mathrm{qc}}{\mathrm{F} 1} \cong \frac{\mathrm{K} \cdot \mathrm{N}}{\mathrm{F} 1} \\
& r_{\ell}=\frac{\mathrm{fs}}{\mathrm{F} 2} \cong \frac{\alpha \cdot \mathrm{K} \cdot \mathrm{N}}{\mathrm{F} 2}
\end{aligned}
$$

N é o valor do SPT obtido nas sondagens à percussão do local onde se instalará a estaca. $\mathrm{O} r_{\ell}$ é o atrito lateral ao longo do comprimento da estaca e depende do solo e tipo de estaca. $\alpha$ e K são apresentados na tabela 2.1. Os valores de $\alpha$ e $\mathrm{K}$ mais prováveis para os solos da cidade de São Paulo são apresentados em ALONSO (1983).

\begin{tabular}{|l|c|c|}
\hline Tipo de Terreno & $\mathrm{K}(\mathrm{MPa})$ & $\alpha(\%)$ \\
\hline Areia & 1,00 & 1,4 \\
\hline Areia siltosa & 0,80 & 2,0 \\
\hline Areia silto argilosa & 0,70 & 2,4 \\
\hline Areia argilosa & 0,60 & 3,0 \\
\hline Areia argilo siltosa & 0,50 & 2,8 \\
\hline Silte & 0,40 & 3,0 \\
\hline Silte arenoso & 0,55 & 2,2 \\
\hline Silte areno argiloso & 0,45 & 2,8 \\
\hline Silte argiloso & 0,23 & 3,4 \\
\hline Silte argilo srenoso & 0,25 & 3,0 \\
\hline Argila & 0,20 & 6,0 \\
\hline Argila arenosa & 0,35 & 2,4 \\
\hline Argila areno siltosa & 0,30 & 2,8 \\
\hline Argila siltosa & 0,22 & 4,0 \\
\hline Argila silto arenosa & 0,33 & 3,0 \\
\hline
\end{tabular}

\begin{tabular}{|l|c|c|}
\hline Tipo de estaca & F1 & F2 \\
\hline Franki & 2,50 & 5,00 \\
\hline Pré-moldadas & 1,75 & 3,50 \\
\hline Escavadas & 3,00 & 6,00 \\
\hline
\end{tabular}

Tabela - 2.1- Característica do solo e tipo de estacas 
Os métodos semi-empíricos para o cálculo da capacidade de carga só podem ser aplicados aos tipos de estacas e regiões geotécnicas para os quais foram estabelecidos.

Dependendo do nível de carga aplicada P, o diagrama de atrito lateral local Q(z) pode não ser compatível com a máxima resistência lateral disponível na seção. Segundo AOKI (1979) as observações experimentais mostram que:

* O atrito lateral total na ruptura PL é quase totalmente mobilizada com o pequeno deslocamento no topo da estaca: $4 \mathrm{~mm}$ a $10 \mathrm{~mm}$, aparentemente independentemente do tipo ou dimensão da estaca;

* A resistência pela ponta na ruptura PP é mobilizada para grandes deslocamentos, sendo dependente das dimensões da estaca. Ou seja, de $8 \%$ do diâmetro para as estacas cravadas e até $30 \%$ do diâmetro para as estacas escavadas.

Estes fatos evidenciam que o atrito lateral é mobilizado antes da base, podendo-se admitir de forma simplificada que a reação na base da estaca só se inicia após a total mobilização do atrito lateral.

Para a carga aplicada $\mathrm{P}$ intermediária entre carga de ruptura PR e da ruptura lateral PL, admite-se que toda a resistência lateral é mobilizada no fuste e a diferença entre P e o PL fornece a carga na base da estaca:

$\mathrm{Pp}=\mathrm{P}-\mathrm{PL}$

O diagrama de força normal na profundidade $\mathrm{z}$ da estaca é:

$\mathrm{N}_{\mathrm{o}}(\mathrm{z})=\mathrm{P}-\mathrm{PL}(\mathrm{z})$

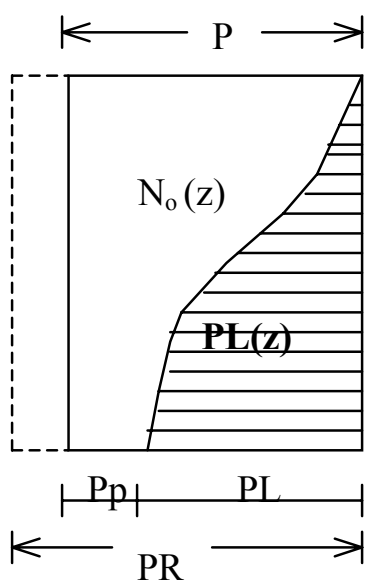

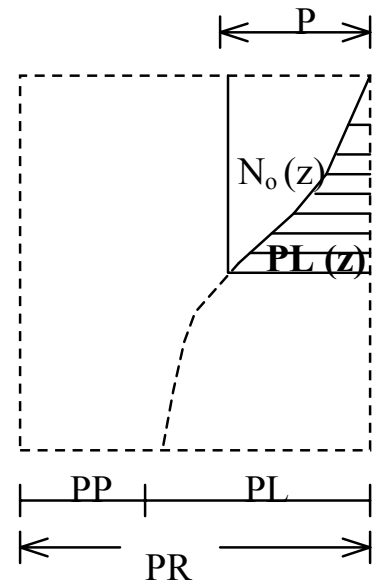

$\mathrm{N}_{\mathrm{o}}(\mathrm{z})=\mathrm{P}-\mathrm{PL}(\mathrm{z})$

( a )
( b )

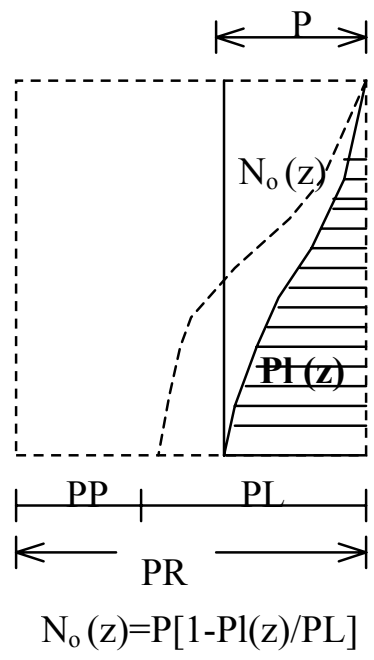

(c)

Figura 2.3 - Modelo de transferência de carga, AOKI (1979) 
No caso em que $\mathrm{P}$ aplicado for menor que a resistência lateral PL, o recalque é da ordem de alguns milímetros e admite-se que todas as cargas são suportados pelo contato lateral do fuste da estaca e o solo. Nesta condição a base da estaca não recebe carregamento e $\mathrm{Pp}=0$.

Neste caso, pode-se recorrer a duas hipóteses:

- Hipótese a, que admite a distribuição parcial da carga à medida que vai vencendo a resistência lateral máxima ao longo do fuste. (Fig. 2.3.b)

- Ou a hipótese $b$, de admitir que a distribuição se manifeste ao longo do fuste da estaca, redistribuindo as cargas (Fig. 2.3.c), neste caso o diagrama de esforço normal da estaca é:

$\mathrm{N}_{\mathrm{o}}(\mathrm{z})=\mathrm{P}[1-\mathrm{Pl}(\mathrm{z}) / \mathrm{PL}]$

Nesta proposição, o diagrama de transferência de carga vai depender somente do conhecimento do diagrama de ruptura estaca - solo e da carga aplicada no topo da estaca.

Desta forma o problema deixa de ser indeterminado e o diagrama de transferência de carga passa a ser conhecido, AOKI (1979).

\subsection{Modelo de estimativa de recalques nas fundações profundas}

A estimativa de tensões e recalques em um ponto no interior do solo, induzido por uma estaca sob carregamento vertical é um problema altamente complexo que envolve inúmeros aspectos:

- A interação solo-elemento de fundação;

- A deformação do solo;

- A deformação do elemento de fundação;

- A mudança nas características do solo e das tensões originais, decorrentes da instalação da estaca.

Para se proceder ao cálculo da parcela $\delta_{\mathrm{s}}$ (recalque na base da estaca) deve-se adotar um modelo matemático representativo do comportamento do solo. Segundo o VESIC (1975) pode-se lançar mão de três modelos:

a ) Função de transferência de carga (curvas $t-z$ );

b ) Meio elástico semi-infinito, isótropo, homogêneo, caracterizado pelo módulo de elasticidade $\mathrm{E}_{\mathrm{s}}$ e pelo coeficiente de Poisson $v$;

c) Elementos finitos. 
A adoção do primeiro tipo em que os apoios que o solo oferece é substituído por molas de rigidez conhecida, obedecendo a lei reológica expressa pela função de transferência de carga, faz crer que um ponto só se desloca se ali for aplicada uma carga. Na realidade, pontos distantes do local carregado, também sofrem deslocamentos, devido a continuidade do meio. Essa continuidade do meio é melhor representado pelos modelos b e c, sendo este ultimo de aplicação restrita.

\subsubsection{Método AOKI- LOPES}

A solução de recalques de um grupo de estacas imersas em solo foi apresentada em AOKI \& LOPES (1975), como uma extensão de VESIC (1975), através da superposição dos efeitos de cargas no interior do solo utilizando a solução de MINDLIN (1936), segundo o qual as cargas que um grupo de estacas transmitem ao terreno são discretizadas em um sistema estaticamente equivalente de cargas concentradas, cujos efeitos são superpostos no ponto em estudo.

a ) Carga na base da estaca, admitida como sendo uniformemente distribuída, é transformado em um sistema estaticamente equivalente de cargas pontuais atuando em cada uma das subáreas divididos em $\mathrm{n}_{1} \times \mathrm{n}_{2}$ partes iguais. Sendo $\mathrm{n}_{1}\left(\mathrm{n}^{\mathrm{o}}\right.$ de divisões da circunferência) e o $n_{2}$ ( $n^{o}$ de divisões do raio da base $R_{b}$ ).

A carga $\mathrm{P}_{\mathrm{b}}$ atuante na base da estaca é subdividido em cada subárea :

$$
\mathrm{P}_{\mathrm{i}, \mathrm{j}}=\frac{\mathrm{P}_{\mathrm{b}}}{\mathrm{n}_{1} \mathrm{n}_{2}} \quad \text { aplicado no ponto } \mathrm{I}_{\mathrm{i}, \mathrm{j}} \text { na profundidade } \mathrm{c}=\mathrm{Z}_{\mathrm{A}}
$$

Os $\quad \mathrm{i}, \mathrm{j}$ são índices para indicar a posição de cada subárea.

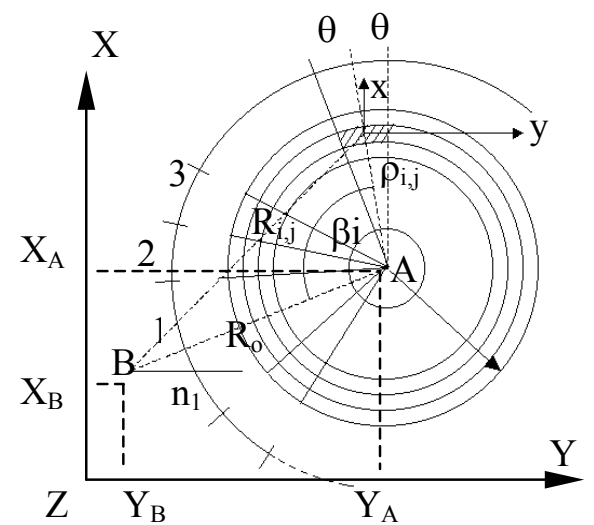

( a )

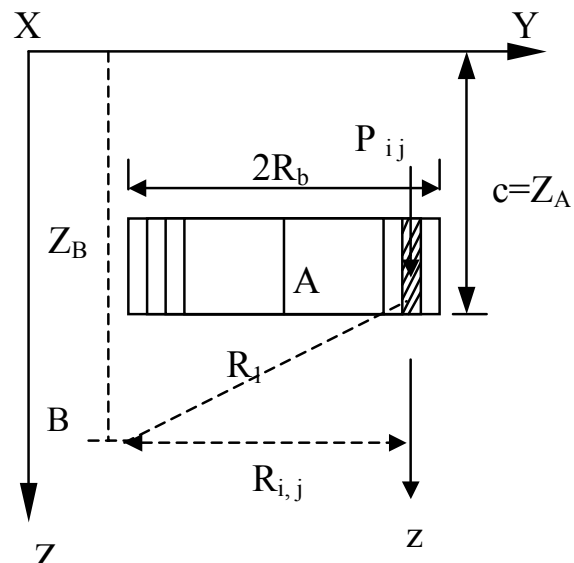

( b )

Figura 2.4 - Divisão da base em $\mathbf{n}_{1} \times \mathbf{n}_{2}$ sub-áreas (AOKI - LOPES, 1975) 
A distância $R_{1}$ entre o ponto aplicado $P_{i, j}$ e o ponto B onde se quer o recalque (Fig. 2.4b)

$$
\mathrm{R}_{1}=\sqrt{\mathrm{R}_{\mathrm{i}, \mathrm{j}}{ }^{2}+(z-c)^{2}} \quad \mathrm{Z}=\mathrm{Z}_{\mathrm{B}}
$$

$R_{i, j}$ é a distância projetada no plano XY entre o ponto de aplicação $P_{i, j}$ e o ponto $B$ (Fig. 2.4a)

$$
\begin{aligned}
& R_{i, j}=\left(R_{o}^{2}+\rho_{i, j}^{2}-2 R_{o} \rho_{i, j} \cos \beta_{i}\right)^{I / 2} \\
& \text { Onde: } \begin{aligned}
R_{o} & =\left[\left(X_{A}-X_{B}\right)^{2}+\left(Y_{A}-Y_{B}\right)^{2}\right]^{1 / 2} \\
\rho_{i, j} & =\frac{2 \operatorname{sen} \theta}{3 \theta} \frac{\mathrm{R}_{\mathrm{b}}}{\sqrt{\mathrm{n}_{2}}}[\mathrm{j} \sqrt{\mathrm{j}}-(\mathrm{j}-1) \sqrt{\mathrm{j}-1}] \\
\beta_{i} & =\frac{180^{\circ}}{\mathrm{n}_{1}}(2 \mathrm{i}-1) \\
\theta & =\frac{180^{\circ}}{\mathrm{n}_{1}}=\left(\frac{\pi}{\mathrm{n}_{1}}\right) \mathrm{rd}
\end{aligned}
\end{aligned}
$$

b) Carga no fuste da estaca, admite-se a distribuição linear. A circunferência, de raio $R_{s}$ é subdividido em $n_{1}$ partes iguais e o trecho do fuste entre as profundidades $\left(D_{2}-D_{1}\right)$ subdivididos em $n_{3}$ partes iguais. Sendo $i, k$ os índices da posição do ponto $I_{i, k}$ da superfície do fuste.
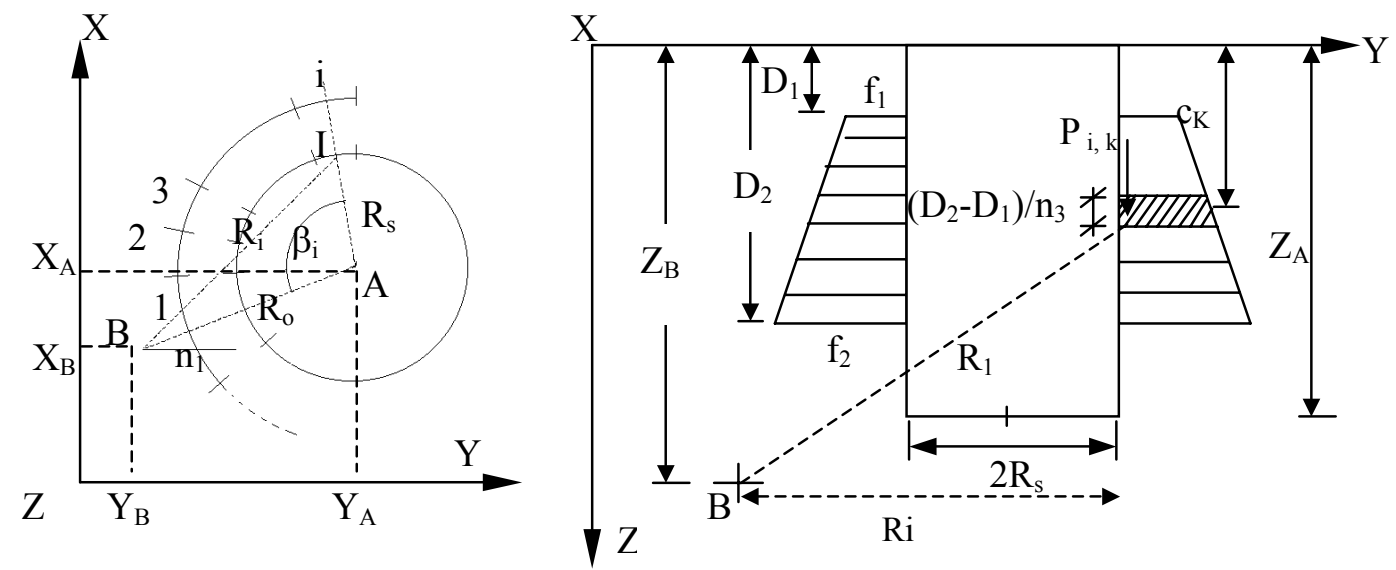

Figura 2.5 - Divisão do fuste da estaca em $n_{1} \times n_{3}$ sub-áreas (AOKI - LOPES, 1975)

A força $P_{i, k}$ aplicada na profundidade $c_{k}$ é:

$$
\mathrm{P}_{\mathrm{i}, \mathrm{k}}=\frac{\left(\mathrm{D}_{2}-\mathrm{D}_{1}\right)}{2 \mathrm{n}_{3}}\left[2 \mathrm{f}_{1}-\frac{2 \mathrm{k}-1}{\mathrm{n}_{3}}\left(\mathrm{f}_{1}-\mathrm{f}_{2}\right)\right]
$$


A profundidade $\mathrm{c}_{\mathrm{k}}$ que varia entre $\mathrm{D}_{1}$ e $\mathrm{D}_{2}$ é:

$$
c_{k}=D_{1}+\frac{D_{2}-D_{1}}{n_{3}}(k-1)+\frac{\frac{\left(D_{2}-D_{1}\right)}{n_{3}}\left[f_{1}+\left(f_{1}-f_{2}\right) \frac{1-3 k}{3 n_{3}}\right]}{2 f_{1}-\left(f_{1}-f_{2}\right) \frac{2 k-1}{n_{3}}}
$$

A distância $R_{1}$ entre o ponto aplicado $P_{i, k}$ na profundidade $c_{k}$ e o ponto $B$ onde se quer recalque é:

$$
\mathrm{R}_{1}=\sqrt{\mathrm{R}_{\mathrm{i}}{ }^{2}+\left(z-c_{k}\right)^{2}} \quad \mathrm{z}=\mathrm{Z}_{\mathrm{B}}
$$

$O R_{i}$ é a distância projetada no plano XY entre os pontos de aplicação de carga $P_{i, k} e$ o ponto $\mathrm{B}$ onde procura-se o recalque:

$$
R_{i}=\left(R_{o}^{2}+R_{s}^{2}-2 R_{o} R_{s} \cos \beta_{\mathrm{i}}\right)^{1 / 2}
$$

$R_{s}$ é o raio do fuste e o $R_{o}$ é a distância projetada no plano $X Y$ entre os pontos $A$ (centro da base) e o ponto B.

\subsubsection{Solução de MINDLIN}

Para o cálculo de recalque imediato, utilizam-se as equações de MINDLIN (1936), considerando o solo como elástico semi-infinito, embora o solo não seja um material perfeitamente elástico, homogêneo e isótropo. Esta equação onde a carga está aplicada em profundidade, fornecem as expressões das tensões verticais e seus correspondentes deslocamentos (recalques). Neste trabalho será abordado apenas a expressão de recalque vertical $r_{z}$.

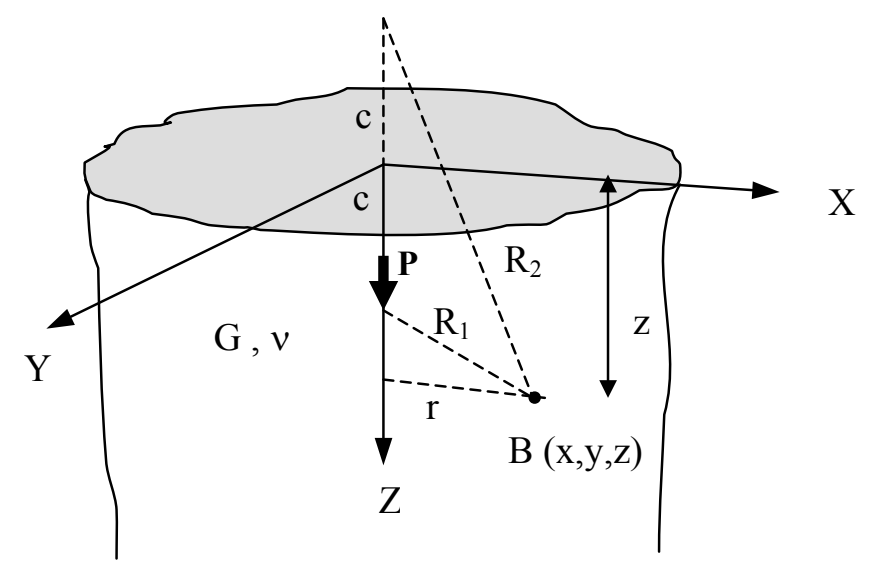

Figura 2.6 - Meio elástico semi - infinito 
Os recalques na direção $\mathrm{z}$ no ponto $\mathrm{B}$ devido a carga pontual $\mathrm{P}$ é:

$$
\begin{aligned}
& \mathrm{r}_{\mathrm{z}}=\frac{\mathrm{P}}{16 \pi \mathrm{G}(1-v)}\left[\frac{3-4 v}{\mathrm{R}_{1}}+\frac{8(1-v)^{2}-(3-4 v)}{\mathrm{R}_{2}}+\frac{(\mathrm{z}-\mathrm{c})^{2}}{\mathrm{R}_{1}^{3}}+\frac{(3-4 v)(z+\mathrm{c})^{2}-2 c z}{\mathrm{R}_{2}^{3}}+\frac{6 c z(\mathrm{z}+\mathrm{c})^{2}}{\mathrm{R}_{2}^{5}}\right] \\
& \text { onde: } \begin{aligned}
& \mathrm{R}_{1}=\sqrt{\mathrm{r}^{2}+(\mathrm{z}-\mathrm{c})^{2}} \\
& \mathrm{R}_{2}=\sqrt{\mathrm{r}^{2}+(\mathrm{z}+\mathrm{c})^{2}} \\
& v=\text { Coeficiente de Poisson } \\
& \mathrm{G}=\text { módulo de elasticidade transversal do solo } \\
& \mathrm{P}=\text { carga aplicada dentro do meio contínuo } \\
& \mathrm{B}(\mathrm{x}, \mathrm{y}, \mathrm{z}) \text { é o ponto em estudo, onde se quer saber o recalque } \mathrm{r}_{\mathrm{z}} \\
& \text { Na notação deste trabalho, } \mathrm{r}_{\mathrm{z}}=\delta_{\mathrm{s}} \text { (recalque na base da estaca) }
\end{aligned}
\end{aligned}
$$

No nosso caso, $\mathrm{B}(\mathrm{x}, \mathrm{y}, \mathrm{z})$ é o próprio ponto na base de cada estaca. (Fig. 2.7)

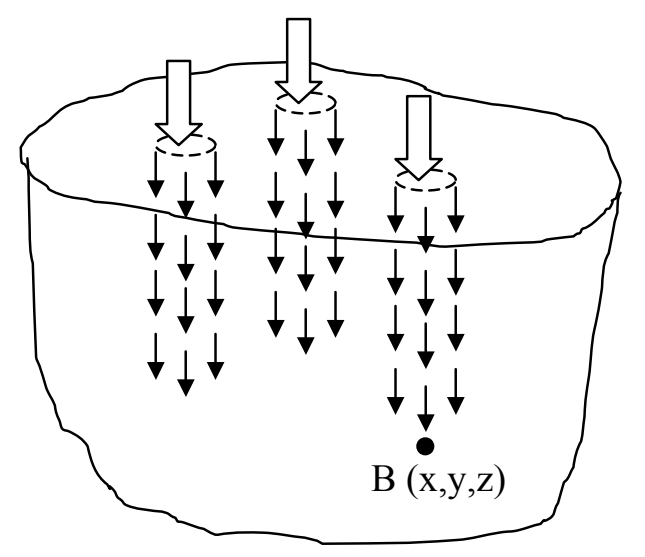

Figura 2.7 - Sistema estaticamente equivalente de cargas

A base da estaca, pode se deslocar devido às cargas aplicadas ao longo do fuste $\mathrm{Q}(\mathrm{z})$ e ou da ponta Pp . De acordo com VESIC (1975) pode-se escrever:

$\delta \mathrm{s}=\delta \mathrm{s}, \mathrm{f}+\delta \mathrm{s}, \mathrm{b}$

$\delta \mathrm{s}, \mathrm{f}=$ parcela de deslocamento na base da estaca devido à ação no fuste;

$\delta \mathrm{s}, \mathrm{b}=$ parcela de deslocamento na base da estaca devido à ação na base da estaca.

Esta idéia em dividir o $\delta$ s em duas parcelas, permitiu a consideração da plastificação do contato do fuste com o maciço de solo que ocorre após a total mobilização da resistência lateral fuste - solo, passando o restante da carga para a base da estaca. Com isso o comportamento da estaca imersa no solo torna-se elástico não linear, como observado em resultados experimentais.

Os recalques, devido a aplicação de um conjunto de cargas pontuais, em um ponto em estudo $\mathrm{B}(\mathrm{x}, \mathrm{y}, \mathrm{z})$ é obtido pela somatória de recalques devido às cargas atuantes nos fustes 
de um grupo de estacas e a somatória dos recalques devido às cargas atuantes nas bases de um grupo de estacas, (Fig. 2.7).

$$
\delta_{\mathrm{s}}=\sum_{\mathrm{n}=1}^{\mathrm{N} \text { estacas }} \sum_{\mathrm{i}=1}^{\mathrm{n} 1} \sum_{\mathrm{j}=1}^{\mathrm{n} 2} \delta_{i, j}+\sum_{\mathrm{n}=1}^{\mathrm{N} \text { estacas }} \sum_{\mathrm{i}=1}^{\mathrm{n} 1} \sum_{\mathrm{k}=1}^{\mathrm{n} 3} \delta_{\mathrm{i}, \mathrm{k}}
$$

Onde, $\delta_{\mathrm{i}, \mathrm{j}}$ é o recalque na base da estaca devido a carga pontual $\mathrm{P}_{\mathrm{i}, \mathrm{j}}$ atuante na base da estaca e $\delta_{i, k}$ é o recalque na base da estaca devido a carga pontual $\mathrm{P}_{\mathrm{i}, \mathrm{k}}$ atuante no fuste da estaca.

\subsubsection{Procedimento de STEINBRENNER}

As fórmulas apresentadas por Mindlin partem da hipótese de que o solo é um meio homogêneo e semi - infinito o que não corresponde à realidade do solo natural que apresenta estratificação e camada indeslocável em uma determinada profundidade. Para levar em conta estes problemas, pode-se recorrer ao artifício proposto por STEINBRENNER (1934), ainda considerando o solo como semi - infinito e com o uso de MINDLIN (1936) calcula-se:

- O recalque $\mathrm{r}_{\mathrm{i}}{ }^{\infty}$ na profundidade "i” no nível entre a superfície e o indeslocável;

- O recalque $\mathrm{r}_{\mathrm{h}}{ }^{\infty}$ na profundidade " $\mathrm{h}$ " escolhido como nível indeslocável.

Como no nível indeslocável o recalque é teoricamente nulo, qualquer recalque no nível "i”"que esteja no nível acima será obtido pela diferença entre os recalques dos dois níveis:

$$
r_{i}=r_{i}^{\infty}-r_{h}^{\infty}
$$

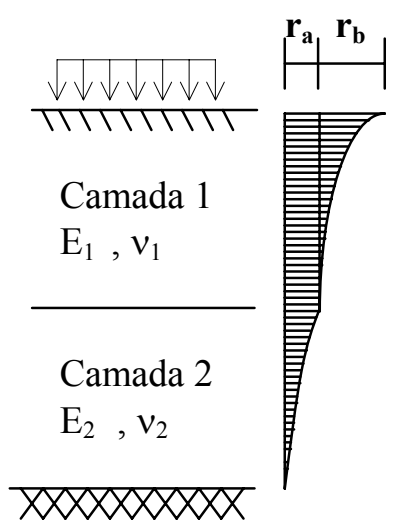

(a) Recalque final

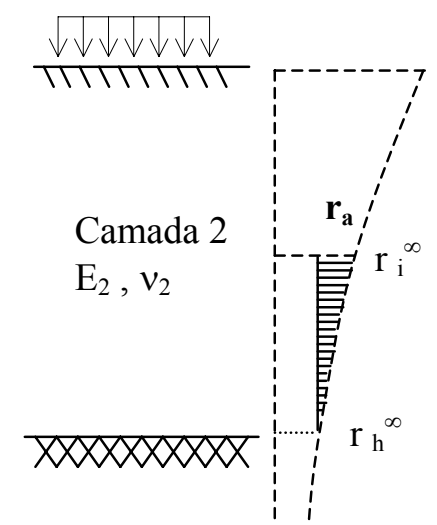

(b)

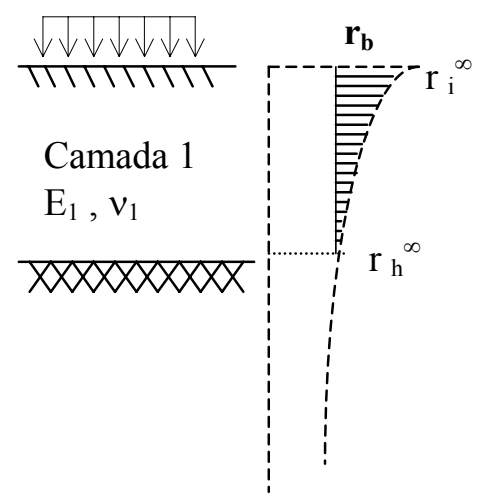

(c)

Figura 2.8 - Aplicação de Steinbrenner para várias camadas 
A proposição de Steinbrenner pode ser generalizada para o caso em que existem várias camadas antes do indeslocável. O cálculo é feito da camada de baixo para cima, admitindo-se que todo o solo, do indeslocável para cima, seja do mesmo material da camada 2 (Fig. 2.8.b). Em seguida, calcula-se o recalque $\mathrm{r}_{\mathrm{i}}^{\infty}$ no topo da camada 2 e $\mathrm{r}_{\mathrm{h}}^{\infty}$ no nível do indeslocável. O recalque nesta camada será $\mathrm{r}_{\mathrm{a}}$, calculado na expressão 2.28.

O procedimento é repetido, levando-se o indeslocável para o nível da camada já calculada e utilizando-se as características do solo imediatamente acima calcula-se o recalque $\mathrm{r}_{\mathrm{b}}$ (Fig. 2.8.c). O recalque no nível da aplicação da carga será obtido pela superposição dos recalques $r_{i}$ das camadas (Fig. 2.8.a).

Aplicando o mesmo raciocínio para caso de estacas imersas no solo, tem-se:

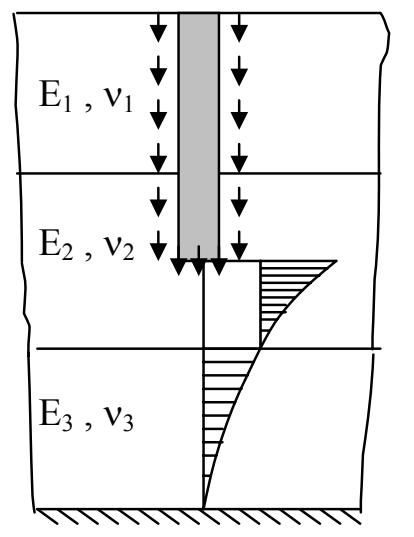

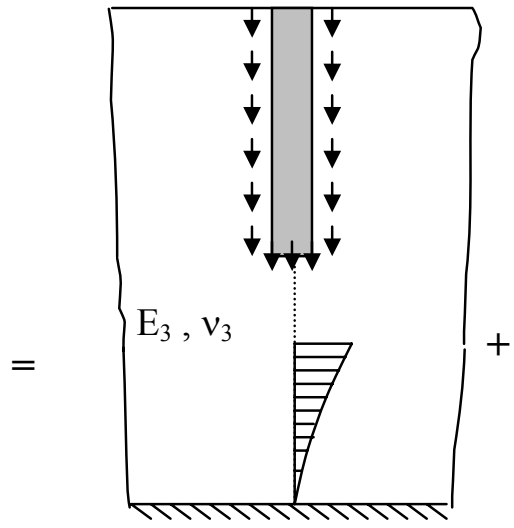

(b)

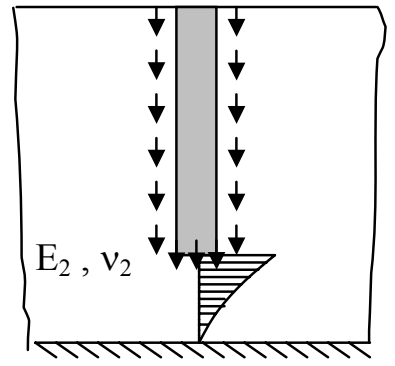

(c)

(a) Recalque final na base da estaca

Figura 2.9 - Procedimento de Steinbrenner para estacas

Onde determina-se para cada nível da camada o correspondente $\mathrm{r}_{\mathrm{i}}$ com características daquela camada em estudo (Fig. 2.9 b, c). Portanto, o recalque $\delta_{\mathrm{s}}$ é a somatória de todos os recalques de n camadas abaixo do nível da base da estaca, (Fig. 2.9 a).

Lembrando-se que os recalques na base da estaca devem levar em conta os efeitos de outras estacas j além da própria estaca i. Feito isso, o recalque no topo da estaca i é a soma do recalque na base da estaca $\delta$ s e a deformação elástica do fuste $\delta p$ :

$\delta o_{i}=\delta s_{i}+\delta p_{i}$

O potencial deste processo que utiliza STEINBRENNER (1934) é comprovado em vários trabalhos entre eles destaca-se o relatório apresentado em KUSAKABE et al. (1989).

Além do processo apresentado acima, pode ser resolvido também, de tal forma que determina-se inicialmente as tensões $\sigma_{\mathrm{x}}, \sigma_{\mathrm{y}}$ e $\sigma_{\mathrm{z}}$ na altura média de cada camada e assim calculam-se deformações daquela camada com espessura $\Delta_{z}$ pela seguinte expressão:

$$
\mathrm{r}_{\mathrm{z}}=\varepsilon_{\mathrm{z}} \Delta_{z}=\frac{1}{\mathrm{E}}\left[\sigma_{\mathrm{z}}-v\left(\sigma_{\mathrm{x}}+\sigma_{\mathrm{y}}\right)\right] \Delta_{\mathrm{z}}
$$




\subsubsection{Consideração do contato bloco diretamente no solo}

DO VAL \& MELLO (1986) apresentam uma adaptação do método de Aoki \& Lopes para se levar em conta o efeito de bloco, a partir de três metodologias conhecidas;

- Estática de estaqueamentos pelo método Schiel;

- Determinação de recalques de grupos de estacas pelo método Aoki-Lopes;

- Determinação de recalques em sapatas.

Trata-se de um método de cálculo que permite estimar os recalques de um grupo de estacas levando-se em conta a capacidade do bloco de capeamento de transmitir diretamente ao solo uma parcela da carga oriunda da estrutura. O processo é iterativo, alcançando na convergência, tanto equilíbrio quanto compatibilidade.

Com esta contribuição do bloco, os autores mostram que houve uma redução significativa de recalques e esforços nas estacas, comparado e observado no caso real de uma fundação com grupo de quatro estacas de um edifício industrial. No entanto, sempre deve ter em conta que um certo grau de adensamento é inevitável quando se está tratando com os solos que são materiais inexoravelmente heterogêneos e anisotrópicos, em contraste com a idealização de cálculo.

AOKI (2000), comenta que a contribuição do bloco de coroamento pode ser obtido pela simples adição de estacas de altura $\mathrm{h} \approx 0$ e de seção quadrangular, por exemplo:

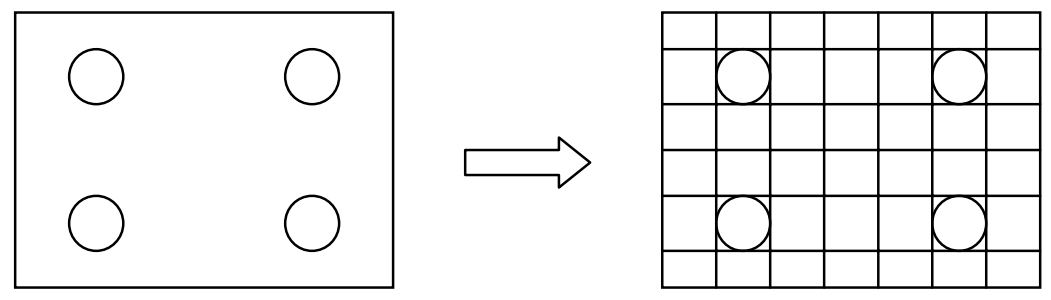

Figura 2.10 - Contribuição do bloco

Onde cada 'pile-raft' será discretizada em pequenas cargas concentradas estaticamente equivalentes. (Figura 2.11)

A distância entre os pontos onde se aplica carga $\mathrm{P}_{\mathrm{i}, \mathrm{j}}$ e o ponto B no plano XY é:

$$
\begin{aligned}
\mathrm{R}_{\mathrm{i}, \mathrm{j}}=\left\{\left[X_{A}-X_{B}+L \frac{2 i-1}{2 n_{1}} \cos \alpha-B \frac{2 j-1}{2 n_{2}} \operatorname{sen} \alpha\right]^{2}+\right. \\
\left.\quad\left[Y_{A}-Y_{B}+L \frac{2 i-1}{2 n_{1}} \operatorname{sen} \alpha+B \frac{2 j-1}{2 n_{2}} \cos \alpha\right]^{2}\right\}^{1 / 2}
\end{aligned}
$$


Onde a profundidade $\mathrm{c}=\mathrm{z}$ (o mesmo nível onde atua carga P), tem-se:

$$
\begin{aligned}
& \mathrm{R}_{1}=\mathrm{R}_{\mathrm{i}, \mathrm{j}} \\
& \mathrm{R}_{2}=\sqrt{\mathrm{R}_{\mathrm{i}, \mathrm{j}}^{2}+4 z^{2}}
\end{aligned}
$$

Quando a sapata está na superfície do terreno, tem-se $\mathrm{c}=\mathrm{z}=0$ e o problema recai na solução particular de Boussinesq.

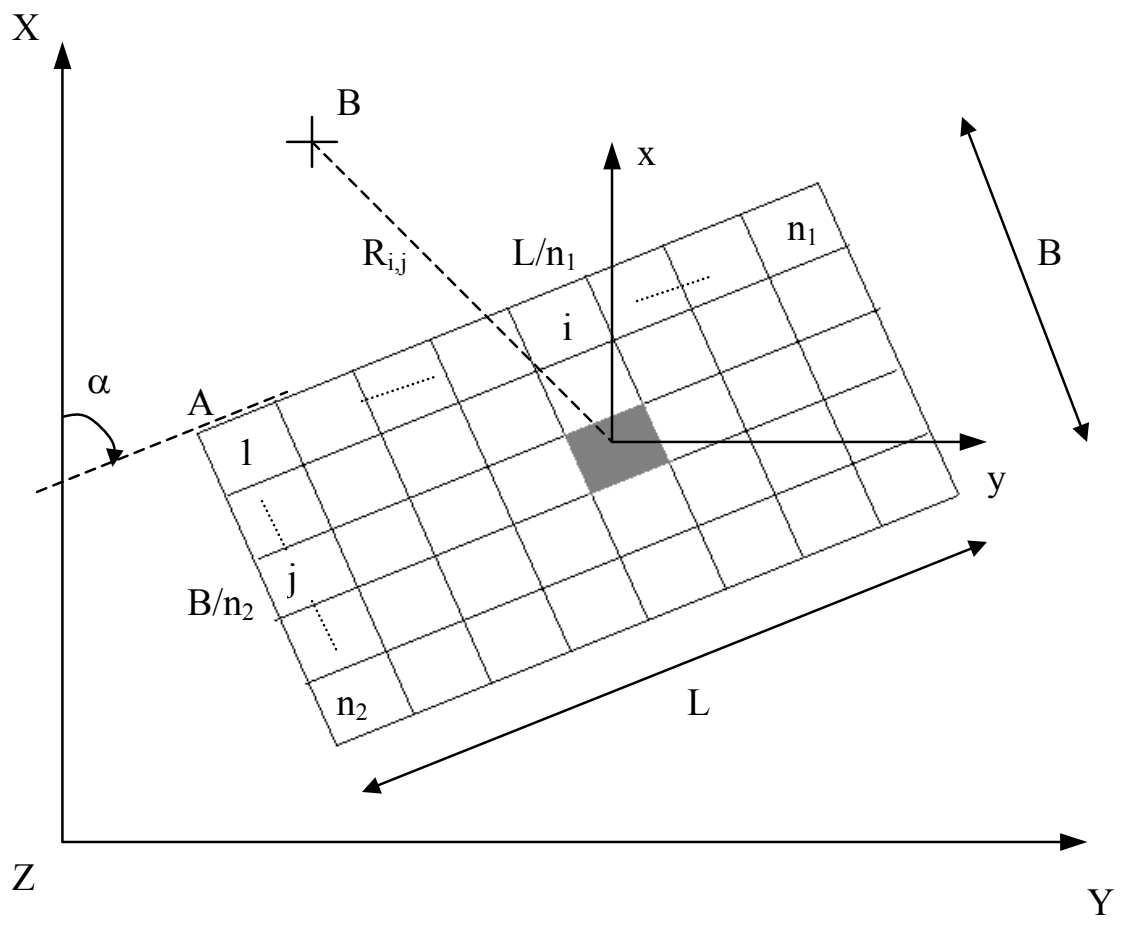

Figura 2.11 - Seção retangular - AOKI-LOPES (1975)

O presente trabalho, esta consideração do contato do bloco com efeitos de grupos de estacas, no programa computacional, pode ser facilmente adaptado. 


\section{MODELO ESTRUTURAL}

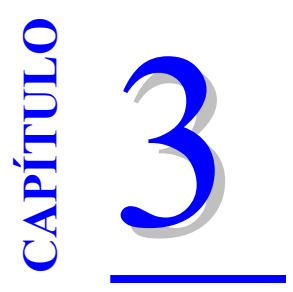

\subsection{Introdução}

A modelagem da estrutura tridimensional para fins de análise de edifícios altos, mostrada neste trabalho, utiliza os recursos computacionais desenvolvidos em ANTUNES (1978), pelo tratamento matricial de métodos dos deslocamentos com elementos de barras e a consideração de diafragma rígido.

PRUDENTE (1983) analisou estruturas constituídas de painéis de contraventamento, formados por vigas e pilares não sujeitos a efeitos de flexo - torção. RIOS (1991) considerou as excentricidades entre os elementos de vigas e pilares. BEZERRA (1995) com a implementação de elementos DKT de placas levou em consideração a contribuição da rigidez transversal à flexão das lajes no comportamento global da estrutura. MARTINS (1998) implementou a não linearidade geométrica dos pilares de seções bi - simétricas e a interface em Visual Basic com geração automática de malha de elementos finitos.

O modelo a ser adotado neste trabalho é um caso particular de MARTINS(1998) de análise tridimensional, com pilares analisados em teoria de primeira ordem, com ou sem a consideração da excentricidade das vigas em relação aos pilares, e contribuição de rigidez de

placas à flexão e admitindo as lajes infinitamente rígidos no seu plano horizontal. É adotada a hipótese de comportamento do material como sendo elástico - linear. 


\subsection{Elementos estruturais}

\subsubsection{Vigas}

São admitidas seções quaisquer para cada trecho, compostas por elementos lineares contidos no plano horizontal, ao nível das lajes. Suas extremidades podem estar conectadas em vigas ou pilares. Neste último caso, a excentricidade pode ser admitida em relação ao centro de gravidade do pilar.

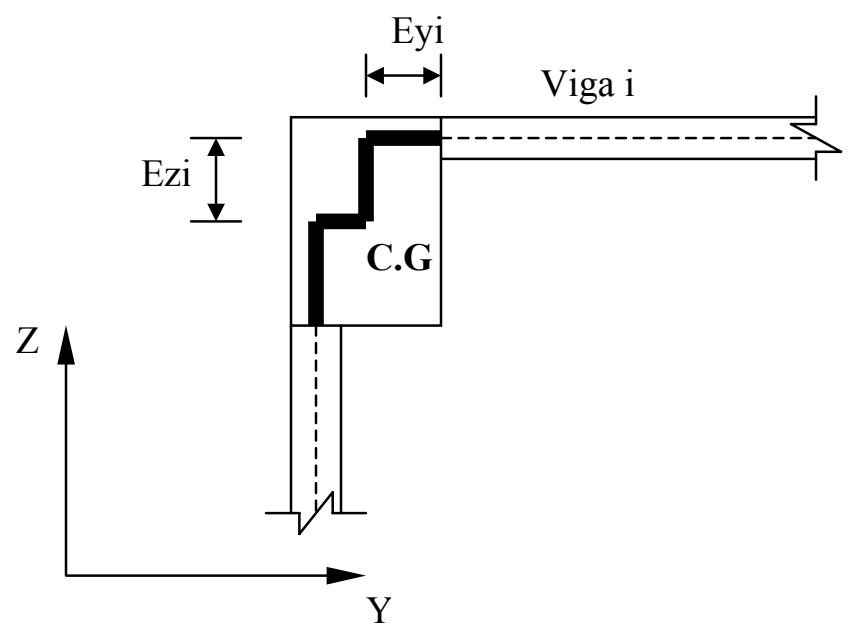

Figura 3.1 - Excentricidade da viga i em relação ao C.G do pilar

\subsubsection{Pilares}

Neste trabalho, os pilares são os únicos elementos estruturais que fazem a conexão entre dois pavimentos consecutivos, devendo apresentar trechos lineares verticais.

Como na análise do sistema, o edifício é dividido em várias subestruturas independentes, não é preciso que um mesmo pilar esteja presente em todos os andares, podendo ocorrer sua interrupção em qualquer pavimento.

Não será considerado o efeito do empenamento das seções transversais dos pilares na flexo - torção. 


\subsubsection{Lajes}

No plano horizontal, será aplicado a hipótese de diafragma infinitamente rígido e assim, compatibilizando as translações horizontais para todos os pilares que estejam conectados no mesmo plano. Na flexão, tem-se a rigidez transversal pelo uso de elementos finitos DKT (Discrete Kirchhoff Theory) de placa. A existência de excentricidade entre o eixo do elemento de viga e o plano médio da laje não será considerado neste trabalho.

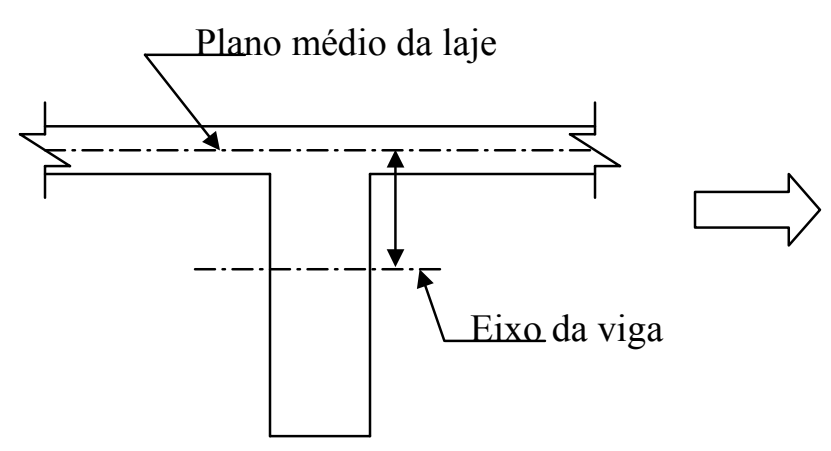

a ) Situação Real

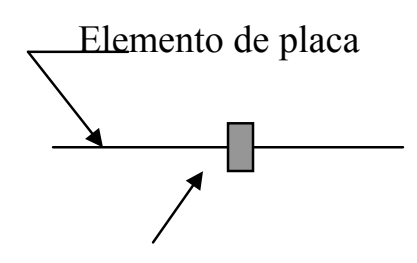

Elemento de barra

b ) Modelo adotado

\subsubsection{Subestruturas}

Neste trabalho, cada subestrutura é representada por um pavimento que compreende os elementos horizontais (vigas e lajes) e elementos verticais (pilares ou pilares paredes). As subestruturas podem ser diferentes entre si, permitindo assim, diferentes tipos de pavimentos ao longo da altura do edifício, tais como: interrupção de pilares, diferentes arranjos de vigas e lajes, mudança nos carregamentos permanentes (verticais), etc. 


\subsection{Sistema de referência}

\subsubsection{Sistema de referência global}

Apesar do argumento mostrado na Fig. 1.1, será preservado o sistema de referência original dos trabalhos anteriores BEZERRA(1995) e MARTINS(1998) pra manter a mesma lógica na entrada de dados e no processamento.

É adotado um sistema de eixos cartesianos $\mathrm{X}, \mathrm{Y}$ e $\mathrm{Z}$ com origem $\mathrm{O}_{\mathrm{G}}$ contida em um ponto arbitrário do plano da base do edifício, conforme a figura:

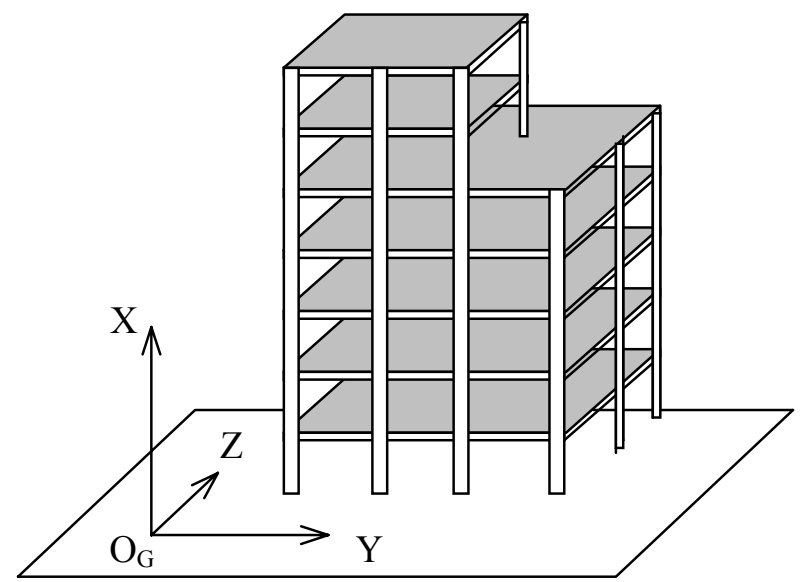

Figura 3.3 - Sistema de referência global da estrutura

\subsubsection{Sistema de referência local das vigas}

Adota-se um sistema de referência local, com origem no centro de gravidade da seção transversal. O eixo Yv é o próprio eixo longitudinal da viga e deve coincidir com o plano médio da laje.

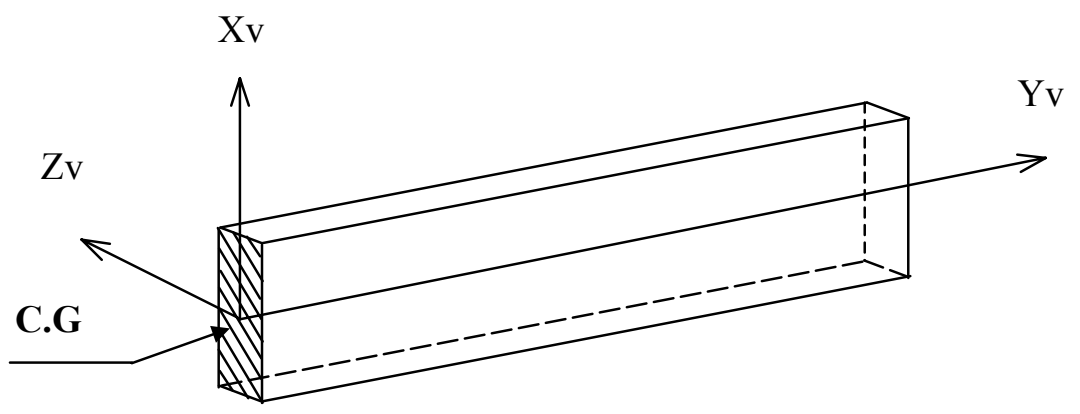

Figura 3.4 - Sistema de referência local das vigas 


\subsubsection{Sistema de referência das lajes}

É definido pelo sistema cartesiano de eixos $\mathrm{Y}$ e Z contidas no plano médio da laje e eixo $\mathrm{X}$ positivo para cima.

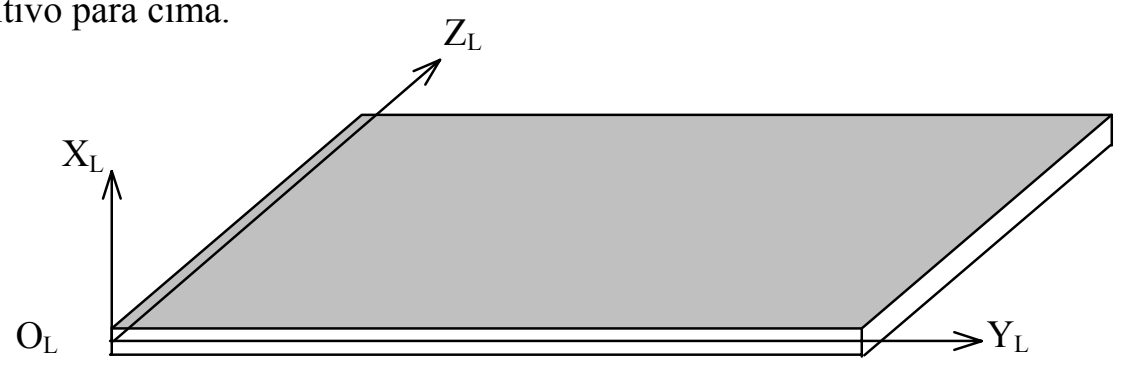

Figura 3.5 - Sistema de referência das lajes

\subsubsection{Sistema de referência dos pilares}

Começa na extremidade inferior da peça, sendo $\mathrm{Yp}$ e $\mathrm{Zp}$ os eixos principais de inércia e o eixo Xp passa na linha do centro de gravidade da seção do pilar.

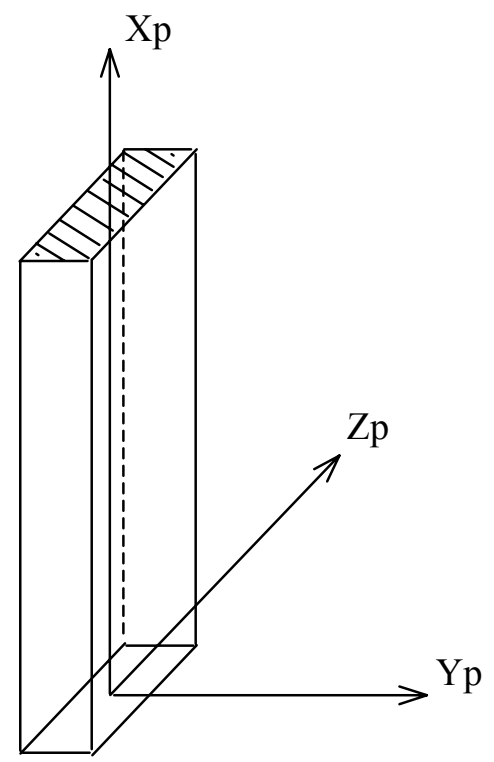

Figura 3.6 - Sistema de referência dos pilares 


\subsubsection{Sistema de referência da subestrutura}

O sistema referente a subestrutura está contida no plano do pavimento correspondente, ou seja é o mesmo das lajes.

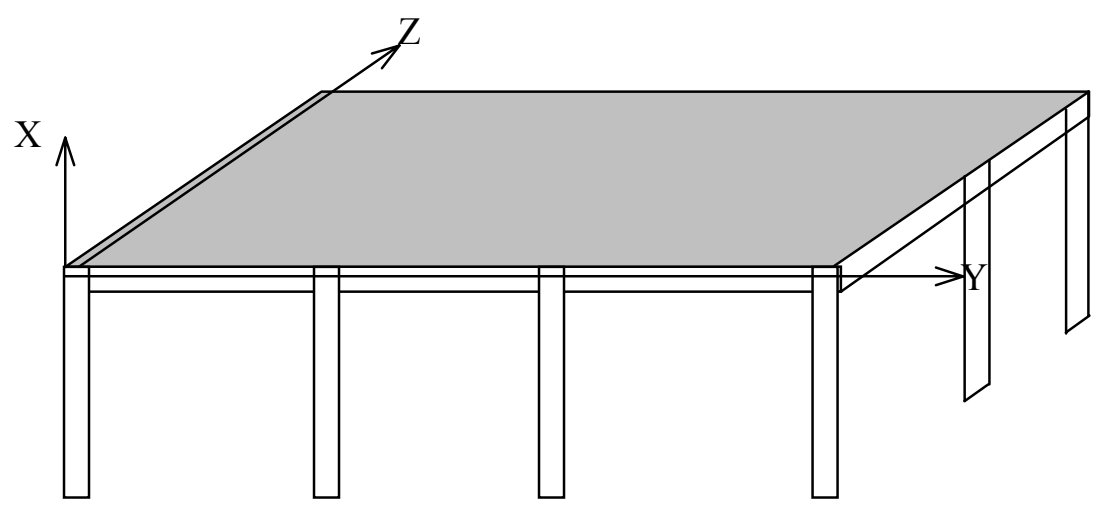

Figura 3.7 - Sistema de referência da subestrutura

\subsection{Sistema de coordenadas dos elementos estruturais}

\subsubsection{Vigas}

As coordenadas dos elementos são deslocamentos possíveis nas extremidades das peças. São adotados as seguintes convenções;

$$
\left\{\mathrm{u}_{\mathrm{V}}\right\}^{\mathrm{t}}=\left\{\begin{array}{llllll}
\delta_{\mathrm{XV} 1} & \phi_{\mathrm{YV} 1} & \phi_{\mathrm{ZV} 1} & \delta_{\mathrm{XV} 2} & \phi_{\mathrm{YV} 2} & \phi_{\mathrm{ZV} 2}
\end{array}\right\}
$$

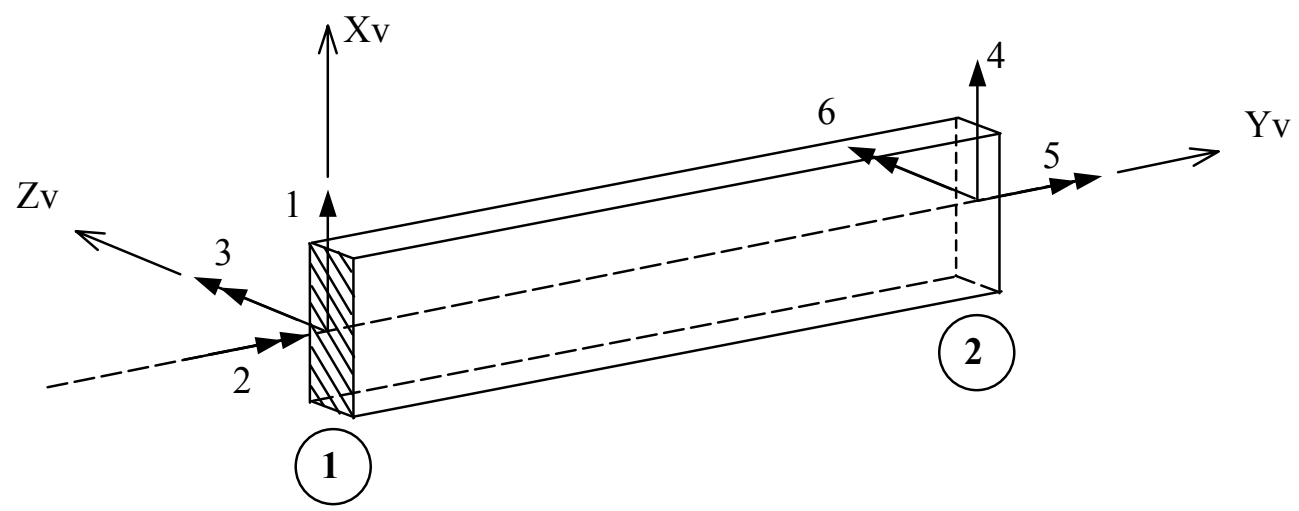

Figura 3.8 - Coordenadas deslocamentos locais de viga

Sendo desprezada a deformação axial da viga pela hipótese adotado de o pavimento se comportar como corpo rígido no seu plano horizontal. 


\subsubsection{Lajes}

A laje é considerada como diafragma infinitamente rígido em seu plano. Com esta hipótese, todas as translações segundo os eixos $\mathrm{Y}, \mathrm{Z}$ e rotação em torno do eixo $\mathrm{X}$ do sistema de referência global da subestrutura são compatibilizados pelo mesmo deslocamento (Fig. 3.9). O vetor deslocamentos referente ao movimento de corpo rígido do pavimento é:

$$
\left\{u_{L}\right\}^{T}=\left\{\begin{array}{lll}
\delta_{Y} & \delta_{Z} & \phi_{X}
\end{array}\right\}
$$

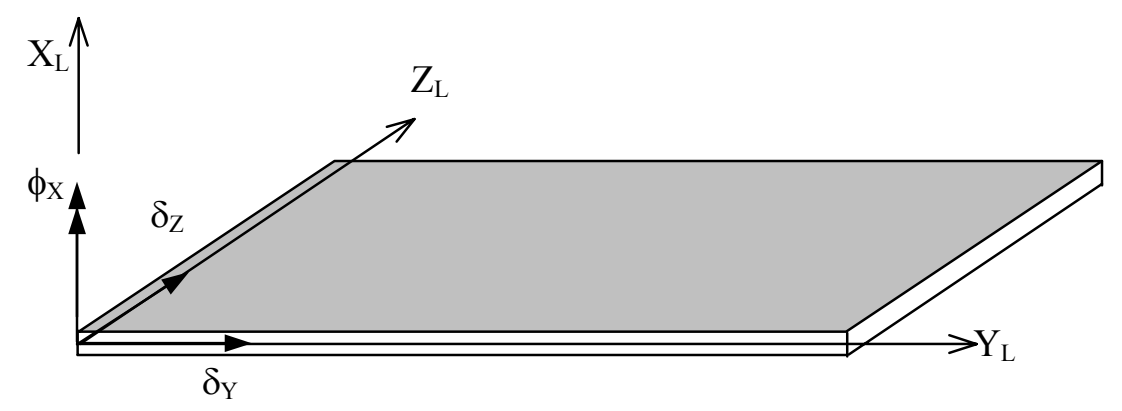

Figura 3.9 - Coordenadas deslocamentos de corpo rígido no plano horizontal da laje

Além destes vetores, a laje discretizado em elementos finitos $D K T$, para levar em consideração a rigidez transversal à flexão, têm-se ainda três coordenadas de deslocamentos por nó (Fig. 3.10). Para cada elemento $D K T$ tem-se então 9 coordenadas:

$$
\left\{\mathrm{u}_{\mathrm{DKT}}\right\}^{\mathrm{T}}=\left\{\begin{array}{lllllllll}
\delta_{\mathrm{X} 1} & \phi_{\mathrm{Y} 1} & \phi_{\mathrm{Z} 1} & \delta_{\mathrm{X} 2} & \phi_{\mathrm{Y} 2} & \phi_{\mathrm{Z} 2} & \delta_{\mathrm{X} 3} & \phi_{\mathrm{Y} 3} & \phi_{\mathrm{Z} 3}
\end{array}\right\}
$$

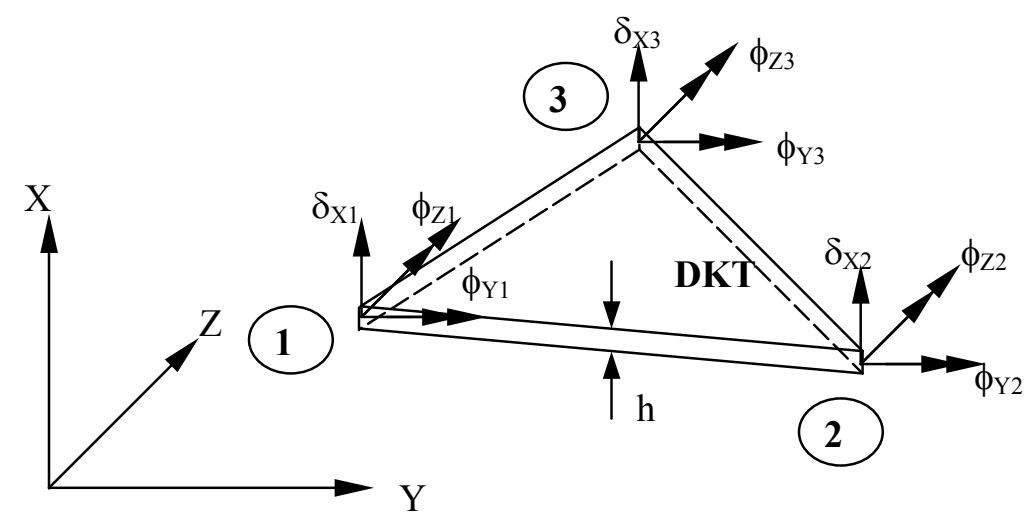

Figura 3.10 - Coordenadas deslocamentos de placa DKT 


\subsubsection{Pilares}

Os pilares tem coordenadas deslocamentos com três rotações e três translações para cada extremidade em relação ao eixo central de inércia da seção. (Fig 3.11)

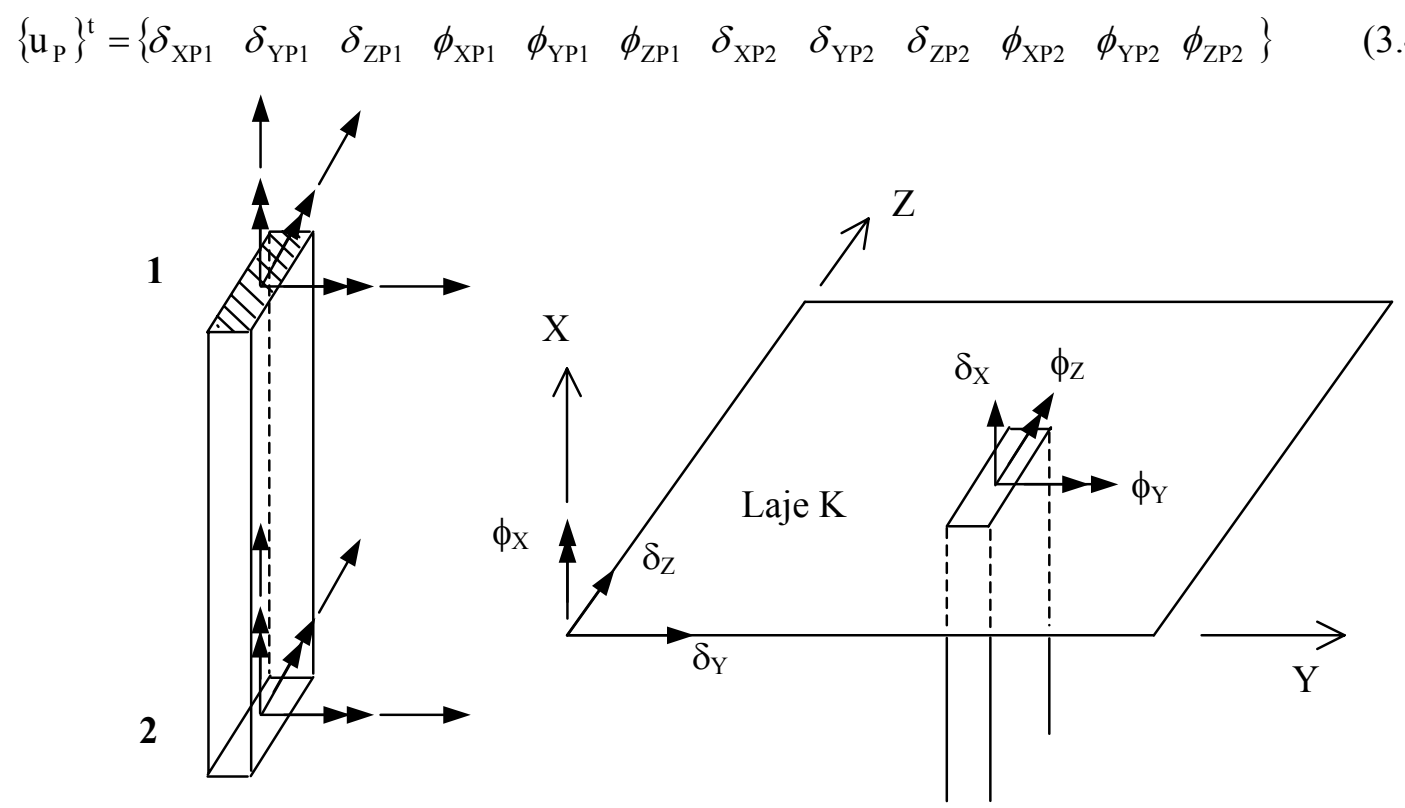

Figura 3.11

Coordenadas deslocamentos locais do pilar
Figura 3.12

Coordenadas deslocamentos locais do nó de pilar na subestrutura

\subsubsection{Subestrutura}

As coordenadas deslocamentos (Fig. 3.12) são discriminados em duas:

- Coordenadas dependentes: são deslocamentos referentes ao movimento de corpo rígido do pavimento; rotação em torno de eixo $\mathrm{X}$ e translação em Y e Z, $\left(\phi_{\mathrm{X}}, \delta_{\mathrm{Y}}\right.$ e $\left.\delta_{\mathrm{Z}}\right)$.

- Coordenadas independentes: são deslocamentos referentes à rotação em torno dos eixos $\mathrm{Y}$ e Z e a translação segundo o eixo $\mathrm{X},\left(\delta_{\mathrm{X}}, \phi_{\mathrm{Y}}\right.$ e $\left.\phi_{\mathrm{Z}}\right)$

$\mathrm{Na}$ subestrutura, todos os deslocamentos de translação segundo os eixos $\mathrm{Y}, \mathrm{Z}$ e rotação no $\mathrm{X}$ dos pilares serão compatibilizados para o movimento de corpo rígido do pavimento. As coordenadas dos elementos finitos DKT que compõem as lajes discretizados serão condensadas para as coordenadas independentes dos pilares, como será mostrado no item 3.7.1. 


\subsubsection{Estaqueamentos}

São adotadas as seguintes hipóteses:

a) As estacas são supostas articuladas no bloco e na ponta, portanto só recebem força normal segundo o seu eixo;

b) O bloco de coroamento é suposto infinitamente rígido, tanto no plano horizontal funcionando como diafragma rígido, quanto no seu plano transversal. Esta simplificação é válida na maior parte dos casos práticos onde os blocos são suficientemente espessos;

c) Despreza-se a contribuição do bloco trabalhando como sapata rasa. Essa hipótese é favor da segurança pois com um assentamento posterior o terreno pode descolar-se do bloco.

d) As estacas são verticais e recebem apenas forças axiais de compressão.

As hipóteses a, b e c são características próprias do método Schiel, enquanto que a d é uma particularização que foi adotado neste trabalho para possibilitar a aplicação do modelo mostrado em AOKI (1987) válido somente para estacas verticais submetidos à esforços axiais de compressão.

Como, neste modelo de estaqueamento as estacas são rotuladas no bloco e todas verticais, é necessário restringir a deslocabilidade nas direções horizontais dos eixos y, z e uma rotação em torno do eixo x, para evitar o sistema hipostático.
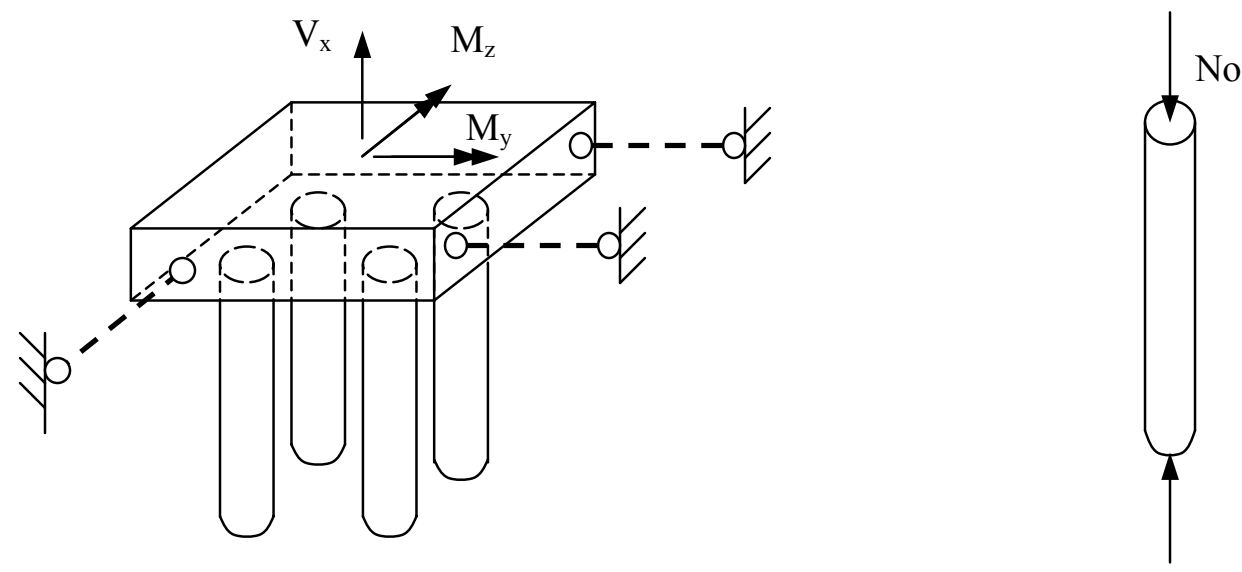

Figura 3.13 - Coordenadas deslocamentos do bloco e estaca 


\subsection{Obtenção de elemento finito quadrangular a partir dos triangulares}

$\mathrm{Na}$ maioria dos casos, as lajes que compõem os pavimentos de edifícios apresentam geometria retangular. Nesse caso, a entrada de dados tanto pelo arquivo quanto pela discretização automática por malhas compostas de elementos quadrangulares torna-se mais simples do que por elementos triangulares.

O elemento quadrangular pode ser obtido pela condensação estática de quatro elementos triangulares DKT. Assim como os elementos triangulares são utilizados em lajes de contorno poligonal qualquer, os elementos quadrangulares também podem ser utilizados.
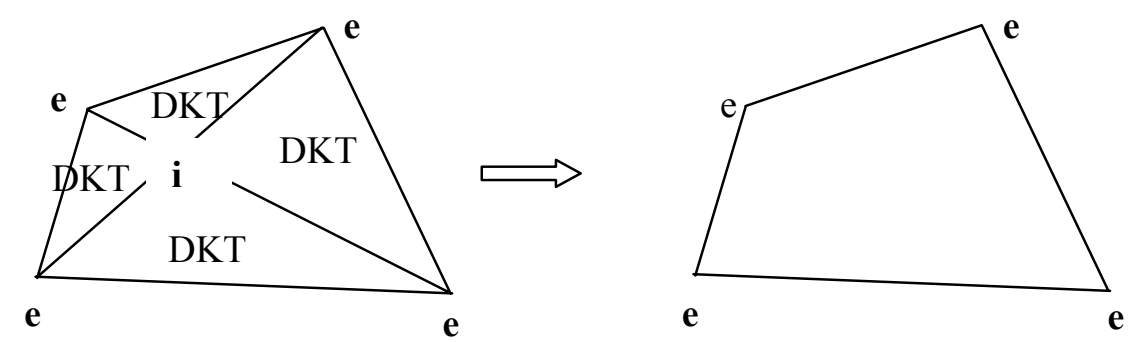

Figura 3.14 - Elemento quadrangular formado a partir de elementos triangulares

$$
\left[\begin{array}{ll}
{\left[r_{\mathrm{ee}}\right]_{12 \times 12}} & {\left[\mathrm{r}_{\mathrm{ei}}\right]_{12 \times 3}} \\
{\left[\mathrm{r}_{\mathrm{ie}}\right]_{3 \times 12}} & {\left[\mathrm{r}_{\mathrm{ii}}\right]_{3 \times 3}}
\end{array}\right]\left\{\begin{array}{l}
\left\{\mathrm{u}_{\mathrm{e}}\right\}_{12 \times 1} \\
\left\{\mathrm{u}_{\mathrm{i}}\right\}_{3 \times 1}
\end{array}\right\}=\left\{\begin{array}{l}
\left\{\mathrm{f}_{\mathrm{e}}\right\}_{12 \times 1} \\
\left\{\mathrm{f}_{\mathrm{i}}\right\}_{3 \times 1}
\end{array}\right\}
$$

Desenvolvendo a equação, tem-se:

$$
\begin{aligned}
& \left\{\mathrm{f}_{\mathrm{e}}\right\}=\left[\mathrm{r}_{\mathrm{ee}}\right]\left\{\mathrm{u}_{\mathrm{e}}\right\}+\left[\mathrm{r}_{\mathrm{ei}}\right]\left\{\mathrm{u}_{\mathrm{i}}\right\} \\
& \left\{\mathrm{f}_{\mathrm{i}}\right\}=\left[\mathrm{r}_{\mathrm{ie}}\right]\left\{\mathrm{u}_{\mathrm{e}}\right\}+\left[\mathrm{r}_{\mathrm{ii}}\right]\left\{\mathrm{u}_{\mathrm{i}}\right\}
\end{aligned}
$$

O objetivo é expressar em função das coordenadas externas, "eliminando" as internas. Da equação 3.7, tem-se:

$$
\left\{\mathrm{u}_{\mathrm{i}}\right\}=\left[\mathrm{r}_{\mathrm{ii}}\right]^{-1}\left\{\left\{\mathrm{f}_{\mathrm{i}}\right\}-\left[\mathrm{r}_{\mathrm{ie}}\right]\left\{\mathrm{u}_{\mathrm{e}}\right\}\right\}
$$

Substituindo na equação 3.6 , tem-se:

$$
\underbrace{\left\{\mathrm{f}_{\mathrm{e}}\right\}-\left[\mathrm{r}_{\mathrm{ei}}\right]\left[\mathrm{r}_{\mathrm{ii}}\right]^{-1}\left\{\mathrm{f}_{\mathrm{i}}\right\}}_{\left\{\mathrm{f}_{\mathrm{c}}\right\}}=\underbrace{\left\{\left[\mathrm{r}_{\mathrm{ee}}\right]-\left[\mathrm{r}_{\mathrm{ei}}\right]\left[\mathrm{r}_{\mathrm{ii}}\right]^{-1}\left[\mathrm{r}_{\mathrm{ie}}\right]\right\}\left\{\mathrm{u}_{\mathrm{e}}\right\}}_{\left[\mathrm{r}_{\mathrm{c}}\right]}
$$

A matriz de rigidez e o vetor forças fica condensado em função apenas dos parâmetros nodais externos:

$$
\left[\mathrm{r}_{\mathrm{c}}\right]_{12 \times 12}\left\{\mathrm{u}_{\mathrm{e}}\right\}_{12 \times 1}=\left\{\mathrm{f}_{\mathrm{c}}\right\}_{12 \times 1}
$$




\subsection{Contribuição dos pilares à rigidez da subestrutura}

Neste modelo estrutural, por conveniência, cada pavimento é admitido como sendo uma subestrutura. Ou seja, para formar a matriz de rigidez global da estrutura de $n$ pavimentos deve-se associar $\mathrm{n}$ matrizes de rigidez da subestrutura para coordenadas correspondentes. A matriz de rigidez da subestrutura é formada pela contribuição das rigidezes dos elementos horizontais (vigas e placas $D K T$ ) e elementos verticais (pilares). Como os pilares são os únicos elementos estruturais que fazem a ligação entre os pavimentos, os termos das matriz de rigidez dos pilares são espalhados nos matrizes $[\mathrm{R}]_{\mathrm{K}, \mathrm{K}}$, $[\mathrm{R}]_{\mathrm{K}, \mathrm{K}-1}$ e $[\mathrm{R}]_{\mathrm{K}-1, \mathrm{~K}-1}$, onde o índice $\mathrm{K}-1$ representa o pavimento imediatamente inferior ao pavimento $\mathrm{K}$ em estudo.

O endereçamento dos termos de coordenadas independentes na subestrutura são:

$$
\begin{aligned}
& \delta_{\mathrm{x}}=3 \mathrm{j}-2 \\
& \phi_{\mathrm{y}}=3 \mathrm{j}-1 \\
& \phi_{\mathrm{z}}=3 \mathrm{j}
\end{aligned}
$$

Onde j é o número do nó do pilar

E o endereçamento das coordenadas dependentes referente ao movimento de corpo rígido do pavimento são:

$$
\begin{aligned}
& \delta_{\mathrm{y}}=\mathrm{N}_{\mathrm{T}}-2 \\
& \delta_{\mathrm{z}}=\mathrm{N}_{\mathrm{T}}-1 \\
& \phi_{\mathrm{x}}=\mathrm{N}_{\mathrm{T}}
\end{aligned}
$$

Onde $\mathrm{N}_{\mathrm{T}}$ é o número total de coordenadas da subestrutura, sendo:

$\mathrm{N}_{\mathrm{T}}=3\left(\mathrm{~N}_{\mathrm{p}}+1\right)$

$\mathrm{N}_{\mathrm{p}}=$ número de pilares do pavimento em questão 


\subsection{Subestruturação}

\subsubsection{Subestruturação em paralelo}

Foi utilizado a técnica de Cholesky Decomposition, pois diferente do processo tradicional de liberação total dos nós, este tem a vantagem de não precisar fazer a operação da matriz inversa. O processo adotado neste trabalho será descrito a seguir:
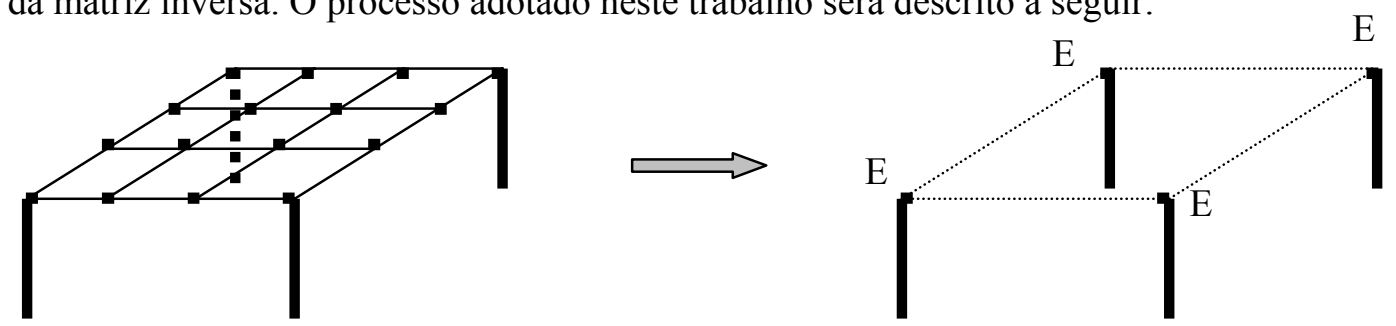

Figura 3.15 - Subestruturação em paralelo

A convenção adotada é:

I = índice de coordenadas não ligadas aos pilares;

$\mathrm{E}=$ índice de coordenadas ligadas diretamente aos pilares.

O objetivo é transformar a matriz de rigidez do pavimento em uma matriz reduzida em função das coordenadas dos pilares. Neste processo, nada é aproximado ou perdido.

$\left[\begin{array}{l}{\left[\mathrm{R}_{\mathrm{II}}\right]\left[\mathrm{R}_{\mathrm{IE}}\right]} \\ {\left[\mathrm{R}_{\mathrm{EI}}\right]\left[\mathrm{R}_{\mathrm{EE}}\right]}\end{array}\right]\left\{\begin{array}{l}\left\{\mathrm{U}_{\mathrm{I}}\right\} \\ \left\{\mathrm{U}_{\mathrm{E}}\right\}\end{array}\right\}=\left\{\begin{array}{l}\left\{\mathrm{F}_{\mathrm{I}}\right\} \\ \left\{\mathrm{F}_{\mathrm{E}}\right\}\end{array}\right\}$

Decompondo a matriz de rigidez em três matrizes:

$\left.\left[\mathrm{R}_{\mathrm{II}}\right]=[\mathrm{L}][\mathrm{D}] \mid \mathrm{L}^{\mathrm{T}}\right]$

$\left[\mathrm{R}_{\mathrm{EI}}\right]=\left[\mathrm{R}_{\mathrm{IE}}^{\mathrm{T}}\right]=[\mathrm{N}][\mathrm{D}]\left[\mathrm{L}^{\mathrm{T}}\right]$

$\left[\mathrm{R}_{\mathrm{EE}}\right]=\left[\mathrm{R}_{\mathrm{EE}}^{*}\right]+[\mathrm{N}][\mathrm{D}]\left[\mathrm{N}^{\mathrm{T}}\right]$

$\left[\begin{array}{l}{[\mathrm{L}][0]} \\ {[\mathrm{N}][\mathrm{I}]}\end{array}\right]\left[\begin{array}{l}{[\mathrm{D}][0]} \\ {[0]\left[\mathrm{R}_{\mathrm{EE}}^{*}\right.}\end{array}\right]\left[\begin{array}{l}{\left[\mathrm{L}^{\mathrm{T}}\right]\left[\mathrm{N}^{\mathrm{T}}\right]} \\ {[0][\mathrm{I}]}\end{array}\right]\left\{\begin{array}{l}{\left[\mathrm{U}_{\mathrm{I}}\right\}} \\ \left\{\mathrm{U}_{\mathrm{E}}\right\}\end{array}\right\}=\left\{\begin{array}{l}\left\{\mathrm{F}_{\mathrm{I}}\right\} \\ \left\{\mathrm{F}_{\mathrm{E}}\right\}\end{array}\right\}$

$\left[\begin{array}{l}{\left[\mathrm{L}^{\mathrm{T}}\right]\left[\mathrm{N}^{\mathrm{T}}\right]} \\ {[0][\mathrm{I}]}\end{array}\right]\left\{\begin{array}{l}\left\{\mathrm{U}_{\mathrm{I}}\right\} \\ \left\{\mathrm{U}_{\mathrm{E}}\right\}\end{array}\right\}=\left\{\begin{array}{l}\left\{\mathrm{U}_{\mathrm{I}}^{*}\right\} \\ \left\{\mathrm{U}_{\mathrm{E}}^{*}\right\}\end{array}\right\} \rightarrow \begin{aligned} & \left\{\mathrm{U}_{\mathrm{I}}^{*}\right\}=\left[\mathrm{L}^{\mathrm{T}}\right]\left\{\mathrm{U}_{\mathrm{I}}\right\}+\left[\mathrm{N}^{\mathrm{T}}\right]\left\{\mathrm{U}_{\mathrm{E}}\right\} \\ & \left\{\mathrm{U}_{\mathrm{E}}^{*}\right\}=\left\{\mathrm{U}_{\mathrm{E}}\right\}\end{aligned}$

$\left[\begin{array}{l}{[\mathrm{D}][0]} \\ {[0]\left[\mathrm{R}_{\mathrm{EE}}^{*}\right]}\end{array}\right]\left\{\begin{array}{l}\left\{\mathrm{U}_{\mathrm{I}}^{*}\right\} \\ \left\{\mathrm{U}_{\mathrm{E}}^{*}\right\}\end{array}\right\}=\left\{\begin{array}{l}\left\{\mathrm{F}_{\mathrm{I}}^{*}\right\} \\ \left\{\mathrm{F}_{\mathrm{E}}^{*}\right\}\end{array}\right\} \longrightarrow \begin{aligned} & {[\mathrm{D}]\left\{\mathrm{U}_{\mathrm{I}}^{*}\right\}=\left\{\mathrm{F}_{\mathrm{I}}^{*}\right\}} \\ & {\left[\mathrm{R}_{\mathrm{EE}}^{*}\right]\left\{\mathrm{U}_{\mathrm{E}}^{*}\right\}=\left\{\mathrm{F}_{\mathrm{E}}^{*}\right\}}\end{aligned}$

$\left[\begin{array}{l}{[\mathrm{L}][0]} \\ {[\mathrm{N}][\mathrm{I}]}\end{array}\right]\left\{\begin{array}{l}\left\{\mathrm{F}_{\mathrm{I}}^{*}\right\} \\ \left\{\mathrm{F}_{\mathrm{E}}^{*}\right\}\end{array}\right\}=\left\{\begin{array}{l}\left\{\mathrm{F}_{\mathrm{I}}\right\} \\ \left\{\mathrm{F}_{\mathrm{E}}\right\}\end{array}\right\} \longrightarrow \begin{aligned} & \left\{\mathrm{F}_{\mathrm{I}}\right\}=[\mathrm{L}]\left\{\mathrm{F}_{\mathrm{I}}^{*}\right\} \\ & \left\{\mathrm{F}_{\mathrm{E}}\right\}=[\mathrm{N}]\left\{\mathrm{F}_{\mathrm{I}}^{*}\right\}+\left\{\mathrm{F}_{\mathrm{E}}^{*}\right\}\end{aligned}$ 
Com as novas equações (3.14), (3.15) e (3.16), resolvem-se em três etapas a seguir:

Etapa 1: Substituição parcial, combinando as equações (3.14) e (3.15)

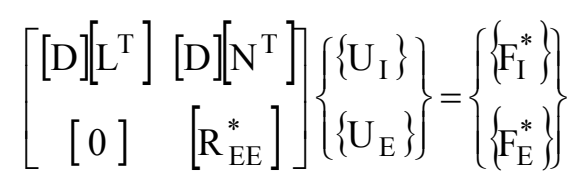

Etapa 2: Solução do sistema de equações condensados do (3.17), determina-se os deslocamentos externos $\mathrm{U}_{\mathrm{E}}$ :

$$
\left[\mathrm{R}_{\mathrm{EE}}^{*}\right]\left\{\mathrm{U}_{\mathrm{E}}\right\}=\left\{\mathrm{F}_{\mathrm{E}}^{*}\right\}
$$

Etapa 3: Retrosubstituição parcial, determina-se deslocamentos internos $U_{I}$ :

$$
\left[\begin{array}{c}
{[\mathrm{D}]\left[\mathrm{L}^{\mathrm{T}}\right][\mathrm{D}]\left[\mathrm{N}^{\mathrm{T}}\right]} \\
{[0]}
\end{array}\right]\left\{\begin{array}{l}
\left\{\mathrm{U}_{\mathrm{I}}\right\} \\
\{\mathrm{I}]
\end{array}\right\}=\left\{\begin{array}{l}
\left\{\mathrm{F}_{\mathrm{I}}^{*}\right\} \\
\left\{\mathrm{U}_{\mathrm{E}}\right\}
\end{array}\right\}
$$

\subsubsection{Subestruturação em série}

O objetivo é transformar a matriz de rigidez global da estrutura para uma matriz de rigidez em função das coordenadas da extremidade inferior dos pilares do primeiro pavimento.

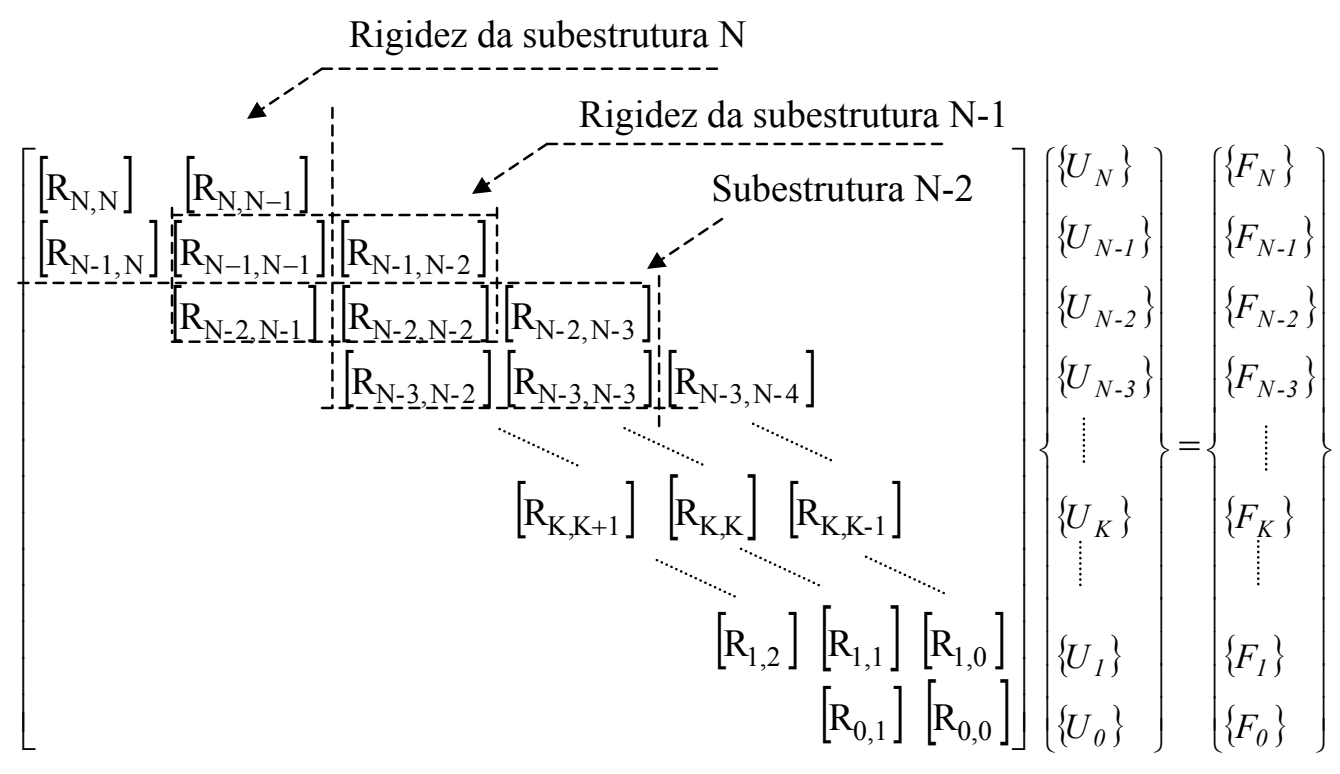

A primeira linha da matriz é a parte da rigidez do ultimo pavimento $\mathrm{N}$, na segunda linha tem-se uma parte da matriz de rigidez do pavimento $\mathrm{N}$ que recebe a contribuição do pavimento imediatamente inferior N-1. A rigidez dos pilares são assim distribuídos entre os pavimentos que tem conexão.

O processo da condensação começa do topo e termina na base da estrutura. 


$$
\begin{aligned}
& \left.\left.\mathrm{N} \longrightarrow \mid \mathrm{R}_{\mathrm{N}, \mathrm{N}}\right\rfloor\left\{\mathrm{U}_{\mathrm{N}}\right\}+\mid \mathrm{R}_{\mathrm{N}, \mathrm{N}-1}\right\rfloor\left\{\mathrm{U}_{\mathrm{N}-1}\right\}=\left\{\mathrm{F}_{\mathrm{N}}\right\} \\
& \mathrm{N}-1 \longrightarrow\left|\mathrm{R}_{\mathrm{N}-1, \mathrm{~N}}\right|\left\{\mathrm{U}_{\mathrm{N}}\right\}+\left[\mathrm{R}_{\mathrm{N}-1, \mathrm{~N}-1}\right]\left\{\mathrm{U}_{\mathrm{N}-1}\right\}+\left\lfloor\mathrm{R}_{\mathrm{N}-1, \mathrm{~N}-2}\right\rfloor\left\{\mathrm{U}_{\mathrm{N}-2}\right\}=\left\{\mathrm{F}_{\mathrm{N}-1}\right\}
\end{aligned}
$$

Pela equação (3.21), tem-se: $\left\{\mathrm{U}_{\mathrm{N}}\right\}=\left[\mathrm{R}_{\mathrm{N}, \mathrm{N}}\right]^{-1}\left(\left\{\mathrm{~F}_{\mathrm{N}}\right\}-\left[\mathrm{R}_{\mathrm{N}, \mathrm{N}-1}\right]\left\{\mathrm{U}_{\mathrm{N}-1}\right\}\right)$

Substituindo a expressão da $U_{\mathrm{N}}$ na equação (3.22), tem-se:

$$
\begin{gathered}
\underbrace{\left(\left[R_{N-l, N-1}\right]-\left[R_{N-l, N}\right]\left[R_{N, N}\right]^{-1}\left[R_{N, N-1}\right]\right)\left\{U_{N-1}\right\}}_{\left[R_{N-1, N-1}^{*}\right]}+\left[R_{N-l, N-2}\right]\left\{U_{N-2}\right\}=\underbrace{\left\{F_{N-1}\right\}-\left[R_{N-l, N}\right]\left[R_{N, N}\right]^{-1}\left\{F_{N}\right\}}\}+\left[R_{N-1, N-2}\right]\left\{U_{N-2}\right\}=\left\{F_{N-1}^{*}\right\}
\end{gathered}
$$

$$
\left.\mathrm{N}-2 \longrightarrow \mid \mathrm{R}_{\mathrm{N}-2, \mathrm{~N}-1}\right\rfloor\left\{\mathrm{U}_{\mathrm{N}-1}\right\}+\left[\mathrm{R}_{\mathrm{N}-2, \mathrm{~N}-2}\right\rfloor\left\{\mathrm{U}_{\mathrm{N}-1}\right\}+\left\lfloor\mathrm{R}_{\mathrm{N}-2, \mathrm{~N}-3}\right\rfloor\left\{\mathrm{U}_{\mathrm{N}-3}\right\}=\left\{\mathrm{F}_{\mathrm{N}-2}\right\}
$$

Pela equação (3.23) tem-se: $\left\{\mathrm{U}_{\mathrm{N}-1}\right\}=\left[\mathrm{R}_{\mathrm{N}-1, \mathrm{~N}-1}^{*}\right]^{-1}\left(\left\{\mathrm{~F}_{\mathrm{N}-1}\right\}-\left[\mathrm{R}_{\mathrm{N}-1, \mathrm{~N}-2}\right]\left\{\mathrm{U}_{\mathrm{N}-2}\right\}\right)$

Substituindo a expressão da $\mathrm{U}_{\mathrm{N}-1}$ na equação (3.24), tem-se:

$$
\begin{aligned}
& \underbrace{\left(\left[R_{N-2, N-2}\right]-\left[R_{N-2, N-1}\right]\left[R_{N-1, N-1}^{*}\right]^{-1}\left[R_{N-1, N-2}\right]\right.})\left\{U_{N-2}\right\}+\left[R_{N-2, N-3}\right]\left\{U_{N-3}\right\}=\underbrace{\left\{F_{N-2}\right\}-\left[R_{N-2, N-1}\right]\left[R_{N-1, N-1}^{*}\right]^{-1}\left\{F_{N-1}^{*}\right\}} \\
& {\left[\mathrm{R}_{\mathrm{N}-2, \mathrm{~N}-2}^{*}\right] \quad\left\{\mathrm{U}_{\mathrm{N}-2}\right\}+\left[\mathrm{R}_{\mathrm{N}-2, \mathrm{~N}-3}\right]\left\{\mathrm{D}_{\mathrm{N}-3}\right\}=\quad\left\{\mathrm{F}_{\mathrm{N}-2}^{*}\right\}}
\end{aligned}
$$

No $\mathrm{k}$ - ésimo pavimento tem-se:

$$
\left[\mathrm{R}_{\mathrm{K}, \mathrm{K}}^{*}\right]\left\{\mathrm{U}_{\mathrm{K}}\right\}+\left[\mathrm{R}_{\mathrm{K}, \mathrm{K}-1}\right]\left\{\mathrm{U}_{\mathrm{K}-1}\right\}=\left\{\mathrm{F}_{\mathrm{K}}^{*}\right\}
$$

Onde: $\quad\left[\mathrm{R}_{\mathrm{K}, \mathrm{K}}^{*}\right]=\left[\mathrm{R}_{\mathrm{K}, \mathrm{K}}\right]-\left[\mathrm{R}_{\mathrm{K}, \mathrm{K}+1}\right]\left[\mathrm{R}_{\mathrm{K}+1, \mathrm{~K}+1}^{*}\right]^{-1}\left[\mathrm{R}_{\mathrm{K}+1, \mathrm{~K}}\right]$

$$
\left\{\mathrm{F}_{\mathrm{K}}^{*}\right\}=\left\{\mathrm{F}_{\mathrm{K}}\right\}-\left[\mathrm{R}_{\mathrm{K}, \mathrm{K}+1}\right]\left[\mathrm{R}_{\mathrm{K}+1, \mathrm{~K}+1}^{*}\right]^{-1}\left\{\mathrm{~F}_{\mathrm{K}+1}\right\}
$$

E finalmente, no pavimento base, tem-se:

$$
\left[\mathrm{R}_{0,0}^{*}\right]\left\{\mathrm{U}_{0}\right\}=\left\{\mathrm{F}_{0}^{*}\right\}
$$

Onde: $\quad\left[\mathrm{R}_{0,0}^{*}\right]=\left[\mathrm{R}_{0,0}\right]-\left[\mathrm{R}_{0,1}\right]\left[\mathrm{R}_{1,1}^{*}\right]^{-1}\left[\mathrm{R}_{1,0}\right]$

$$
\left\{\mathrm{F}_{0}^{*}\right\}=\left\{\mathrm{F}_{0}\right\}-\left[\mathrm{R}_{0,1}\right]\left[\mathrm{R}_{1,1}^{*}\right]^{-1}\left\{\mathrm{~F}_{1}\right\}
$$

A matriz de rigidez $\left[\mathrm{R}_{0,0}^{*}\right]$ representa toda a rigidez da estrutura acima, em função das coordenadas inferiores dos pilares do primeiro pavimento. A técnica da subestruturação apesar de laborioso em algoritmo, computacionalmente tem inúmeras vantagens por permitir a análise de estruturas com muitos graus de liberdade e como no caso de aplicação de interação solo - estrutura do modelo adotado neste trabalho que requer processo iterativo. 
O deslocamento $\left\{U_{0}\right\}$ da base da estrutura pode ser nulo, quando não considera a interação solo - estrutura, e diferente de zero quando considera a deformabilidade do solo. Esta parte será mostrado no capítulo 5 .

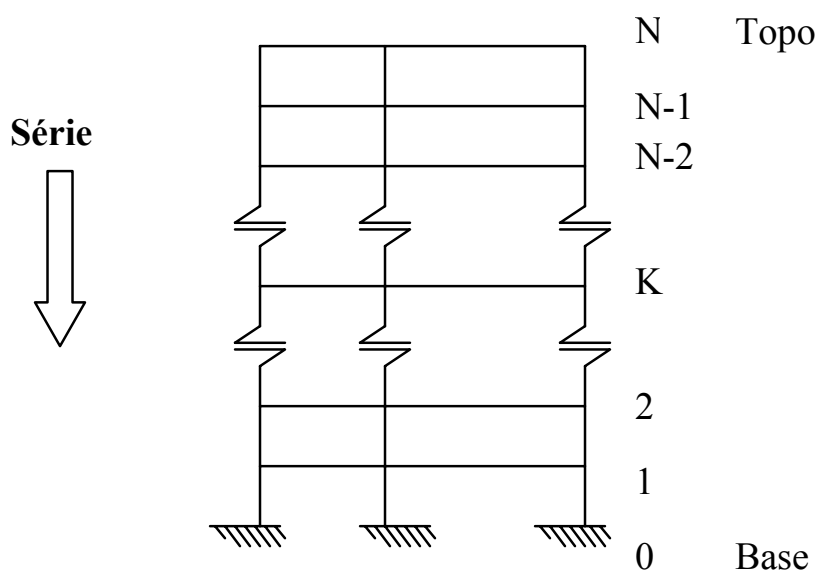

Figura 3.16 - Subestruturação em série

\subsection{Esforços solicitantes nas extremidades dos elementos estruturais}

Nas vigas os esforços solicitantes são obtidas pela superposição de forças nodais segundo as coordenadas locais, sem que existam deslocamentos correspondentes mais a parcela de esforço $\left[\mathrm{r}_{\mathrm{V}}\right]\left\{\mathrm{u}_{\mathrm{V}}\right\}$ proveniente de deslocamentos nodais. Os deslocamentos locais $\{\mathrm{u}\}$ são determinados a partir dos deslocamentos globais $\{\mathrm{U}\}$ da estrutura, mediante a matriz de incidência cinemática $[\beta]$.

$$
\{\mathrm{u}\}=[\beta]\{\mathrm{U}\}
$$

Os esforços solicitantes são:

$$
\begin{array}{ll}
\text { Para vigas } & \left\{\mathrm{f}_{\mathrm{V}}\right\}=\left[\mathrm{r}_{\mathrm{V}}\right]\left\{\mathrm{u}_{\mathrm{V}}\right\}+\left\{\mathrm{f}_{0}\right\} \\
\text { Para pilares } & \left\{\mathrm{f}_{\mathrm{P}}\right\}=\left[\mathrm{r}_{\mathrm{P}}\right]\left\{\mathrm{u}_{\mathrm{P}}\right\}
\end{array}
$$

Para os pilares, o $\left\{\mathrm{f}_{\mathrm{o}}\right\}$ é nulo, pois não considera carregamentos ao longo do trecho, como acontece nas vigas. 


\section{INTERAÇÃO SOLO-ESTRUTURA}

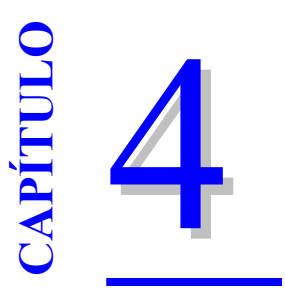

\subsection{Breve histórico}

Os primeiros estudos no Brasil sobre o problema, foram feitos por CHAMECKI (1956) e posteriormente aplicado para o problema do adensamento do solo (1969).

Embora os engenheiros geotécnicos brasileiros tenham-se preocupado com a medida de recalques de edifícios altos, pouco interesse tinha sido dado aos problemas de redistribuição dos esforços na estrutura e a modificação dos recalques na fundação com a interação solo - estrutura, até a década de 80 . O reaparecimento desse interesse está documentado na tese de BARATA (1986) e posteriormente esse interesse foi confirmado com a contribuição de GUSMÃO \& LOPES (1990).

O estudo da interação solo - estrutura é um assunto novo, tanto é que somente em novembro de 1994 no COBRAMSEF, realizada em Foz do Iguaçu que foi incluída a sessão técnica de "Fundações e Interação Solo - Estrutura", na ocasião em que foram apresentados os trabalhos de GUSMÃO (1994) e FONTE (1994) para fundações rasas. Outros trabalhos tem se sucedido como MOURA (1995), HOLANDA Jr. (1998), REIS (2000) também para sapatas, no entanto pesquisas para fundações profundas em estacas interagindo com a estrutura de edifícios de múltiplos andares ainda é precário no nosso meio.

AOKI (1987) tornou possível essa análise com a aplicação dos métodos AOKIVELLOSO (1975) para diagrama de ruptura do solo como uma das ferramentas para a obtenção do diagrama de transferência, AOKI-LOPES(1975) para recalques de um grupo de estacas, SCHIEL(1957) para distribuição de cargas do bloco para as estacas e a idéia do processo iterativo de CHAMECKI (1956) e (1969) para considerar a rigidez da estrutura.

Por ser um assunto relativamente complexo que envolve muitas equações e parâmetros, a questão da interação solo - estrutura está intimamente ligada com a utilização dos computadores e programas computacionais, que só assim, possibilitam a sua viabilidade nos projetos de estruturas usuais.

O presente capítulo mostra o modelo do AOKI (1987). 


\subsection{Modelo de estaqueamento}

Adota-se um sistema global de referência constituído por eixos cartesianos, de preferência em que a sua origem coincida com o centróide entre o bloco e o pilar.

O carregamento externo que o pilar transmite ao bloco, pode ser reduzido a origem desse sistema de referência, admitindo-se o bloco como infinitamente rígido:

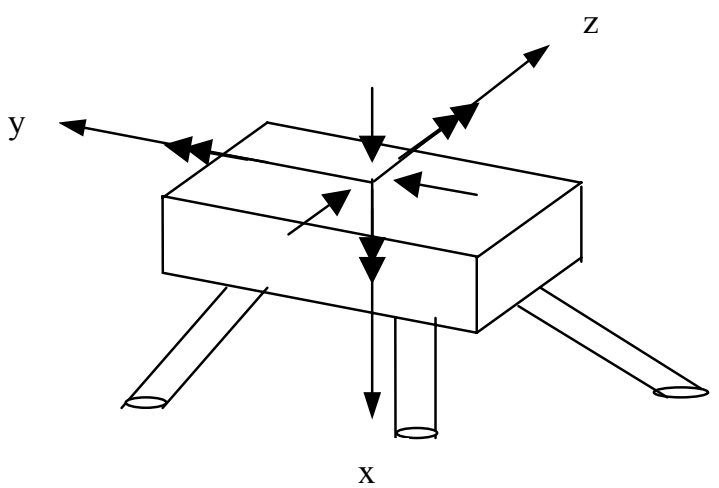

$$
\{\mathrm{F}\}=\left\{\begin{array}{l}
H_{x} \\
H_{y} \\
H_{z} \\
M_{x} \\
M_{y} \\
M_{z}
\end{array}\right\}
$$

Figura 4.1 - Sistema de referência e coordenadas do bloco

Definem-se as coordenadas $\mathrm{x}_{\mathrm{i}}, \mathrm{y}_{\mathrm{i}}, \mathrm{z}_{\mathrm{i}}$ do extremo das estacas $\mathrm{i}$ que liga ao bloco, em relação ao sistema de referência, assim como os ângulos $\alpha_{i}$ e $\omega_{i}$ :

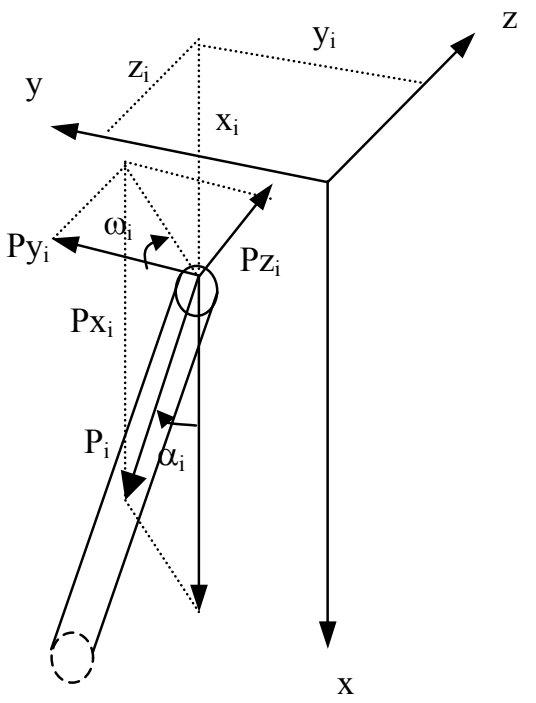

* Para $\mathrm{P}_{\mathrm{i}}=1$ ( vetor unitário na estaca i ), tem-se :

$\mathrm{Px}_{\mathrm{i}}=\cos \alpha_{\mathrm{i}}$

Cossenos diretores $\mathrm{x}$

$\mathrm{Py}_{\mathrm{i}}=\operatorname{sen} \alpha_{\mathrm{i}} * \cos \omega_{\mathrm{i}}$

Cossenos diretores y

$\mathrm{Pz}_{\mathrm{i}}=\operatorname{sen} \alpha_{\mathrm{i}} * \operatorname{sen} \omega_{\mathrm{i}}$

Cossenos diretores $\mathrm{z}$

$\mathrm{Pa}_{\mathrm{i}}=\mathrm{y}_{\mathrm{i}} * \mathrm{Pz}_{\mathrm{i}}-\mathrm{z}_{\mathrm{i}} * \mathrm{Py}_{\mathrm{i}} \quad$ Vetor momento $\mathrm{x}$

$\mathrm{Pb}_{\mathrm{i}}=\mathrm{z}_{\mathrm{i}} * \mathrm{Pz}_{\mathrm{i}}-\mathrm{x}_{\mathrm{i}} * \mathrm{Py}_{\mathrm{i}} \quad$ Vetor momento $\mathrm{y}$

$\mathrm{Pc}_{\mathrm{i}}=\mathrm{x}_{\mathrm{i}} * \mathrm{Py}_{\mathrm{i}}-\mathrm{y}_{\mathrm{i}} * \mathrm{Px}_{\mathrm{i}} \quad$ Vetor momento $\mathrm{z}$

A matriz [ $\mathrm{P}$ ] das estacas i que compõem o bloco $\mathrm{k}$

$$
[P]=\left[\begin{array}{ccccc}
\mathrm{Px}_{1} & \mathrm{Px}_{2} & \mathrm{Px}_{3} & \ldots & \mathrm{Px}_{\mathrm{n}} \\
\mathrm{Py}_{1} & \mathrm{Py}_{2} & \mathrm{Py}_{3} & \ldots & \mathrm{Py}_{\mathrm{n}} \\
\mathrm{Pz}_{1} & \mathrm{Pz}_{2} & \mathrm{Px}_{3} & \ldots & \mathrm{Pz}_{\mathrm{n}} \\
\mathrm{Pa}_{1} & \mathrm{~Pa}_{2} & \mathrm{Px}_{3} & \ldots & \mathrm{Pa}_{\mathrm{n}} \\
\mathrm{Pb}_{1} & \mathrm{~Pb}_{2} & \mathrm{Px}_{3} & \ldots & \mathrm{Pb}_{\mathrm{n}} \\
\mathrm{Pc}_{1} & \mathrm{Pc}_{2} & \mathrm{Px}_{3} & \ldots & \mathrm{Pc}_{\mathrm{n}}
\end{array}\right]
$$

Figura 4.2 - Sistema de referência da estaca i

Estaca 1

Estaca $n$ 
Tendo as ações atuando no bloco k (Fig. 4.1), calcula-se através do método proposto pelo SCHIEL (1956) a distribuição das reações para cada estaca i que compõem o bloco k.

Este método admite que:

a) O bloco pode ser considerado como corpo rígido em relação as estacas;

b) As estacas são rotuladas no bloco e no solo (as estacas só recebem esforços axiais) e a base da estaca sobre o indeslocável (desprezando a existência de material compressível sob a ponta das estacas);

c) Consideram-se que a contenção lateral do maciço de solo seja suficientemente resistente e por isso não ocorre flambagem;

d) Não se consideram as reações que ocorrem sob o bloco e ao longo do fuste.

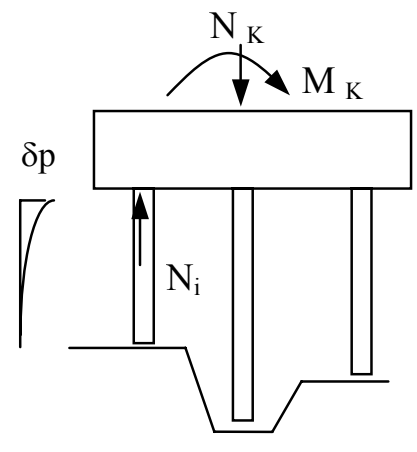

Figura 4.3 - Hipótese do Schiel

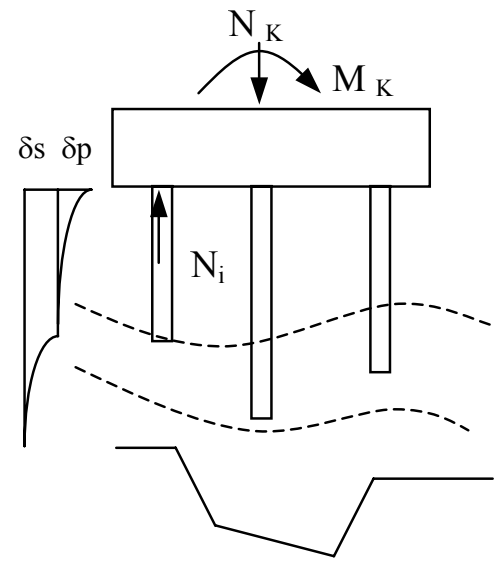

Figura 4.4 - Modelo mais realista

Sabe-se que a hipótese do Schiel não corresponde exatamente a realidade, pois não considera o atrito existente entre o fuste e o solo, não leva em conta a possível existência da camada compressível entre a base da estaca e a rocha (este sim indeslocável). Então a matriz de rigidez $[\mathrm{R}]$ do bloco $\mathrm{k}$, que depende do $\mathrm{S}_{\mathrm{i}}$ das estacas é válido somente para compressão das estacas i entre duas camadas rígidas (indeformáveis) que são o bloco e a rocha (Fig. 4.3).

No entanto, pode-se contornar esta limitação, e aplicar para casos como da Fig. 4.4, onde existem os efeitos de deformação do fuste devido ao atrito com o solo e o deslocamento da própria estaca no maciço, aproximando a rigidez $\mathrm{S}_{\mathrm{i}}$ das estacas dentro de várias iterações.

Antes da iteração, deve-se calcular a primeira aproximação de cargas que serão passadas para cada estaca que formam num bloco. Esta será obtida considerando como se a estaca estivesse apoiada na camada indeslocável. 
A matriz de rigidez do bloco $\mathrm{k}$ é dado por:

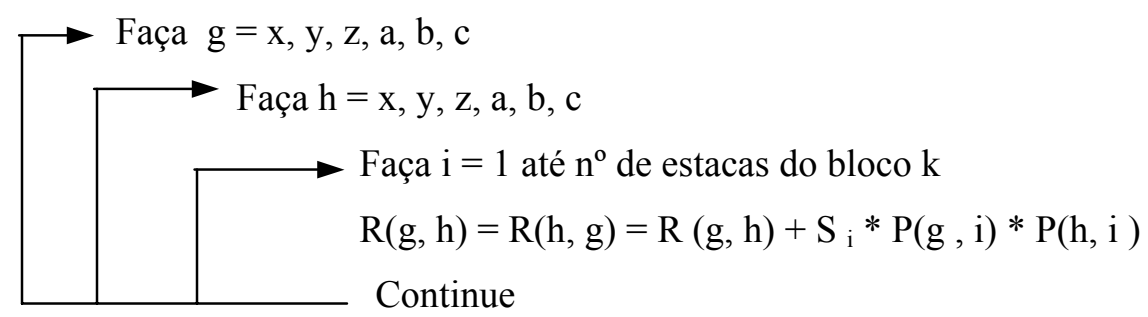

Onde $\mathrm{S}_{\mathrm{i}}$ é a rigidez de uma estaca $\mathrm{i}$, para esforço axial:

$$
S_{i}=\frac{E_{i} A_{i}}{L_{i}}
$$

O deslocamento $\{U\}$ do bloco k se obtém pela:

$$
\{\mathrm{U}\}=\left\{\begin{array}{l}
V x_{k} \\
V y_{k} \\
V z_{k} \\
V a_{k} \\
V b_{k} \\
V c_{k}
\end{array}\right\}=[\mathrm{R}]^{-1} *\left\{\begin{array}{l}
H_{x} \\
H_{y} \\
H_{z} \\
M_{x} \\
M_{y} \\
M_{z}
\end{array}\right\}
$$

Vetor carregamento externo ( ações no bloco )

Conhecido o vetor $\{\mathrm{U}\}$, calcula-se a carga na estaca i :

$$
\mathrm{N}_{\mathrm{i}}=\mathrm{S}_{\mathrm{i}} *\{\mathrm{U}\}^{\mathrm{T}} *\left\{\begin{array}{c}
P x_{i} \\
P y_{i} \\
P z_{i} \\
P a_{i} \\
P b_{i} \\
P c_{i}
\end{array}\right\}
$$


Obtidas as cargas $\mathrm{N}_{\mathrm{i}}$ para cada estaca i do bloco k, a partir de então será considerada a interação entre as estacas e o maciço de solo.

Determina-se diagramas individuais de transferência de carga ao longo do fuste e da base de acordo com o modelo adotado pelo AOKI (1987).

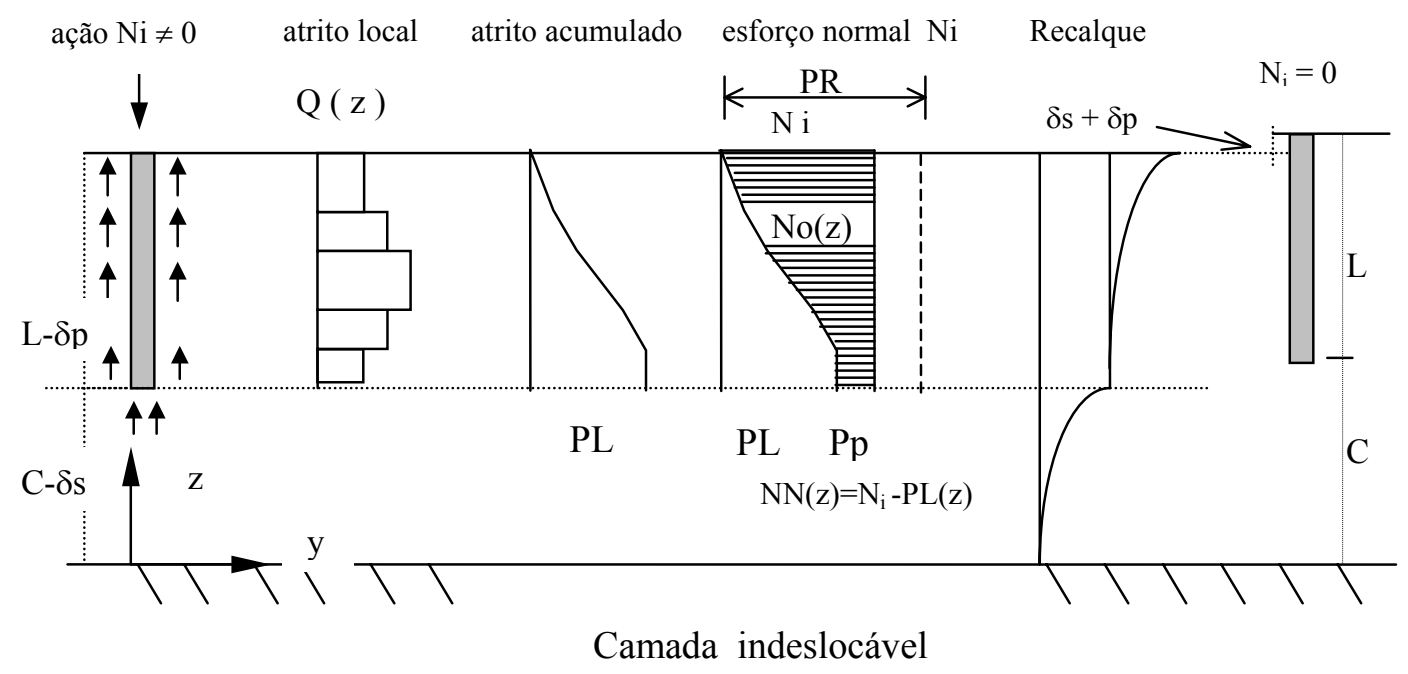

Figura 4. 5 - Diagrama de transferência de atrito lateral e de ponta

$\mathrm{Pl}(\mathrm{z})=$ parcela do carregamento $\mathrm{N}_{\mathrm{i}}$ transmitida ao solo por atrito lateral do fuste

$\operatorname{Pp}(\mathrm{z})=$ parcela do carregamento $\mathrm{N}_{\mathrm{i}}$ transmitida ao solo pela ponta da estaca

$\operatorname{No}(z)=$ diagrama de esforço normal da estaca $\mathrm{i}$

Para o carregamento $\mathrm{N}_{\mathrm{i}}$ menor que a resistência lateral do fuste PL, o deslocamento é tão pequeno na ordem de milímetros, tal que toda a carga é equilibrada pelo atrito entre fuste e o solo. Nesse caso não acontecerá a transferência para a base da estaca e $\mathrm{Pp}=0$.

a) Determinam-se o deslocamento $\delta$ s na base da estaca i, considerando o efeito do grupo de estacas pelo AOKI-LOPES (1975) que utilizam equação de MINDLIN (1936) e a simplificação de STEINBRENNER (1934) para consideração do meio elástico estratificado.

Segundo VESIC ${ }^{1}$ apud AOKI(1987) $\longrightarrow \delta \mathrm{s}=\delta \mathrm{s}, \mathrm{L}+\delta \mathrm{s}, \mathrm{p}$

$\delta \mathrm{s}, \mathrm{L}=$ deslocamento do solo na base da estaca devido a ação no fuste $\mathrm{Q}(\mathrm{z})$

$\delta \mathrm{s}, \mathrm{p}=$ deslocamento do solo na base da estaca devido a ação na base da estaca Pp

b) Determinam-se através do diagrama de força normal No(z) a parcela do recalque devido a deformação do fuste: $\delta \mathrm{p}$

$$
\delta \mathrm{p}(\mathrm{z})=\int_{C}^{Z} \frac{N o(z)}{A^{*} E} d z \cong \frac{1}{A^{*} E} \sum_{C}^{Z} N o(z) * \Delta Z
$$

\footnotetext{
${ }^{1}$ VESIC, A. S. (1975). Priciples of pile foundation design, SM.38 Duke University.
} 
O recalque no topo da estaca i será:

$\delta \mathrm{o}_{\mathrm{i}}=\delta \mathrm{s}_{\mathrm{i}}+\delta \mathrm{p}_{\mathrm{i}}$

O processo é repetido para todas as estacas i que compõem o bloco k, resultando em recalque do bloco. Todo esse processo acontecerá nos demais blocos que fazem parte de uma estrutura. Para continuar é necessário o conhecimento da nova rigidez de cada estaca i em função do ultimo recalque:

Determinam-se esta rigidez dividindo a ação normal da iteração anterior $\mathrm{N}^{(\mathrm{n}-1)}{ }_{\mathrm{i}}$ pelo recalque $\delta o^{(n)}{ }_{i}$ desta iteração, $S^{(n)}{ }_{i}=N^{(n-1)}{ }_{i} \quad / \delta o^{(n)}{ }_{i}$. Com o uso do método Schiel, recalculam-se a nova rigidez [ R ] do bloco k, em função dos novos Si das estacas i.

A nova matriz de rigidez do bloco $\mathrm{k}$ é dado por:

$\mathrm{Rgh}=\mathrm{Rhg}=\sum_{i=1}^{n} \mathrm{Si}^{*}$ pgi $*$ phi $\quad\left\{\begin{array}{l}\mathrm{g}=\mathrm{x}, \mathrm{y}, \mathrm{z}, \mathrm{a}, \mathrm{b}, \mathrm{c} \\ \mathrm{h}=\mathrm{x}, \mathrm{y}, \mathrm{z}, \mathrm{a}, \mathrm{b}, \mathrm{c}\end{array}\right.$

Calculam-se os deslocamentos do bloco k:

$\{\mathrm{U}\}=\left\{\begin{array}{l}V x_{k} \\ V y_{k} \\ V z_{k} \\ V a_{k} \\ V b_{k} \\ V c_{k}\end{array}\right\}=[\mathrm{R}]^{-1} *\left\{\begin{array}{l}H_{x} \\ H_{y} \\ H_{z} \\ M_{x} \\ M_{y} \\ M_{z}\end{array}\right\}$

E tem-se o carregamento $\mathrm{N}_{\mathrm{i}}$ da estaca i :

$$
\mathrm{N}_{\mathrm{i}}=\mathrm{S}_{\mathrm{i}} *\{\mathrm{U}\}^{\mathrm{T}} *\left\{\begin{array}{l}
P x_{i} \\
P y_{i} \\
P z_{i} \\
P a_{i} \\
P b_{i} \\
P c_{i}
\end{array}\right\}
$$

Repete-se a operação até que $\mathrm{N}_{\mathrm{i}}{ }^{(\mathrm{n}-1)} \cong \mathrm{N}_{\mathrm{i}}{ }^{(\mathrm{n})}$

A simplificação adotado neste processo é que não se levou em conta o efeito de grupo de estacas na obtenção do diagrama de transferência de carregamento que continua a mesma da estaca isolada.

Calcula-se o vetor deslocamento pela multiplicação da matriz inversa da rigidez do bloco $\mathrm{k}$ e o vetor das ações aplicadas sobre o bloco: $\{\mathrm{U}\}=[\mathrm{R}]^{-1} *\{\mathrm{~F}\}$ e obtém-se os deslocamentos Vx, Vy, Vz, Va, Vb e Vc para cada bloco k. 


\subsection{Consideração da rigidez da estrutura nos recalques}

O roteiro proposto em AOKI (1987) para interação solo - estrutura pode ser resumido como:

- Calculam-se as reações nos apoios considerando-os indeslocáveis; (fig. 4.6)

- Estas reações aplicadas nos blocos e calculados com a consideração do grupo de estacas, fornecerão os recalques nos blocos; (fig. 4.8)

- Calculam-se a rigidez equivalente do apoio “ $\mathrm{i}$ ” dividindo a reação $\left(\mathrm{V}_{\mathrm{x}}, \mathrm{M}_{\mathrm{y}}, \mathrm{M}_{\mathrm{z}}\right)$ com os seus respectivos deslocamentos; $\left(\delta_{\mathrm{x}}, \theta_{\mathrm{y}}, \theta_{\mathrm{z}}\right)$

- As rigidezes $R_{i}$ serão impostas nos respectivos apoios “ $i$ ” da estrutura, que recalculados (mantendo os mesmos carregamentos na estrutura) fornecem os novos esforços e reações diferentes dos obtidos quando consideravam os apoios indeslocáveis; (fig. 4.7)

- Esse procedimento é repetido até que ocorra a convergência dos recalques (ou das reações) obtidos em duas iterações consecutivas.

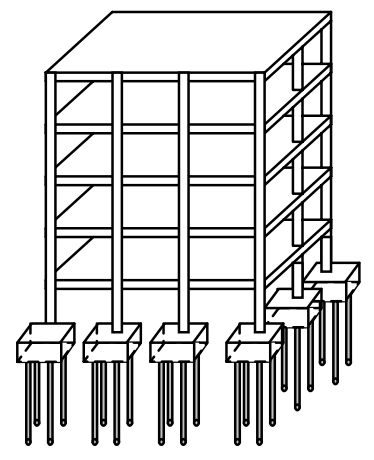

Figura 4. 6 Engastamento perfeito nos apoios

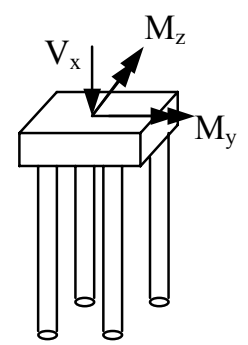

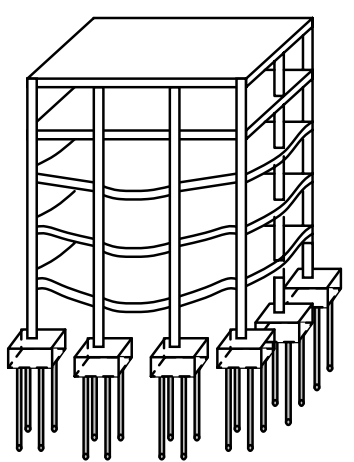

Figura 4.7

Imposição das rigidezes Ri nos apoios

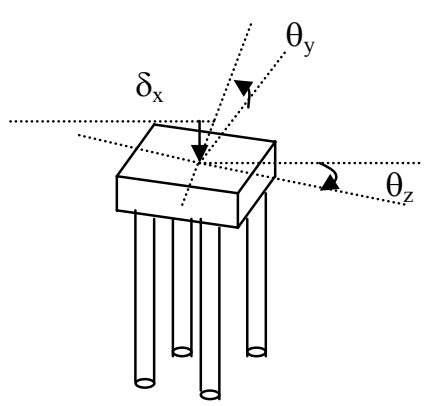

Figura 4.8 - Cargas aplicadas e recalques no bloco

Neste processo, a $\mathrm{R}_{\mathrm{i}}$ não é simplesmente mola isolada, mas rigidez que depende dos deslocamentos do solo no ponto "i" e dos outros pontos " "j" do grupo de estacas, garantindo assim a representação da continuidade do solo no meio. 
No procedimento da imposição de recalques na base da estrutura proposto em CHAMECKI (1956), dependendo da rigidez relativa da estrutura e da fundação, observou-se que o processo iterativo era demorado e às vezes não convergia. Um exemplo desse tipo seria quando os pilares da estrutura apresentam rigidezes altas e a fundação de rigidez baixa. Devido a ação do vento, quanto maior a inércia do pilar menos o edifício deformava mas em compensação absorvia um momento muito grande na base que aplicado para a fundação com rigidez relativamente baixa, na iteração seguinte, provocaria uma rotação relativamente grande. Estas rotações impostos na base da estrutura da iteração seguinte provocariam uma perturbação grande e com isso demorava a sua convergência ou até divergia devido à deformação improvável para aquela estrutura de rigidez alta.

O procedimento de imposição da rigidez equivalente de AOKI (1987), que faz a adição da rigidez $\mathrm{K}_{\mathrm{i}}$ na diagonal principal do pavimento zero (pavimento base), mostrou-se eficiente e muito mais realista do ponto de vista estrutural, pois :

- Não impõem recalques isolados de um bloco na estrutura. Para representar a rigidez relativa entre a estrutura e o solo, os recalques da base são calculados através da resolução de um sistema que já estão incluídos as rigidezes equivalentes dos apoios. Com isso, logo na primeira iteração, as reações (ou recalques) serão próximo dos valores das iterações seguintes.

- Devido a ausência de perturbações que a imposição de recalques provocariam nas estruturas, neste procedimento a sua convergência é rápida. Nos exemplos calculados até então, depois de oitava iteração as diferenças ficaram tão pequenas que mais iterações tornaram-se quase desnecessárias. 


\subsection{Recalques Admissíveis}

O recalque absoluto é definido pelo deslocamento vertical descendente de um elemento de fundação. A diferença entre os recalques absolutos de dois elementos de fundação é recalque diferencial. O recalque diferencial, pelo fato de impor distorções às estruturas, pode acarretar em fissuras, dependendo da sua magnitude, daí a necessidade de quantificar recalques admissíveis do ponto de vista estrutural.

Mostra-se a seguir, os recalques diferenciais admissíveis preliminares para estruturas de edifícios altos de concreto armado, resultados de observações em VARGAS \& SILVA (1973).

Obs:. Os números em \% fora dos parênteses se referem aos edifícios estreitos (dimensão padrão menor que $15 \mathrm{~m}$ ) e os que estão dentro dos parênteses são para edifícios largos (dimensão padrão maior que $15 \mathrm{~m}$ ).

- Recalque diferencial inferior a $0,18 \%(0,20 \%)$ do vão considerado, não produzirá danos nem inclinação em prédios altos;

- Recalque diferencial inferior a $0,31 \%(0,26 \%)$ do vão considerado, dará origem a fissuras nas alvenarias mas não inclinação em prédios altos;

- Recalque diferencial inferior a $0,42 \%(0,60 \%)$ do vão considerado, dará origem a fissuras na estrutura e pequena inclinação em prédios altos;

- Recalque diferencial inferior a $0,45 \%(0,80 \%)$ do vão considerado, dará origem a fissuras na estrutura e inclinação notável; exigirá reforço de fundações.

É importante fazer uma observação de que, em alguns prédios (edifícios com 6 pavimentos no máximo) tem-se verificado que mesmo com os recalques diferenciais superiores aos indicados acima, nada sofreram em termos estruturais.

O conceito de recalque admissível, pelo menos para os prédios, está intimamente ligado à tradição da comunidade.

O caso mais conhecido no Brasil são nos edifícios da orla marítima de Santos - SP, com movimentos mais próximos a corpo rígido, pois os recalques provém de camadas de argilas subjacentes que sofrem adensamento; a camada de areia sobre a qual se apoiam os elementos de fundações diretas tendem a absorver grande parte das distorções da estrutura. 
Golombek $^{2}$ apud ALONSO (1991), cita uma palestra do prof. Milton Vargas "Recalque excessivo é questão de temperamento. Nos EUA um recalque de $2 \mathrm{~cm}$ é um escândalo nacional; em Santos (SP) quando um prédio recalca só $50 \mathrm{~cm}$ todo mundo fica feliz". Hoje, em Santos esta posição está mudando, reduzindo os valores de recalques com o uso de fundações profundas, pois o temperamento do usuário de Santos está mudando. A Folha de São Paulo em 29/07/90, apud ALONSO (1991) afirma que os edifícios tortos de Santos chegam a valer $40 \%$ do preço de mercado.

Em 1963, Bjerrum, com base no trabalho de Skempton \& McDonald, publicado em 1956, propôs os limites da distorção angular para vários tipos de obra.
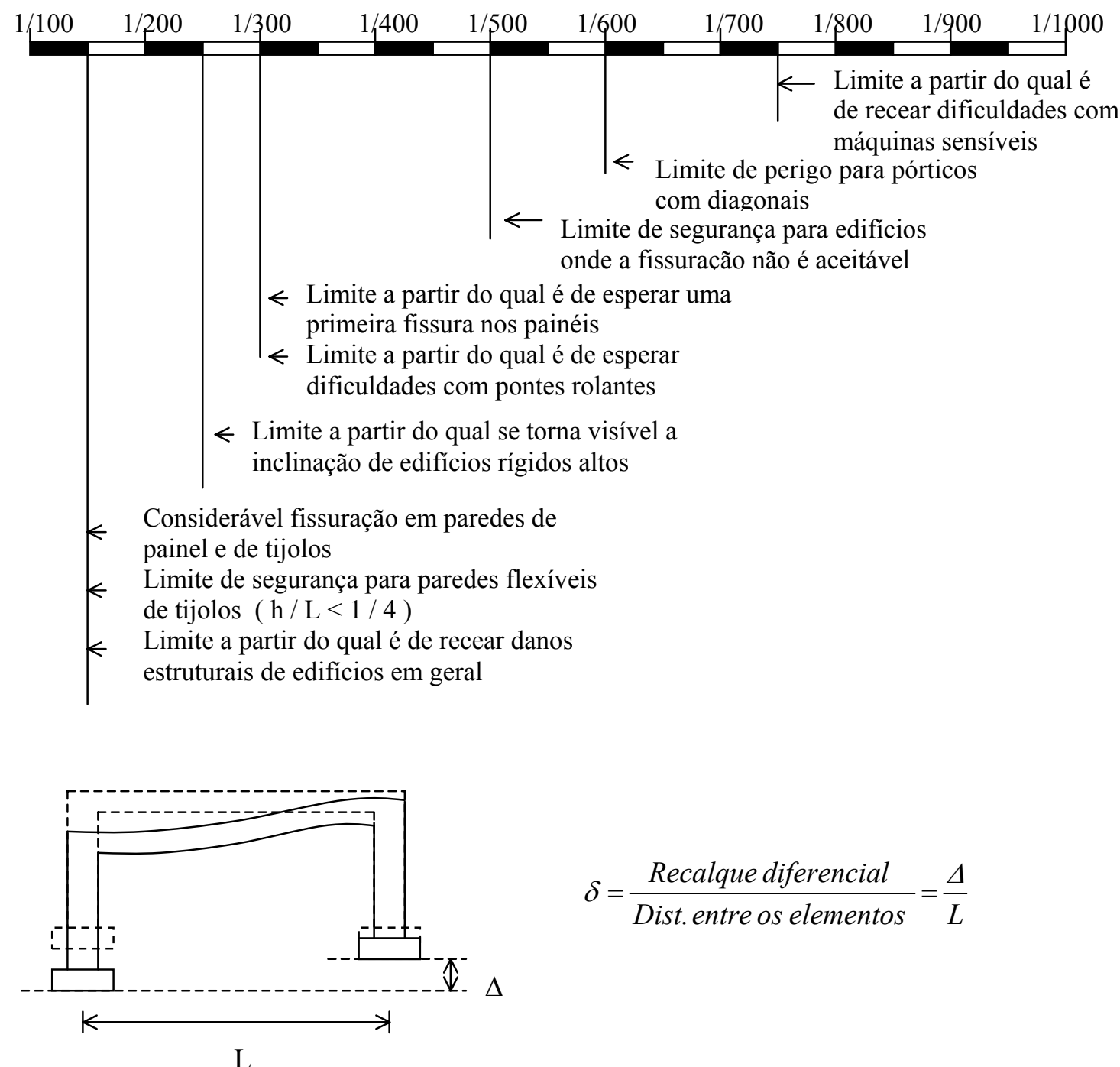

Figura 4.9 - Distorção angular limite

${ }^{2}$ GOLOMBEK, S. C. (1979). Reforço das fundações. Palestra na Sociedade Mineira de Engenheiros - Belo Horizonte. 
CHAMECKI (1958) critica a maneira como o conceito de recalques admissíveis estão sendo aplicados na prática de engenharia. O recalque diferencial estimado, sem a consideração da rigidez da estrutura, cuja sua relação com o recalque diferencial real é desconhecido, é utilizado como padrão para o projeto de fundações de estruturas. Enquanto uns prescrevem para recalque diferencial admissível 1/1000 do vão, outros oferecem valores mais tentadores como 1/500 e 1/300. Concluindo-se que para um mesmo valor de recalque diferencial estimado (sem a interação solo - estrutura) pode o recalque diferencial real variar desde valores muito próximos a zero (estruturas com altíssima rigidez) até o valor muito próximo a do calculado (estrutura com baixíssima rigidez). Assim, um mesmo valor admissível pode oferecer desde a segurança exagerada e anti - econômica até perigo de ruína para a estrutura.

O autor manifesta que já está em tempo de fazer uma revisão nesse procedimento onde parte do problema pode ser resolvido se levasse em conta a rigidez da estrutura no cálculo dos recalques da fundação. 


\subsection{Edifícios de múltiplos andares e tipos de fundações}

GUSMÃO FILHO (1995) mostra o resultado de um levantamento de edificações no Recife - PE com vista à sua localização, tipo de fundações e porte dos prédios, formando-se um banco de dados representativos de 196 edifícios na cidade, correspondente a um período de mais de 20 anos.

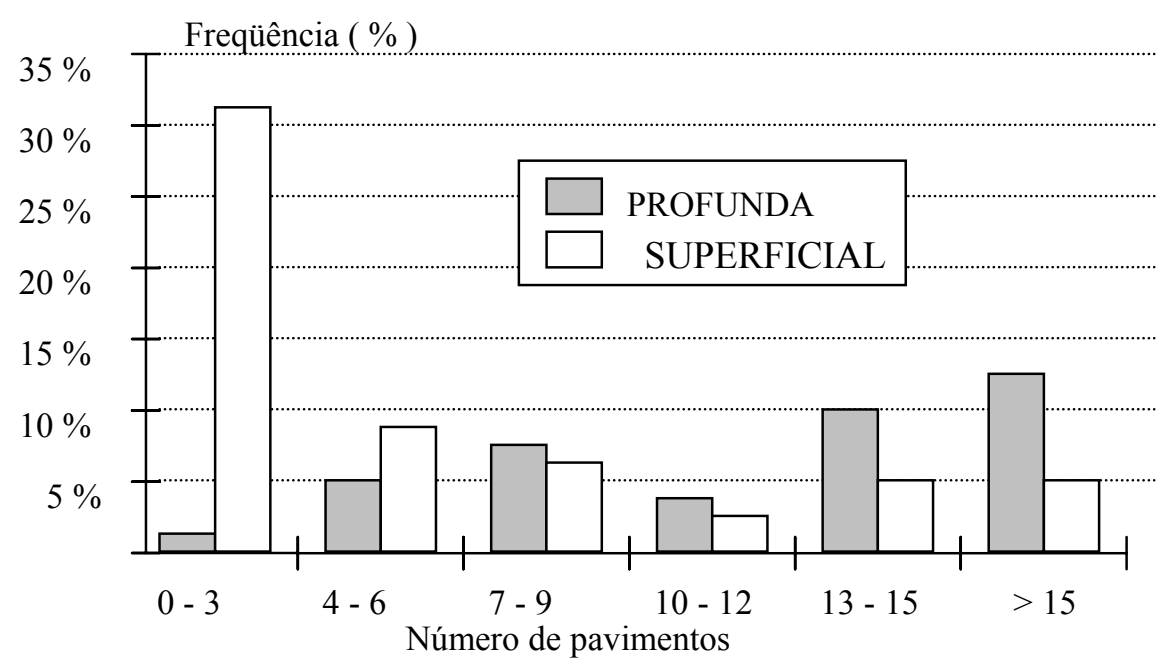

Figura 4.10 - Tipo de fundação segundo o porte dos prédios para toda a cidade de Recife, GUSMÃO FILHO (1995)

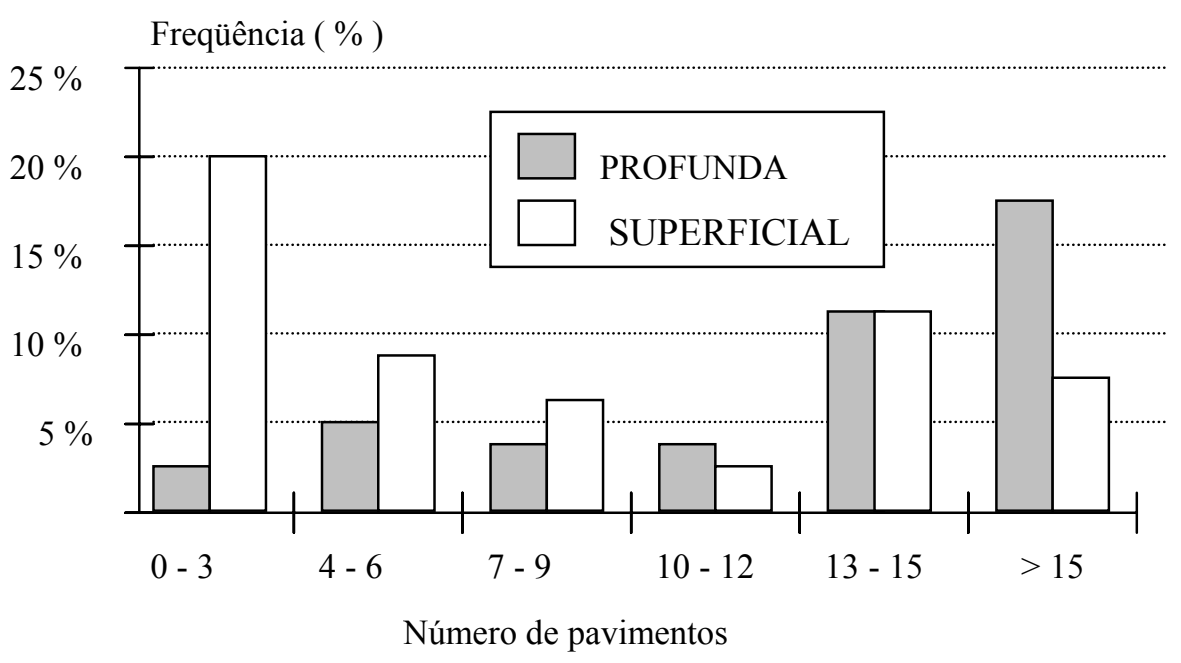

Figura 4.11 - Tipo de fundação segundo o porte dos prédios para o eixo sul da cidade, GUSMÃO FILHO(1995) 


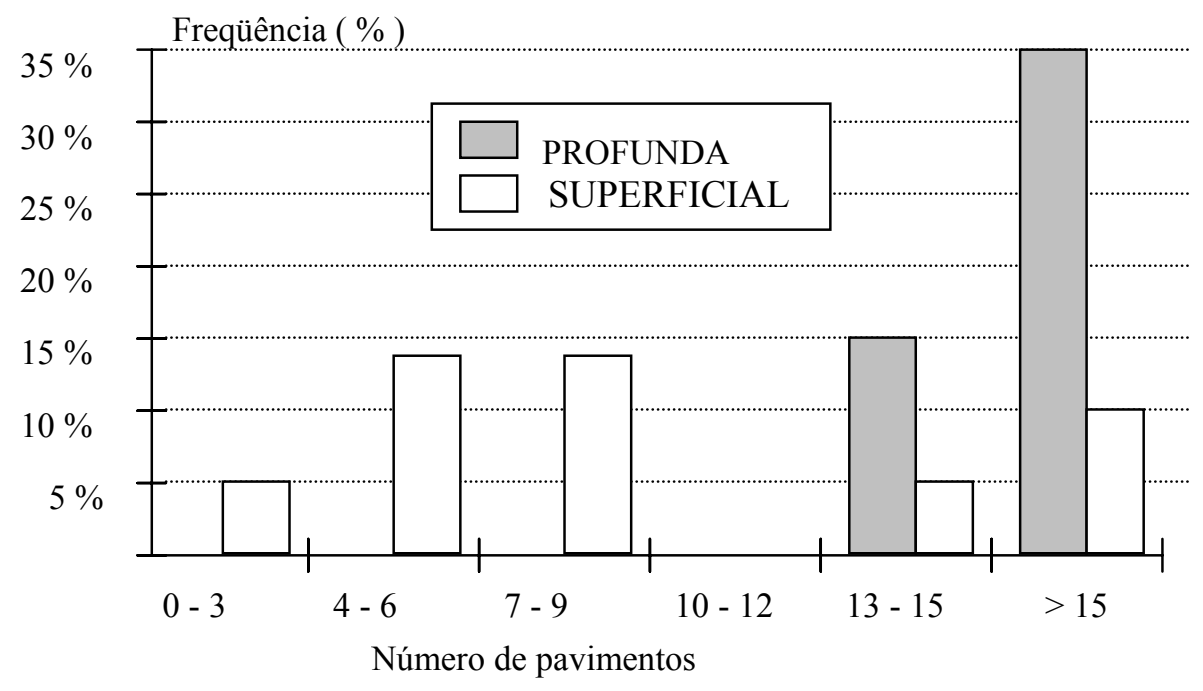

Figura 4.12 - Tipo de fundação segundo o porte dos prédios para o eixo L W do continente, GUSMÃO FILHO(1995)

Nestas amostras, podem-se verificar que a grande maioria dos edifícios com mais de 10 pavimentos, a solução foi o uso em fundações profundas, mostrando embora parcialmente, a vantagem deste tipo de fundação para os edifícios de múltiplos andares para aquela região.

\begin{tabular}{|c|l|l|c|}
\hline $\begin{array}{l}\text { Tipo de } \\
\text { Fundação }\end{array}$ & $\begin{array}{l}\text { Porcentagem sobre } \\
\text { total \% }\end{array}$ & Tipo de solução & $\begin{array}{c}\text { Percentagem } \\
\text { relativa \% }\end{array}$ \\
\hline \multirow{2}{*}{ Direta } & \multirow{2}{*}{59,80} & Sapata isolada & 71,43 \\
\cline { 3 - 4 } & & Sapata corrida & 26,05 \\
\cline { 3 - 4 } & & Placa ou radier & 2,52 \\
\hline \multirow{3}{*}{ Profunda } & Estaca moldada loco & 67,50 \\
\cline { 3 - 4 } & \multirow{3}{*}{40,20} & Estaca pré - moldada & 25,00 \\
\cline { 3 - 4 } & & Outras & 7,50 \\
\hline
\end{tabular}

Tabela 4.1 - Resumo das soluções de fundações levantadas no Recife, GUSMÃo FILHO(1995) 


\section{PROGRAMA COMPUTACIONAL}

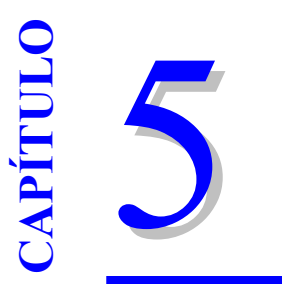

\subsection{Introdução}

Os algoritmos apresentados no capítulo 4 e no anexo serão implementados no programa computacional desenvolvido em MARTINS(1998).

O objetivo do programa é a determinação dos esforços e deslocamentos na estrutura, assim como a previsão dos recalques. O processamento é feito pelo FORTRAN 90 e a interface de entrada e saída em Visual Basic. O programa é capaz de analisar edifícios de múltiplos andares considerando ou não a rigidez transversal das lajes e trechos rígidos nas vigas, junto aos pilares.

Para que o sistema computacional seja eficiente na resolução da estrutura de grande porte, são utilizadas as técnicas de subestruturação:

- Subestruturação em paralelo: depois de definir todos os nós que compõem o pavimento, os pontos nodais que se conectam aos pilares são definidos como nós externos e os que não apresentam a conectividade, como nós internos. $\mathrm{Na}$ condensação estática foi utilizado o método Choleski Decomposition;

- Subestruturação em série: cada pavimento forma uma subestrutura. A matriz de rigidez global é constituído pela contribuição da matriz de rigidez de todos os pavimentos já na forma condensada, onde a primeira linha da matriz corresponde ao último pavimento $\mathrm{n}$ e a última linha refere-se a base do edifício (Eq. 5.1). A resolução do sistema é feito através da eliminação em série e depois pelo processo de retro - substituição, calculando-se todos os deslocamentos externos em cada subestrutura, da base até o topo, item 5.3. 


\subsection{Modularização do programa computacional}

O programa original EDIFICIO encontra-se dividido em cinco "Workspaces" ou módulos descritos a seguir:

- Workspace MATRIZ, realiza a leitura de dados dos arquivos referentes a pavimentos ( vigas e placas ) e pilares.

- Montagem da matriz de rigidez local de cada elemento;

- Montagem da matriz de rigidez e do vetor de forças nodais de cada subestrutura;

- Montagem da matriz de rigidez condensada do pavimento.

- Workspace MONTAGEM, realiza a composição da matriz de rigidez global do edifício a partir da matriz de rigidez das subestruturas, adicionando-se a parcela da rigidez das coordenadas de uma subestrutura anterior com as coordenadas de topo da subestrutura seguinte, até que se chegue ao primeiro andar do edifício.

- Workspace SERIE, realiza a subestruturação em série do sistema construído pelo módulo anterior e resolve o novo sistema pelo método de eliminação de GAUSS, obtendo os deslocamentos independentes dos pilares e o deslocamento de corpo rígido dos $\mathrm{N}$ pavimentos.

- Workspace DESLOCAMENTO, este módulo calcula os deslocamentos dos nós internos do pavimento, representados pelos elementos de viga e placa que não tem conectividade direta com os pilares.

- Workspace ESFORCO, realiza o cálculo dos esforços nas extremidades de vigas e pilares de cada pavimento do edifício, em função dos deslocamentos, obtidos no módulo DESLOCAMENTO.

Para tornar possível a consideração da interação solo-estrutura foi necessário algumas modificações e acréscimos nos módulos apresentados acima.

O Workspace SERIE foi adaptado para receberem as rigidezes equivalentes nas bases dos pilares do primeiro pavimento, onde serão processados os recalques da base e os deslocamentos dos pavimentos acima . O esquema é mostrado no item 5.3.

No presente trabalho foi elaborado o sexto Workspace, GRUPOBLOCO, de fundação em estacas, que recebem os dados referentes aos carregamentos no bloco (vertical $\mathrm{X}$, momento $\mathrm{Y}$ e momento $\mathrm{Z}$ ), para processarem os recalques (vertical X e rotações nos eixos $\mathrm{Y}$ e Z). Com a divisão da reação aplicada com o recalque, tem-se a rigidez equivalente que volta no Workspace SERIE durante a iteração. 


\subsection{Adaptação do workspace SERIE}

As coordenadas na extremidade de um pilar são seis: três independentes (rotações nos eixos $\mathrm{Y}$ e $\mathrm{Z}$ e uma translação $\mathrm{X}$ vertical) e três dependentes devido a consideração de diafragma rígido da laje. Para possibilitar a análise do modelo de estaqueamento que trabalha com estacas verticais somente na compressão, as coordenadas da extremidade inferior do pilar do primeiro pavimento terá três coordenadas, as rotações nos eixos $\mathrm{Y}$ e Z e uma translação no eixo $\mathrm{X}$ (vertical), Fig. 4.8. Os deslocamentos horizontais $\mathrm{Y}, \mathrm{Z}$ e rotação no $\mathrm{X}$ (torção) serão considerados nulos.

Dado a expressão da subestruturação em série para $\mathrm{N}$ pavimentos:

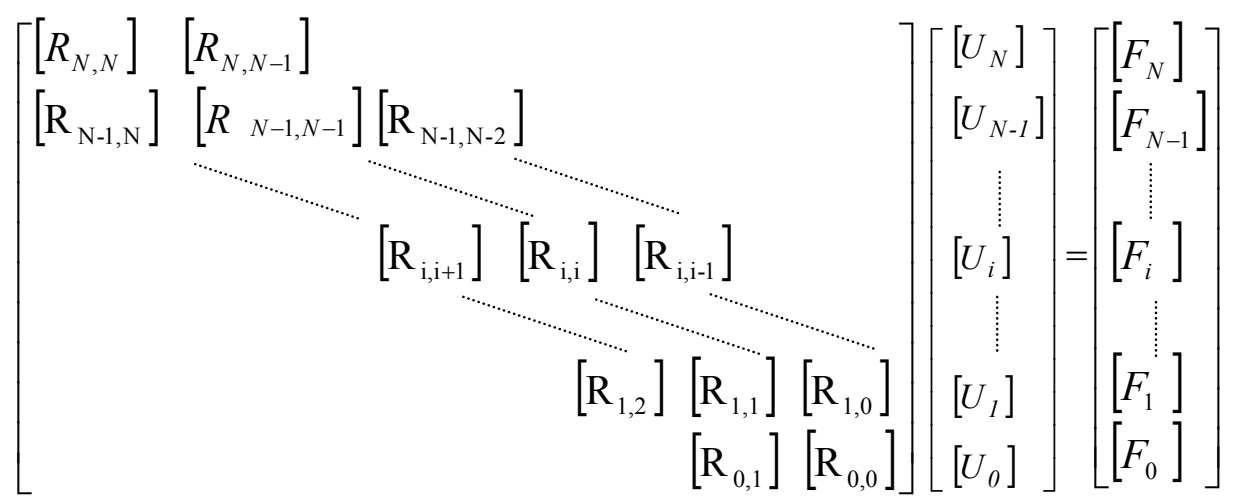

Antes da iteração, para simular o engastamento perfeito, somam-se rigidezes “infinitos" nas coordenadas da diagonal principal da $\left[R_{0,0}\right]$.

$\mathrm{Na}$ i-nésima iteração, somam-se as rigidezes equivalentes das fundações nas coordenadas correspondentes da diagonal principal da matriz $\left\lfloor R_{0,0}\right\rfloor$, que representa a rigidez das coordenadas externas do pavimento base.

Para tornar possível a sua resolução, faz-se a eliminação mostrado abaixo.

$$
\begin{array}{ll}
{\left[R_{N-1, N-1}^{*}\right]=\left[\mathrm{R}_{\mathrm{N}-1, \mathrm{~N}-1}\right]-\left[\mathrm{R}_{\mathrm{N}-1, \mathrm{~N}}\right]\left[R_{N, N}\right]^{-1}\left[\mathrm{R}_{\mathrm{N}, \mathrm{N}-1}\right]} & {\left[F_{N-1}^{*}\right]=\left[F_{N-1}\right]-\left[R_{N-1, N}\right]\left[R_{N, N}\right]^{-1}\left[F_{N}\right]} \\
{\left[R_{i, 1}^{*}\right]=\left[\mathrm{R}_{\mathrm{i}, \mathrm{i}}\right]-\left[\mathrm{R}_{\mathrm{i}, \mathrm{i}+1}\right]\left[R_{i+1, i+1}^{*}\right]^{-1}\left[\mathrm{R}_{\mathrm{i}+1, \mathrm{i}}\right]} & {\left[F_{i}^{*}\right]=\left[F_{i}\right]-\left[R_{i, i+1}\right]\left[R_{i+1, i+1}^{*}\right]^{-1}\left[F_{i+1}^{*}\right]} \\
\left.\left.\vdots R_{1,1}^{*}\right]=\left[\mathrm{R}_{1,1}\right]-\left[\mathrm{R}_{1,2}\right] \mid R_{2,2}^{*}\right]^{-1}\left[\mathrm{R}_{2,1}\right] & {\left[F_{1}^{*}\right]=\left[F_{1}\right]-\left[R_{1,2}\right]\left[R_{2,2}^{*}\right]^{-1}\left[F_{2}^{*}\right]} \\
\left.\left\lfloor R_{0,0}^{*}\right]=\left[\mathrm{R}_{0,0}\right]-\left[\mathrm{R}_{0,1}\right] \mid R_{1,1}^{*}\right]^{-1}\left[\mathrm{R}_{1,0}\right] & {\left[F_{0}^{*}\right]=\left[F_{0}\right]-\left[R_{0,1}\right]\left[R_{1,1}^{*}\right]^{-1}\left[F_{1}^{*}\right]}
\end{array}
$$


O sistema fica então :

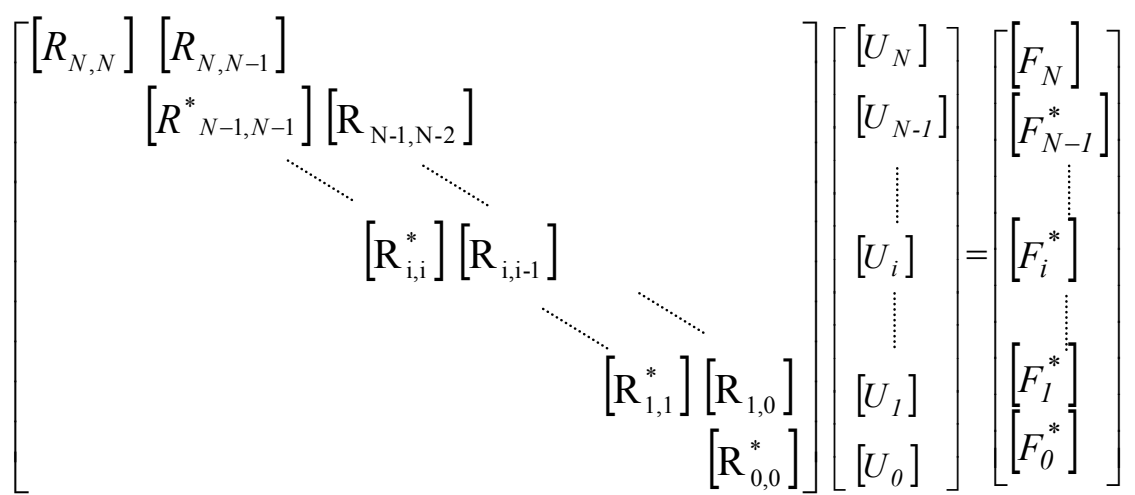

Resolvendo o sistema pela retro-substituição, tem-se:

$$
\begin{aligned}
& \left\lfloor R_{0,0}^{*} \mid\left[U_{0}\right]=\left\lfloor F_{0}^{*}\right\rfloor \quad \longrightarrow\left[U_{0}\right]=\left[R_{0,0}^{*}\right]^{-1}\left[F_{0}^{*}\right]\right. \\
& \left\lfloor R_{l, 1}^{*} \mid\left[U_{1}\right]+\left[R_{1,0}\right]\left[U_{0}\right]=\left\lfloor F_{1}^{*}\right\rfloor \quad \longrightarrow \quad\left[U_{1}\right]=\left[R_{l, 1}^{*}\right]^{-1}\left(\left[F_{1}^{*}\right]-\left[R_{l, 0}\right]\left[U_{0}\right]\right)\right. \\
& \left\lfloor R_{i, i}^{*} \mid\left[U_{i}\right]+\left[R_{i, i-1}\right]\left[U_{i-1}\right]=\left\lfloor F_{i}^{*}\right\rfloor \quad \rightarrow \quad\left[U_{i}\right]=\left[R_{i, i}^{*}\right]^{-1}\left(\left[F_{i}^{*}\right]-\left[R_{i, i-1}\right]\left[U_{i-1}\right]\right)\right. \\
& \left\lfloor R_{N, N}^{*}\left|\left[U_{N}\right]+\left[R_{N, N-I}\right]\left[U_{N-I}\right]=\right| F_{N}^{*}\right\rfloor \quad \longrightarrow \quad\left[U_{N}\right]=\left[R_{N, N}^{*}\right]^{-1}\left(\left[F_{N}^{*}\right]-\left[R_{N, N-I}\right]\left[U_{N-I}\right]\right)
\end{aligned}
$$

Cujo os vetores $\left[U_{0}\right],\left[U_{1}\right] \ldots\left[U_{i}\right] \ldots\left[U_{n}\right]$, são deslocamentos dos pavimento base, pavimento 1 .... pavimento i .... e pavimento N, respectivamente, Fig. 3.16.

As reações serão obtidas com a lei de Hook:

$$
\begin{aligned}
& \text { Reac }=-\mathrm{R} * \mathrm{U} \\
& \mathrm{R}=\text { rigidez equivalente dos apoios } \\
& \mathrm{U}=\text { deslocamentos dos apoios (recalques e rotações) }
\end{aligned}
$$

Sendo que antes da iteração, serão impostos os valores de K “infinitos"e em conseqüência os deslocamentos muito pequenos, $\delta \cong 0$. Na $1^{\text {a }}$ iteração depois de resolver o sistema é que começa o processo de aproximação das rigidezes nos apoios. 


\subsection{Workspace GRUPOBLOCO}

Este módulo que foi acrescentado no programa EDIFICIO, pode ser resumido como a seguir.

A leitura de arquivos de entrada:

- Dados relativos a estacas (diâmetro, elasticidade, raio da estaca, comprimento e suas coordenadas)

- Dados relativos ao solo ( $\mathrm{n}^{\circ}$ de camadas, profundidade e características do solo)

Quanto a leitura de carregamentos no bloco, são lidas as reações calculadas no módulo SERIE, guardados no arquivo temporário.

Utilizando a rotina apresentado em STAMATO (1971) sobre o cálculo de estaqueamento idealizado pelo SCHIEL (1957) é processado o carregamento axial de compressão que será transmitida para cada estaca que compõem um bloco. Estes carregamentos serão passadas na subrotina ESTACA, que através do diagrama de transferência de carga lateral no fuste, calculam os esforços normais $\mathrm{N}(\mathrm{z})$ da estaca e com isso a deformação do fuste e a parcela de carregamento $\mathrm{Pp}$ na base da estaca. $\mathrm{O}$ deslocamento do grupo de estacas no meio estratificado será processado na subrotina AOKILOPES que utiliza equação de MINDLIN (1936) e o procedimento de STEINBRENNER (1934) para considerar várias camadas antes do indeslocável, já apresentado em AOKI\&LOPES (1975).

Utilizando-se o método SCHIEL, dentro de várias iterações, calculam-se as novas rigidezes das estacas dividindo o carregamento da iteração anterior pelo recalque (deslocamento + deformação da estaca) para determinarem os novos carregamentos nas estacas. Este processo será repetido até que aconteça uma certa convergência em todos os carregamentos axiais das estacas de uma iteração para outra.

Este módulo fornece os esforços nas estacas o os recalques do bloco de coroamento.

O esquema resumido da interação bloco - estaca - solo é:

Faça $\mathrm{I}=1$ até $\mathrm{N}$ de iterações

Método SCHIEL (Calculam os recalques no bloco e os esforços nas estacas)

ESTACAS (Cálculo de diagrama de transferência de carga e a deformação elástica do fuste da estaca)

MINDLIN (Cálculo dos deslocamentos do grupo de estacas em meio estratificado)

Obtenção das novas rigidezes nas estacas

Continue 
O esquema geral da seqüência de processamento do programa EDIFÍCIO, com seis Workspaces, pode ser resumido como:

\begin{tabular}{|c|c|}
\hline \multirow{2}{*}{\multicolumn{2}{|c|}{ montagem da matriz de rigidez dos pavimentos }} \\
\hline & \\
\hline MONTAGEM & montagem da matriz de rigidez global \\
\hline \multicolumn{2}{|c|}{ Faça $\mathrm{I}=1$ até $\mathrm{N}$ de iteração desejada } \\
\hline SERIE & resolução do sistema de equações \\
\hline DESLOCAMENTO & cálculo dos deslocamentos internos do pavimento \\
\hline ESFORCO & cálculo dos esforços nas vigas e pilares \\
\hline GRUPOBLOCO $\longrightarrow$ & cálculo dos recalques no bloco de coroamento \\
\hline $\mathrm{R}=$ Ação / deslocamento & (rigidez equivalente dos apoios) \\
\hline
\end{tabular}




\subsection{Entrada de dados via arquivo}

\subsubsection{Estruturas}

Para cada tipo de subestrutura são elaborados dois arquivos:

- Dados referentes aos elementos horizontais (elementos de viga e placas) que compõem o pavimento e as cargas verticais;

- Dados referentes aos elementos verticais (pilares) e às forças horizontais (vento).

\section{Leitura.Ist}

PavBase

0,1

c: \msdev $\backslash$ Modelo2 $\backslash$ ibracon $\backslash$ pavbase.dat

c: $\backslash$ msdev $\backslash$ Modelo2libracon $\backslash$ pavbase.str 1

pavTipo

\section{5,1}

c: \msdev $\backslash$ Modelo2 $\backslash$ ibracon\pavtipo.dat

c: \msdev $\backslash$ Modelo2 $\backslash$ ibracon $\backslash$ pavtipo.str

2

Os dados dos elementos de vigas e placas, podem ser lidos pelo programa desenvolvido de duas maneiras:

- Via arquivo de dados, não recomendável para estruturas com muitas discretizações;

- Via interface em Visual Basic, implementado em MARTINS(1998) que possibilita a geração automática da malha de elementos finitos quadrangulares para pavimentos de geometria retangular.

Leitura2.Ist (faz a ordenação de dados lidos na Leitura.lst para formar a estrutura global do edifício)

- Leitura do número de pavimentos totais do edifício;

- Número de diferentes tipos de subestrutura;

- Numeração da saída de dados de tipos de subestrutura, neste exemplo 1 é o que identifica o arquivo do PavBase e 2 é a de PavTipo;

- Número de repetições de subestruturas nos pavimentos do edifício;

- Numeração dos pavimentos do topo para a base da estrutura. 


\subsubsection{Fundações}

5.5.2.1 Dados do bloco de coroamento (Estaqueamento SCHIEL)

Número de estacas que compõem o bloco k, diâmetros e módulo de elasticidades e coordenadas $\mathrm{X}$, Y e $\mathrm{Z}$ das estacas.

\subsubsection{Dados do grupo de estacas (Método AOKI - LOPES)}

Número total de estacas, raio do fuste e da base das estacas, número de subdivisões $\mathrm{n}_{1}, \mathrm{n}_{2}$ e $\mathrm{n}_{3}$. (ver Fig. 2.4 e 2.5 do item 2.4.1)

Número de camadas do solo, módulo de deformabilidade e coeficientes de Poisson da cada camada do solo.

Dados de distribuição de resistência lateral local / unidade de comprimento entre fuste da estaca e o solo, previamente determinado pelo método AOKI - VELLOSO ou similar.

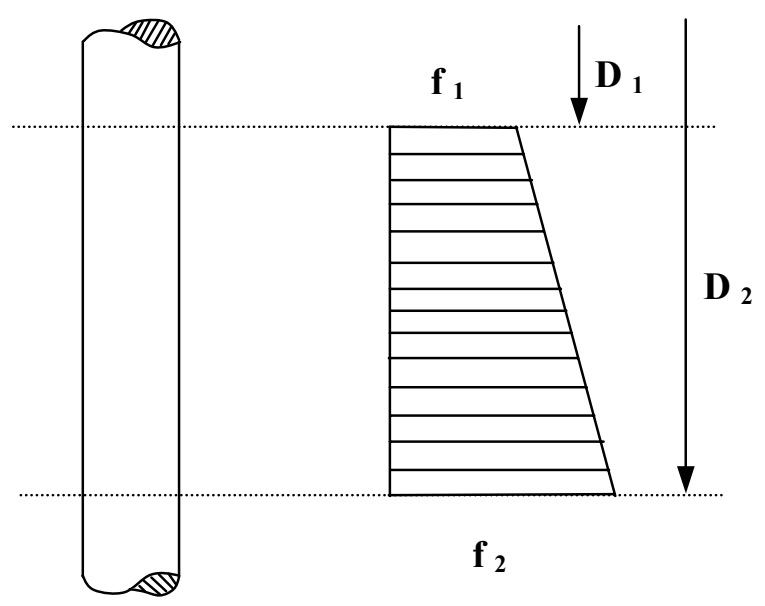

Figura 5.1 - Trapézio do atrito lateral entre a estaca e o solo

$\mathbf{f}_{1}$ e $\mathbf{f}_{2}$ são coeficientes de atrito lateral local superior e inferior do trapézio.

$\mathbf{D}_{1}$ e $\mathbf{D}_{2}$ são profundidades superior e inferior do trapézio.

Unidades do f (força / comprimento) 
5.6 Entrada de dados via interface em Visual Basic

G. PROGRAMA PARA ANALISE DE EDIFÍCIOS ALTOS

\section{UNIVERSIDADE DE SÃO PAULO} Escola de Engenharia de São Carlos

Departamento de Engenharia de Estruturas

PROGRAMA PARA ANÁLISE DE EDIFÍCIOS ALTOS

Bolsista de Iniciação Cientifica : Roberto Medeiros Urioste Aluno de Mestrado : Eng. Roberto Kunihiro lwamoto Aluno de Doutorado: Eng. Carlos Humberto Martins Orientadora : Profa. Dra. Helena M. C. Carmo Antunes

$\underline{O K}$ Cancelar

Figura 5.2 - Tela de apresentação

9. Dados do Edifício

Digite o numero de andares, sub estruturas do edifício e o arquivo d dados sobre as sub estruturas.

15 Número de Andares

2 Número de Sub estruturas

9 Número de blocos na base da estrutura

c: `exemplo \

Nome do diretório com dados de super estrutura (c:łexemplo... V)

pavbase2.dat

Nome do arquivo com dados do pavimento base (*.dat)

pavbase21.str

Nome do arquivo com dados do pavimento base (* -str)

pavtipo.dat

Nome do arquivo com dados do pavimento tipo ( ${ }^{*}$.dat)

pavtipo21.sth

Nome do arquivo com dados do pavimento tipo (*.str)

OK

Cancelar

Figura 5.3 - Dados gerais do edifício 


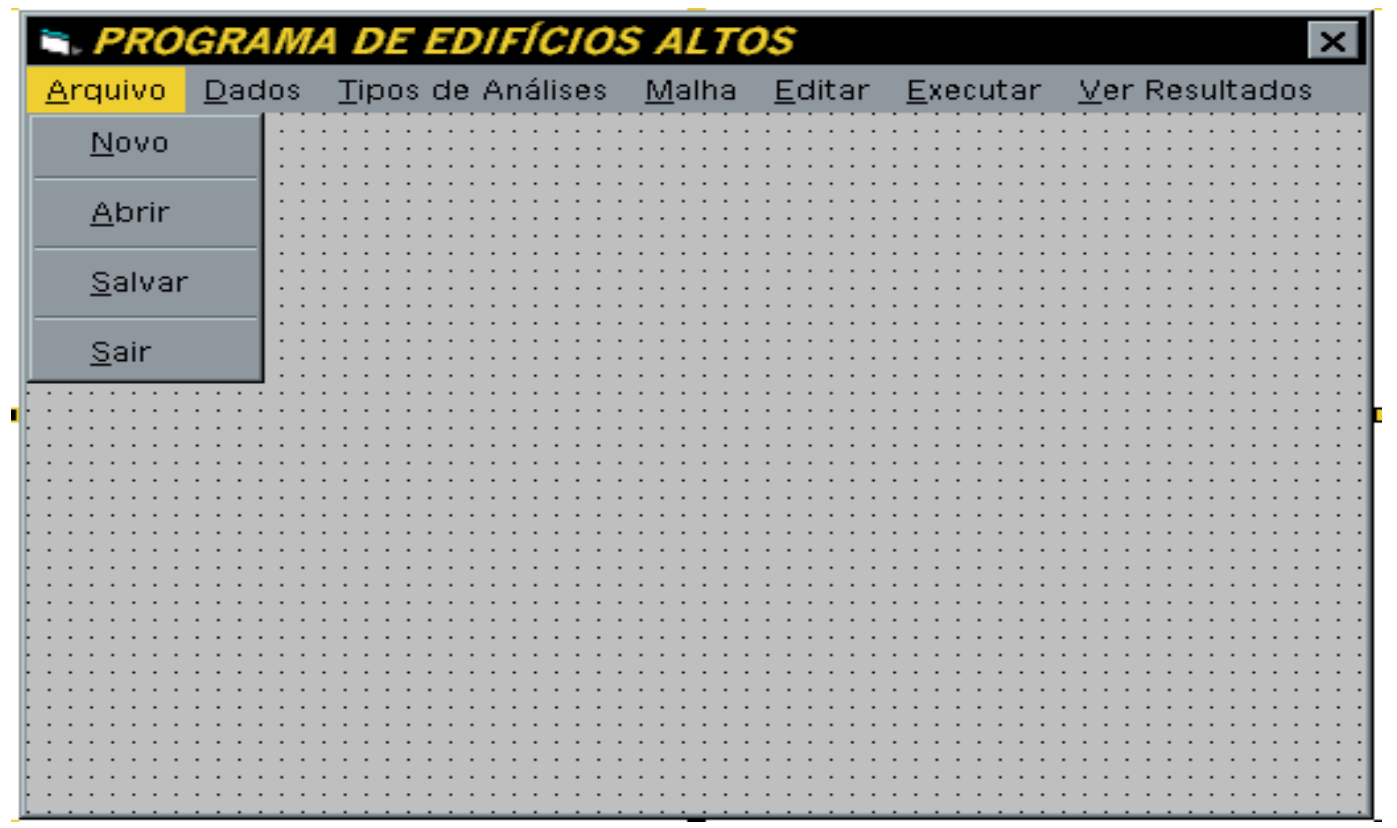

Figura 5.4 - Menu principal de entrada de dados

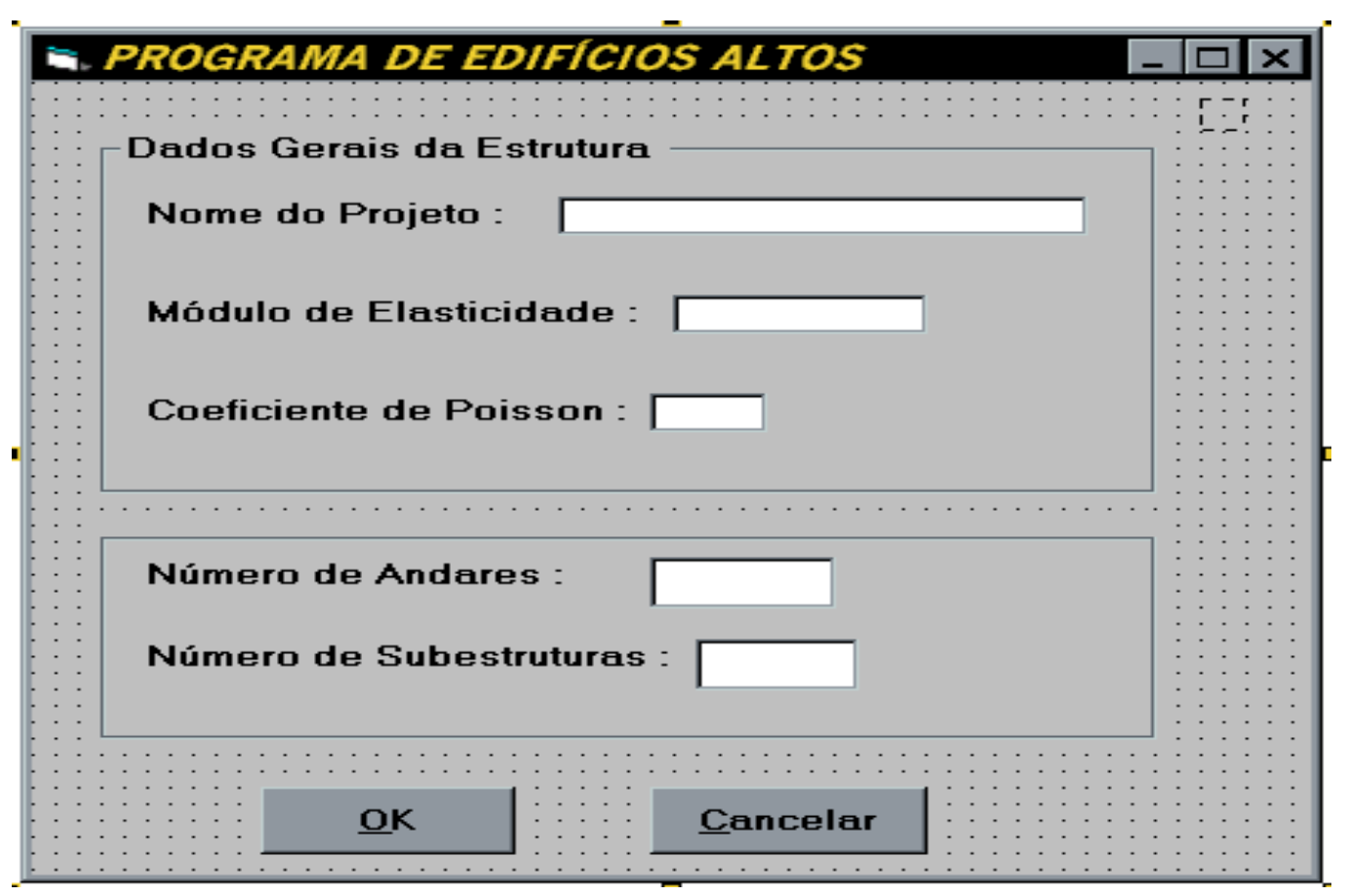

Figura 5.5 - Menu dados gerais da estrutura 


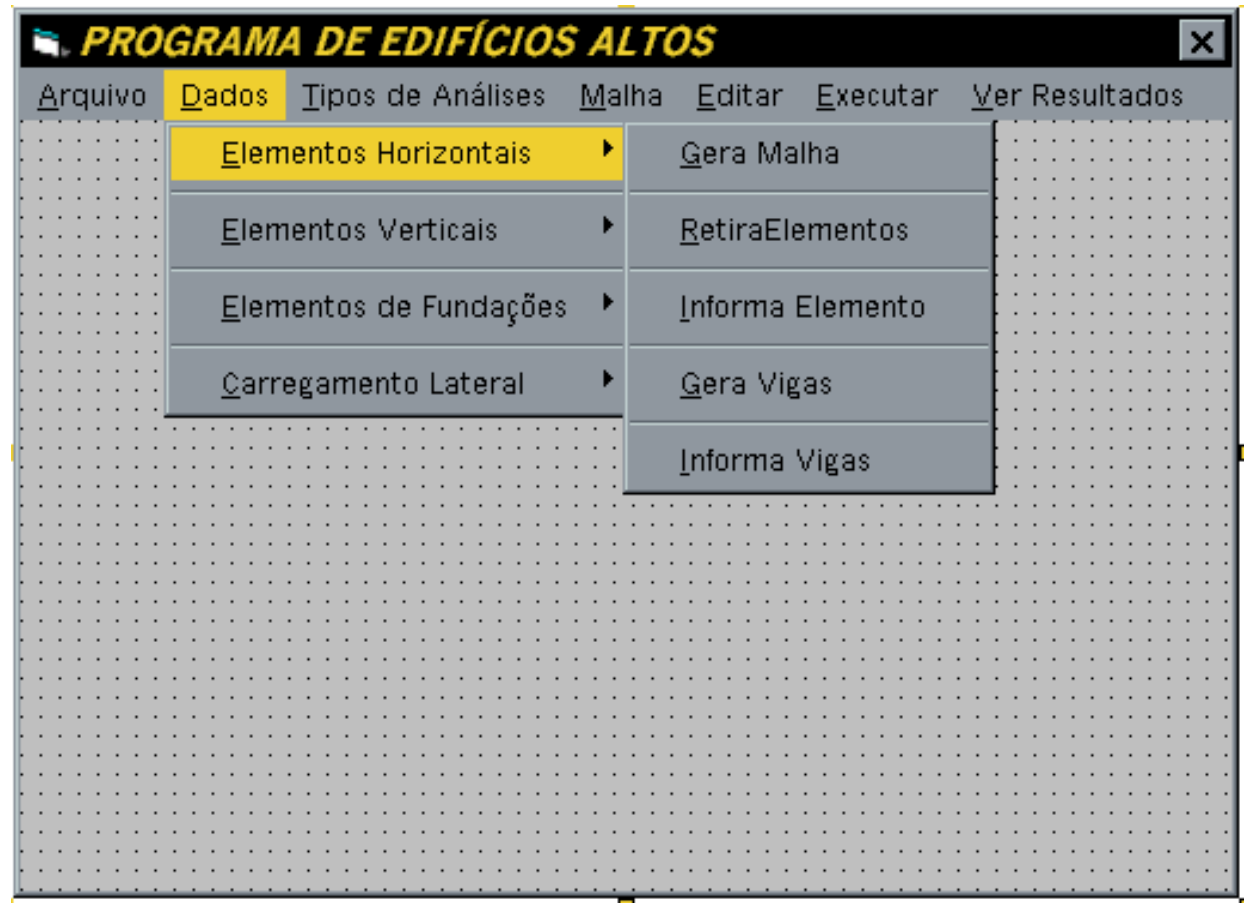

Figura 5.6 - Menu opção de entrada de dados

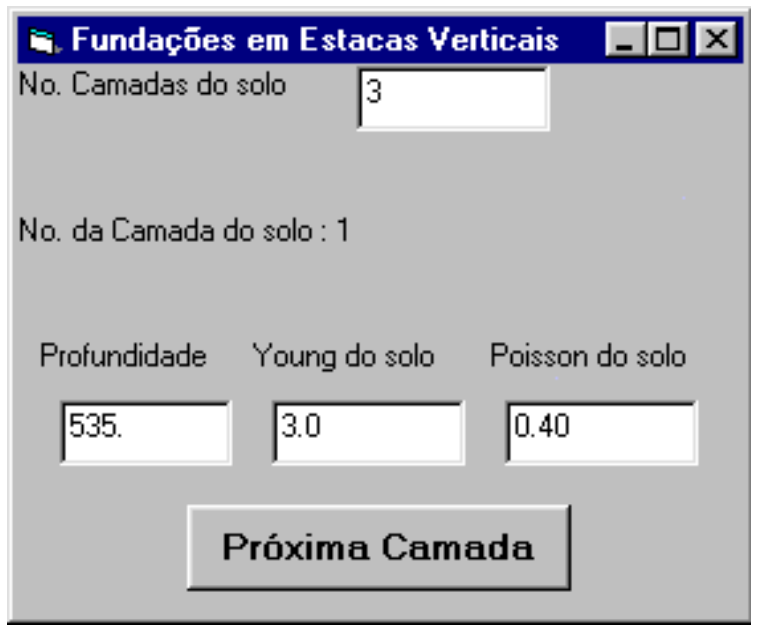

Figura 5.7 - Menu características do solo 
E. Fundaçōes em Estacas Yerticais

Dados sobre o bloco: 1

Próximo Bloco

Convenção de Eixos:

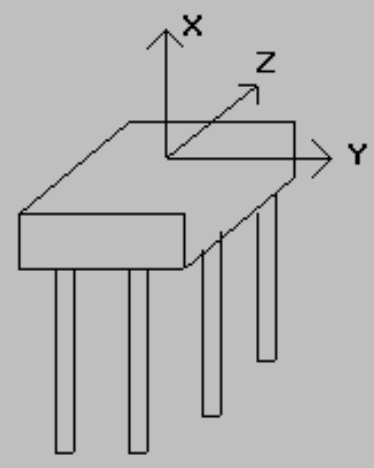

No. Estacas $\longdiv { 4 }$

Estaca

1

Comp.

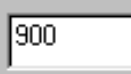

Diầmetro

50

Figura 5.8 - Menu entrada de dados do estaqueamento

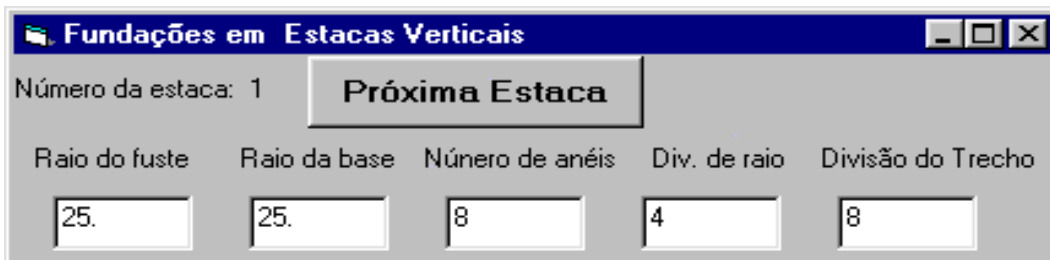

Coordendas globais da estaca:

$$
X \longdiv { - 9 0 0 } \text { Y }
$$

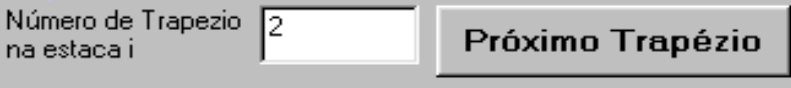

Trapezio: 1

D1

f1

D2

I2

Dist. Superior Atrito Superior Dist. Inferio Atrito Inferior
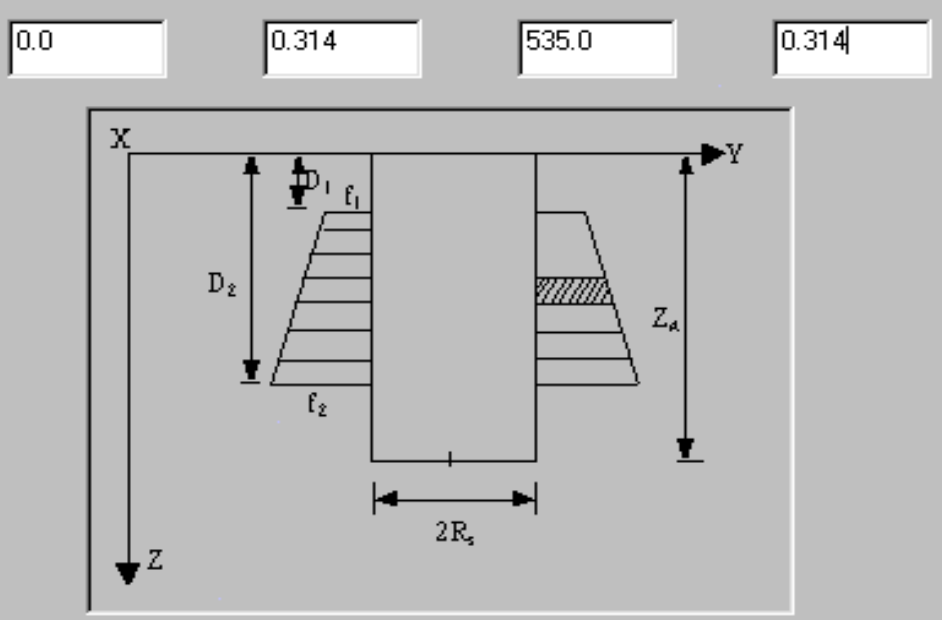

Figura 5.9 - Menu grupo de estacas e atrito lateral máximo 


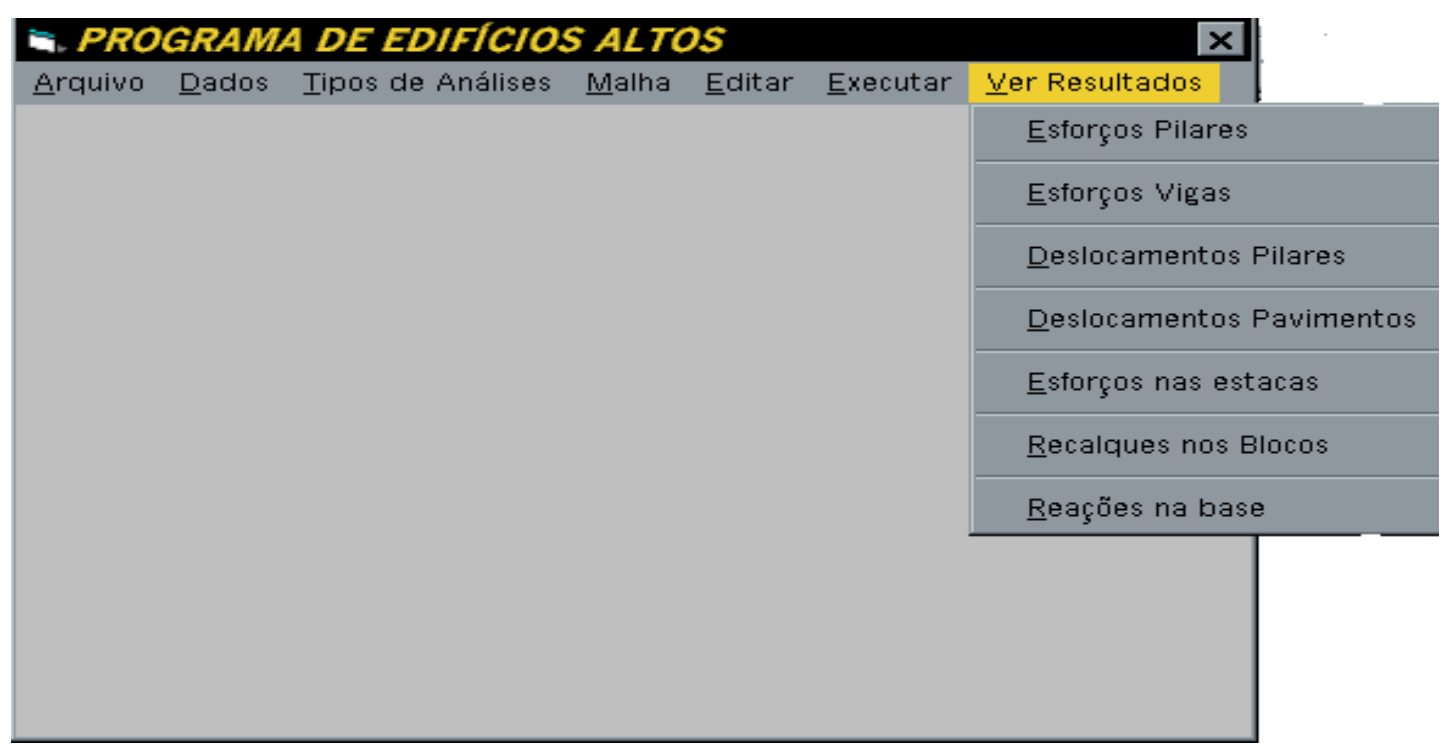

Figura 5.10 - Menu opção para saída de dados no WORDPAD

\subsection{Saída de dados no WordPad}

\subsubsection{Saída de resultados da estrutura}

Andar: Lista deslocamentos $\delta_{\mathrm{x}}, \phi_{\mathrm{y}}$ e $\phi_{\mathrm{z}}$ de todos os pilares e deslocamentos $\phi_{\mathrm{x}}, \delta_{\mathrm{y}}$ e $\delta_{\mathrm{z}}$ do corpo rígido de cada pavimento.

Pavim: Lista deslocamentos dos nós internos (nós dos elementos de viga e placa que não tem conectividade direta com os pilares).

Viga: Lista esforços solicitantes nas extremidades das vigas relacionados de acordo com o sistema de coordenadas locais.

Pilar: Lista os esforços nas extremidades dos pilares relacionados com o sistema de coordenadas locais.

\subsubsection{Saída de resultados dos elementos estruturais de fundações}

Bloco: Lista deslocamentos (recalque segundo eixo $\mathrm{X}$, rotações em torno dos eixos $\mathrm{Y}$ e $\mathrm{Z}$ da coordenada global da estrutura) e cargas axiais nas estacas.

Grupo: Lista distribuição de transferência de esforço axial $\mathrm{N}_{\mathrm{o}}(\mathrm{z})$ nas estacas, a deformação axial elástica, o deslocamento na base e os recalques nas estacas.

Reação: Reações nos apoios da estrutura segundo coordenada global.

Recalque: Recalques no X e rotações nos eixos $\mathrm{Y}$ e Z nos apoios, da coordenada global. 


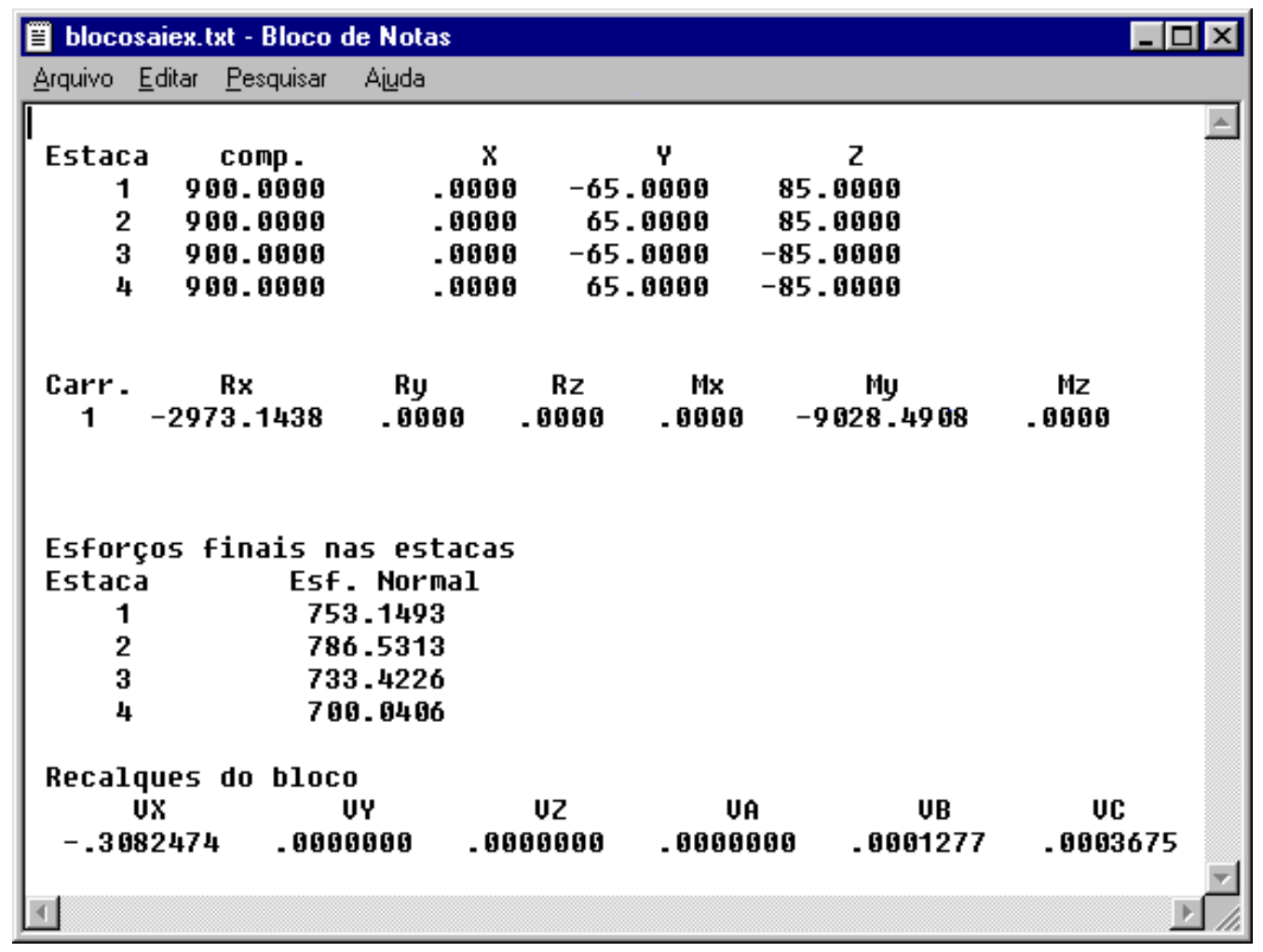

Figura 5.11 - Saída de dados no WordPad 


\subsection{Saída Gráfica}

O usuário poderá confirmar se as coordenadas e incidências dos elementos estruturais foram corretamente endereçadas, através da saída gráfica tridimensional da estrutura. Os dados geométricos são lidos e montados em FORTRAN que mediante a uma subrotina cria-se um arquivo "dxf" para ser aberto em AutoCAD.

Como exemplo, mostra-se a estrutura do exemplo 2 do capítulo 6 :

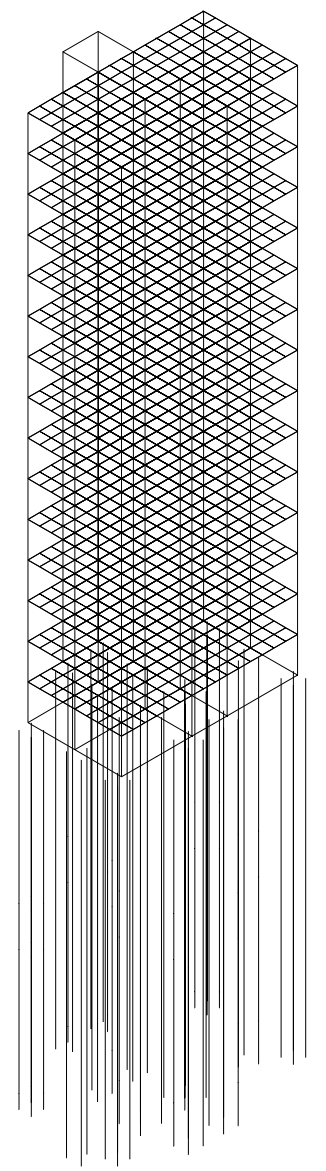

Figura 5.12 - Saída gráfica tridimensional da estrutura

A vantagem desse processo é que uma vez criado o desenho em AutoCAD, pode-se verificar não só as coordenadas nodais e distâncias entre os eixos dos elementos mas também visualizar a estrutura em diversos ângulos para constatar um eventual erro na entrada de dados do programa computacional. 


\section{EXEMPLOS NUMÉRICOS}

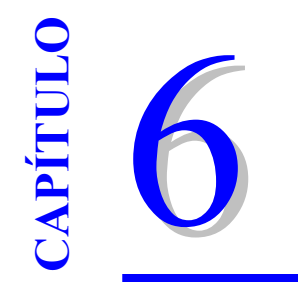

\subsection{Introdução}

Apresenta-se a seguir quatro exemplos numéricos, cujos resultados são analisados com o intuito de se obter algumas conclusões importantes a respeito do comportamento de grupo de estacas e os efeitos da interação solo - estrutura nos edifícios de múltiplos andares.

No primeiro exemplo será analisado um caso de fundações de um silo com resultados de provas de carga para uma estaca isolada. A partir desses dados serão feitas previsões, com o objetivo de verificar os efeitos do grupo de estacas nos recalques.

Nos dois exemplos seguintes serão mostrados edifícios submetidos à cargas verticais e ações horizontais para analisar os efeitos mais comuns da interação solo - estrutura como redistribuições dos esforços nos elementos estruturais, as mudanças nas reações e a deformada nos apoios. Mostra-se também a convergência do processo iterativo nas reações.

No último exemplo foi feito uma comparação entre resultados de recalques medidos num edifício no interior de São Paulo e o modelo numérico adotado no presente trabalho como uma forma de validação do programa computacional. Neste último exemplo o programa computacional foi adaptado para analisar fundações em tubulões, onde considerouse apenas a deslocabilidade vertical para cada apoio, restringindo as outras (duas rotações) e portanto, dispensando o roteiro de estaqueamento de SCHIEL (1957) onde além das cargas verticais os momentos fletores nos apoios podem ser absorvidos através do bloco de coroamento, suposto rígido, para as estacas, em forma de esforços axiais. 


\section{Exemplo 1}

Neste exemplo, será analisada a fundação de dois reservatórios da Termoelétrica Gdansk (Polônia) cujos os dados foram enviados pelo Technical Committee of "Pile Driving" (TC 18) com a finalidade de fazer previsões dos recalques do grupo de estacas.

Serão feitas duas análises:

A primeira, será estimado um diagrama de ruptura do contato estaca - solo a partir da Norma Polonesa No.PN-83/B-02482 "Foundation bearing capacity of piles and pile foundation" segundo GWIZDALA (1997) e este será utilizado no programa computacional como entrada de dados (diagrama de ruptura do sistema estaca - solo) para o cálculo de recalque da estaca;

A segunda, com os dados da curva carga - recalque da estaca (prova de carga realizado no local), o diagrama de ruptura será ajustado em proporção ao da primeira previsão, um novo diagrama de ruptura mais provável para o terreno.

Tem-se:

6 blocos de fundações para servir de apoio para dois silos.

Dimensões e tipo de estaca:

4 Blocos: $4,3 \mathrm{~m} \mathrm{x} \quad 4,5 \mathrm{~m} ; \mathrm{H}=2,0 \mathrm{~m}$

2 Blocos: 4,3 $\mathrm{m} \times 10,0 \mathrm{~m} ; \mathrm{H}=2,0 \mathrm{~m}$

72 estacas tipo "Vibro - Fundex":

Diâmetro do fuste $\phi 45,7 \mathrm{~cm}$ e Diâmetro da base $\phi 53,0 \mathrm{~cm}$

Comprimento da estaca $\mathrm{L}=17,6 \mathrm{~m}$

Módulo da estaca $\mathrm{E}_{\mathrm{p}}=2400 \mathrm{kN} / \mathrm{cm}^{2}$

Segundo TC 18, estima-se que cada estaca receberá em torno de $953 \mathrm{kN}$ de carga oriundas do silo.

\begin{tabular}{|c|c|c|c|c|}
\hline $\begin{array}{c}\text { Nível das } \\
\text { camadas }(\mathrm{m})\end{array}$ & Tipo de solo & $\begin{array}{c}\text { Densidade } \\
\text { relativa }\end{array}$ & $\begin{array}{c}\mathrm{E}_{\mathrm{s}} \\
\left(\mathrm{kN} / \mathrm{cm}^{2}\right)\end{array}$ & Poisson \\
\hline$-3,85$ & Areia fina & 0,51 & 4,74 & 0,30 \\
\hline$-4,40$ & Argila mole & - & 0,06 & 0,32 \\
\hline$-4,70$ & Aluvião & - & 0,21 & 0,30 \\
\hline$-13,20$ & Areia fina & 0,72 & 6,50 & 0,30 \\
\hline$-14,50$ & Areia fina & 0.51 & 4,74 & 0,30 \\
\hline- & Areia fina & 0,72 & 6,50 & 0,30 \\
\hline
\end{tabular}

Tabela 6.1 - características do solo 
1.1 Resistência característica $\mathrm{N}$ da estaca isolada, segundo a Norma Polonêsa:

$\mathrm{N}=\mathrm{N}_{\mathrm{P}}+\mathrm{N}_{\mathrm{S}}\left\{\begin{array}{l}\mathrm{N}_{\mathrm{P}}=\mathrm{S}_{\mathrm{P}} \mathrm{q}^{(\mathrm{r})} \mathrm{A}_{\mathrm{P}} \longrightarrow \text { Resistência do fuste } \\ \mathrm{N}_{\mathrm{S}}=\sum \mathrm{S}_{\mathrm{Si}} \mathrm{t}_{\mathrm{i}}^{(\mathrm{r})} \mathrm{A}_{\mathrm{si}} \longrightarrow \text { Resistência da base }\end{array}\right.$

$\mathrm{i}=$ índice das camadas do solo

$\mathrm{S}_{\mathrm{s}}$ e $\mathrm{S}_{\mathrm{P}}=$ fatores construtivos

$\mathrm{q}=$ resistência unitária da base

$\mathrm{q}^{(\mathrm{r})}=\gamma_{\mathrm{m}} \mathrm{q} \quad \mathrm{t}=$ resistência unitária do fuste

$\mathrm{t}^{(\mathrm{r})}=\gamma_{\mathrm{m}} \mathrm{t} \quad \gamma_{\mathrm{m}}=$ coeficiente de material ( depende do $\mathrm{I}_{\mathrm{D}}$ ou $\mathrm{I}_{\mathrm{L}}$ )

$\mathrm{I}_{\mathrm{D}}=$ índice de densidade do solo

$\mathrm{I}_{\mathrm{L}}=$ índice de liquidez do solo

\begin{tabular}{|c|c|c|c|c|c|c|}
\hline Camada & Tipo de solo & $\mathrm{I}_{\mathrm{D}}$ & $\mathrm{q}(\mathrm{kPa})$ & $\mathrm{t}(\mathrm{kPa})$ & $\mathrm{S}_{\mathrm{p}}$ & $\mathrm{S}_{\mathrm{s}}$ \\
\hline 1 & Areia fina & 0,51 & 2205,88 & 47,41 & 1,4 & 1,1 \\
\hline 2 & Argila mole & - & - & - & - & - \\
\hline 3 & Aluvião & - & - & - & - & - \\
\hline 4 & Areia fina & 0,72 & 2912,12 & 67,75 & 1,1 & 1,0 \\
\hline 5 & Areia fina & 0.51 & 2205,88 & 47,41 & 1,4 & 1,1 \\
\hline 6 & Areia fina & 0,72 & 2912,12 & 67,75 & 1,1 & 1,0 \\
\hline
\end{tabular}

Tabela 6.2 - Resistência na base e no fuste

Para o tipo "Vibro-Fundex" a Norma Polonesa recomenda o acréscimo de 20\% para promover a melhor compatibilização dos valores de q e t.

A máxima resistência na base da estaca é:

$\mathrm{N}_{\mathrm{P}}=\mathrm{S}_{\mathrm{P}} \mathrm{q}^{(\mathrm{r})} \mathrm{A}_{\mathrm{P}}=1,1 \times(0,291212+20 \%) \times 2206,18=848,05 \mathrm{kN}$

A máxima resistência no fuste da estaca é:

$\mathrm{N}_{\mathrm{S}}=\sum_{i} \mathrm{~S}_{\mathrm{Si}} \mathrm{t}_{\mathrm{i}} \mathrm{A}_{\mathrm{Si}}$

\begin{tabular}{cccc}
$\mathrm{S}_{\mathrm{Si}}$ & $\mathrm{t}_{\mathrm{i}}\left(\mathrm{kN} / \mathrm{cm}^{2}\right)$ & $\mathrm{A}_{\mathrm{Si}}\left(\mathrm{cm}^{2}\right)$ & $\mathrm{N}_{\mathrm{Si}}(\mathrm{kN})$ \\
1,1 & $0,003650+20 \%$ & 42353,38 & 204,09 \\
- & - & - & - \\
- & - & - & - \\
1,0 & $0,006775+20 \%$ & 122035,16 & 992,14 \\
1,1 & $0,004741+20 \%$ & 18664,20 & 116,80 \\
1,0 & $0,006775+20 \%$ & 57428,31 & 466,89 \\
\cline { 3 - 3 } & & & $1779,92 \mathrm{kN}$
\end{tabular}


O valor da ruptura contato estaca - solo pela Norma fica:

$\mathrm{N}=\mathrm{N}_{\mathrm{P}}+\mathrm{N}_{\mathrm{S}}=848,05+1779,92=2627,97 \mathrm{kN}$
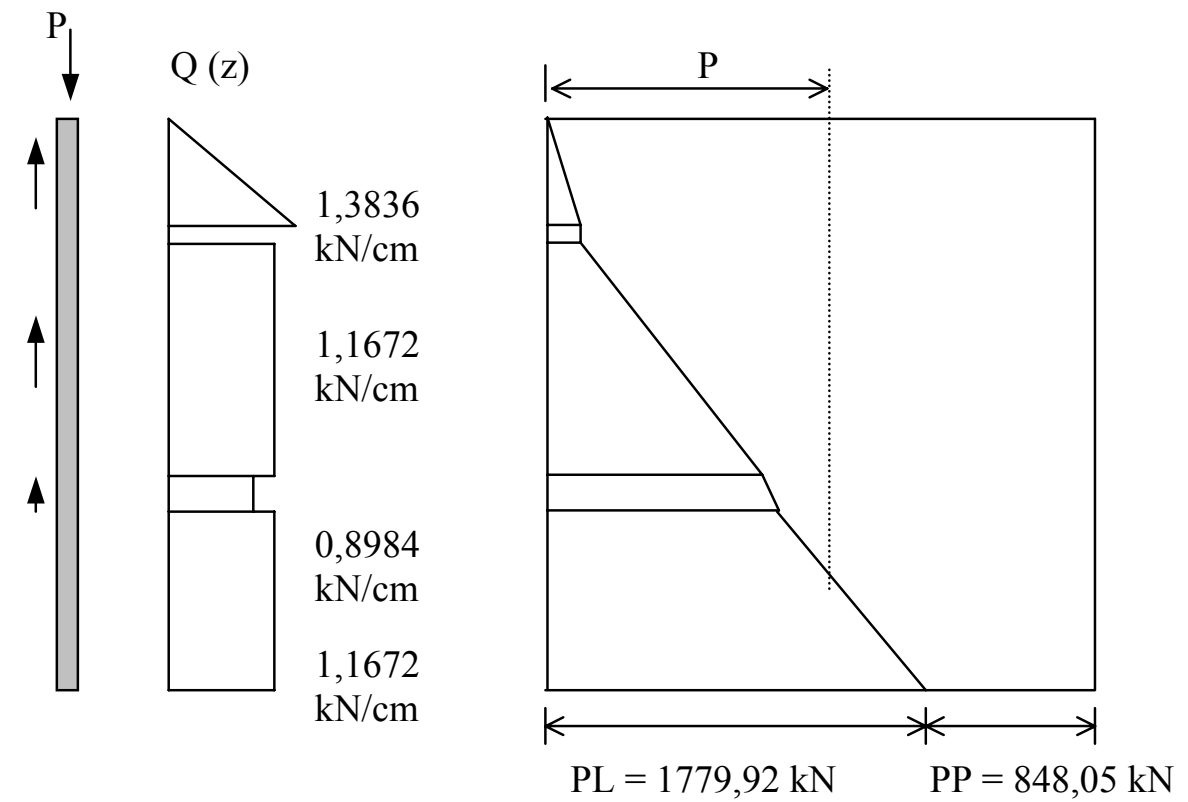

Figura 6.1 - Diagrama de ruptura

Com os dados da prova de carga da estaca 55 (Fig. 6.4) realizada no terreno, pode-se ajustar o mais provável diagrama de ruptura, (Fig. 6.2).
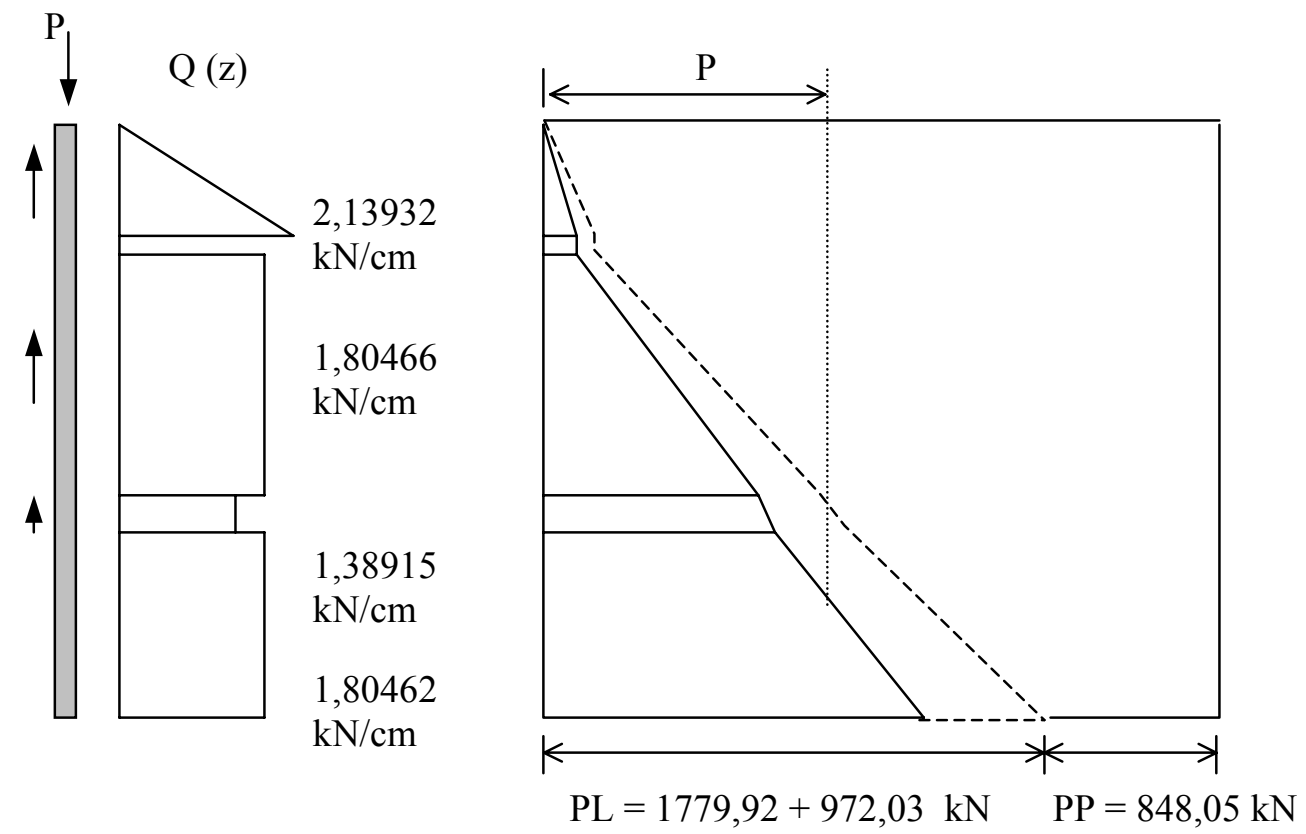

Figura 6.2 - Diagrama de ruptura ajustado 
Com o diagrama de ruptura ajustado com a retro - análise, foram calculados os recalques da estaca para cargas crescentes e o resultado mostrou-se bem mais representativo, (Fig.6.3).

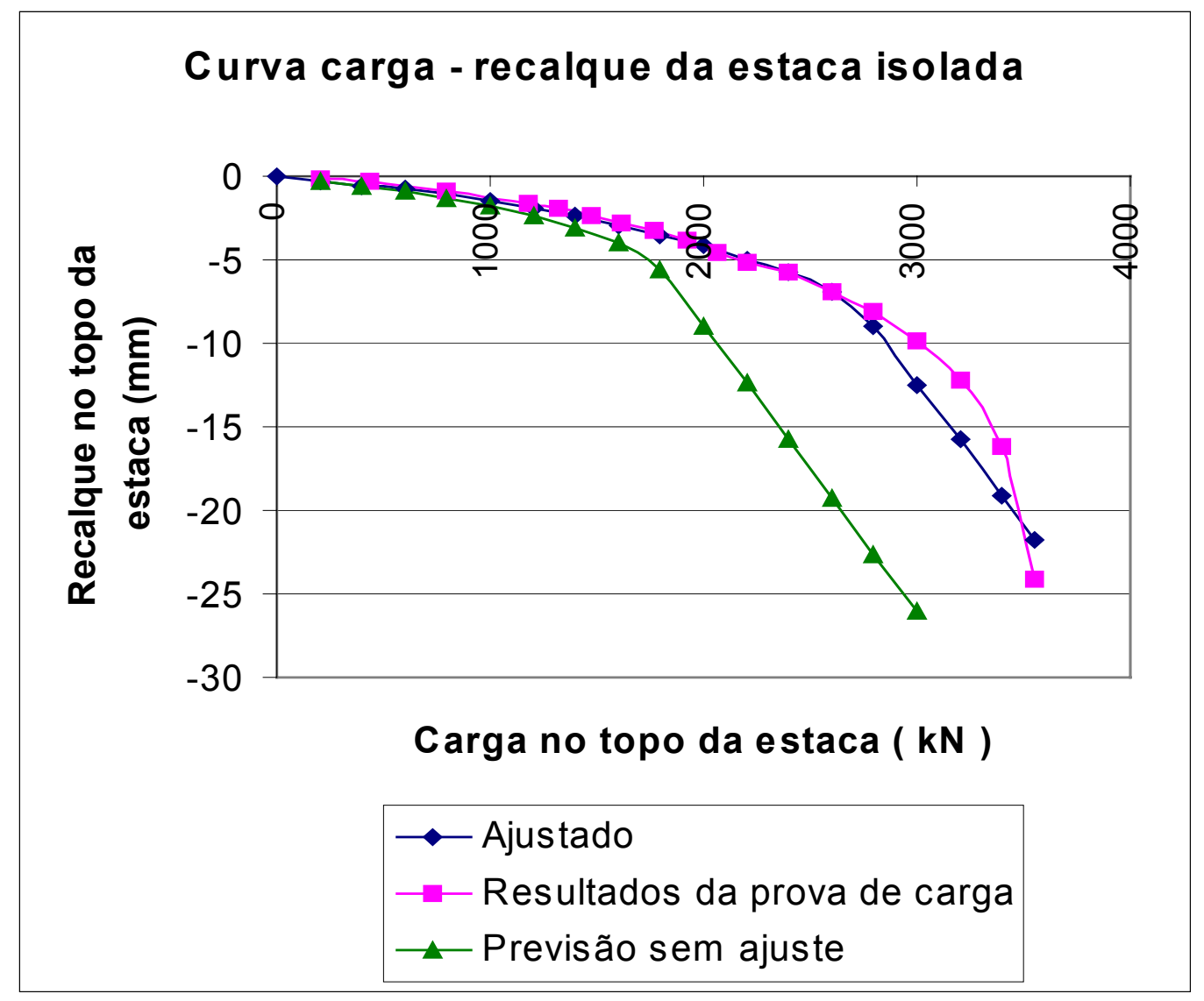

Figura 6.3 - Comparação

Com os dados do diagrama de ruptura ajustado, realizou-se uma estimativa numérica levando em conta o efeito de grupo para 72 estacas e os resultados foram:

Sendo: Deform. $=$ deformação elástica do fuste da estaca;

Desloc. $=$ deslocamento do solo na base da estaca.

Estaca Deform. Desloc. Recalque (cm)

$\begin{array}{llll}1 & .10753 & .13934 & .24687 \\ 2 & .10469 & .14953 & .25421 \\ 3 & .10865 & .15290 & .26155\end{array}$

$\begin{array}{llll}55 & .09557 \quad .20651 \quad .30208\end{array}$ 


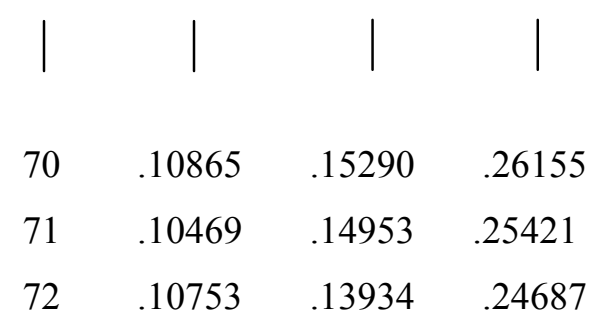

$\mathrm{Na}$ prova de carga para estaca isolada, a carga aplicada de $953 \mathrm{kN}$ na estaca 55 provocou um recalque de $1,14 \mathrm{~mm}$ (Fig. 6.3). Esta mesma estaca, quando estimado numericamente à ação do grupo de estacas, salta para 3,02 $\mathrm{mm}$ de recalque, ou seja mais que o dobro do recalque medido na estaca isolada. Na realidade, como existe o contato direto do bloco de coroamento com o terreno, é bem provável que este recalque do grupo seja menor que o previsto neste modelo numérico, no entanto o exemplo mostra a importância da consideração dos efeitos de grupo nos recalques das estacas.

Os recalques no bloco de coroamento considerando que todas as cargas serão transmitidas diretamente para as estacas sem o contato do bloco com o solo, fica:

$\begin{array}{lcc}\text { Recalques }(\mathrm{cm}) & \text { Rotação Y (rd) } & \text { Rotação Z (rd) } \\ -.2600225047 & .0000322707 & .0000407756 \\ -.3020747575 & .0000484832 & .0000000000 \\ -.2600225047 & .0000322707 & -.0000407756 \\ -.2600225047 & -.0000322707 & .0000407756 \\ -.3020747575 & -.0000484832 & .0000000000 \\ -.2600225047 & -.0000322707 & -.0000407756\end{array}$
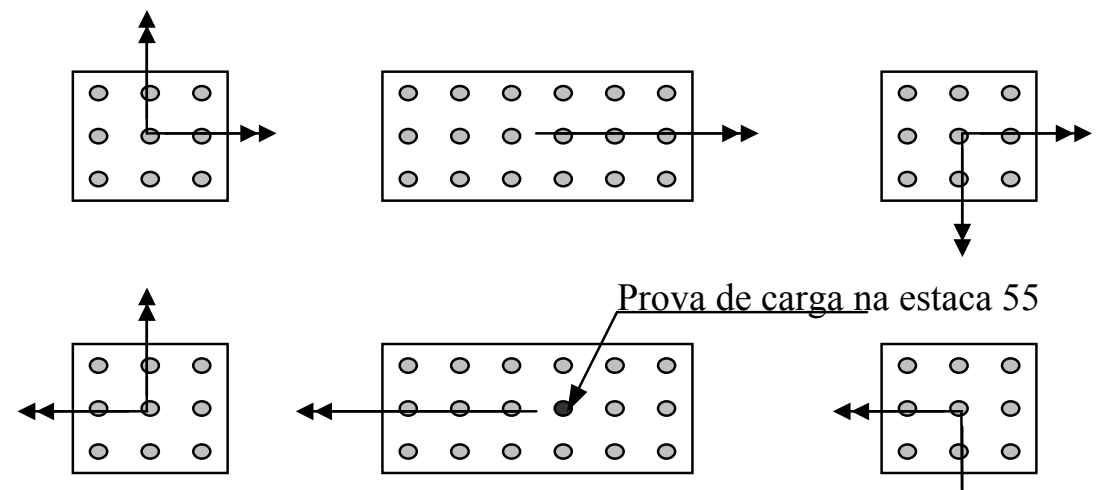

Prova de carga na estaca 55

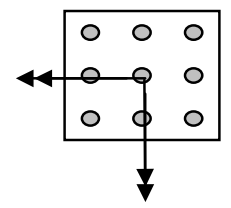

Figure 6.4 - Movimento do bloco rígido 


\section{Exemplo 2}

Neste exemplo aproveita-se de um edifício com 15 pavimentos - tipo e um pavimento - base, cujos resultados são analisados com o intuito de verificar a diferença no comportamento estrutural de um edifício de múltiplos andares entre considerar ou não a interação solo - estrutura: as estacas são pré - moldados de $\phi 42$ e $\phi 50 \mathrm{~cm}$ de diâmetro e o perfil do solo foi adotado de uma região da Baixada Santista, GOMES(1986).

Espessura da laje: $\quad 10 \mathrm{~cm}$ com carga uniformemente distribuída nas lajes $0.001 \mathrm{kN} / \mathrm{cm}^{2}$

Pé-direito dos andares: $300 \mathrm{~cm}$

Módulo de Elasticidade: $2000 \mathrm{kN} / \mathrm{cm}^{2}$

Vigas do pavimento tipo: dimensões de $20 \times 60 \mathrm{~cm}$ com carga uniformemente distribuída de $0,1 \mathrm{kN} / \mathrm{cm}$

Ação do vento segundo NBR 6123

Velocidade básica do vento $30 \mathrm{~m} / \mathrm{s}$

Categoria II (terreno aberto em nível), vento não turbulento

Classe B (maior dimensão do edifício inferior a 50m)

Coeficiente de arrasto $\mathrm{Ca}=1,43$

\begin{tabular}{|c|c|c|c|c|c|c|}
\hline Trechos & $\mathrm{H}(\mathrm{m})$ & $\mathrm{Vo}_{1} \mathrm{~S}_{3}$ & $\mathrm{~S}_{2}$ & $\mathrm{~V}_{\mathrm{k}}(\mathrm{m} / \mathrm{s})$ & $\mathrm{q}\left(\mathrm{kN} / \mathrm{m}^{2}\right)$ & $\mathrm{Q}_{\mathrm{eq}}(\mathrm{kN} / \mathrm{m})$ \\
\hline 1 & 9 & 30 & 0,98 & 29,4 & 0,53 & 11,37 \\
\hline 2 & 18 & 30 & 1,04 & 31,2 & 0,60 & 12,80 \\
\hline 3 & 27 & 30 & 1,08 & 32,4 & 0,64 & 13,80 \\
\hline 4 & 36 & 30 & 1,11 & 33,3 & 0,68 & 14,58 \\
\hline 5 & 45 & 30 & 1,13 & 33,9 & 0,70 & 15,11 \\
\hline
\end{tabular}

Tabela 6.3 - Ação horizontal do vento

As lajes são discretizados em elementos finitos quadrangulares, condensadas a partir de quatro elementos triangulares $D K T$ de acordo com o Capítulo 3, item 3.5. 


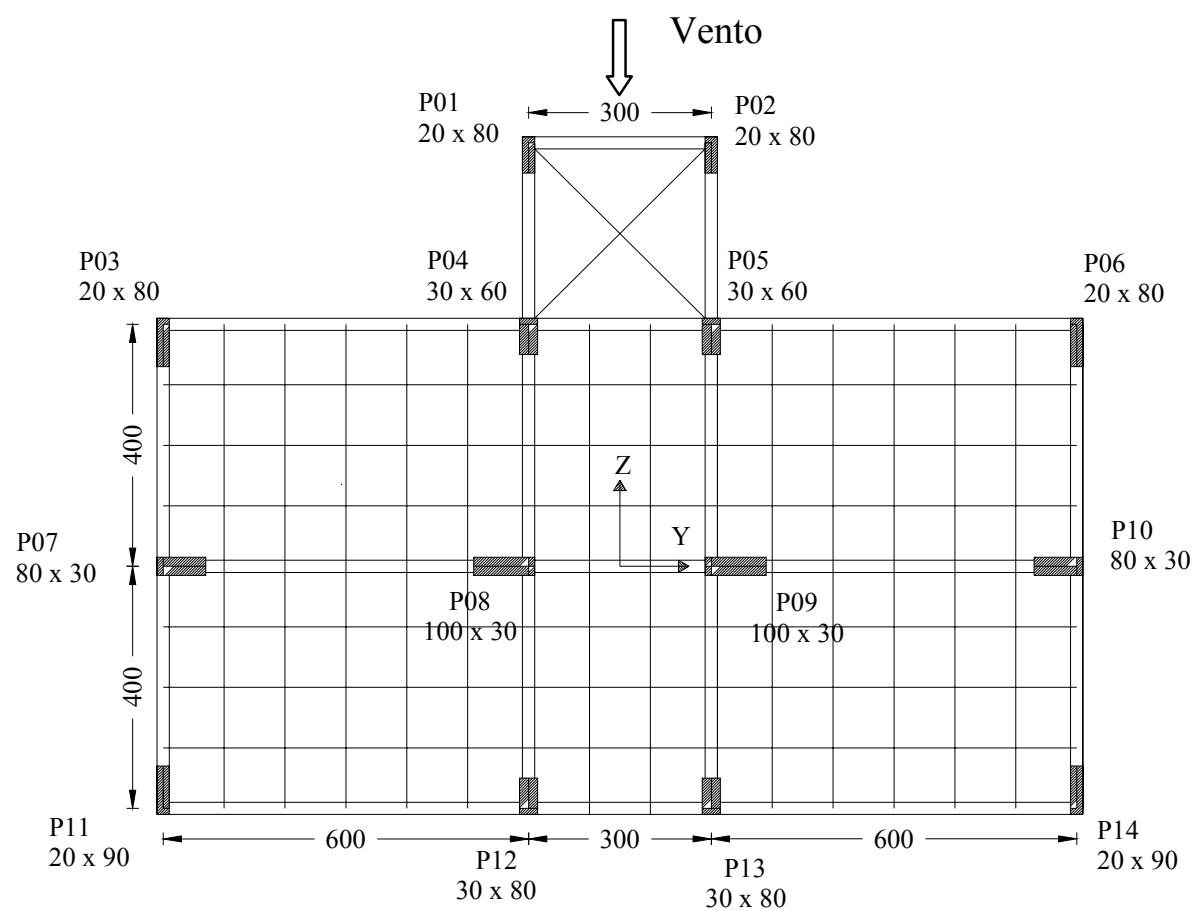

Figura 6.5 - Pavimento tipo

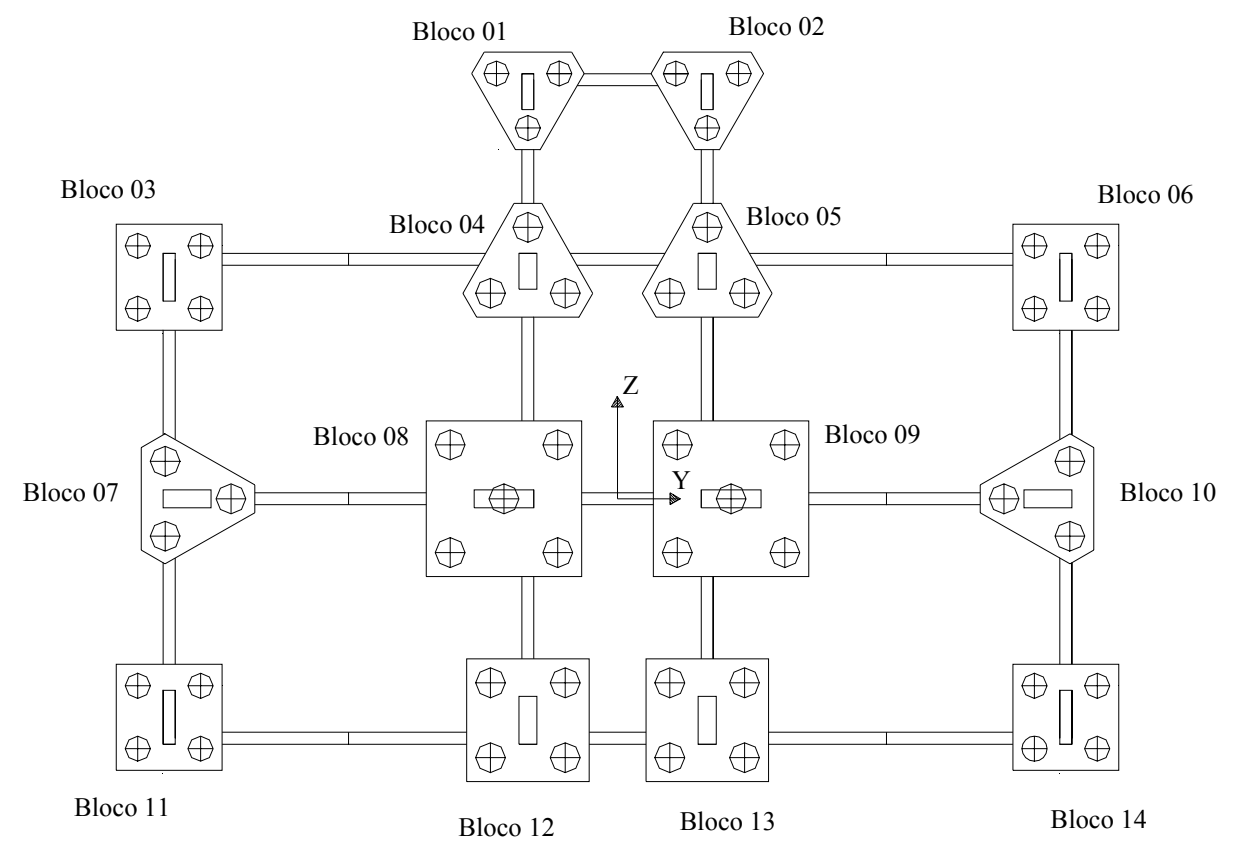

Figura 6.6 - Pavimento base

As vigas de cintamento tem dimensões $20 \times 30 \mathrm{~cm}$.

Os blocos 01, 02, 03, 06, 11 e 14 foram adotados estacas de $\phi 42 \mathrm{~cm}$ com o comprimento de $28 \mathrm{~m}$. Os demais blocos, são de estacas $\phi 50 \mathrm{~cm}$ de diâmetro com $30 \mathrm{~m}$ de comprimento. 
O perfil do solo adotado tem seguintes características:

Número de camada: 8

Camada ( m ) Classificação

0,0 a $2,2 \quad$ Silte argilo arenoso

Módulo de Young adotado da estaca :

2,2 a $14,8 \quad$ Argila $2500 \mathrm{kN} / \mathrm{cm}^{2}$

14,8 a $18,2 \quad$ Areia siltosa

18,2 a 28,8 Argila

28,8 a $34,0 \quad$ Areia

34,0 a $35,8 \quad$ Areia siltosa

35,8 a 41,6 Argila

41,6 a $45,45 \quad$ Areia

O diagrama de ruptura lateral PL e na ponta da estaca PP será determinado com o método AOKI - VELLOSO (1975) conhecendo-se o tipo de solo e número de SPT para cada metro de profundidade. Segundo este método, tem-se para a estaca de $\varnothing 42 \mathrm{PL}=407,90 \mathrm{kN}$ e $\mathrm{PP}=1187,52 \mathrm{kN}$ portanto $\mathrm{PR}=1595,42 \mathrm{kN}$. Para $\varnothing 50$ tem-se $\mathrm{PL}=711,80 \mathrm{kN}$ e $\mathrm{PP}=1683,00$ $\mathrm{kN}$ e portanto $\mathrm{PR}=2394,80 \mathrm{kN}$ como ruptura do sistema estaca - solo.

Estaca $\phi 42$ comp. $28 \mathrm{~m} \quad$ Estaca $\phi 50$ comp. $30 \mathrm{~m}$

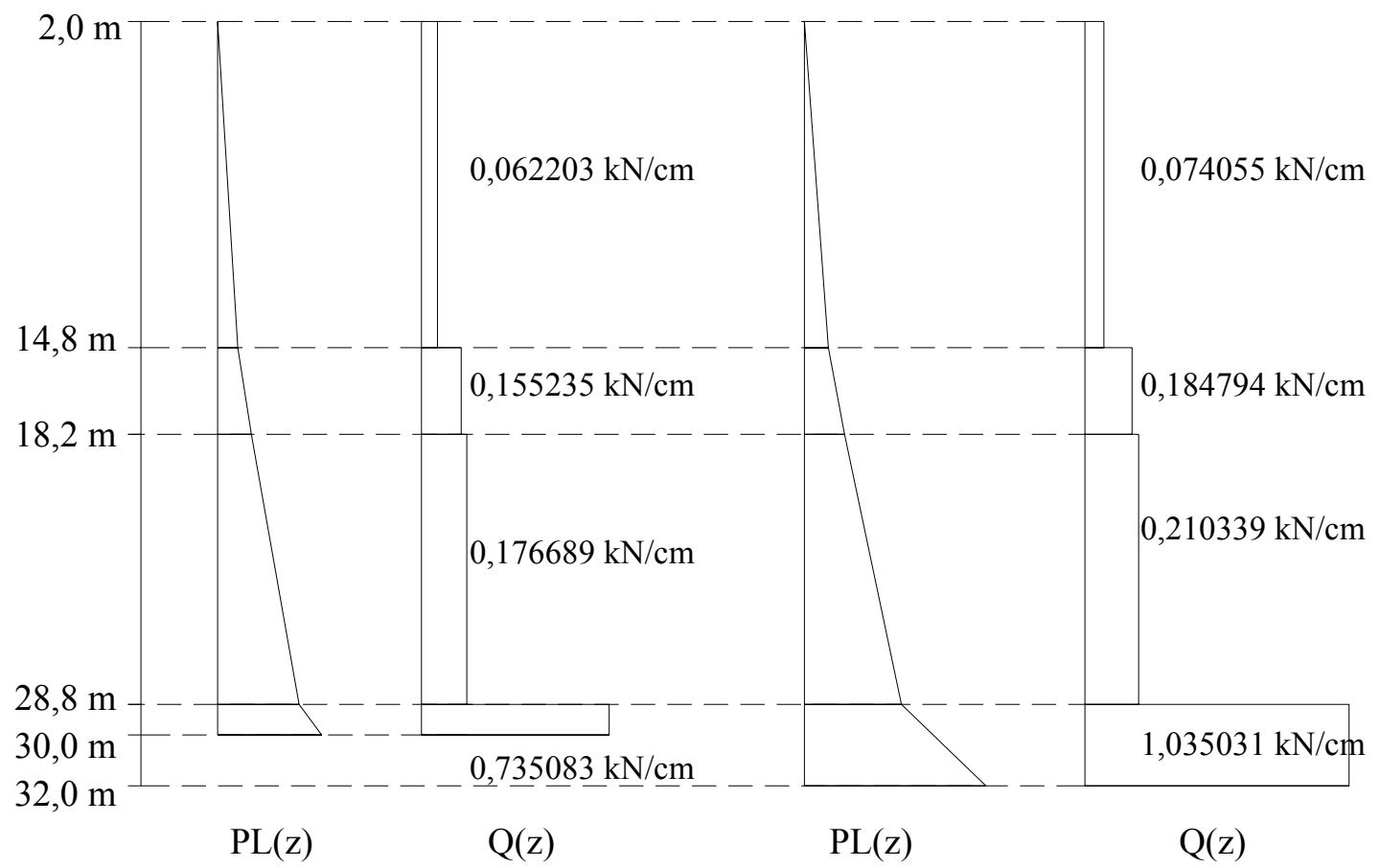

Figura 6.7 - Diagrama de atrito acumulado e local 
A diferença de fluxo de carregamento axial nos pilares considerando ou não a interação:
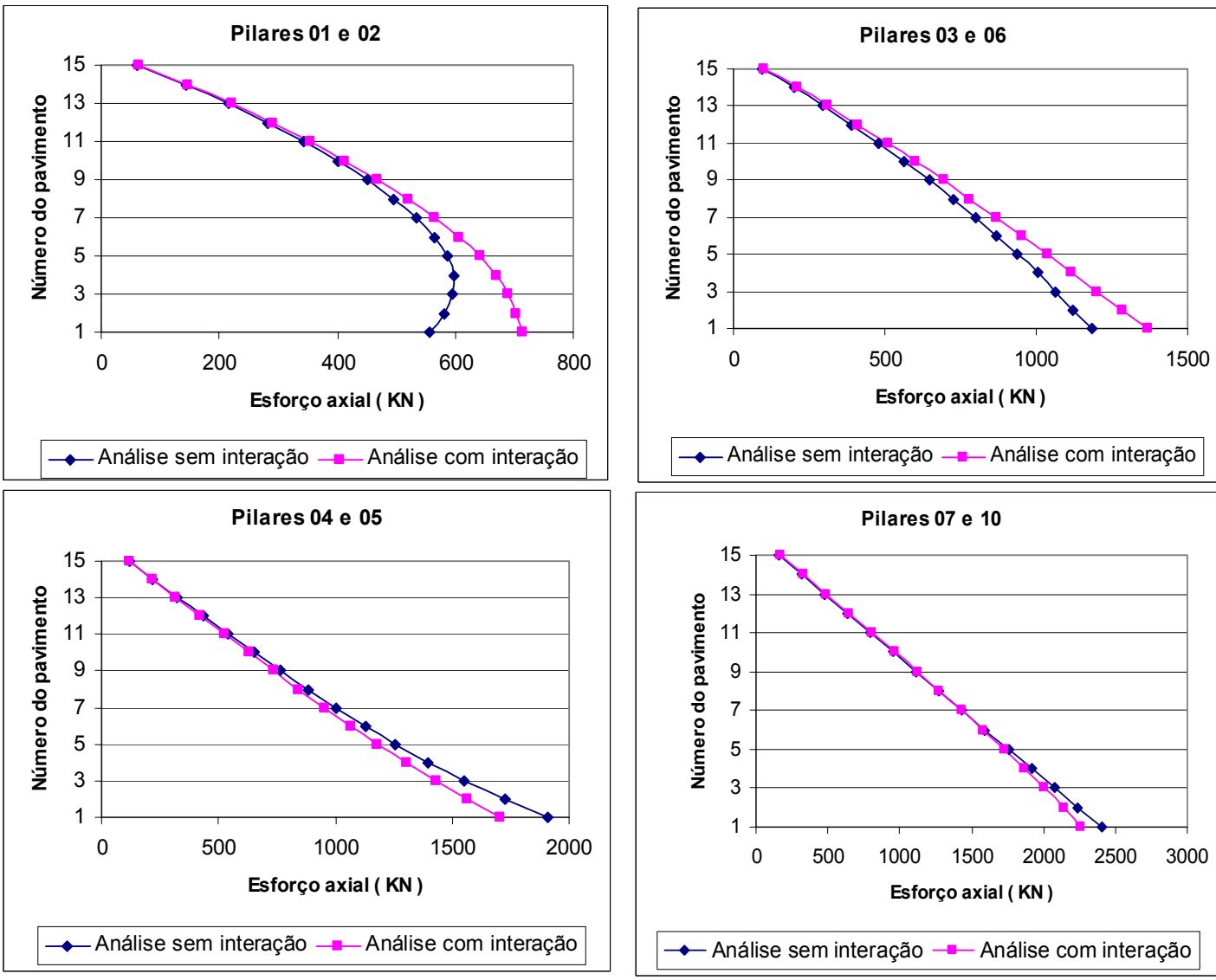

$\multimap$ Análise sem interação $\longrightarrow$ Análise com interação
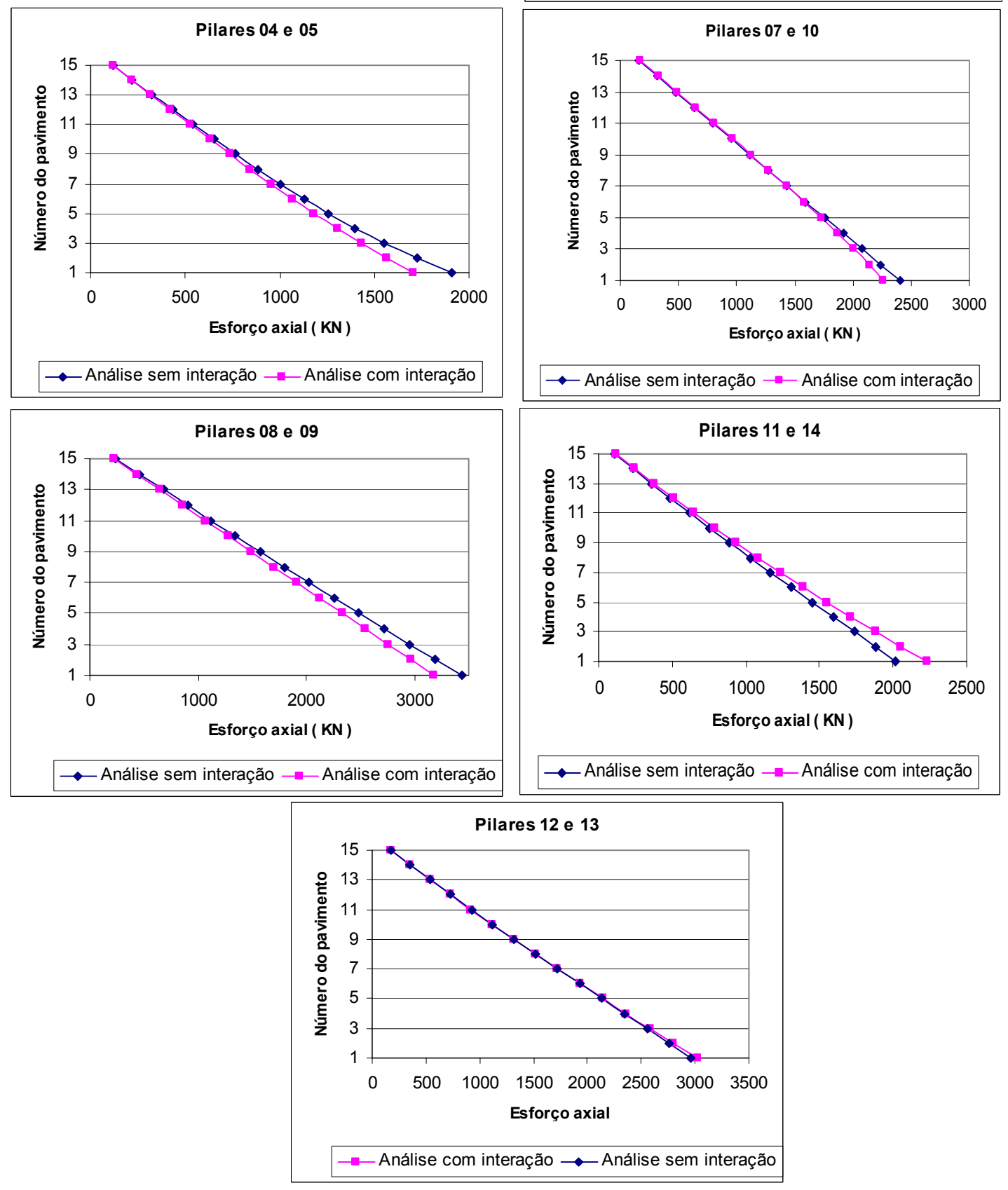

Figura 6.8 - Esforços axiais nos pilares 

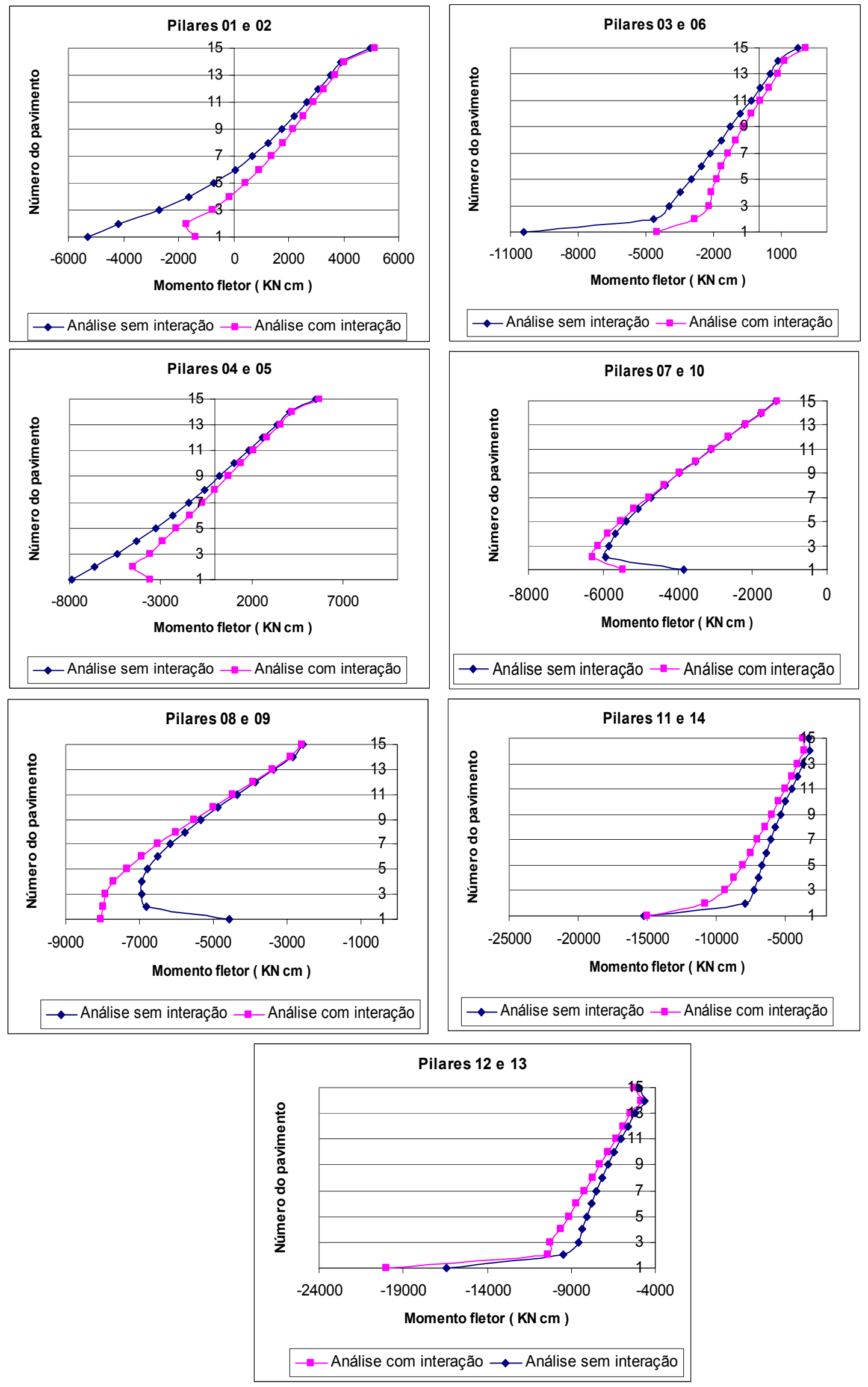

Figura 6.9 - Momentos fletores nos pilares em torno do eixo y 
Esforço cortante e momento fletor na viga 02 (conexão com o P04)
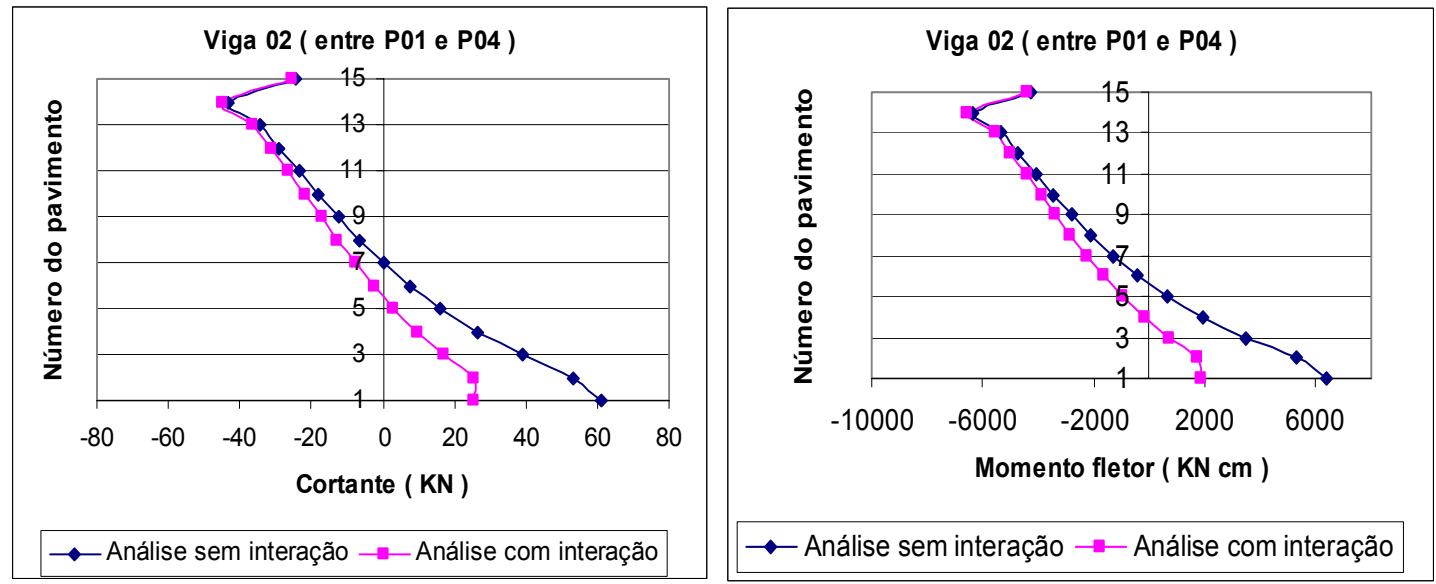

Esforço cortante e momento fletor na viga 09 (no meio do vão)
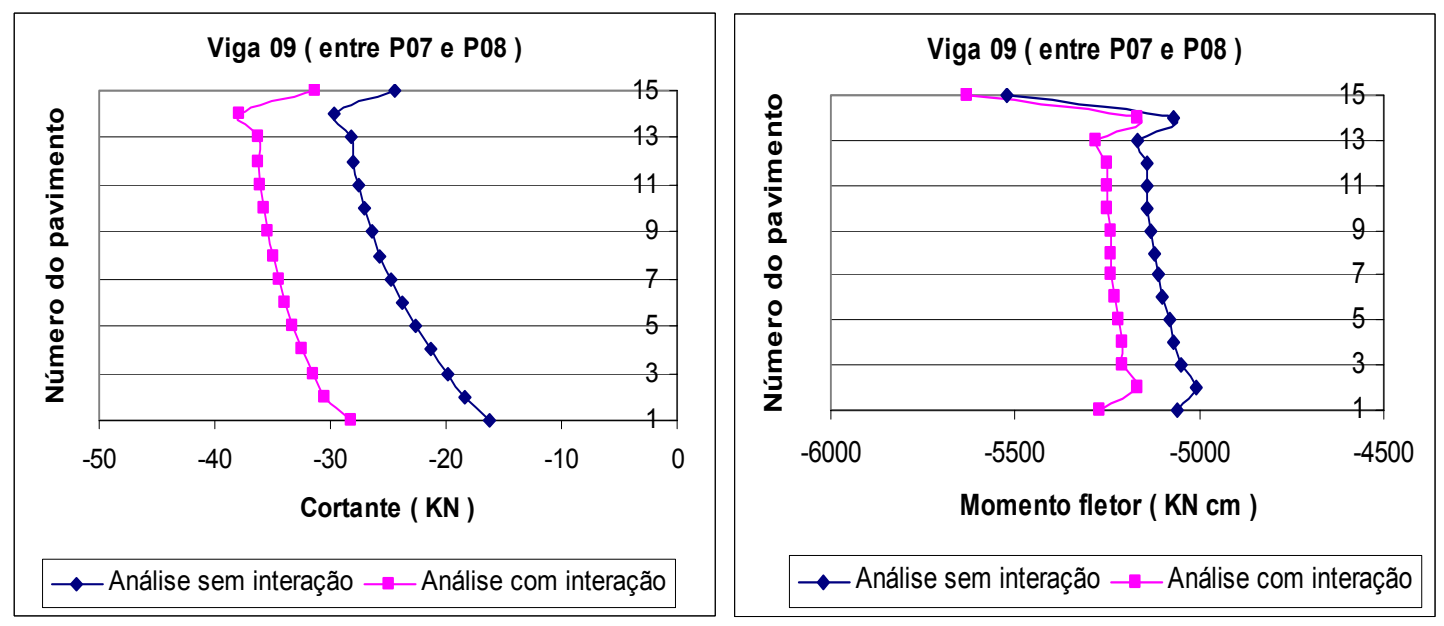

Esforço cortante e momento fletor na viga 06 (no meio do vão)
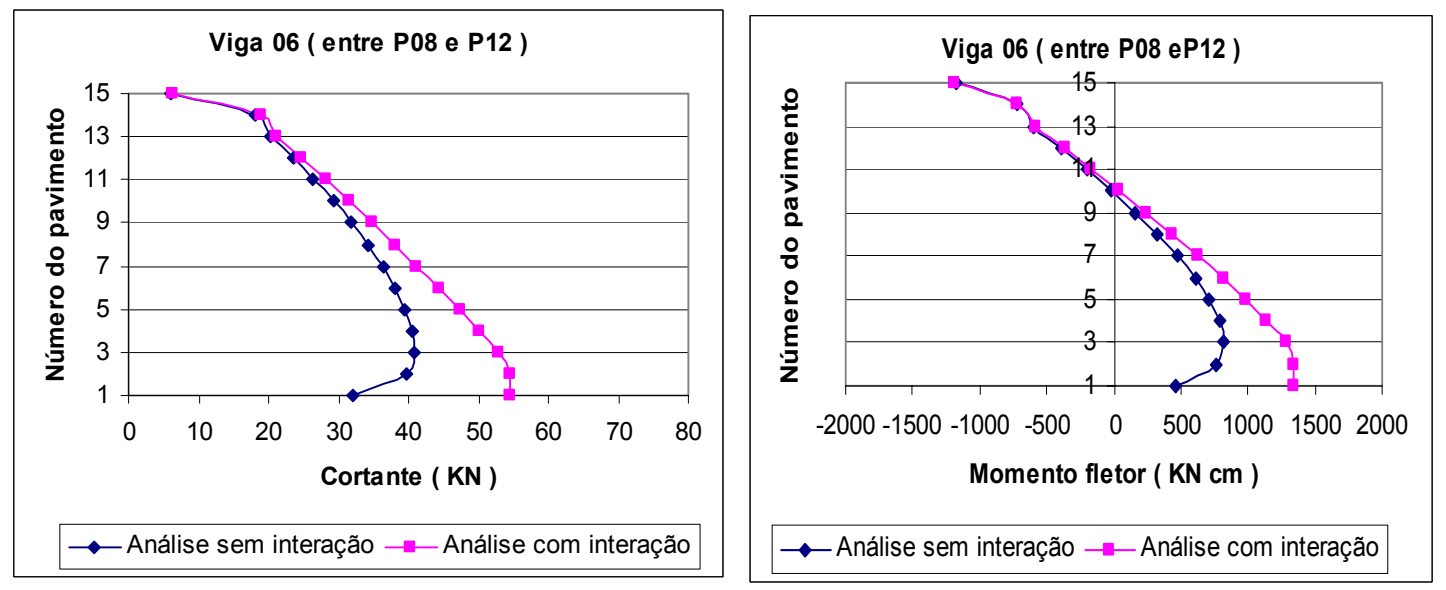

Figura 6.10 - Esforços nas vigas 


\begin{tabular}{|c|c|c|c|c|}
\hline & $\begin{array}{l}\text { Sem interação } \\
\text { Reações ( kN ) }\end{array}$ & Recalques ( cm ) & $\begin{array}{l}\text { Com interação } \\
\text { Reações ( kN ) }\end{array}$ & Recalques $(\mathrm{cm})$ \\
\hline Bloco 01 & 557.1724 & -0.6183 & 726.4973 & -0.6339 \\
\hline Bloco 02 & 557.1724 & -0.6183 & 726.4973 & -0.6339 \\
\hline Bloco 03 & 1182.2877 & -0.6685 & 1386.8180 & -0.7101 \\
\hline Bloco 04 & 1909.7045 & -1.0928 & 1691.3367 & -0.9868 \\
\hline Bloco 05 & 1909.7045 & -1.0928 & 1691.3367 & -0.9868 \\
\hline Bloco 06 & 1182.2877 & -0.6685 & 1386.8180 & -0.7101 \\
\hline Bloco 07 & 2409.7047 & -1.1983 & 2218.4043 & -1.0854 \\
\hline Bloco 08 & 3433.8335 & -1.3456 & 3143.3733 & -1.2386 \\
\hline Bloco 09 & 3433.8335 & -1.3456 & 3143.3733 & -1.2386 \\
\hline Bloco 10 & 2409.7047 & -1.1983 & 2218.4043 & -1.0854 \\
\hline Bloco 11 & 2017.9063 & -1.0551 & 2264.0244 & -1.1861 \\
\hline Bloco 12 & 2964.3909 & -1.3665 & 3044.5460 & -1.3888 \\
\hline Bloco 13 & 2964.3909 & -1.3665 & 3044.5460 & -1.3888 \\
\hline Bloco 14 & 2017.9063 & -1.0551 & 2264.0244 & -1.1861 \\
\hline
\end{tabular}

Tabela 6.4 - Comparação nas reações e recalques

Verificou-se que os recalques diferenciais são menores quando se considera a interação solo - estrutura, face a rigidez da estrutura que serve como restrição parcial aos movimentos relativos nos apoios. Devido a esta absorção dos esforços, não previsto em análises convencionais, a estrutura pode apresentar comportamento com diferenças significativas em alguns elementos estruturais com fluxo de carregamentos diferentes da previsão. Esta rigidez nos edifícios de múltiplos andares é determinada pelo número de pavimentos e a integridade existente entre os elementos estruturais que formam um fator predominante na uniformização dos recalques diferenciais (Tab. 6.4). Em geral, as cargas axiais dos pilares centrais transmitem uma parte da carga através das vigas para os pilares da periferia que tem a tendência de recalcarem menos. Este comportamento foi constatado no exemplo apresentado e as diferenças são maiores (para menos ou para mais) quanto mais perto for o pavimento nas fundações, diminuindo nos pavimentos superiores. No caso, os pilares centrais P04, P05, P07, P08, P09 e P10 tiveram o alívio de cargas resultando acréscimos em todos os pilares restantes da periferia (Fig. 6.8). Nos momentos fletores dos pilares as diferenças foram verificadas com reduções em P01, P02, P03, P04, P05 e P06 e acréscimos em restante dos pilares. (Fig. 6.9). Ou seja, mostra-se claramente que não somente os esforços axiais dos pilares mas também nos momentos fletores tiveram seus esforços redistribuídos. 


\section{Exemplo 3}

Apresenta-se um exemplo numérico, cujos resultados são analisados com o intuito de verificar o comportamento estrutural de um edifício de múltiplos andares quando se considera a interação solo - estrutura. O tipo de estaca e o solo foi inteiramente aproveitado de um exemplo apresentado em AOKI (1985). Dentre o modelo de análise da estrutura, foi adotado o modelo que considera a rigidez transversal à flexão das lajes e teoria de $1^{\mathrm{a}}$ ordem nos pilares.

Para verificar o comportamento da interação solo - estrutura, adotou-se uma estrutura de 15 pavimentos tipo e 9 pilares ( 4 de 30x70, 2 de 80x30, 2 de 60x30 e 1 de 40x80).

Tendo as seguintes características:

Espessura constante da laje:

$10 \mathrm{~cm}$

Pé-direito dos andares: $300 \mathrm{~cm}$

Módulo de Elasticidade: $2000 \mathrm{kN} / \mathrm{cm}^{2}$

Coeficiente de Poisson: 0,25

Carga uniformemente distribuída nas lajes:

Carga distribuída nas vigas:

$0,001 \mathrm{kN} / \mathrm{cm}^{2}=10 \mathrm{kN} / \mathrm{m}^{2}$

Ação do vento $0,1 \mathrm{kN} / \mathrm{cm}=10 \mathrm{kN} / \mathrm{m}$

$\mathrm{Vo}=30 \mathrm{~m} / \mathrm{s}$

Categoria II ( terreno aberto em nível )

Classe B ( maior dimensão inferior a $50 \mathrm{~m}$ )

Vento não turbulento

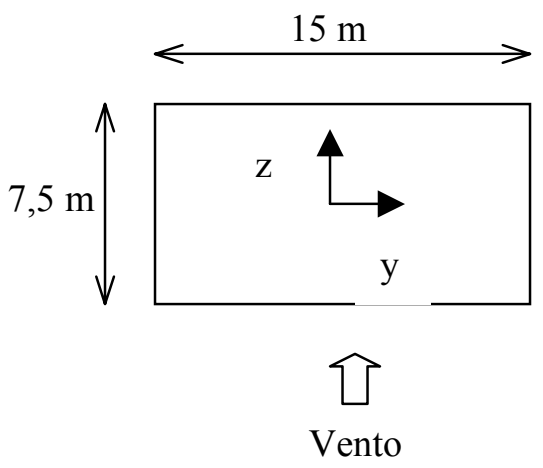

Figura 6.11 - Ação do vento no edifício

Coeficiente de arrasto $\mathrm{Ca}=1,45$

$\begin{array}{ccccccr}\text { Trechos } & \text { Hi }(\mathrm{m}) & \mathrm{VoS}_{1} \mathrm{~S}_{3} & \mathrm{~S}_{2} & \mathrm{~V}_{\mathrm{k}}(\mathrm{m} / \mathrm{s}) & \mathrm{q}\left(\mathrm{kN} / \mathrm{m}^{2}\right) & \mathrm{q}_{\text {eq }}(\mathrm{kN} / \mathrm{m}) \\ 1 & 10 & 30 & 0,98 & 29,4 & 0,530 & 11,53 \\ 2 & 20 & 30 & 1,04 & 31,2 & 0,597 & 12,98 \\ 3 & 30 & 30 & 1,08 & 32,4 & 0,644 & 14,01 \\ 4 & 40 & 30 & 1,11 & 33,3 & 0,680 & 14,79 \\ 5 & 45 & 30 & 1,12 & 33,6 & 0,692 & 15,05\end{array}$


Todas as vigas do pavimento tipo tem dimensões $15 / 80$, os quadriculados que aparecem nas lajes são elementos finitos de placa quadrangular condensados a partir de 4 elementos triangulares $D K T$ :

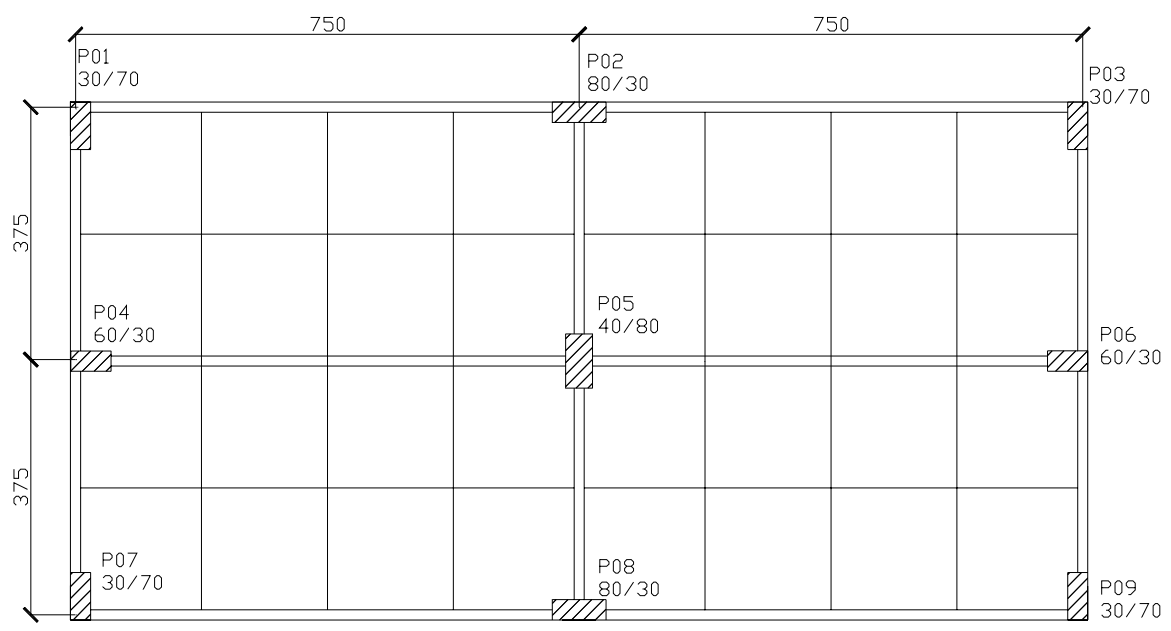

Figura 6.12 - Planta baixa do pavimento tipo

Todas as estacas são de concreto pré-moldado com $50 \mathrm{~cm}$ de diâmetro onde os comprimentos das estacas são: $10 \mathrm{~m}$ para o Bloco 5 e $9 \mathrm{~m}$ para os restantes. As vigas baldrames tem dimensões 15/40.

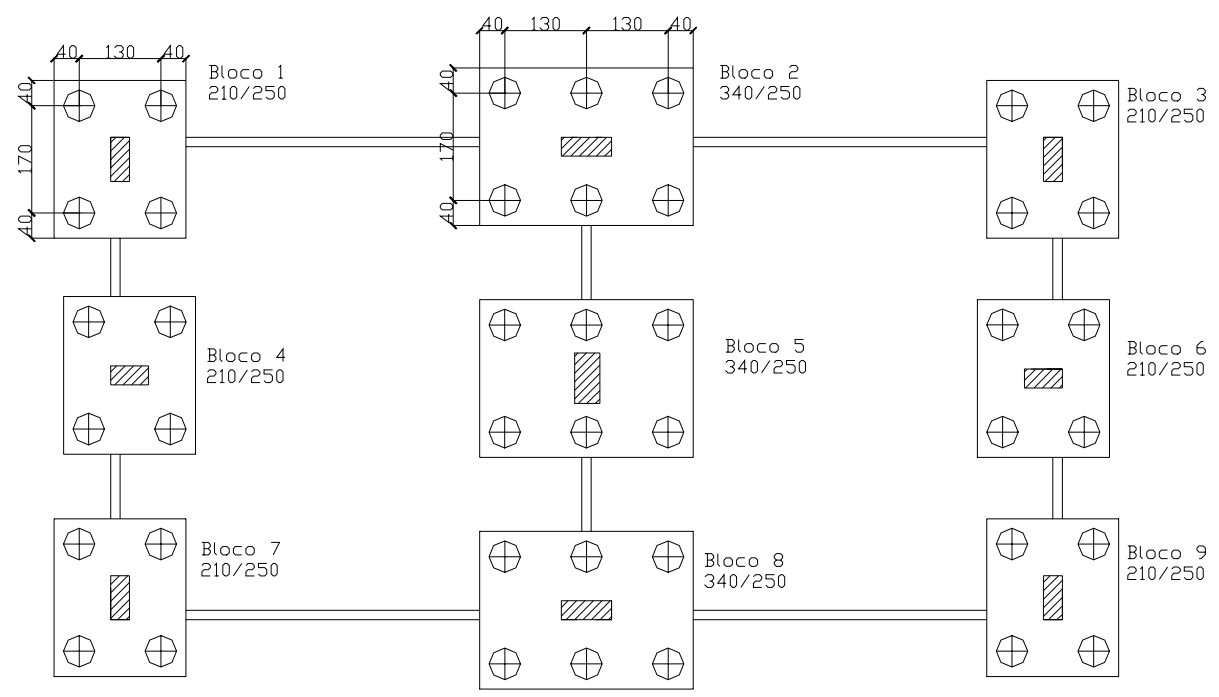

Figura 6.13 - Planta baixa do pavimento base

A camada indeslocável se encontra a $21,80 \mathrm{~m}$ de profundidade.

Características do solo são:

$\begin{array}{ccc}\text { Prof. }(\mathrm{cm}) & \mathrm{E}\left(\mathrm{kN} / \mathrm{cm}^{2}\right) & \text { Coef. Poisson } \\ 535 & 3 & 0,40 \\ 1645 & 12 & 0,25 \\ 2180 & 24 & 0,20\end{array}$


Mostra-se a seguir a convergência do processo iterativo nas reações dos apoios:
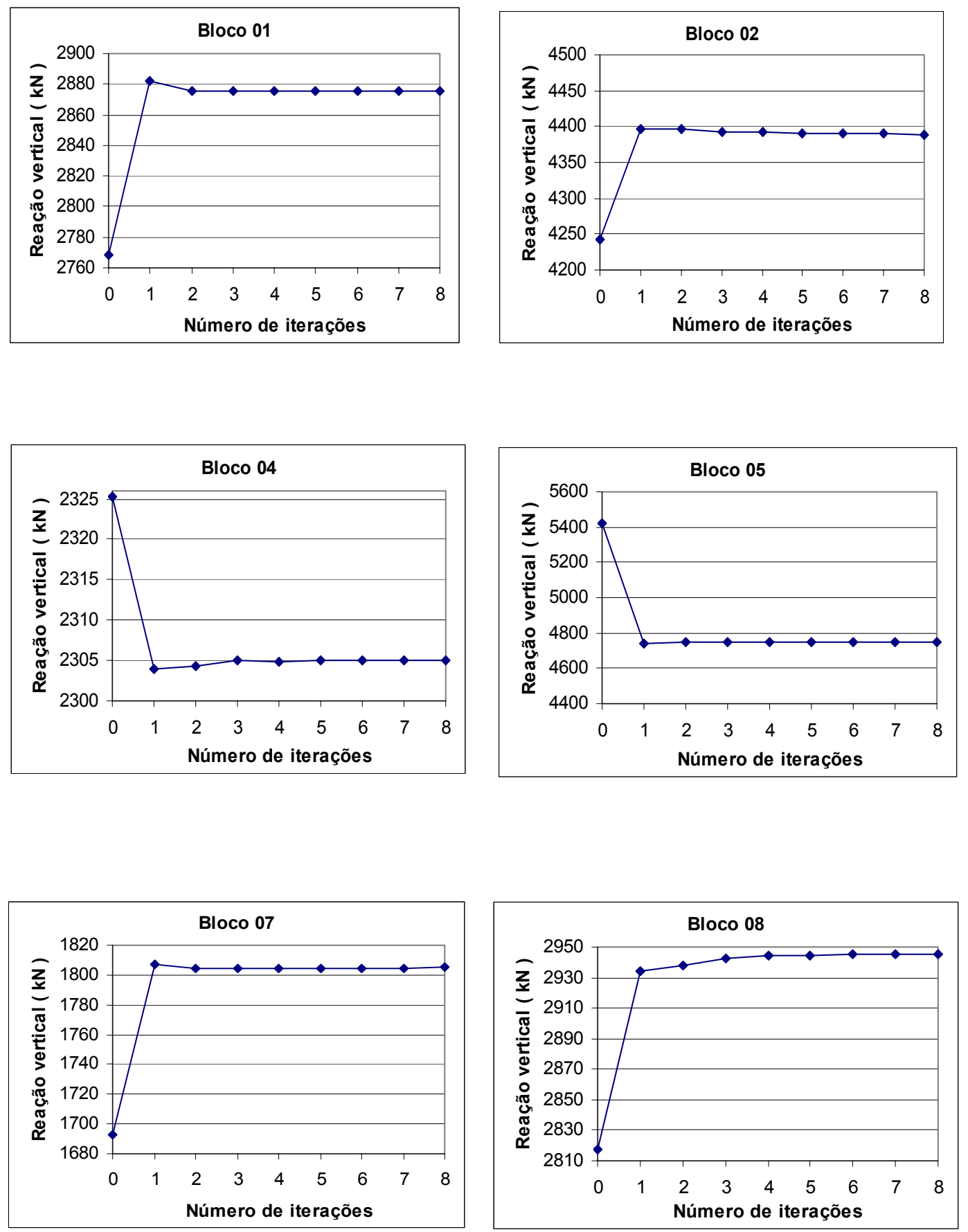

Figura 6.14 - Reações verticais nos apoios 

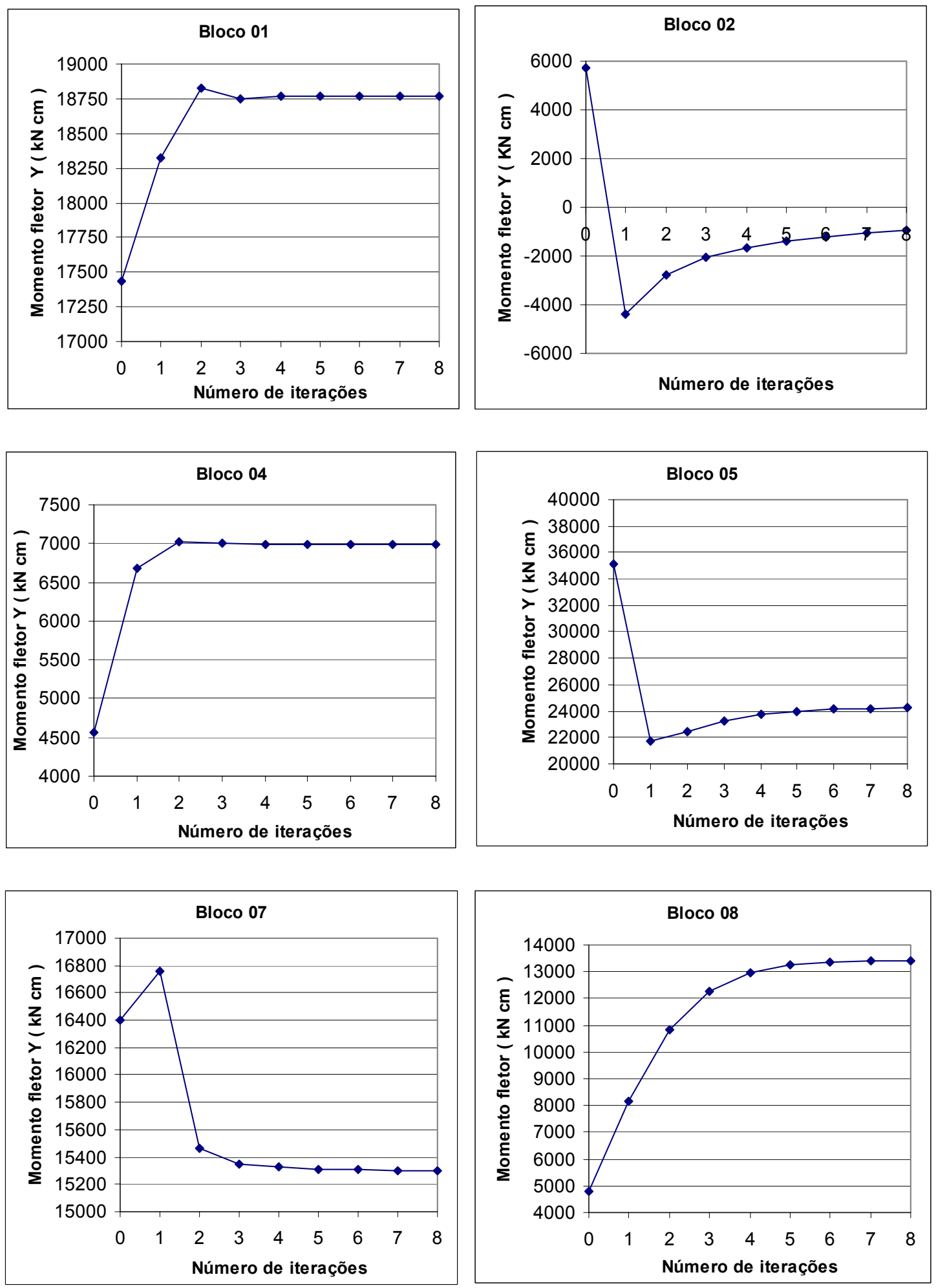

Figura 6.15 - Momentos fletores nos apoios na direção $Y$ 
Quando uma estrutura apoiada sobre uma base suposta rígida é submetido a combinação de ações verticais e horizontais, seus pavimentos sofrem deslocamentos devido à deformação dos elementos. No entanto se esta base for substituída por uma fundação flexível, esses deslocamentos tornam-se maiores por causa da ocorrência de recalques.

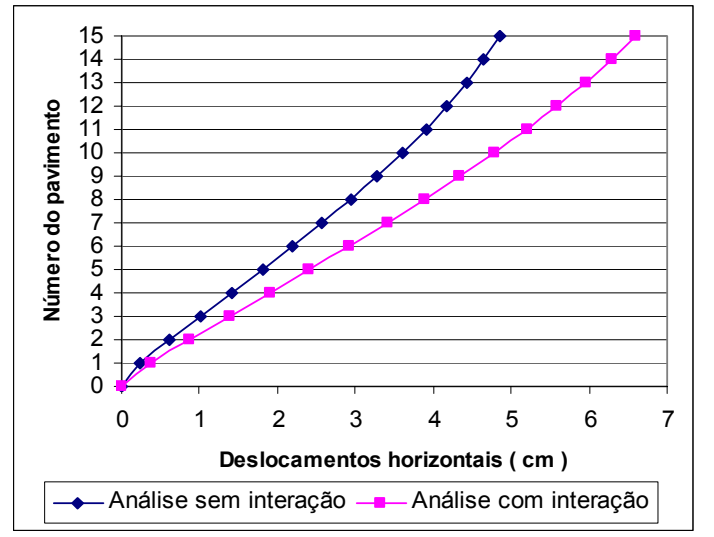

Figura 6.16 - Deslocamentos horizontais

Mostra-se a seguir, os esforços de alguns elementos nos pilares e vigas comparando a análise sem e com a interação solo - estrutura. Verifica-se que a diferença é maior nas proximidades dos pavimentos inferiores, onde o efeito da interação é mais pronunciado, e vai diminuindo com a altura do edifício.
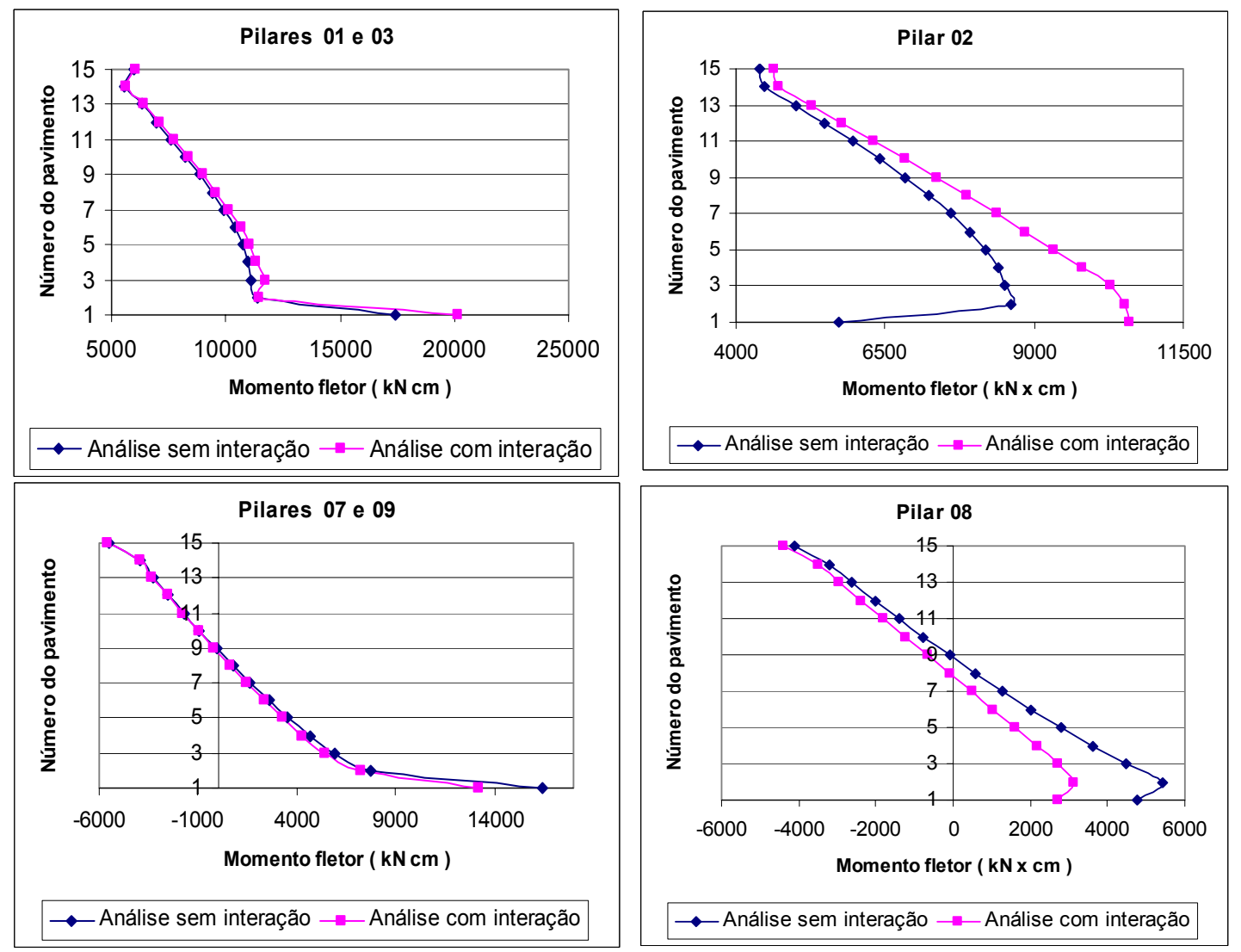

Figura 6.17 - Momentos fletores nos pilares 

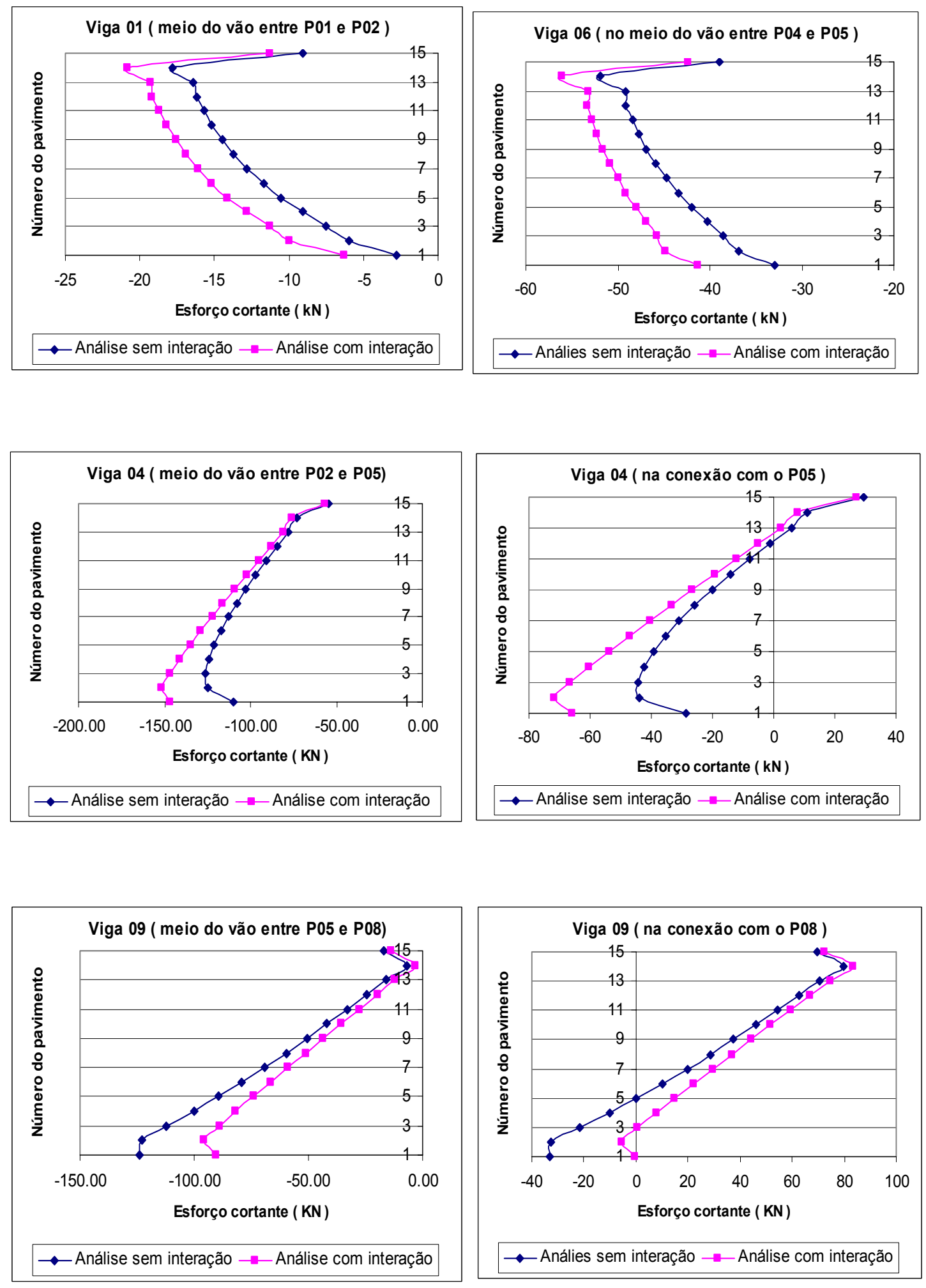

Figura 6.18 - Esforços cortantes nas vigas 

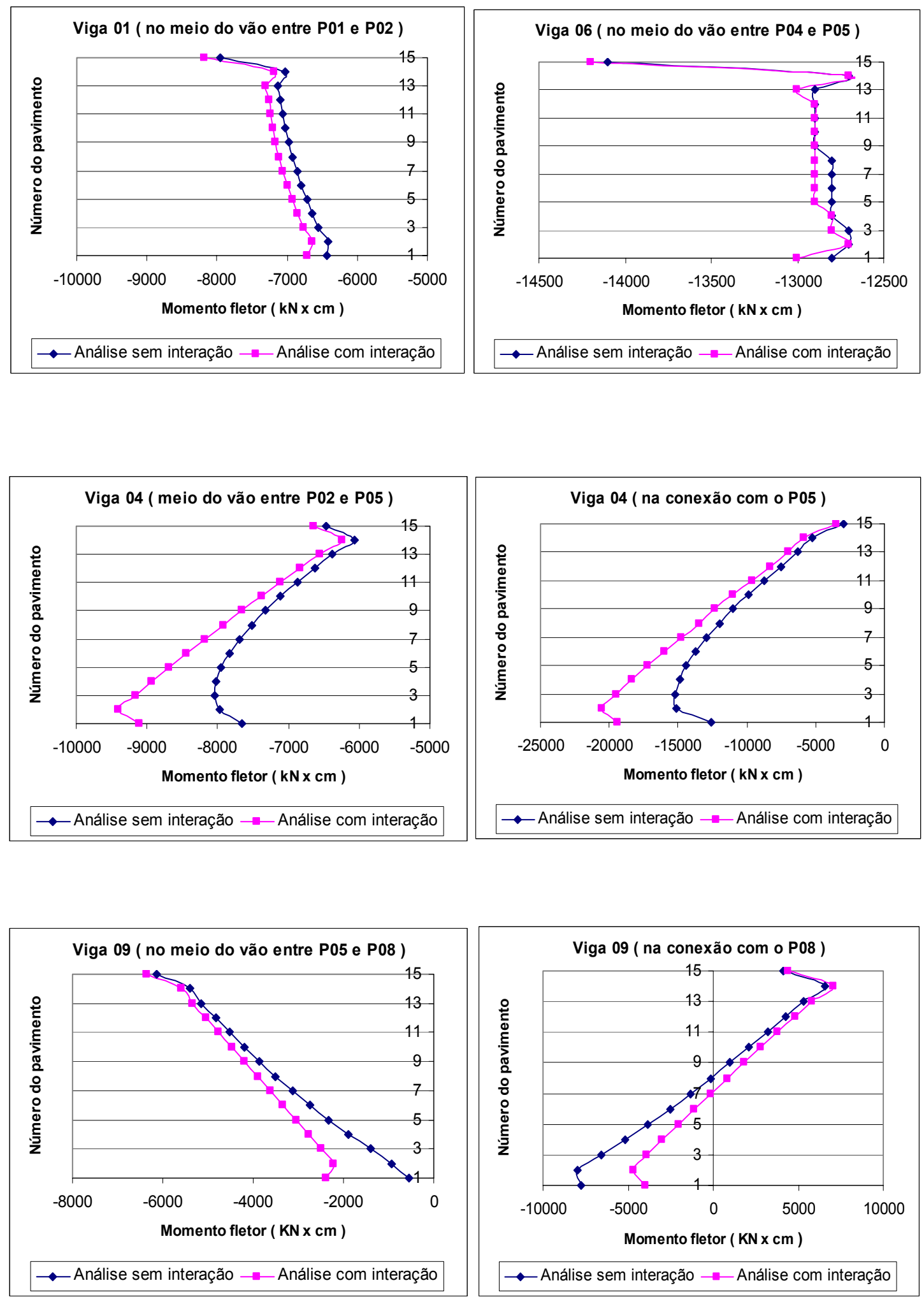

Figura 6.19 - Momentos fletores nas vigas 

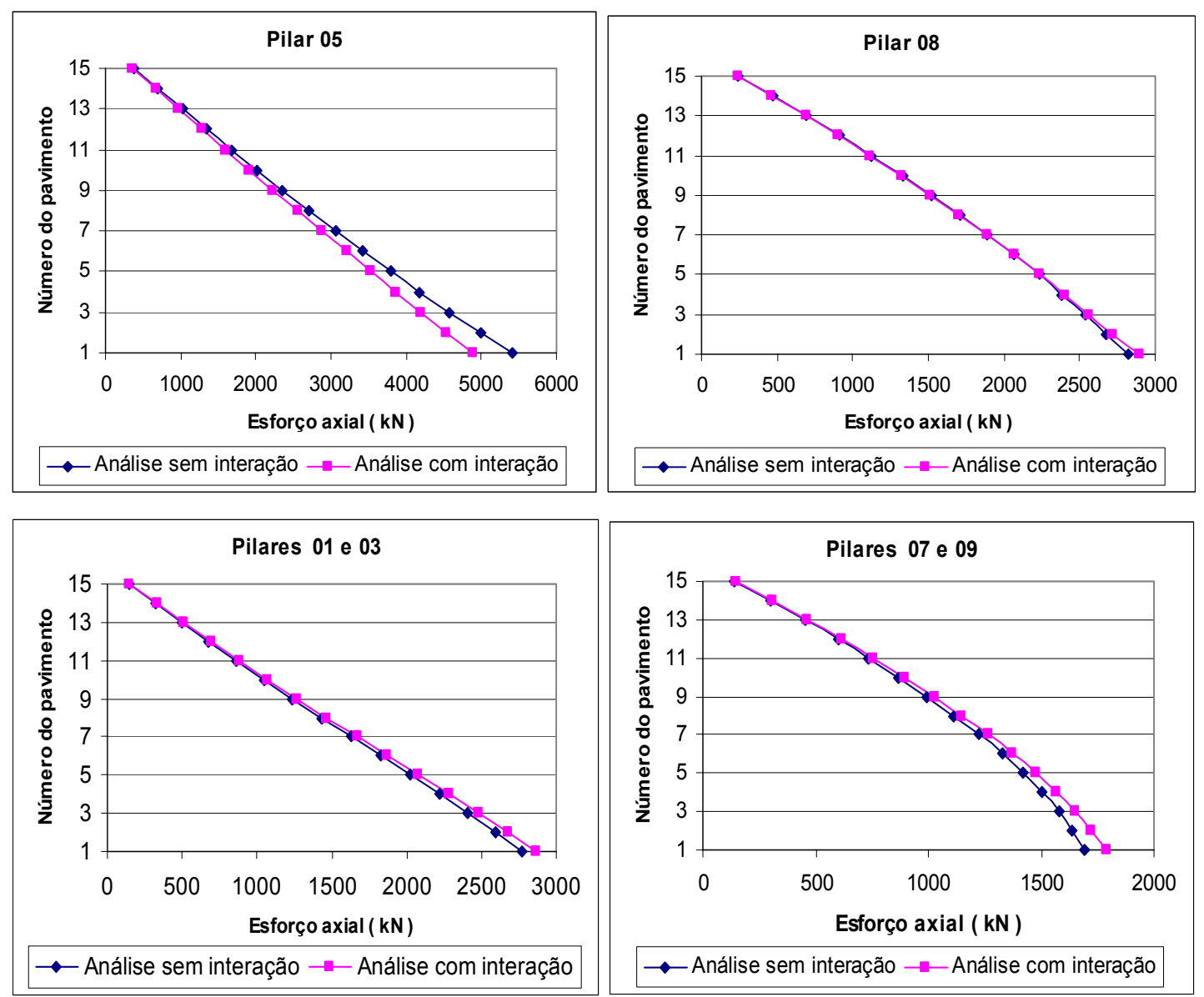

Figura 6.20 - Esforços axiais nos pilares

\begin{tabular}{|l|c|c|c|c|c|c|}
\hline & Sem interação & Com interação & & Sem interação & Com interação & \\
\hline & Reação & Reação & Recalque & Momento Y & Momento Y & Rotação \\
\hline & $\mathrm{kN}$ & $\mathrm{kN}$ & $\mathrm{cm}$ & $\mathrm{kN} \mathrm{x} \mathrm{cm}$ & $\mathrm{kN} \mathrm{x} \mathrm{cm}$ & $\mathrm{rd}$ \\
\hline Bloco 1 & 2768.9114 & 2875.1894 & -0.6447 & 17431.9231 & 18771.3027 & 0.0003551 \\
\hline Bloco 2 & 4242.9166 & 4389.4721 & -0.7770 & 5732.8042 & -950.0622 & -0.0004437 \\
\hline Bloco 3 & 2768.9114 & 2875.1894 & -0.6447 & 17431.9231 & 18771.3027 & 0.0003551 \\
\hline Bloco 4 & 2325.3519 & 2304.9725 & -0.5307 & 4568.4479 & 6979.9610 & 0.0003083 \\
\hline Bloco 5 & 5420.3319 & 4750.2660 & -0.7900 & 35156.2166 & 24246.6309 & 0.0006528 \\
\hline Bloco 6 & 2325.3519 & 2304.9725 & -0.5307 & 4568.4479 & 6979.9610 & 0.0003083 \\
\hline Bloco 7 & 1692.8165 & 1804.9108 & -0.3571 & 16396.1851 & 15299.3379 & 0.0006119 \\
\hline Bloco 8 & 2817.5910 & 2945.1152 & -0.4866 & 4774.3893 & 13418.6476 & 0.0007286 \\
\hline Bloco 9 & 1692.8164 & 1804.9108 & -0.3571 & 16396.1851 & 15299.3379 & 0.0006119 \\
\hline
\end{tabular}

Tabela 6.5 - Comparação das reações entre considerar ou não a interação 
Como apresentado nos resultados numéricos, dependendo do desempenho entre a estrutura e o maciço de solo, pode existir diferenças significativas nos esforços atuantes nos edifícios devido à mudança do fluxo de carregamento nos apoios provocados pela deformação do maciço e elementos estruturais de fundações. Estas diferenças são maiores nas imediações do pavimento inferior onde a influência da interação entre a estrutura e o solo são mais acentuadas, como já foi mostrado no exemplo anterior.

Em geral, as cargas axiais dos pilares centrais transmitem uma parte da carga através das vigas para os pilares da periferia que tem a tendência de recalcarem menos. Este comportamento foi constatado no exemplo apresentado e verificou-se que as diferenças são menores nos pavimentos superiores e estas crescem a medida que se aproximam nos pavimentos inferiores (para menos ou para mais) tanto para pilares quanto para vigas. No caso, o pilar P05 foi o único que teve alívio de carregamento, enquanto que todos os pilares restantes tiveram acréscimo de cargas, como pode ser observado nos gráficos dos esforços axiais e nos resultados das reações verticais. Nos momentos fletores dos pilares foram verificados mudanças significativas de valores com acréscimos e reduções. 


\section{Exemplo 4}

Poucos trabalhos mostram comparação entre resultados de medições na obra e resultados numéricos quando se trata de interação solo - estrutura. As dificuldades na modelagem começam desde a simulação da seqüência construtiva e propriedades reológicas dos materiais até na escolha representativa do módulo de deformabilidade de $\mathrm{n}$ camadas do maciço de solo e a influência do tempo nos parâmetros geotécnicos. Dentre estas dificuldades, procurou-se um caso real de medições de recalques que esteja dentro do contexto da pesquisa, ou seja:

- Fundações profundas (estacas ou tubulões);

- Medições de recalques no solo arenoso onde o efeito do adensamento não seja tão significativo, como acontece em solos argilosos.

Neste exemplo, analisou-se um edifício de concreto armado com fundações profundas em tubulões construído na cidade de Bauru e as medições de recalques acompanhados e documentados em LOBO; FERREIRA \& ALBIERO(1996). Os recalques de todos os pilares foram medidos desde agosto de 1994 logo após a concretagem da primeira laje do andar tipo e a desforma dos pilares do pavimento térreo. O último levantamento foi realizado em agosto de 1996.

Na tabela 6.9 são fornecidos cargas e recalques estimados e os recalques de cada pilar medidos na obra. Serão comparados com dois resultados numéricos:

- Modelo 1: considerando o efeito de grupo de tubulões com as cargas estimadas sem a interação solo - estrutura;

- Modelo 2: considerando o efeito de grupo de tubulões e cargas estimadas com a interação solo - estrutura;

\section{Características geotécnicas do solo local}

Segundo FERREIRA(1991) os resultados de sondagens de simples reconhecimento na cidade de Bauru em geral apontam nos primeiros metros com SPT variando entre 2 e 6 até aproximadamente 5 a 6 metros. A variação dos valores do SPT é praticamente linear com a profundidade até 9 a $13 \mathrm{~m}$, quando então ocorre um crescimento mais acentuado, até atingir camadas impermeáveis a percussão por volta de 20 a 25 metros. 
Aproximadamente $80 \%$ dos edifícios construídos nesta região do estado tem sido sob tubulões a céu aberto por ser relativamente fácil de ser escavado e o nível de água freático profundo. Para a tensão máxima de cisalhamento fuste - solo adotou-se $30 \mathrm{kPa}=30 \mathrm{kN} / \mathrm{m}^{2}$ de LOBO et al.(1997) estimado a partir da interpretação curva carga $\mathrm{x}$ recalque para solos com características idênticas deste exemplo e da mesma cidade.

A fig. 6.21 mostra resultados de uma sondagem de simples reconhecimento típica, realizada no local da edificação.

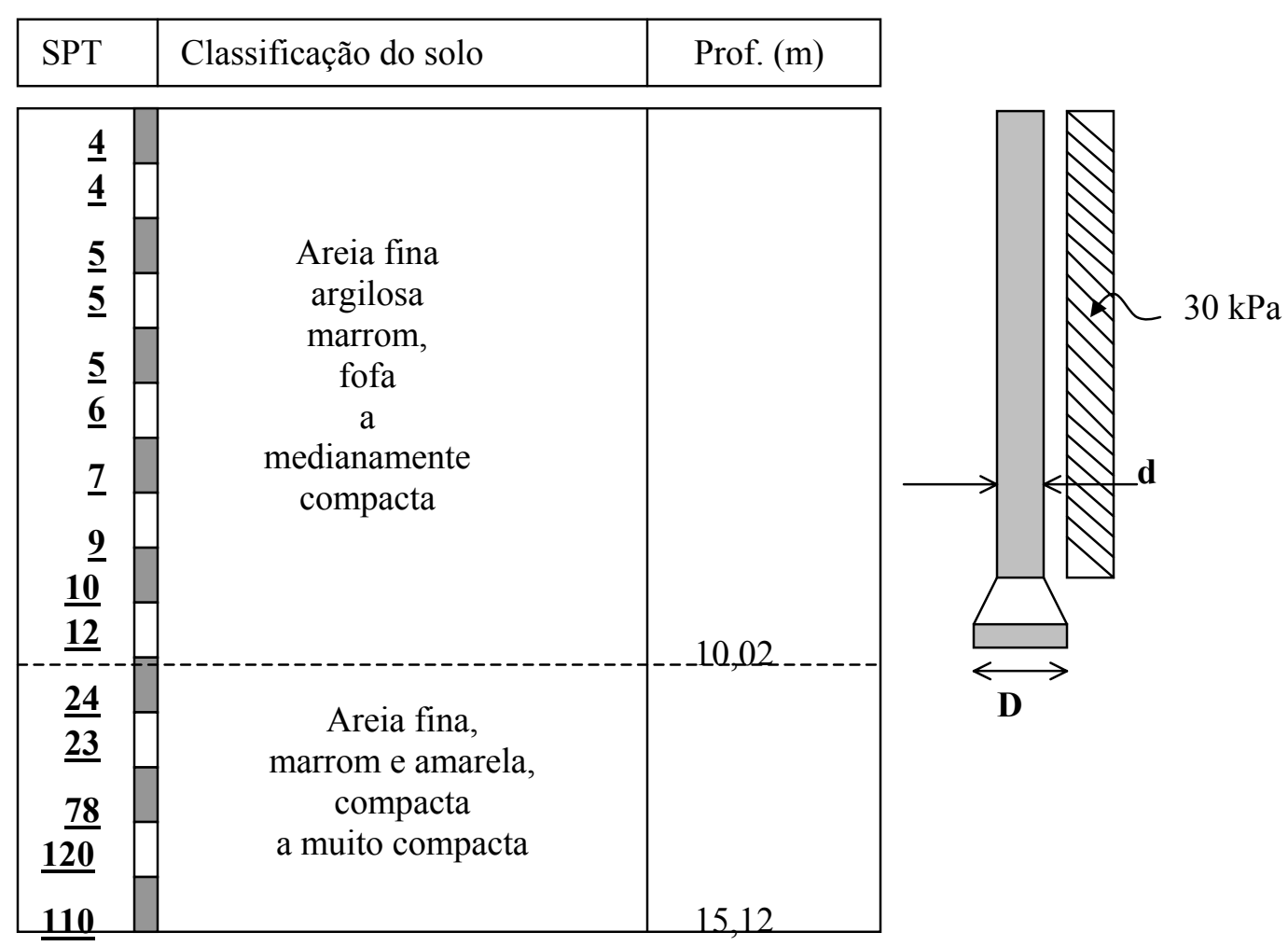

Figura 6.21 - Perfil do solo, LOBO et al. (1996)

Os resultados da sondagem só são conhecidos até a profundidade $15 \mathrm{~m}$. Para poder analisar o caso foram adotados o número de SPT e características do solo abaixo deste como sendo constante até a profundidade $25 \mathrm{~m}$ onde considerou-se como camada indeslocável.

MELO(1971) apud ALBIERO et al.(1993) apresenta uma expressão empírica para previsão do módulo de deformabilidade $\mathrm{E}_{\mathrm{S}}$ para solos arenosos em função dos valores do SPT: $\quad \mathrm{E}=220 \times 10^{(1,224+0,405 \log \mathrm{N})}(\mathrm{kPa})$, onde $\mathrm{N}$ é o número de SPT da sondagem.

A expressão acima mostrou-se bastante satisfatória quando comparado com o $E_{S}$ resultante dos ensaios de compressão simples mostrado em FERREIRA(1991), razão pelo qual foi adotado aqui para estimar os $E_{S}$ deste exemplo. Foi adotado $v=0,3$ para todas as camadas. ( Tab. 6.6) 


\section{A influência da colapsibilidade em fundações}

Segundo CINTRA(1998) os solos colapsíveis do Brasil em particular do sedimento cenozóico, o colapso só ocorre se for atingido uma carga limite ou crítica (sobrecarga), diferente do "loess" russo, que ao serem inundados entram em colapso apenas pelo peso próprio da camada do solo sem necessariamente com carregamento externo. Existem trabalhos sobre o comportamento de sapatas e estacas em solos colapsíveis, mas ainda não há na literatura pesquisas sobre o comportamento de tubulões, pela dificuldade e alto custo para realizar prova de carga neste tipo de fundação.

$\mathrm{Na}$ tabela 6.9 , observa-se que apesar de o edifício apresentar em planta relativamente simétrica, os pilares P14, P15, P17, P18, P21 e P22 recalcaram entre 7 a $9 \mathrm{~mm}$ enquanto que os pilares P2, P3, P5 e P6 não passam de 4 mm. Segundo LOBO et al.(1996), exatamente nessa região de maior recalque, ocorria acúmulo de águas pluviais durante a época de chuva pois houve uma escavação de aproximadamente $2 \mathrm{~m}$ para se fazer o subsolo. O maior umedecimento nessa região pode ter provocado uma redução na resistência lateral ao longo do fuste, aumentando a parcela de carga para o contato base - solo, resultando em maior recalque desses tubulões, fato associado à colapsibilidade do solo de Bauru.

Para o caso em estudo, foram adotadas as seguintes hipóteses:

- Com a inundação, a resistência lateral diminui de $1 / 3$ no topo até $1 / 2$ na base, AOKI \& CINTRA (2000).

- Além da perda de contato fuste - solo, para simular a queda do módulo de deformabilidade do solo foi adotado: $2 / 3$ de redução para solos que envolvem tubulões 19 e 15, 1/2 de redução para solos que envolvem tubulões 14 e 20 e redução de 1/3 para solos que envolvem tubulões 17, 18, 21 e 22 onde houve a maior inundação e maior recalque de acordo com o LOBO et al. (1996).

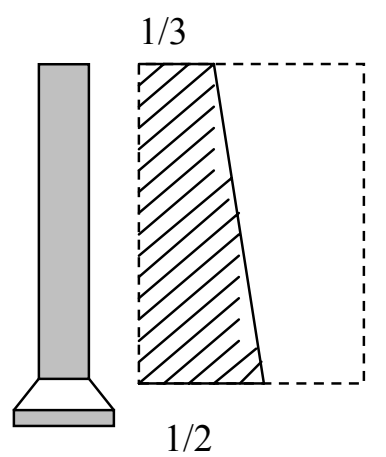

\begin{tabular}{|c|c|c|}
\hline Prof $(\mathrm{cm})$ & $\mathrm{E}_{\mathrm{S}}\left(\mathrm{kN} / \mathrm{cm}^{2}\right)$ & $v$ \\
\hline 250 & 4,2 & 0,3 \\
\hline 750 & 8,0 & 0,3 \\
\hline 1002 & 9,4 & 0,3 \\
\hline 1300 & 13,3 & 0,3 \\
\hline 2500 & 24,7 & 0,3 \\
\hline
\end{tabular}

Tabela 6.6 - Camadas de solo

Figura 6.22 - Redução do contato fuste - solo, AOKI \& CINTRA (2000) 


\section{Descrição do edifício}

O edifício tem estrutura de concreto armado convencional e utiliza no fechamento, alvenaria de tijolos cerâmicos vazados, possui um pavimento térreo de garagem, o primeiro andar e 10 pavimentos tipo sendo o último de cobertura. Cada andar possui quatro apartamentos de dois quartos e servidos por dois elevadores.

\begin{tabular}{|c|c|}
\hline Etapa & Carga \\
\hline Concreto & 4,86 \\
\hline Alvenaria & 2,73 \\
\hline Revestimento da laje & 0,38 \\
\hline Revestimento de paredes internas & 1,65 \\
\hline Revestimento de paredes externas & 0,67 \\
\hline Regularização do piso & 1,03 \\
\hline Piso & 0,26 \\
\hline Carga acidental & 1,32 \\
\hline Total & 12,90 \\
\hline
\end{tabular}

Tabela 6.7 - Carga kN/m², LOBO et al. (1996)

Segundo LOBO et al.(1996) quando na última medição de recalques estavam concluídos: a estrutura de concreto armado, o fechamento interno e externo de alvenaria, o revestimento inferior das lajes de forro, e as paredes internas estavam quase na totalidade revestidas. Faltando a colocação dos azulejos, a regularização do concreto do piso, a colocação de pisos, o revestimento externo; estima-se que estavam atuando nos pilares $75 \%$ da soma da carga prevista no projeto. Neste exemplo foi adotado a metade da carga acidental prevista no projeto para simular o peso devido aos movimentos dos operários e eventuais cargas oriundas de diversos materiais.

Segundo a NB $-1 / 78$, a estimativa de módulo de elasticidade do concreto armado em função do $\mathrm{f}_{\mathrm{ck}}(\mathrm{MPa})$ é : $\quad \mathrm{E}=0,9 * 6600 \sqrt{\mathrm{f}_{\mathrm{ck}}+3,5}$

Tem-se assim, para a estrutura do edifício com $\mathrm{f}_{\mathrm{ck}}=25 \mathrm{MPa}, \mathrm{E}_{\mathrm{c}} \cong 3171 \mathrm{kN} / \mathrm{cm}^{2}$

E para tubulões com $\mathrm{f}_{\text {ck }}=15 \mathrm{MPa}$, tem-se: $\mathrm{E}_{\mathrm{t}} \cong 2555 \mathrm{kN} / \mathrm{cm}^{2}$

Para a análise foram adotados $\mathrm{E}_{\mathrm{c}}=3100 \mathrm{kN} / \mathrm{cm}^{2}$ e $\mathrm{E}_{\mathrm{t}}=2500 \mathrm{kN} / \mathrm{cm}^{2}$.

O pavimento foi discretizado em elementos de placa, $D K T$, e elementos de barra com o recurso de interface gráfica PEC - SOUSA JUNIOR (1996) disponível no Departamento de Estruturas, que tornou possível a entrada de dados graficamente e a emissão do arquivo de entrada para o programa computacional do presente trabalho. 

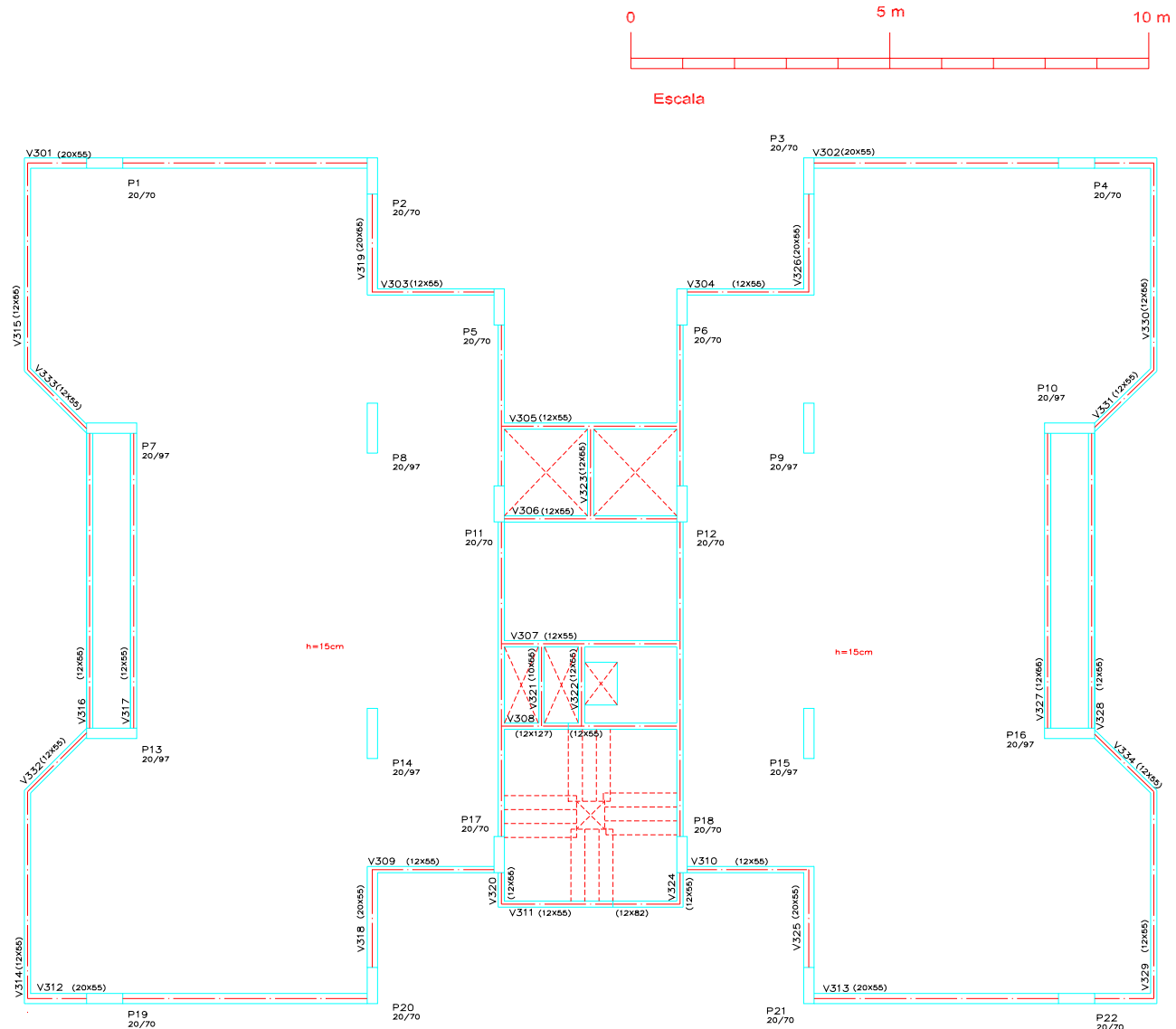

Figura 6.23 - Pavimento tipo

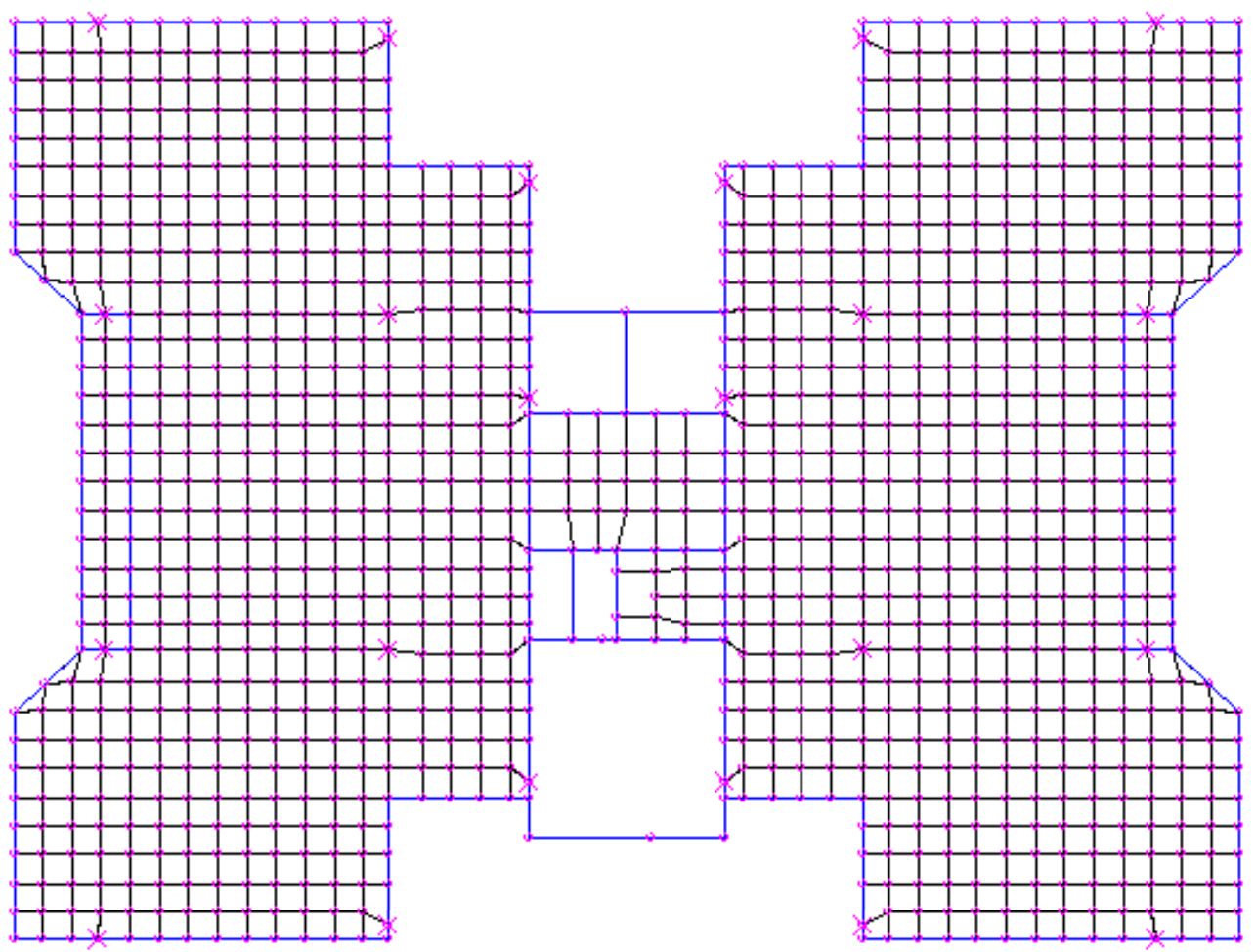

Figura 6.24 - Pavimento tipo discretizado em elementos finitos DKT 


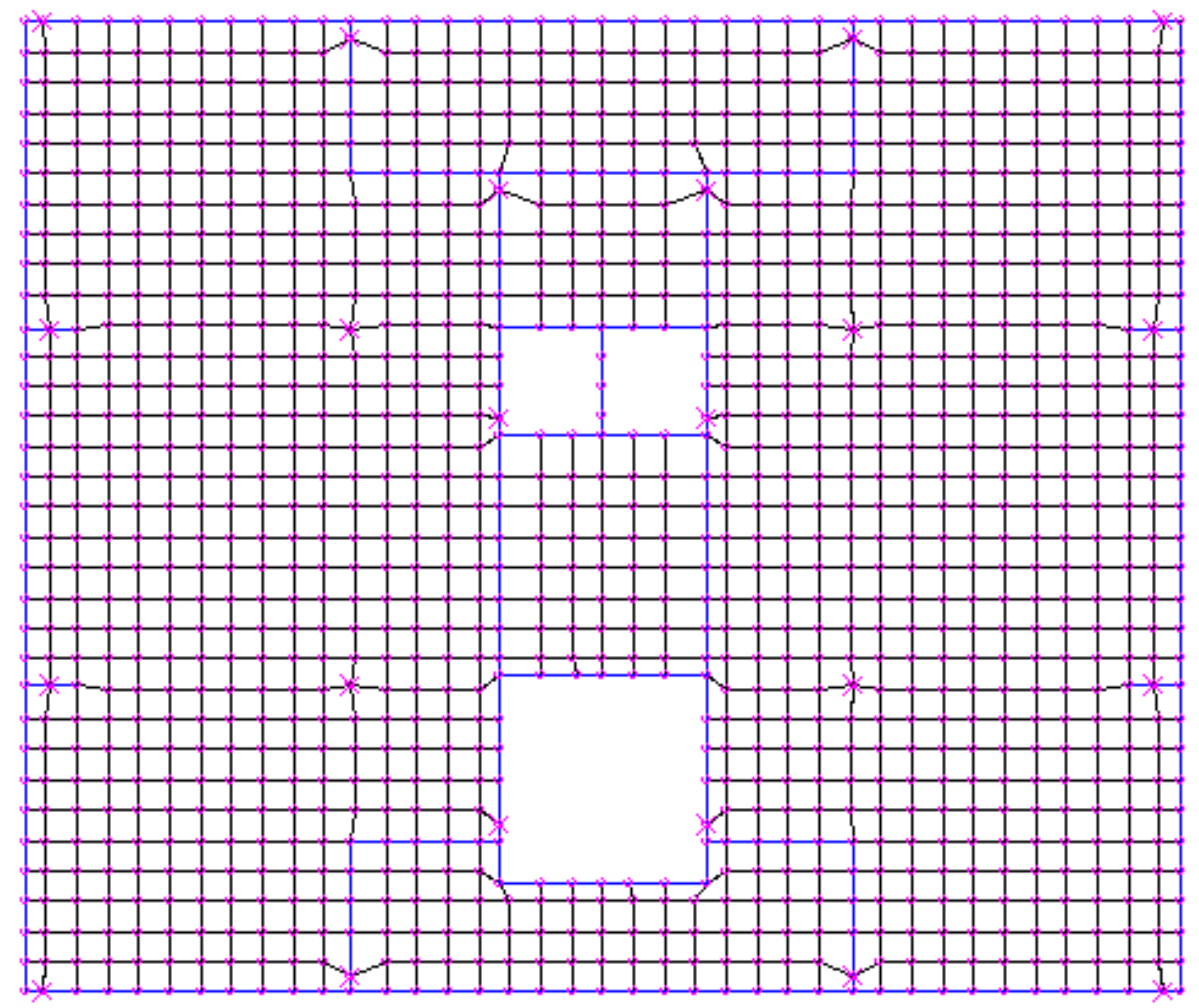

Figura 6.25 - Pavimento térreo

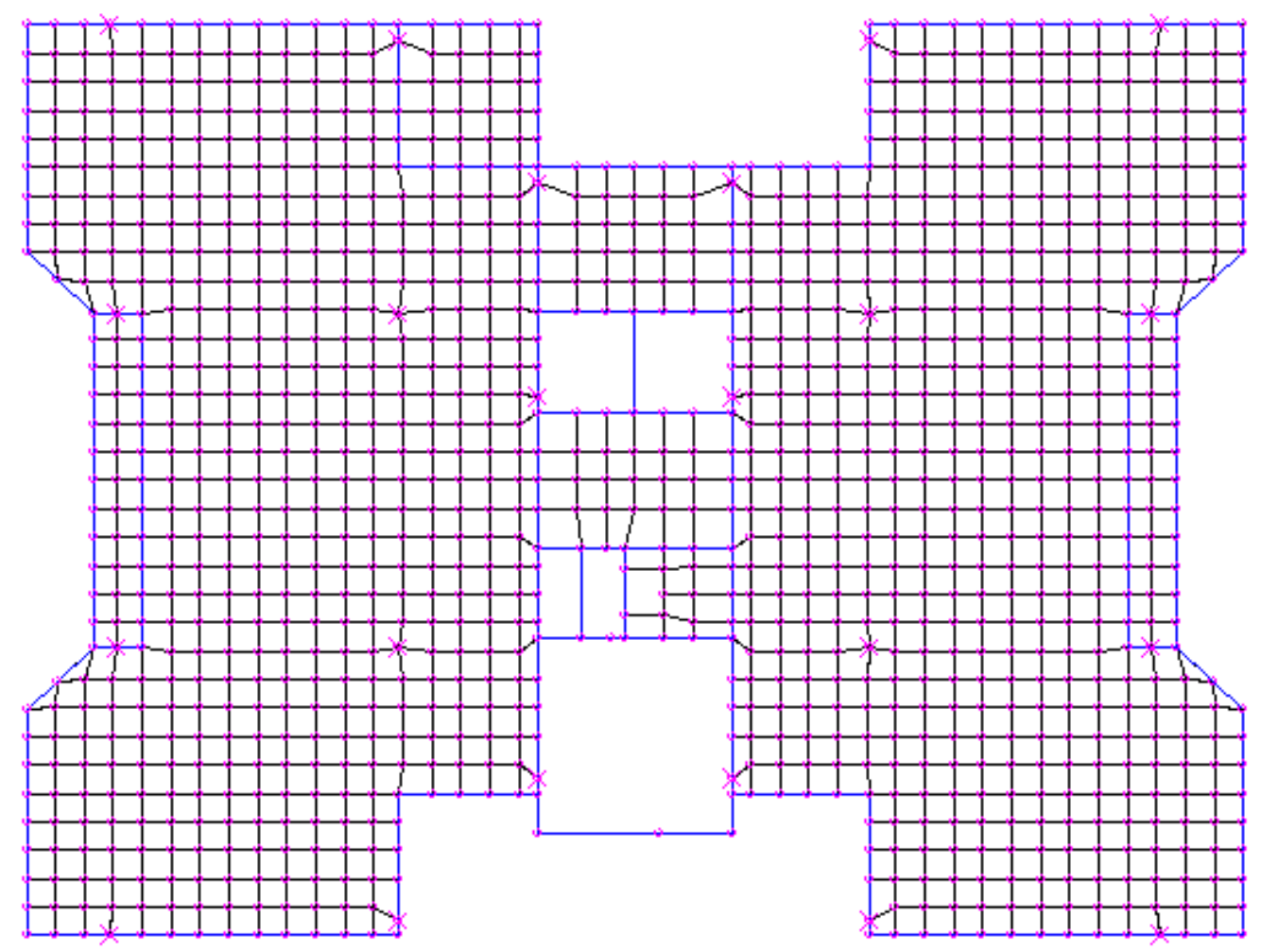

Figura 6.26 - Primeiro pavimento 


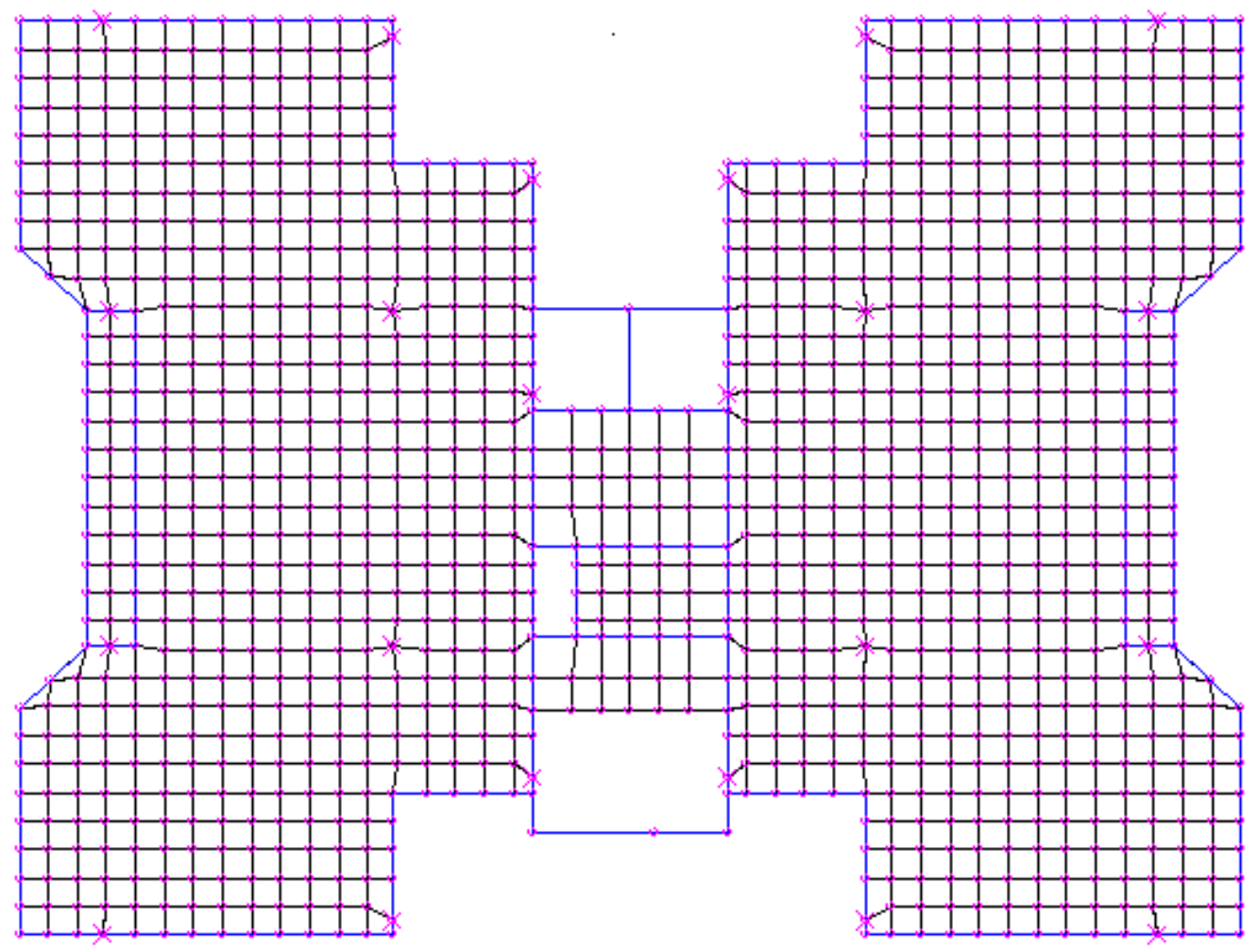

Figura 6.27 - Pavimento cobertura

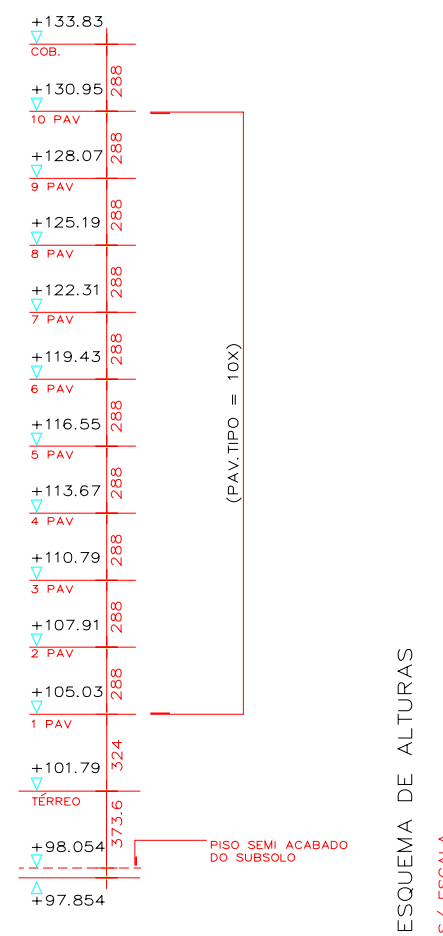

Figura 6.28 - Esquema de alturas 


\section{Descrição de tubulões}

Para cada pilar foi projetado um tubulão a céu aberto, com diâmetro do fuste $\mathbf{d}$ e de base alargada $\mathbf{D}$, apoiado a 10 metros de profundidade.

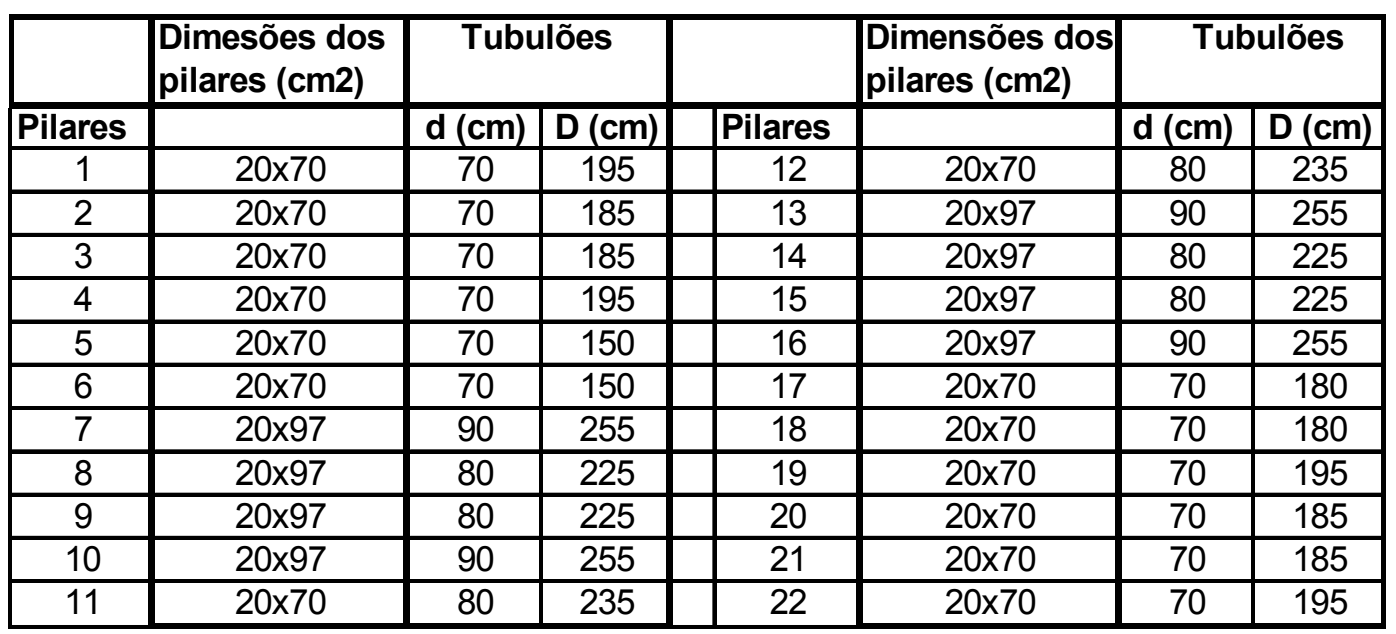

Tabela 6.8 - Dimensões dos pilares e tubulões

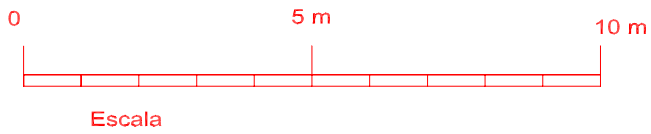

T.1

T.3 
As deformadas dos recalques estimados e medidos são:
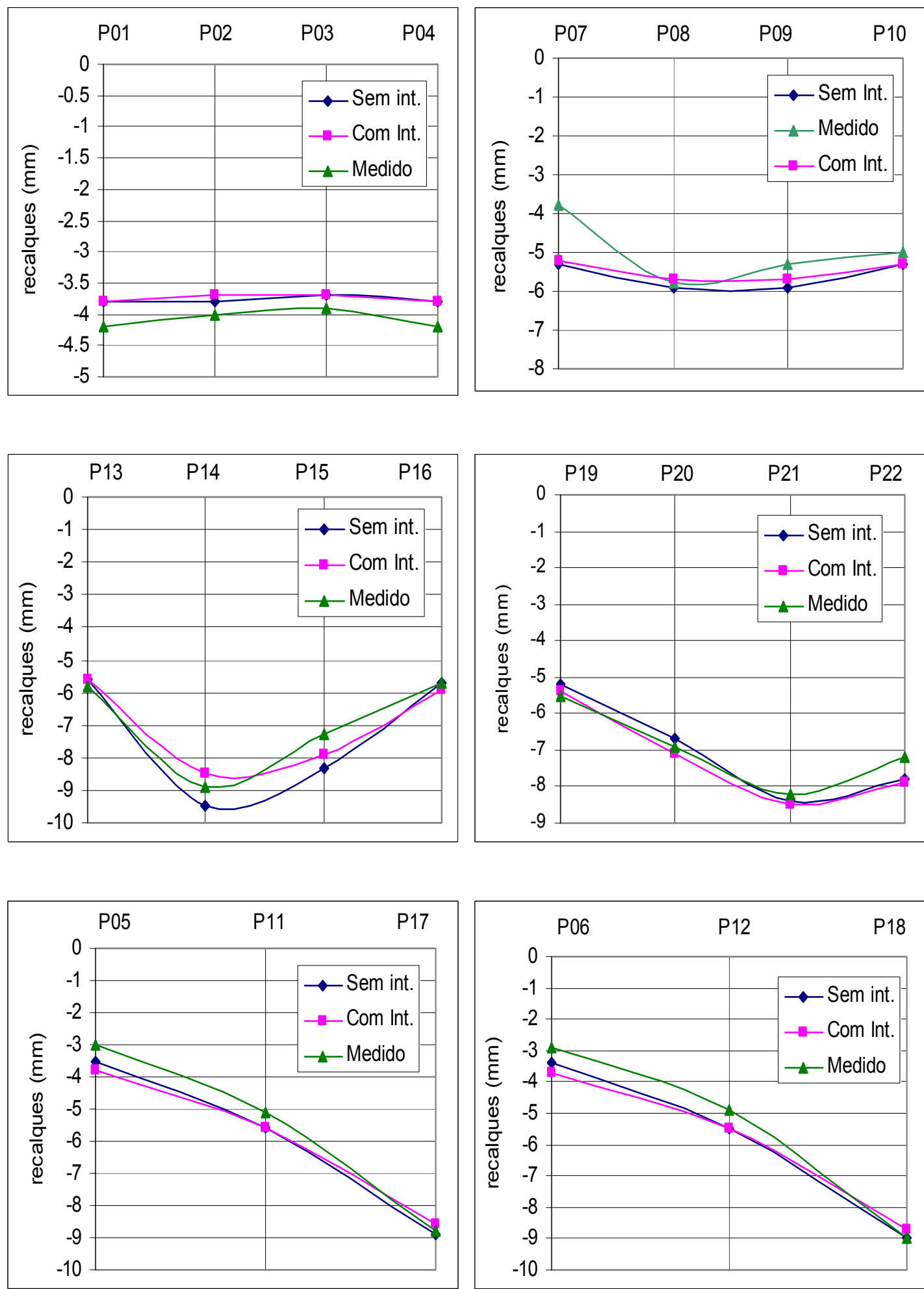

Figura 6.30 - Deformada dos recalques 

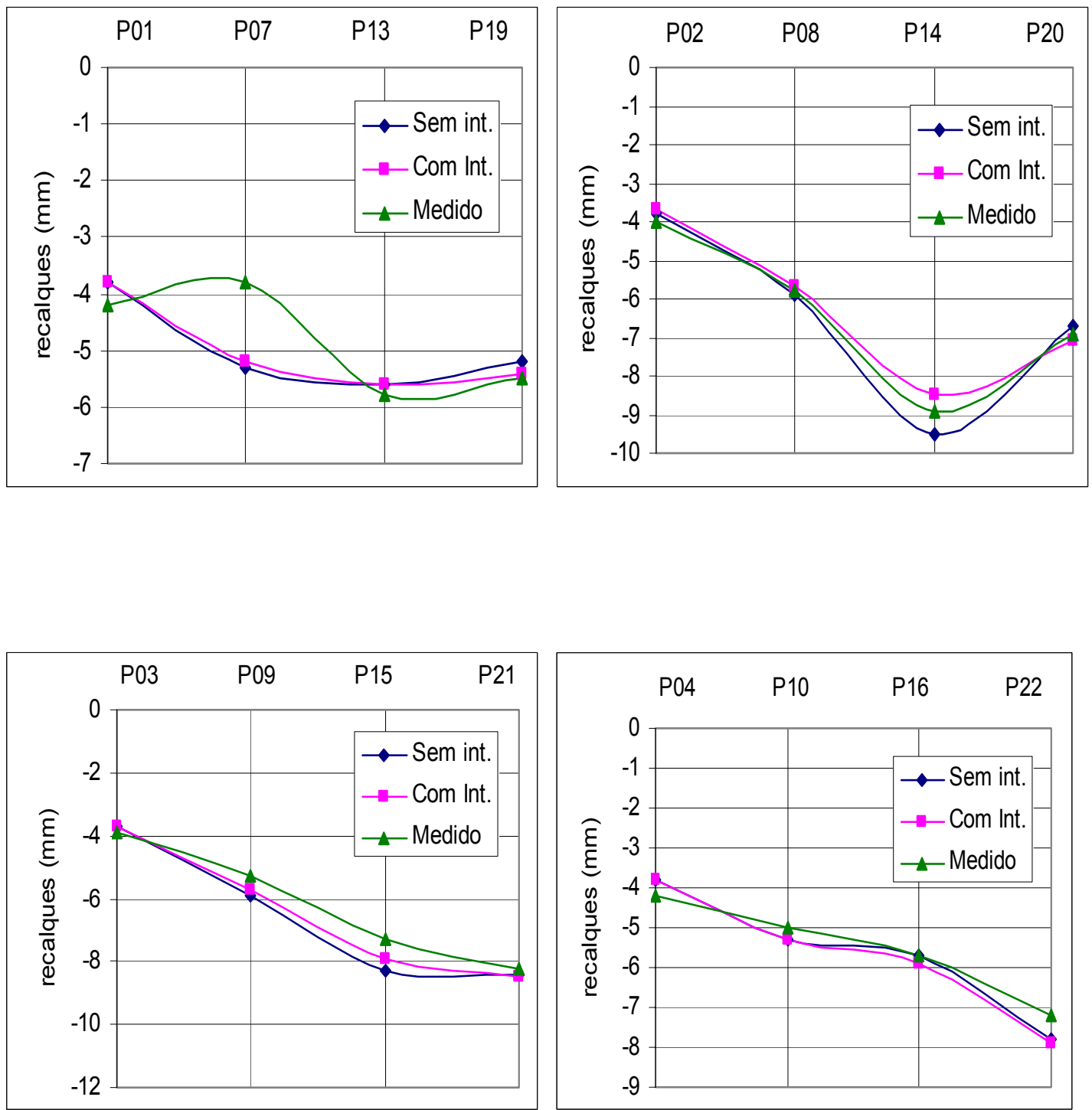

Figura 6.31 - Deformada dos recalques 


\begin{tabular}{|c|c|c|c|c|c|}
\hline \multicolumn{5}{|c|}{ Cargas e recalques nos tubulões } & \multicolumn{2}{l|}{ Com interação } & Medido \\
\hline & \multicolumn{1}{|c|}{ Sem interação } & Carga & Recalques & Recalques \\
\hline Pilar & Carga & Recalques & $(\mathrm{kN})$ & $(\mathrm{mm})$ & $(\mathrm{mm})$ \\
\hline & $(\mathrm{kN})$ & $(\mathrm{mm})$ & 1196,63 & 3,8 & $\mathbf{4 , 2}$ \\
\hline 1 & 1198,82 & 3,8 & 1013,00 & 3,7 & $\mathbf{4 , 0}$ \\
\hline 2 & 1011,69 & 3,8 & 996,00 & 3,7 & $\mathbf{3 , 9}$ \\
\hline 3 & 997,85 & 3,7 & 1208,90 & 3,8 & $\mathbf{4 , 2}$ \\
\hline 4 & 1203,29 & 3,8 & 737,11 & 3,8 & $\mathbf{3 , 0}$ \\
\hline 5 & 628,31 & 3,5 & 715,99 & 3,7 & $\mathbf{2 , 9}$ \\
\hline 6 & 608,87 & 3,4 & 2264,72 & 5,2 & $\mathbf{3 , 8}$ \\
\hline 7 & 2270,83 & 5,3 & 1836,63 & 5,7 & $\mathbf{5 , 8}$ \\
\hline 8 & 1921,18 & 5,9 & 1818,60 & 5,7 & $\mathbf{5 , 3}$ \\
\hline 9 & 1918,20 & 5,9 & 2259,98 & 5,3 & $\mathbf{5 , 0}$ \\
\hline 10 & 2268,33 & 5,3 & 1268,72 & 5,6 & $\mathbf{5 , 1}$ \\
\hline 11 & 1219,87 & 5,6 & 1257,90 & 5,5 & $\mathbf{4 , 9}$ \\
\hline 12 & 1221,29 & 5,5 & 2324,38 & 5,6 & $\mathbf{5 , 8}$ \\
\hline 13 & 2256,21 & 5,6 & 1796,86 & 8,5 & $\mathbf{8 , 9}$ \\
\hline 14 & 2067,75 & 9,5 & 1936,45 & 7,9 & $\mathbf{7 , 3}$ \\
\hline 15 & 2070,62 & 8,3 & 2360,42 & 5,9 & $\mathbf{5 , 7}$ \\
\hline 16 & 2253,40 & 5,7 & 1042,83 & 8,6 & $\mathbf{8 , 8}$ \\
\hline 17 & 1081,23 & 8,9 & 1047,97 & 8,7 & $\mathbf{9 , 0}$ \\
\hline 18 & 1089,25 & 9,0 & 1300,21 & 5,4 & $\mathbf{5 , 5}$ \\
\hline 19 & 1225,50 & 5,2 & 1235,58 & 7,1 & $\mathbf{6 , 9}$ \\
\hline 20 & 1138,69 & 6,7 & 1156,86 & 8,5 & $\mathbf{8 , 2}$ \\
\hline 21 & 1138,67 & 8,4 & 1241,20 & 7,9 & $\mathbf{7 , 2}$ \\
\hline 22 & 1227,09 & 7,8 & & & \\
\hline & & & & & \\
\hline
\end{tabular}

Tabela 6.9 - Recalques estimados $x$ recalques medidos

Os recalques absolutos medidos na obra variam entre 2,9 e 9,0 $\mathrm{mm}$ com valores médios de 5,7 mm. Segundo LOBO et al.(1996) esses valores estão muito próximos dos observados em edifícios de mesmo porte, construídos na cidade de Bauru, utilizando o mesmo tipo de fundação.

A pequena magnitude desses recalques deve-se ao fato de uma grande parcela da carga atuante nos tubulões está sendo resistida pelo atrito lateral ao longo do fuste (nesta análise adotou-se $30 \mathrm{kPa}$ para resistência lateral máxima como entrada de dados do programa) e não exclusivamente pelas tensões na base como a maioria dos projetistas admitem neste tipo de fundação.

Segundo esse mesmo autor, os recalques diferenciais específicas (distorções) são os que normalmente provocam problemas estruturais; variam entre praticamente zero e 1:1500 nesta etapa de construção, estando muito abaixo daquelas consideradas possíveis de apresentar algum problema de fissuração no concreto ou alvenaria. 
No gráfico de deformadas dos recalques, apresentados nas figuras 6.30 e 6.31, com a análise da interação estrutura - solo, verifica-se nitidamente a contribuição da rigidez da estrutura interferindo nos recalques dos pilares centrais P08, P09, P14 e P15, enquanto que nos demais pilares esta contribuição foi pequena em relação ao processo convencional. Algumas discrepâncias entre os resultados do modelo numérico e o medido (pilares P01, P04, P07, P21, P22) podem ter surgido pelos diversos fatores como a adoção de uma única sondagem para toda a fundação do edifício, a influência da inundação do solo para tubulões e a não consideração da seqüência construtiva na análise numérica.

Um fato importante é que a não consideração da seqüência construtiva na análise pode levar o projetista de estruturas a estimativa de um comportamento estrutural distinto do real. Como na prática a estrutura recebe acréscimo de cargas e aumento da rigidez para cada pavimento levantado, e estes dependem também da velocidade da construção (idade do concreto e tempo de escoramento, ou seja a reologia do material concreto durante e depois da construção) suas conseqüências na redistribuição das reações, recalques e esforços nos elementos estruturais podem apresentar diferenças significativas em relação aos modelos com carregamento instantâneo e edifício totalmente construído. Alguns autores como FONTE; JUCÁ; PONTES FILHO(1994) e GUSMÃO; GUSMÃO FILHO(1994), vem mostrando a importância da consideração desta análise. A consideração destes fatores no modelo numérico, certamente proporcionará resultados mais representativos e confiáveis. 


\section{CONCLUSÕES}

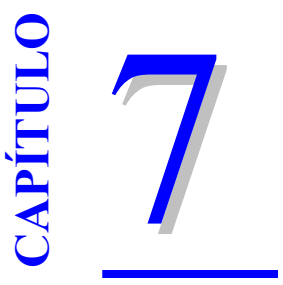

O modelo tridimensional de interação solo - estrutura que considera a contribuição da rigidez à flexão das lajes com os elementos de vigas e pilares, aliado ao modelo de interação com efeitos de grupos de estacas e a não linearidade na estimativa dos recalques, torna o presente processo uma grande vantagem em relação aos modelos que tradicionalmente aplicam molas de rigidez isoladas para cada apoio e que ignoram completamente a continuidade parcial do solo, ou admitem apoios totalmente engastados.

Com a análise integrada entre a estrutura e o maciço de solo estratificado, pode-se avaliar numericamente os efeitos como redistribuição dos esforços nos elementos estruturais, as reações e o comportamento dos recalques devido à deslocabilidade dos apoios.

Nos exemplos analisados, verificou-se que a rigidez da estrutura contribui para diminuir os recalques diferenciais e distorções angulares tornando-se um fator mais favorável do que se tratar estruturas e solos separadamente. Os esforços secundários provenientes da interação são maiores nos pavimentos inferiores, mas dependendo da rigidez relativa estrutura - solo podem em alguns casos propagarem aos pavimentos superiores, (caso do exemplo 2 do capítulo 6).

A validação do programa computacional de interação solo - estrutura pode ser feita de duas maneiras:

* Comparação com um outro programa computacional devidamente testado e reconhecido no mercado;

* Comparação com os dados medidos no campo devidamente documentados e de fonte segura.

Dificuldades encontradas;

Dificuldades de comparar numericamente com outros pacotes de softwares:

- Em nível nacional, praticamente não se tem notícias sobre pacote de programa de interação solo - estrutura para fundações em estacas. 
- Os pacotes como Ansys e Abacus são programas de uso específico em estruturas especiais (cascas, volumes, peças mecânicas, etc), problemas de contato, danos de materiais e análise de distribuição de tensões e deformações, não sendo adequado e viável para analisar um edifício que interage com múltiplas camadas de solo e a consideração da plastificação do grupo de estacas no maciço de solo.

Quanto a comparação com os recalques medidos na obra, as dificuldades são:

- A impossibilidade de ensaiar nos laboratórios, por razões óbvias, e a falta de interesse dos construtores (ou projetistas) em acompanhar e documentar os recalques da obra, quanto menos para fundações profundas em estacas por acreditarem que os recalques são menores que as fundações rasas e portanto desprezíveis, fazem com que a comparação numérica com a real seja muito difícil devido a sua extrema escassez.

\section{SUGESTÕES PARA TRABALHOS FUTUROS}

- A necessidade da consideração da reologia do material, concreto, no modelo estrutural;

- A contribuição da rigidez das alvenarias de fechamento na análise da estrutura;

- Consideração do carregamento horizontal nas estacas e tubulões, relevantes para fundações de pontes;

- Comparação com os resultados medidos no campo para validação do programa computacional;

- A inclusão da rotina de automatização no programa computacional para simular a seqüência construtiva e comparar suas diferenças em relação aos modelos que consideram o carregamento e a rigidez instantânea;

- Necessidade da elaboração de rotinas no programa computacional para tornar possível a otimização nas estruturas de fundações em estacas a fim de tornar mínimo os recalques diferenciais, nocivos nas estruturas do edifício.

- O recurso gráfico no pré-processador de fundações para tornar menos cansativo a entrada de dados com o uso, por exemplo, de AutoLisp para passar as informações diretamente do desenho elaborado em AutoCad, em vez da entrada pelo arquivo.

- A necessidade de verificar as envoltórias dos esforços para diferentes combinações de ações na estrutura a fim de estudar as cargas críticas e o limite da sua segurança.

- Análise considerando a não linearidade física da estrutura e verificação da estabilidade.

- A inclusão dos núcleos estruturais como mais um sistema de contraventamento e seus efeitos na interação solo - estrutura. 


\section{ALGUMAS CRÍTICAS SOBRE O MODELO ADOTADO}

O método AOKI-LOPES(1975) à luz da teoria da elasticidade com o uso de solução de MINDLIN(1936) e processo de STEINBRENNER(1934) tornou possível a interação de ações de grupos de elementos de fundações, porém a transferência de cargas para o solo adjacente é feita como se fosse contínuo, incluindo o espaço preenchidos pelas estacas, portanto não considera a descontinuidade do maciço. Esta 'lacuna' só é resolvido com os uso de ferramentas mais sofisticadas como a combinação de método dos elementos de contorno e método dos elementos finitos discretizando tanto o maciço de solo como elementos de estacas para simular a existência de diferentes materiais.

Seria interessante verificar mediante a comparação dos dois métodos, se esta descontinuidade ocupada pelas estacas até que ponto são realmente significativas ou não. Também é importante enfatizar que nem todos os resultados numéricos mais sofisticados são verdadeiras para o uso prático pois o solo é um material que dificilmente pode-se simular numericamente com perfeição.

Outra simplificação do modelo é quanto à transferência de carregamento da estaca. A resistência máxima de contato fuste - solo pode mudar com o efeito do grupo de estacas devido a deformação do solo adjacente provocados pela interação do conjunto e não está sendo considerado neste modelo.

O domínio do estudo da interação solo - estrutura não tem o objetivo somente em prever os possíveis esforços secundários devido aos recalques diferenciais, mas também para ajustar melhor no dimensionamento dos elementos estruturais de fundações e do edifício simultaneamente para minimizar os efeitos nocivos dos recalques diferenciais nas estruturas.

Com essas considerações procura-se otimizar a distribuição de esforços, pois neste caso, analisa-se integralmente a estrutura e o maciço de solo.

Finalmente enfatiza-se que devido a alta complexidade do fenômeno, o modelo de interação solo - estrutura mostrado no presente trabalho ainda está longe de ser considerado como concluído. Trata-se de um trabalho que pode servir como base nas futuras implementações ou como primeiro parâmetro de interação entre estrutura de edifícios de múltiplos andares com fundações em estacas e solos estratificados, com os modelos mais sofisticados como a combinação de métodos dos elementos de contorno e finitos que recentemente tem mostrado aplicações para grupo de estacas.

Conclui-se que a continuidade da pesquisa é necessário, com maior intercâmbio entre as áreas de Engenharia de Estruturas e Geotecnia, uma vez que não existem fundações sem estruturas acima ou estruturas com apoios indeslocáveis. 


\section{FLUXOGRAMA GERAL DA INTERAÇÃO ESTRUTURA - SOLO}
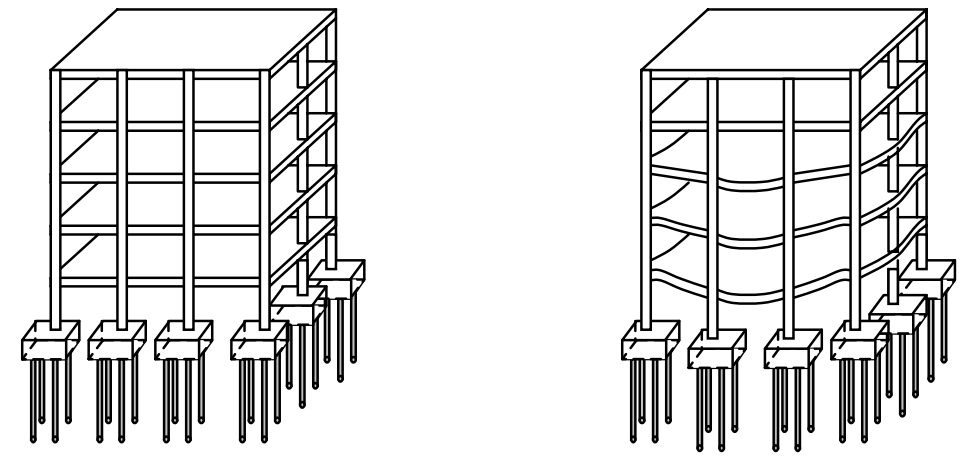

$\sqrt{ }$ Cargas no bloco de coroamento

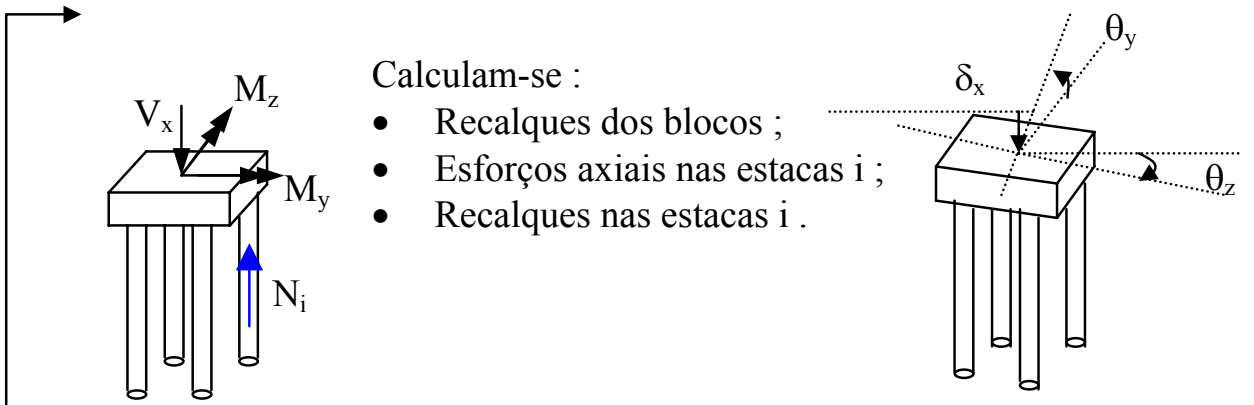

Repete-se a iteração até que $\mathrm{N}_{\mathrm{i}}{ }^{(\text {iteração })} \cong \mathrm{N}_{\mathrm{i}}{ }^{(\text {iteração -1) }}$

Calcula-se novas rigidezes nos apoios $\mathrm{K}_{\mathrm{k}}=\frac{\text { Ação no Bloco de coroamento }}{\text { Recalque no Bloco }}$

Repete-se a iteração até que Ação no Bloco ${ }^{(\text {iteração })} \cong$ Ação no Bloco ${ }^{\text {(iteração - 1) }}$

Observe que existem duas iterações:

- A iteração para convergência entre bloco e grupo de estacas, dispensa-se para tubulões;

- E a iteração para convergência entre a estrutura e o solo.

Nas próximas páginas serão mostrados os algoritmos da subrotina GRUPOBLOCOS implementado neste trabalho. Quanto ao modelo da estrutura do edifício tridimensional poderá ser consultado em ANTUNES \& BEZERRA(1995) e ANTUNES \& MARTINS(1998). 


\section{FLUXOGRAMA GERAL DA INTERAÇÃO ESTACA - SOLO}

Inicialmente, calcula-se as reações $\mathrm{N}_{\mathrm{i}}^{(0)}$ nas estacas com o estaqueamento SCHIEL considerando apenas as características físicas da estaca.
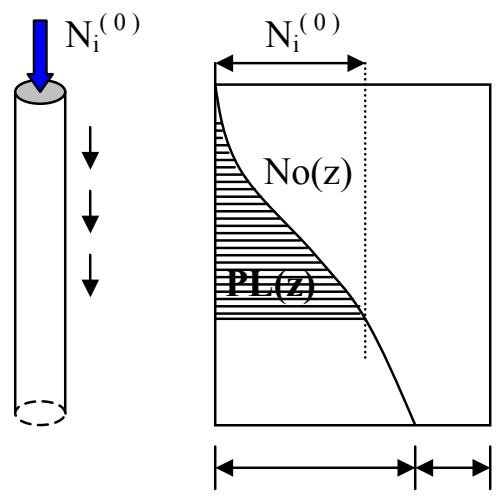

PL

PP

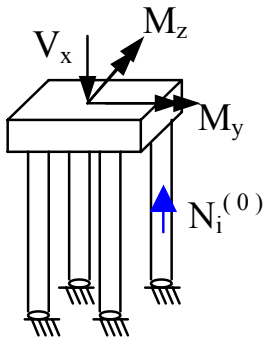

Rigidez da estaca $\mathrm{i}$

$S_{i}^{(0)}=\frac{A_{i} E_{i}}{L_{i}}$

- Com a carga $\mathrm{N}_{\mathrm{i}}$ e diagrama de ruptura estaca - solo conhecido, calcula-se a transferência de cargas na estaca i ;

- A deformação elástica da estaca i é obtida com o conhecimento do diagrama de esforço normal No(z).

$$
\delta_{\mathrm{p}}(\mathrm{z}) \cong \frac{1}{\mathrm{~A}_{\mathrm{i}} * \mathrm{E}_{\mathrm{i}}} \sum_{C}^{Z} \mathrm{No}(\mathrm{z}) * \mathrm{Z}
$$

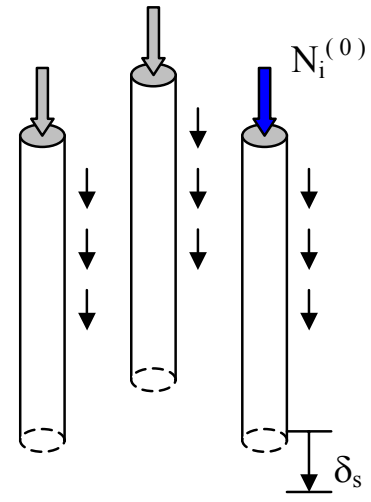

Com as novas rigidezes $\mathrm{S}_{i}^{(1)}$ nas estacas, calcula-se as novas reações $\mathrm{N}_{\mathrm{i}}^{(1)}$ pelo estaqueamento SCHIEL .
Método AOKI-LOPES

- Calcula-se deslocamento $\delta_{\mathrm{s}}$ na base da estaca considerando a interação com todas as estacas do grupo

Recalque da estaca $\mathrm{i}$ :

$\delta_{\mathrm{i}}=\delta_{\mathrm{s}}+\delta_{\mathrm{p}}$

O processo se repete até que $\mathrm{N}_{\mathrm{i}}^{(\mathrm{n})} \cong \mathrm{N}_{\mathrm{i}}^{(\mathrm{n}-1)}$ 


\section{Algoritmo da subrotina GRUPOBLOCO}

Estaqueamento sobre a camada indeslocável (antes da iteração)

$$
\begin{aligned}
\text { Faça } \mathrm{J}=1, \mathrm{~N}\left(\mathrm{n}^{\mathrm{o}} \text { de estacas }\right) \\
\text { Área }(\mathrm{J})=\pi *(\operatorname{Diametro}(\mathrm{J}) / 2)^{2} \\
\mathrm{~S}_{\mathrm{i}}(\mathrm{J})=\text { Área }(\mathrm{J}) * \mathrm{E}(\mathrm{J}) / \mathrm{L}(\mathrm{J})
\end{aligned}
$$

Próximo J

Geração da matriz de rigidez 6 × 6 do estaqueamento

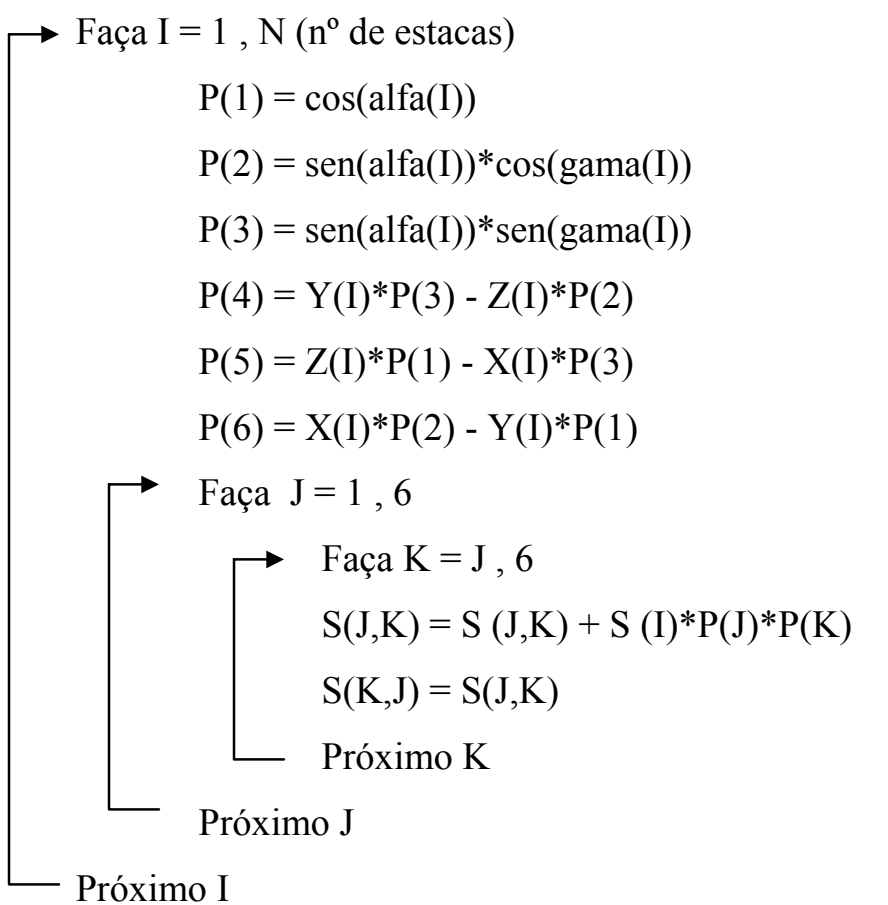

Chama a subrotina para inversão da matriz de rigidez $\mathbf{S}_{6 \times 6}$

Leitura dos carregamentos aplicados nos blocos (obtidos da estrutura)

Leia Reac(3*In-2), Reac(3*In-1), Reac(3*In)

Cálculo dos deslocamentos do bloco em função da rigidez e carga aplicada no bloco

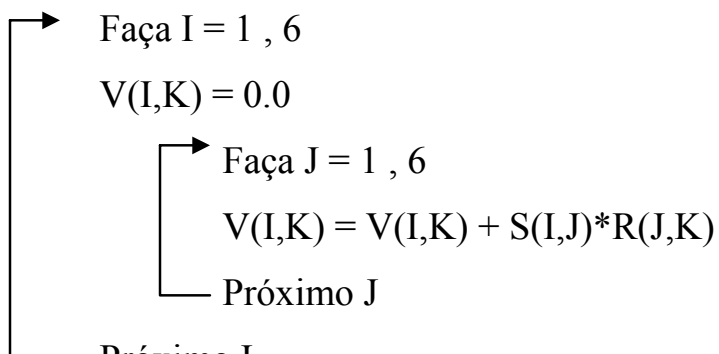

Próximo I 
Cálculo dos esforços Normais nas estacas

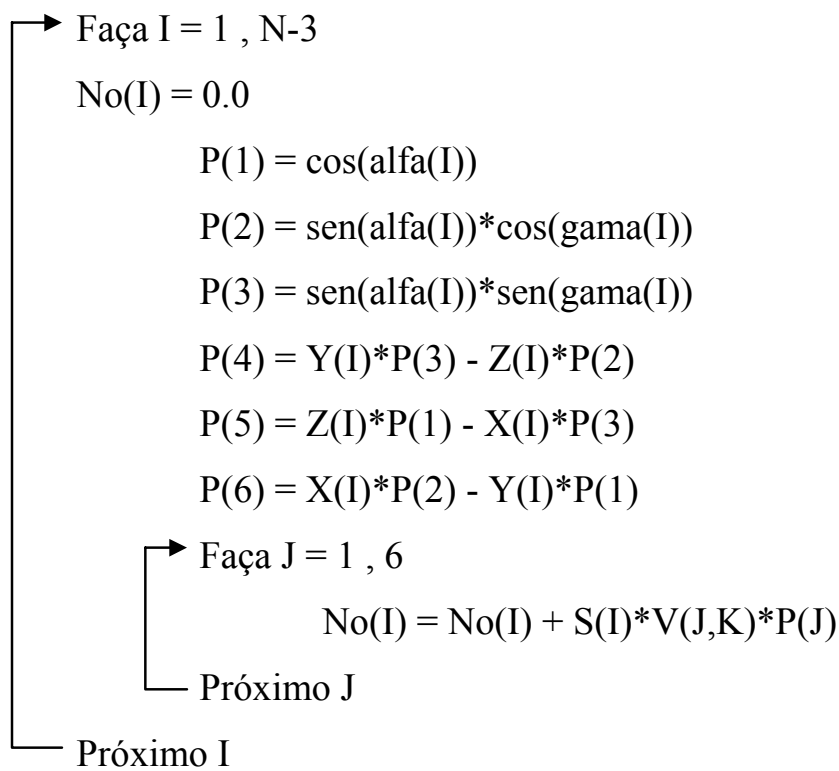

Condição para o caso de considerar interação solo - estacas $\left(\mathrm{n}^{\circ}\right.$ de iteração $\neq 0$ )

Se NItera $\neq 0$ então faça

Chama subrotina ESTACA (para determinar o diagrama de transferência, deformação elástica da estaca e carga que vai para a base da estaca)

Chama subrotina AOKI-LOPES (para calcular os deslocamentos na base, considerando os efeitos de grupo de estacas)

Recalques no topo das estacas

$\rightarrow$ Faça $\mathrm{I}=1, \mathrm{C} 1$

Recalque( I ) = Deformação( I ) + Deslocamento( I )

Próximo I

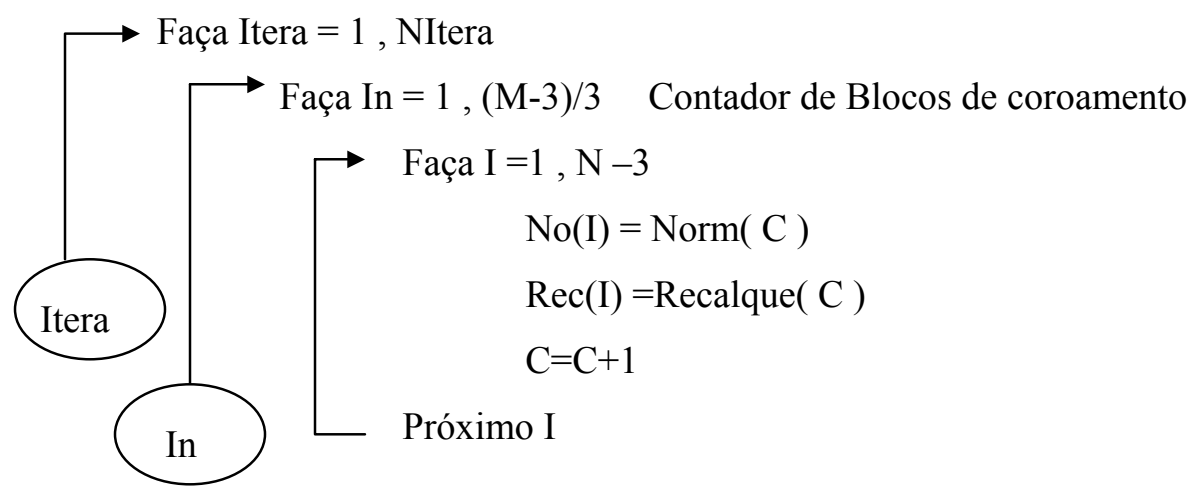


Cálculo de novas rigidezes em função dos recalques anteriores

$\longrightarrow$ Faça $\mathrm{I}=1, \mathrm{~N}$

$$
S_{i}(I)=\operatorname{No}(I) / \operatorname{Rec}(I)
$$

— Próximo I

Geração da nova matriz de rigidez do estaqueamento

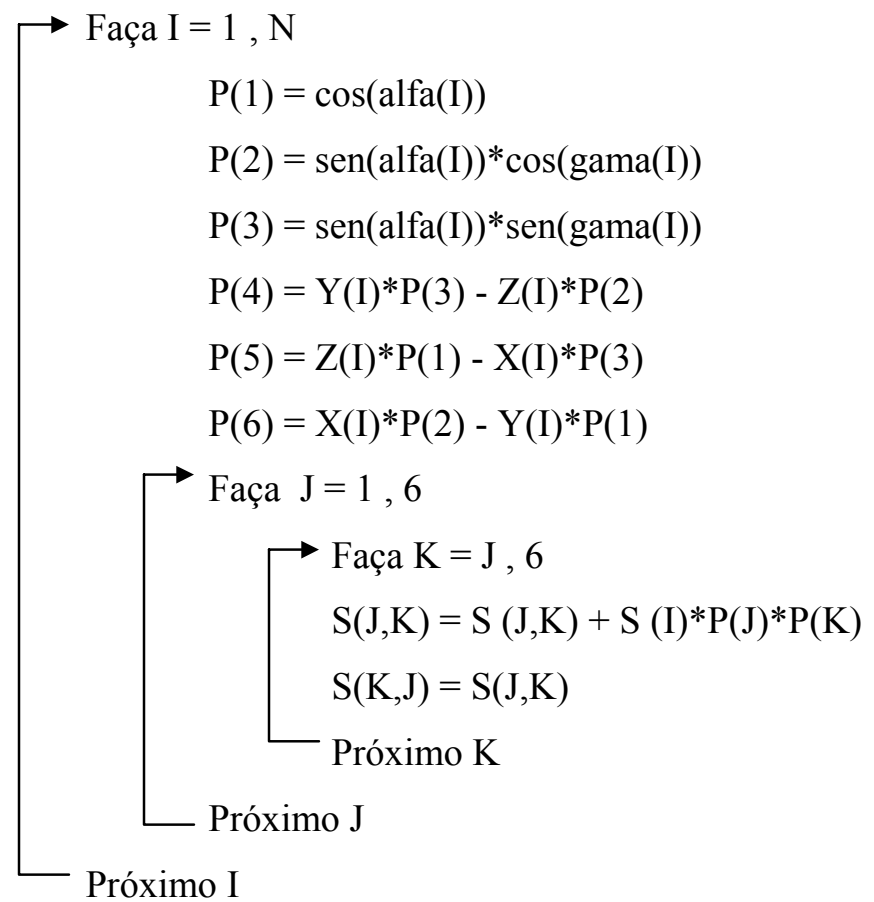

\section{Chama a subrotina para inversão da matriz de rigidez $\mathbf{S}_{6 \mathbf{6} 6}$}

Chama ações atuantes nos blocos (Já lido anteriormente)

Cálculo dos deslocamentos do bloco em função da nova rigidez

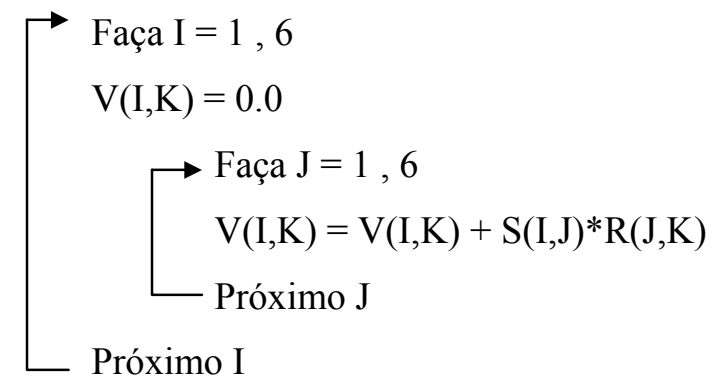


Condição para não incluir uma iteração a mais

Se Itera $\neq$ NItera então faça

Cálculo dos esforços Normais nas estacas

$$
\begin{aligned}
& \longrightarrow \text { Faça I }=1, \mathrm{~N}-3 \\
& \mathrm{No}(\mathrm{I})=0.0 \\
& \mathrm{P}(1)=\cos (\mathrm{alfa}(\mathrm{I})) \\
& \mathrm{P}(2)=\operatorname{sen}(\operatorname{alfa}(\mathrm{I})) * \cos (\text { gama }(\mathrm{I})) \\
& \mathrm{P}(3)=\operatorname{sen}(\operatorname{alfa}(\mathrm{I})) * \operatorname{sen}(\text { gama }(\mathrm{I})) \\
& \mathrm{P}(4)=\mathrm{Y}(\mathrm{I}) * \mathrm{P}(3)-\mathrm{Z}(\mathrm{I}) * \mathrm{P}(2) \\
& \mathrm{P}(5)=\mathrm{Z}(\mathrm{I}) * \mathrm{P}(1)-\mathrm{X}(\mathrm{I}) * \mathrm{P}(3) \\
& \mathrm{P}(6)=\mathrm{X}(\mathrm{I}) * \mathrm{P}(2)-\mathrm{Y}(\mathrm{I}) * \mathrm{P}(1) \\
& \rightarrow \text { Faça } \mathrm{J}=1,6 \\
& \mathrm{No}(\mathrm{I})=\mathrm{No}(\mathrm{I})+\mathrm{S}(\mathrm{I}) * \mathrm{~V}(\mathrm{~J}, \mathrm{~K}) * \mathrm{P}(\mathrm{J}) \\
& \text { Próximo J }
\end{aligned}
$$

Termina a condição Se

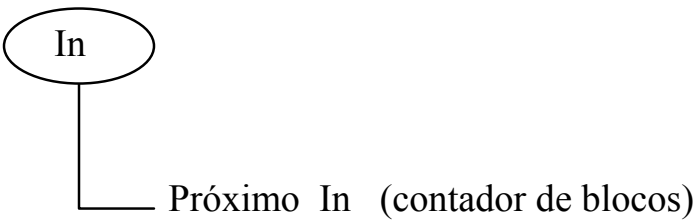

Se Itera $\neq$ NItera então faça (para não incluir uma iteração a mais)

Chama subrotina ESTACA (para determinar o diagrama de transferência, deformação elástica da estaca e carga que vai para a base da estaca)

Chama subrotina AOKI-LOPES (para calcular os deslocamentos na base , considerando os efeitos de grupo de estacas)

Itera Recalques no topo das estacas

$$
\begin{aligned}
& \longrightarrow \text { Faça I = } 1, \mathrm{C} 1 \text { ( } \mathrm{n}^{\mathrm{o}} \text { total de estacas do grupo) } \\
& \qquad \operatorname{Recalque(}(\mathrm{I})=\operatorname{Deformação(~} \mathrm{I})+\operatorname{Deslocamento}(\mathrm{I}) \\
& \text { Próximo I }
\end{aligned}
$$

Termina condição Se (condição para não incluir uma iteração a mais)

Próximo Itera (número de iteração)

Termina condição Se (condição quando existe interação solo - estaca) 


\section{Algoritmo da subrotina ESTACA}

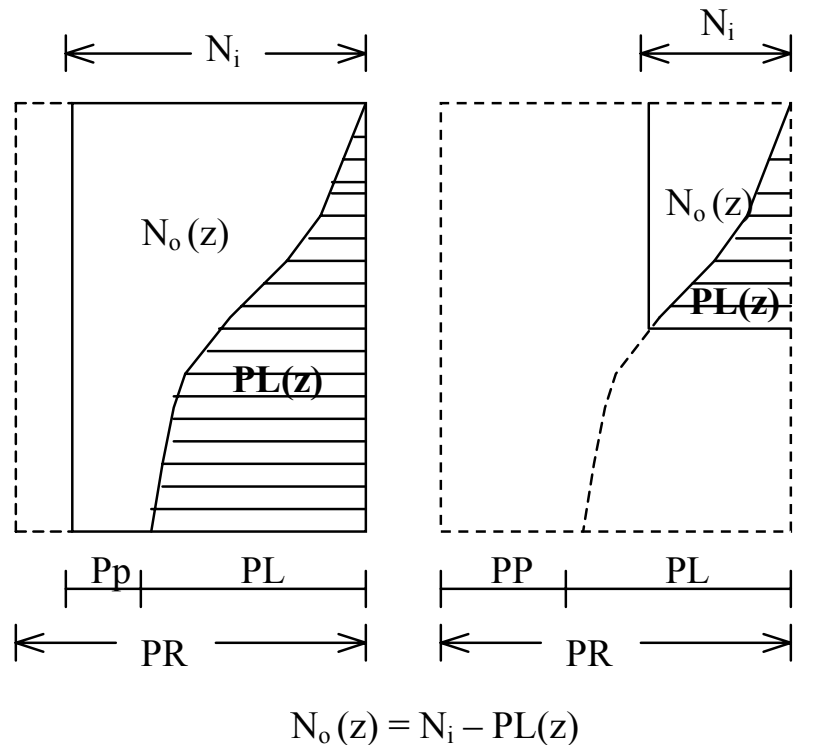

( a )

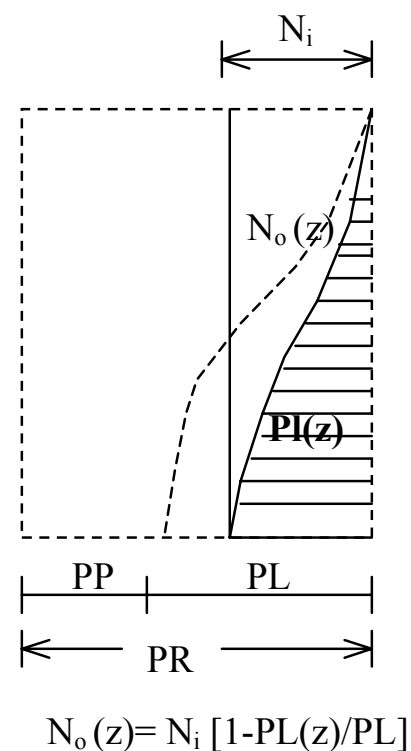

( b )

O modelo adotado no programa será o caso a onde admite-se que a transferência de carga na estaca acontece parcialmente à medida que a carga $\mathrm{N}_{\mathrm{i}}$ vai vencendo o atrito lateral máxima de contato fuste - solo.

\section{1 ) Determinação do diagrama $\operatorname{PL}(z)$ na estaca}

Admitindo a variação linear no fuste da estaca, tem-se:

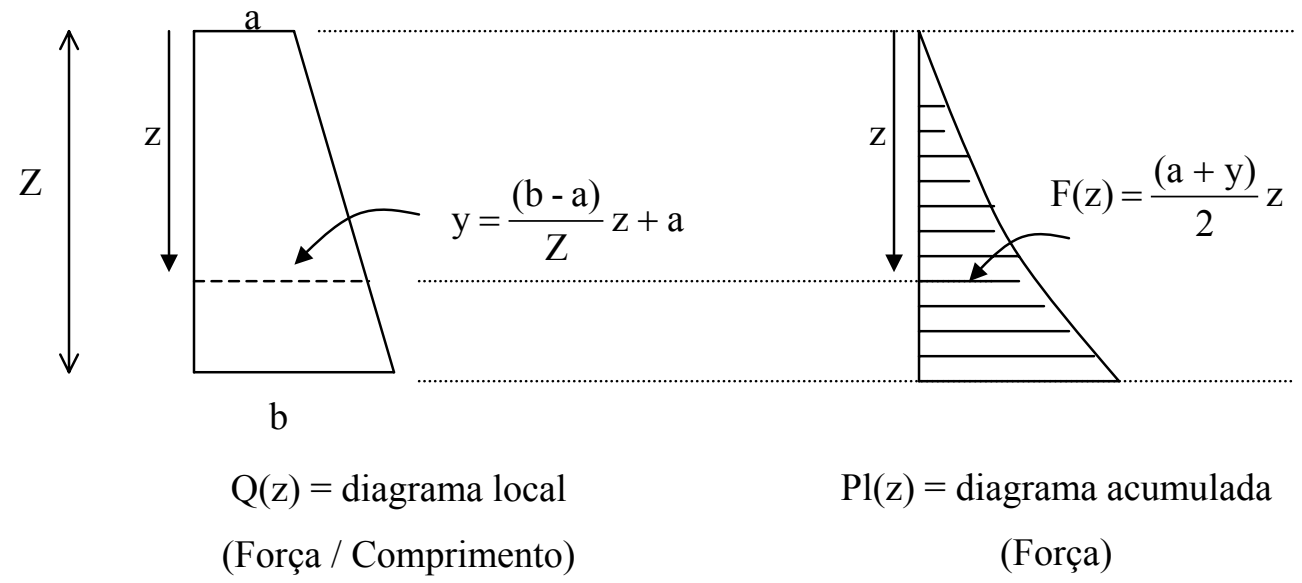


Sendo: $\mathrm{Z}=$ Dist $(\mathrm{K}+1, \mathrm{C})=\mathrm{D}(\mathrm{C}, 2 *(\mathrm{~K}+1))-\mathrm{D}(\mathrm{C}, 2 * \mathrm{~K}+1) \quad$ é a espessura da camada $\mathrm{K}+1$ $\mathrm{K}$ índice das camadas e $\mathrm{C}$ índice das estacas $(\mathrm{b}-\mathrm{a})=\operatorname{Coef}(\mathrm{K}+1)$ inclinação da reta

A força acumulada é :

Substituindo a expressão do y em F(z), tem-se:

$$
\mathrm{F}(\mathrm{z})=\text { Force }(\mathrm{K}+2)=\frac{(\mathrm{b}-\mathrm{a})}{2 \mathrm{Z}} \mathrm{z}^{2}+\mathrm{a} \mathrm{z}
$$

Determinam-se as forças F(z) em cada camada e faz-se a somatória, acumulando-os;

Um caso particular de (1) fazendo $z=Z=D i s t ~(K+1, C)$, ou seja espessura da camada, tem-se:

$\mathrm{F}(\mathrm{z})=\mathrm{F}(\mathrm{Z})=\left[\frac{(\mathrm{b}-\mathrm{a})}{2}+\mathrm{a}\right] \mathrm{Z}$

No algoritmo da subrotina ESTACA pode ser escrito:

Force $(K+2)=\left[\frac{\operatorname{Coef}(K+1)}{2}+F(C, 2 * K+1)\right] \operatorname{Dist}(K+1, C)+$ Force $(K+1)$

Sendo Force $(\mathrm{K}+1)$, a força acumulada na extremidade inferior da camada $\mathrm{K}+1$, que está imediatamente acima da camada $\mathrm{K}+2$ e será adicionado para acumular .

A expressão de $\mathrm{F}(\mathrm{z})$ dentro da camada $\mathrm{K}+1$ é:

$\mathrm{F}(\mathrm{z})=\frac{(\mathrm{b}-\mathrm{a})}{2 * \mathrm{Z}} * z^{2}+\mathrm{a} * \mathrm{z}=\frac{\operatorname{Coef}(\mathrm{K}+1)}{2 * \operatorname{Dist}(\mathrm{K}+1, \mathrm{C})} * z^{2}+\mathrm{F}(\mathrm{C}, 2 * \mathrm{~K}+1) * \mathrm{z}$

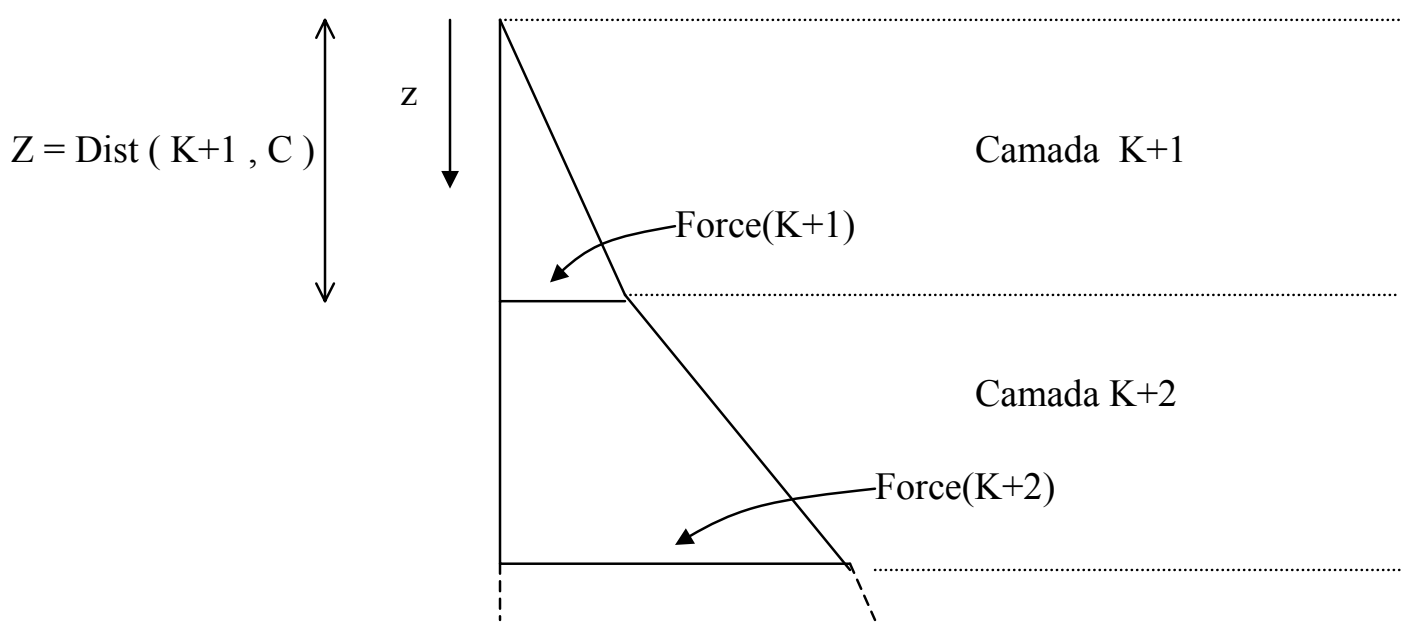




\section{2 ) Diagrama de esforços normais na estaca}
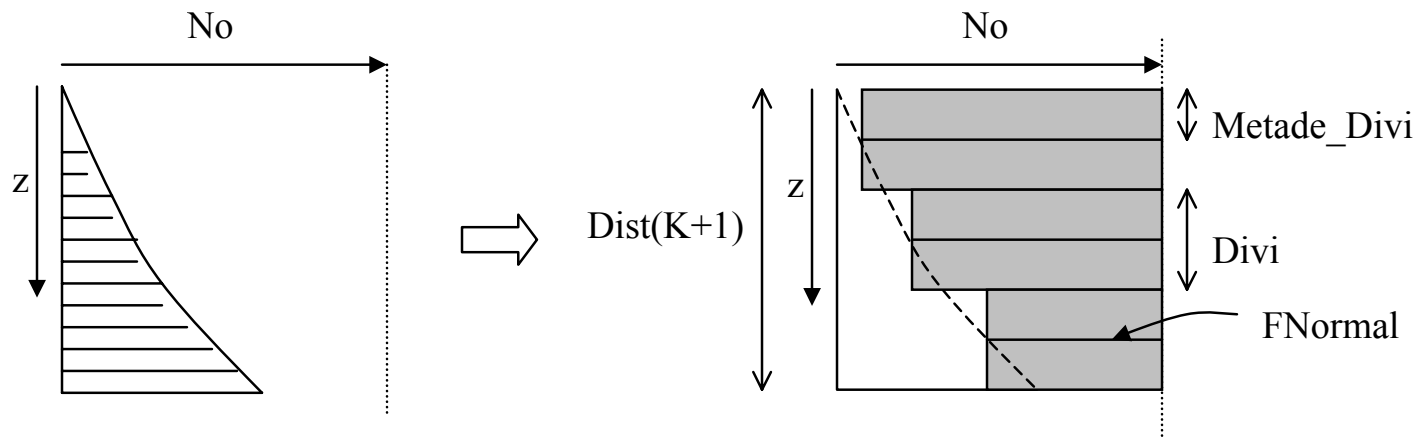

$\mathrm{Z}=$ Metade_Divi, até ( Dist - Metade_Divi ), passo Divi

$\mathrm{Na}$ camada inicial, no caso $\mathrm{K}+1$ é :

FNormal $=$ No $-\frac{\text { Coef }(\mathrm{K}+1)}{2 * \operatorname{Dist}(\mathrm{K}+1)} * \mathrm{Z}^{2}+\mathrm{F}(\mathrm{C}, 2 * \mathrm{~K}+1)$

A partir da segunda camada $\mathrm{K}+2$, deve-se descontar os acúmulos Force $(\mathrm{K}+1)$ anterior:

FNormal=No $-\frac{\text { Coef }(\mathrm{K}+1)}{2 * \operatorname{Dist}(\mathrm{K}+1)} * Z^{2}+\mathrm{F}(\mathrm{C}, 2 * \mathrm{~K}+1)-$ Force $(\mathrm{K}+1)$

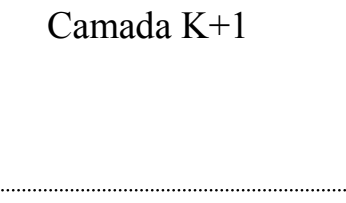

Camada $\mathrm{K}+2$

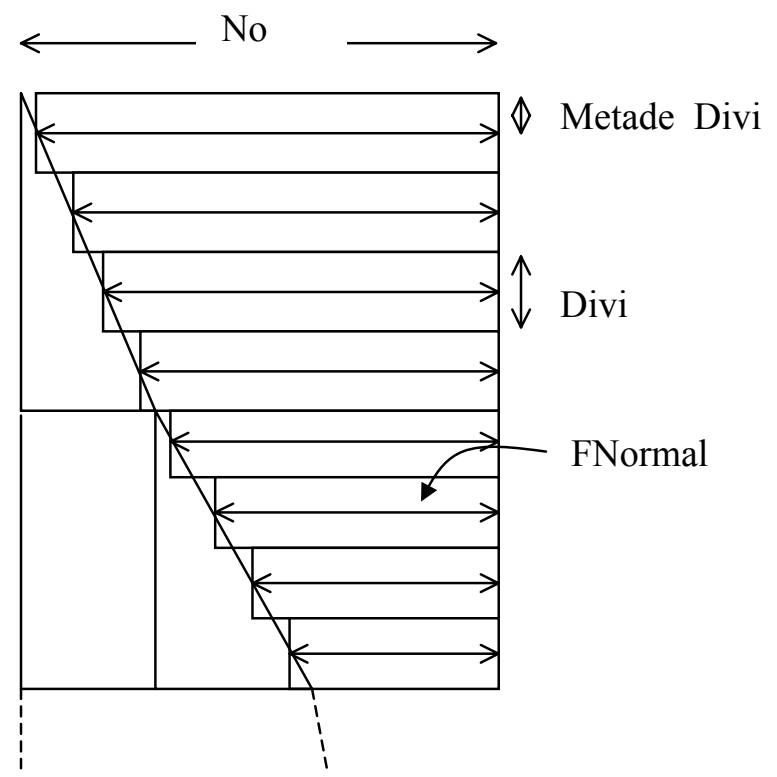

Determina-se, se houver, a parcela da carga que passa para a base da estaca:

Carga $(\mathrm{C})=\mathrm{No}(\mathrm{C})-$ Force $(\mathrm{PO}(\mathrm{C}, 8)+1)$

Onde: $\quad \operatorname{No}(\mathrm{C})$ é a carga aplicada no topo da estaca $\mathrm{C}$

Force $(\mathrm{PO}(\mathrm{C}, 8)+1)$ é força acumulada no nível da base da estaca $\mathrm{C}$ 
Deformação elástica da estaca na compressão axial: $\quad \delta=\frac{1}{\mathrm{AE}} \sum_{\mathrm{i}} \mathrm{N}_{\mathrm{i}} \mathrm{L}_{\mathrm{i}}$

A parcela $\sum_{\mathrm{i}} \mathrm{N}_{\mathrm{i}} \mathrm{L}_{\mathrm{i}}$ da equação pode ser calculado pelo seguinte algoritmo:

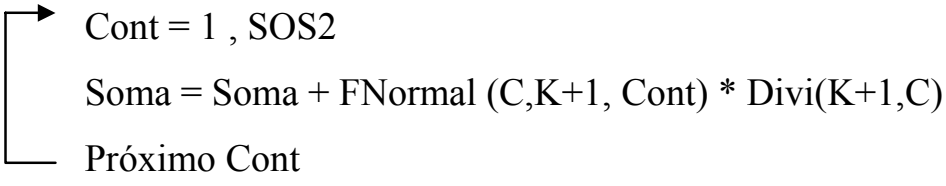

Acumulo $=$ Acumulo + Soma

Onde: $\quad$ C é o índice da estaca

K é o índice da camada

Cont é o contador para percorrer as camadas divididas

Acumulo são os valores de $\sum_{\mathrm{i}} \mathrm{N}_{\mathrm{i}} \mathrm{L}_{\mathrm{i}}$ para cada camada de solo

$\operatorname{Deform}(\mathrm{C})=\frac{\text { Acumulo }}{\left[\pi\left(\frac{\text { Diametro }(\mathrm{C})}{2}\right)^{2} \operatorname{Elast}(\mathrm{C})\right]}$

Onde: $\quad$ Diametro( $\mathrm{C}$ ) é o diâmetro do fuste da estaca C

Elast( C ) é o módulo de elasticidade da estaca C

O algoritmo elaborado neste trabalho admite-se constante o diâmetro da estaca ao longo do seu comprimento, portanto não se aplica para o caso de estacas de seção variável ao longo do fuste. 


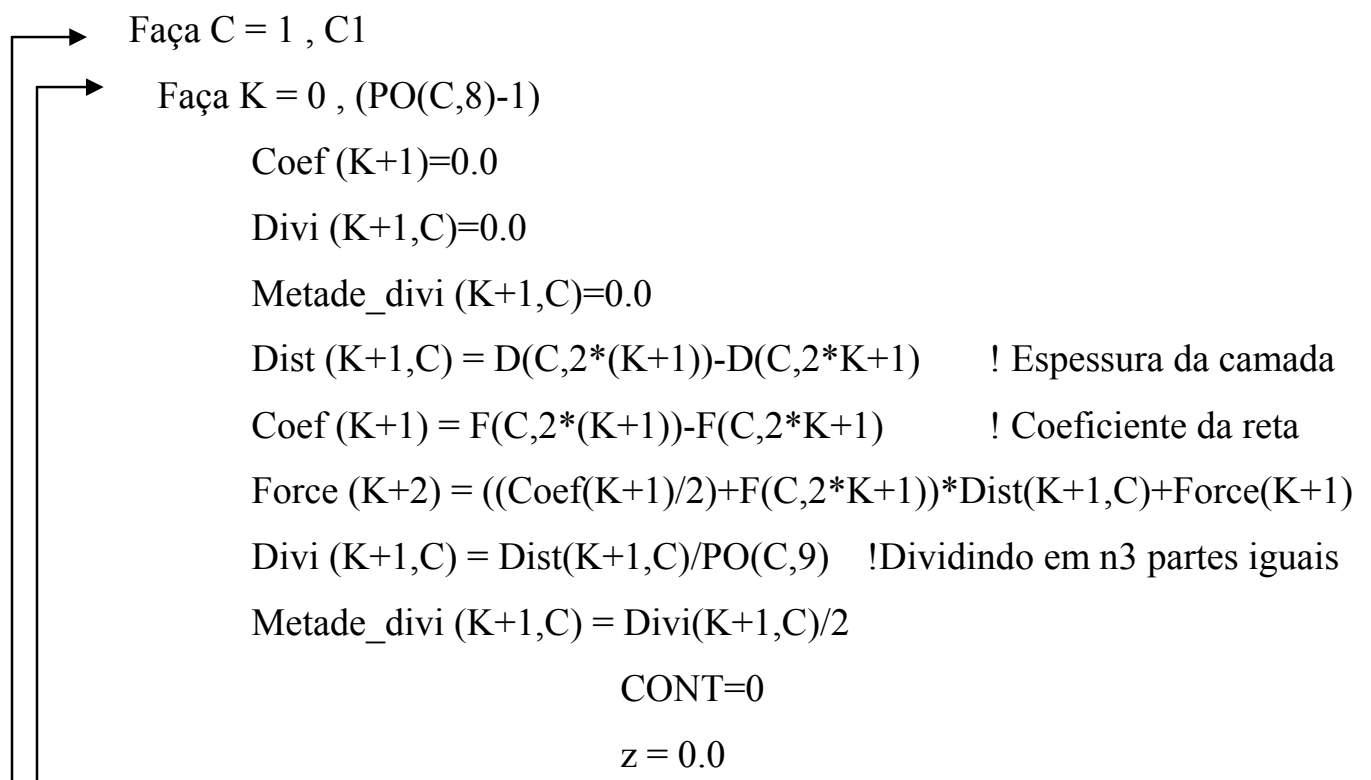

$\rightarrow$ Faça $\mathrm{z}=$ Metade_divi $(\mathrm{K}+1, \mathrm{C}),(\operatorname{Dist}(\mathrm{K}+1, \mathrm{C})-$ Metade_divi $(\mathrm{K}+1, \mathrm{C})), \operatorname{Divi}(\mathrm{K}+1, \mathrm{C})$

$\mathrm{CONT}=\mathrm{CONT}+1$

FNormal $(\mathrm{C}, \mathrm{K}+1, \mathrm{CONT})=\operatorname{Norm}(\mathrm{C})-\left((\operatorname{Coef}(\mathrm{K}+1) /(2 * \operatorname{Dist}(\mathrm{K}+1, \mathrm{C}))) * \mathrm{z}^{2}+\right.$

$\mathrm{F}(\mathrm{C}, 2 * \mathrm{~K}+1) * \mathrm{Z})$-Force $(\mathrm{K}+1)$

Quando a carga da estaca não atinge até a base

Se FNormal $(\mathrm{C}, \mathrm{K}+1, \mathrm{CONT}) \leq 0$ então faça

$$
\operatorname{FNormal}(\mathrm{C}, \mathrm{K}+1, \mathrm{CONT})=0.0 \quad \operatorname{Normal}(\mathrm{z})=0.0
$$$$
\operatorname{PONTO}(\mathrm{C}, \mathrm{K}+1, \mathrm{CONT})=1.0
$$

Termina condição Se

$\mathrm{i}=\mathrm{D}(\mathrm{C}, 1) \quad$ ! Para incluir a cota de arrasamento

Imprimir $\mathrm{z}+\operatorname{Dist}(\mathrm{K}, \mathrm{C})+\mathrm{i}, \mathrm{FNormal}(\mathrm{C}, \mathrm{K}+1, \mathrm{CONT})$

Próximo z

Dist $(\mathrm{K}+1, \mathrm{C})=\operatorname{Dist}(\mathrm{K}+1, \mathrm{C})+\operatorname{Dist}(\mathrm{K}, \mathrm{C})$

Próximo K

Carga na base da estaca

$$
\mathrm{Carga}(\mathrm{C})=\operatorname{Norm}(\mathrm{C})-\text { Force }(\mathrm{PO}(\mathrm{C}, 8)+1)
$$

Quando a Carga na ponta da estaca é nulo

Se $\operatorname{Carga}(C) \leq 0$ então faça

$\operatorname{Carga}(\mathrm{C})=0$

Termina Condição Se

Imprimir $\mathrm{C}$, Carga $(\mathrm{C})$

Próximo C 
Deformação da estaca

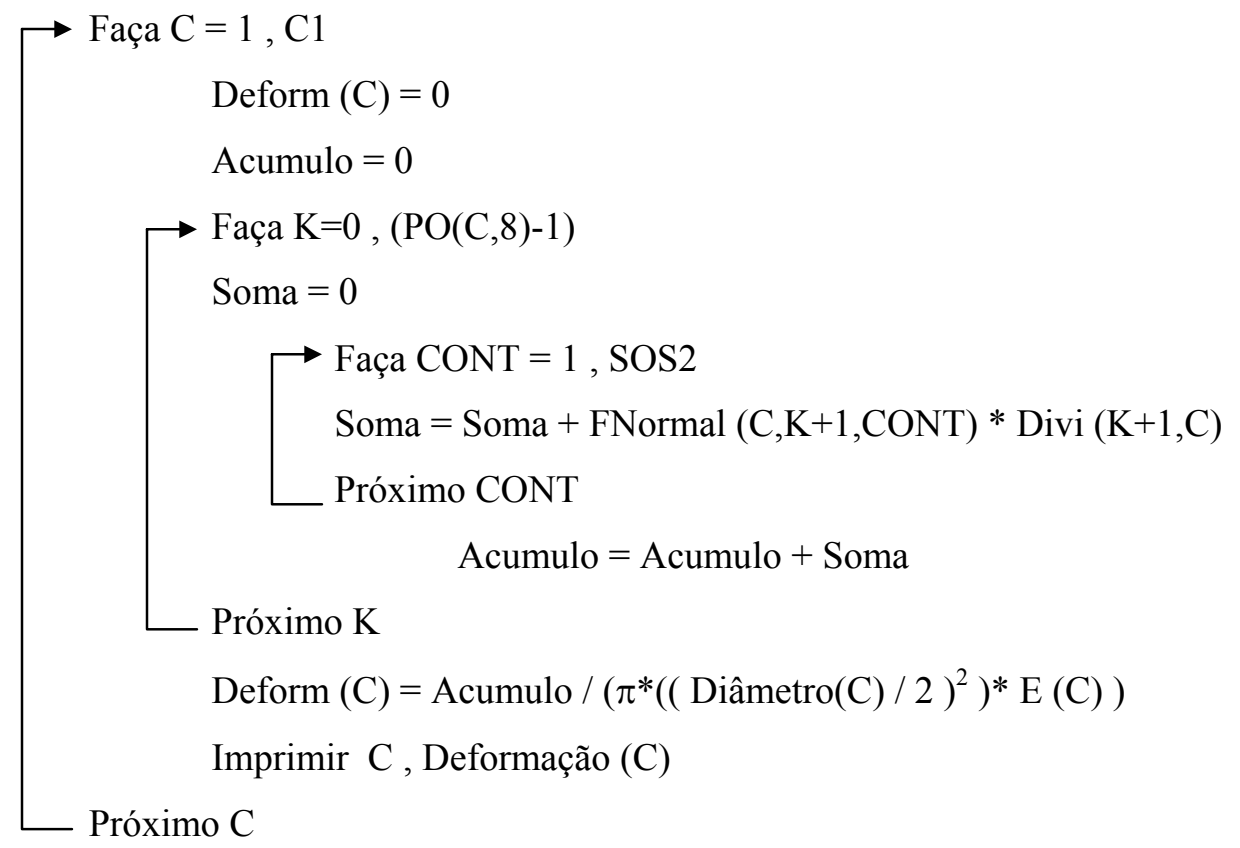




\section{Algoritmo da subrotina AOKI-LOPES}

Como o modelo de transferência de carga adotado admite-se que a carga na base da estaca só é despertado após a total mobilização da ruptura lateral PL e que, durante $\mathrm{N}_{\mathrm{i}}<\mathrm{PL}$ a carga é transmitida ao longo do fuste parcialmente (modelo a); uma maneira dessa representação no algoritmo é identificar a profundidade $\mathrm{z}$ onde, $\mathrm{N}_{\mathrm{i}}-\mathrm{PL}(\mathrm{z})=0$ e este será a condição para tornar nula a aplicação de cargas abaixo do nível z

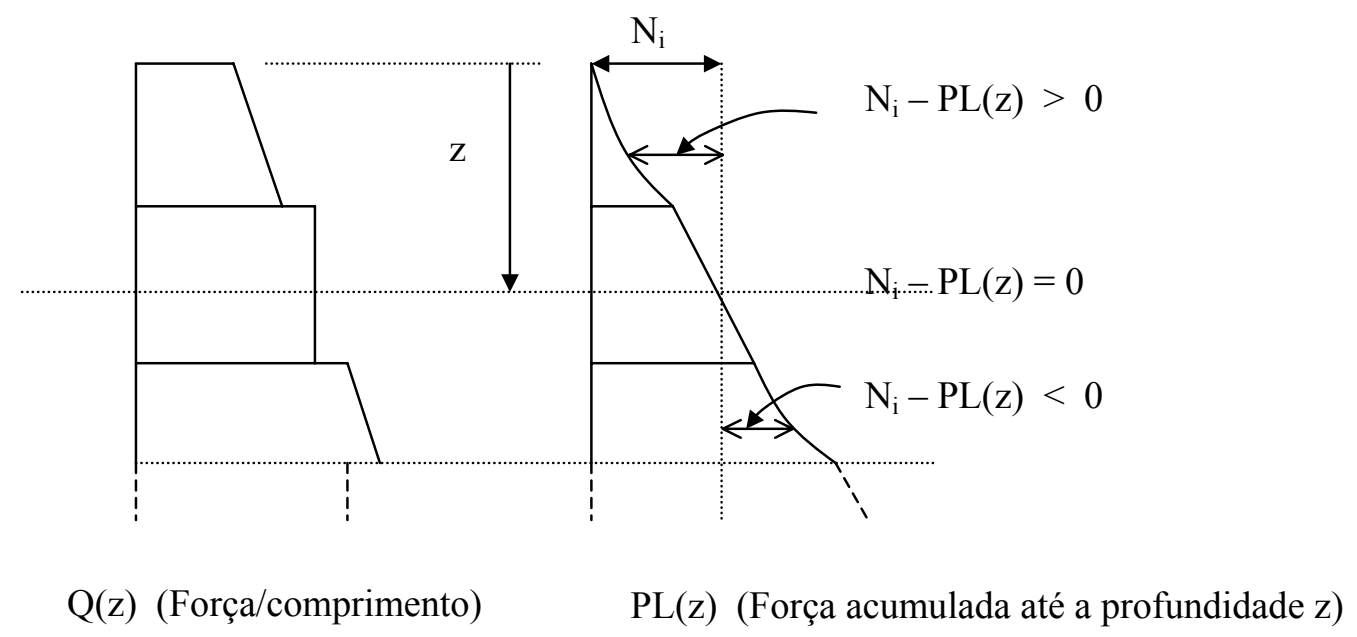

$$
\begin{array}{|c}
\longrightarrow \text { Faça } \mathrm{C}=1, \mathrm{C} 1 \text { (número de estacas) } \\
\begin{array}{c}
\text { * Faça } \mathrm{G}=1, \mathrm{C} 2 \text { (número de pontos onde se quer recalques) } \\
\mathrm{P}=\frac{\mathrm{P}_{\mathrm{b}}}{\mathrm{n}_{1} \mathrm{n}_{2}} \\
\mathrm{Ro}=\left[\left(\mathrm{X}_{\mathrm{A}}-\mathrm{X}_{\mathrm{B}}\right)^{2}+\left(\mathrm{Y}_{\mathrm{A}}-\mathrm{Y}_{\mathrm{B}}\right)^{2}\right]^{1 / 2} \\
\theta=\left(\frac{180}{\mathrm{n}_{1}}\right)^{o}=\left(\frac{\pi}{\mathrm{n}_{1}}\right) \mathrm{rad} \\
\alpha_{2}=\operatorname{arctg} \frac{\mathrm{X}_{\mathrm{A}}-\mathrm{X}_{\mathrm{B}}}{\mathrm{Y}_{\mathrm{A}}-\mathrm{Y}_{\mathrm{B}}} \\
\mathrm{A} 1=\frac{2 \operatorname{sen} \theta}{3 \theta} \frac{\mathrm{R}_{\mathrm{b}}}{\sqrt{\mathrm{n}_{2}}}
\end{array}
\end{array}
$$




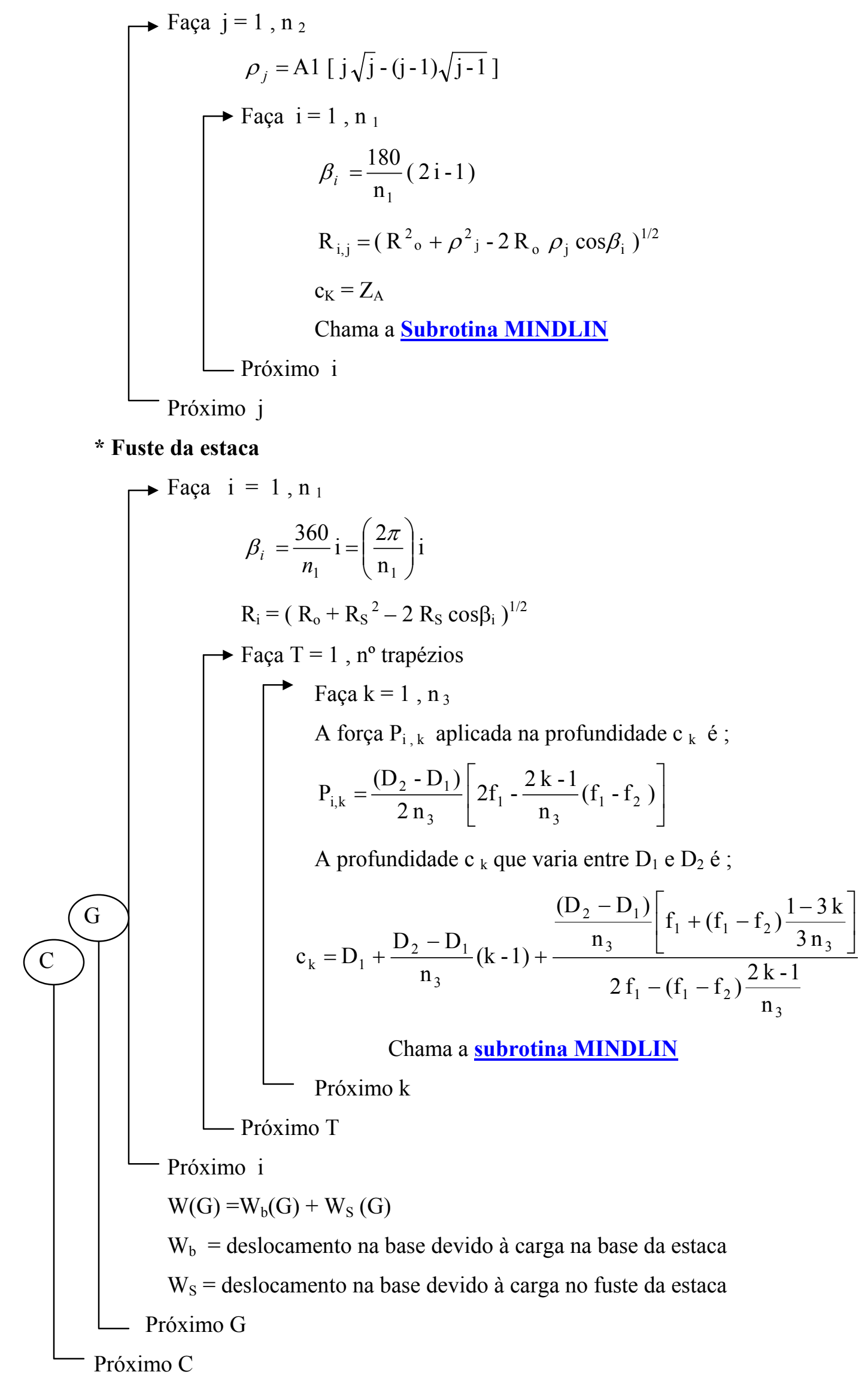


Subrotina MINDLIN (Solução de Mindlin e procedimento de Steinbrenner)

Faça G1 = 1, NCamadas

Condição para considerar $\mathrm{n}$ camadas abaixo da base da estaca

Se $\mathrm{z}<$ Profundidade da camada G1 Então faça

$\longrightarrow$ Faça $\mathrm{K}=\mathrm{G} 1$, NCamadas

$\rightarrow$ Faça $\mathrm{L}=\mathrm{K}, \mathrm{K}+1$

$$
\begin{aligned}
& R_{1}=\sqrt{R_{i, j}^{2}+\left(z_{B}-c_{K}\right)^{2}} \\
& R_{2}=\sqrt{R_{i, j}^{2}+\left(z_{B}+c_{K}\right)^{2}} \\
& r_{z}(L)= \frac{P(1+v)}{8 \pi E(1-v)}\left[\frac{3-4 v}{R_{1}}+\frac{8(1-v)^{2}-(3-4 v)}{R_{2}}+\frac{(z-c)^{2}}{R_{1}^{3}}+\right. \\
&\left.+\frac{(3-4 v)(z+c)^{2}-2 c z}{R_{2}^{3}}+\frac{6 c z(z+c)^{2}}{R_{2}^{5}}\right]
\end{aligned}
$$

Simplificação de STEINBRENNER

$\Delta \mathrm{r}=\mathrm{r}_{\mathrm{z}}(\mathrm{L})-\mathrm{r}_{\mathrm{z}}(\mathrm{L}-1)$

- Próximo L

Se for devido a base:

$$
\mathrm{W}_{\mathrm{b}}(\mathrm{G})=\mathrm{W}_{\mathrm{b}}(\mathrm{G})+\Delta \mathrm{r}
$$

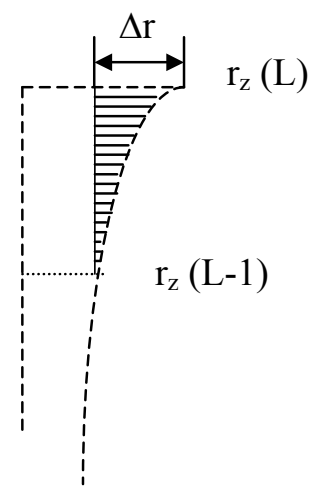

Próximo K

Termina condição Se

Próximo G1

Sendo:

$\mathrm{z}=$ profundidade onde pretende-se obter deslocamento vertical devido a força $\mathrm{P}$

$\mathrm{c}=$ profundidade onde atua uma força concentrada $\mathrm{P}$ vertical no meio elástico 


\section{REFERÊNCIAS BIBLIOGRÁFICAS}

AlBIERO, J. H.; CARVAlHO, D.; LOBO, A. S. (1993). Fundações. Capítulo 9 da Publicação "Solos no interior de São Paulo. Mesa redonda. Escola de Engenharia de São Carlos - Universidade de São Paulo.

ALONSO, U. R. (1983). Exercícios de fundações, Editora Edgard Blücher LTDA.

ALONSO, U. R. (1991). Previsão e controle das fundações, editora Edgard Blücher LTDA.

ANTUNES, H. M. C. C. (1978). Carregamento crítico de instabilidade geral pra estruturas tridimensionais de edificios altos. São Carlos. Tese ( Doutorado) - Escola de Engenharia de São Carlos - Universidade de São Paulo.

ANTUNES, H. M. C. C.; BEZERRA, D. P. (1995). Estudo da contribuição da laje na distribuição de esforços em estruturas de edificios altos. In: JORNADAS SUDAMERICANAS DE INGENIERIA ESTRUCTURAL, Tucumán, Argentina. Memorias.

ANTUNES, H. M. C. C.; MARTINS, C. H. (1998). Second order analysis of tall buildings considering the contribution of the transverse stiffness of the slabs. In: 4 TH. CONF. ON COMPUTATIONAL STRUCTURES TECHNOLOGY, Edinburgh, Escócia. Anais.

AOKI, N.; VELLOSO, D. A. (1975). An aproximate method to estimate the bearing capacity of piles. In: V TH PAN AMERICAN CONFERENCE ON SOIL MECHANICS AND FOUNDATION ENGINEERING, Buenos Aires, Tomo I, p.367-376.

AOKI, N.; LOPES, F. R. (1975). Estimating stress and settlements due to deep foundation. In: V TH PAN AMERICAN CONFERENCE ON SOIL MECHANICS AND FOUNDATION ENGINEERING, Buenos Aires, Tomo I, p.377-386.

AOKI, N. (1979). Considerações sobre projeto e execução de fundações profundas. Seminário de Fundações, Sociedade Mineira de Engenharia, Belo Horizonte. 
AOKI, N. (1985). Considerações sobre previsão e desempenho de alguns tipos de fundações profundas sobre ação de cargas verticais. In: SIMPÓSIO TEORIA E PRÁTICA DE FUNDAÇÕES PROFUNDAS. Outubro de 1985. Porto Alegre - Brasil.

AOKI, N. (1985). Prática de Fundações em Estacas pré - moldadas em terra. Palestra proferida no Curso "Pile Foundation for Offshore Structures", COPPE Coordenação Programas Pós - Graduação, Engenharia - UFRJ, Rio de Janeiro.

AOKI, N. (1987). Modelo simples de transferência de carga de estaca vertical sujeita a carga axial de compressão. III Ciclo de palestras sobre Engenharia de Fundações, ABMS/NR Nordeste, Recife.

AOKI, N.; CINTRA, J. C. (1996). Influência da variabilidade do maciço de solos no comprimento de estacas. $3^{\circ}$ Seminário de Engenharia de Fundações Especiais e Geotecnia, v. I - São Paulo. Novembro, ABEF/ABMS-SP.

AOKI, N. (1997). Aspectos geotécnicos da interação estrutura - maciço de solos. In: XXVIII JORNADAS SUL - AMERICANAS DE ENGENHARIA ESTRUTURAL, Vol. 1. São Carlos.

AOKI, N. (2000). Comunicação pessoal.

AOKI, N.; CINTRA, J. C. A. (2000). Comunicação pessoal

ASSOCIAÇÃO BRASILEIRA DE NORMAS TÉCNICAS (1978). NBR- 6118 - Projeto e execução de obras de concreto armado. Rio de Janeiro.

ASSOCIAÇÃO BRASILEIRA DE NORMAS TÉCNICAS (1980). NBR-6123. Ações devidas ao vento em edificações. Rio de Janeiro.

BARATA, F. E. (1986). Recalques de edifícios sobre fundações diretas em terrenos de compressibilidade rápida e com consideração da rigidez da estrutura. Rio de Janeiro. Tese de concurso para professor Titular do Departamento de Construção Civil do Setor de Geomecânica da EEUFRJ. 
BECKER, E. P. (1989). Edificios altos: interação tridimensional das peças de contraventamento. Dissertação (Mestrado) - Escola de Engenharia de São Carlos, Universidade de São Paulo.

BEZERRA, D. P. (1995). Análise de estruturas tridimensionais de edifícios altos considerando a rigidez transversal à flexão das lajes. São Carlos. Dissertação (Mestrado) - Escola de Engenharia de São Carlos, Universidade de São Paulo.

BROWN, P.; YU, S. K. R. (1986). Loads sequence and structure - foundation interaction. Journ. Structural Engineering. v.112, n.3, Março.

CHAMECKI, S. (1956). Structural rigidity in calculating settlements, Journal of Soil Mechanics and Foundation Division, ASCE, v.82, n.SM-1, p.1-19.

CHAMECKI, S. (1958). Novo conceito de recalque diferencial admissivel. In: II CONGRESSO BRASILEIRO DE MECÂNICA DOS SOLOS v.I, Recife - PE. Anais.

CHAMECKI, S. (1969). Calcul des tassements progressifs des foundations en tenant compte de l'interaction des structures et du sol, Annales de l'ITBTP, $\mathrm{n}^{\circ} .261$.

CINTRA, J. C. A. (1998). Fundações em solos colapsíveis. Publicações do projeto REENGE, Escola de Engenharia de São Carlos - Universidade de São Paulo.

CHOW, Y. K. (1985). Analysis of vertically loaded pile groups. Int. Journ. Num. Anal. Methods Geomech. (in press - apud CHOW(1985a))

CHOW, Y. K. (1986a). Analysis of vertically loaded pile groups. Intern. Journ. For Num. And Analytical Methods in Geomechanics. v.10, p.59-72.

CHOW, Y. K. (1986b). Discrete element analysis of settlement of pile groups. Computers \& Structures. v.24. n.1, p.157-166.

CHOW, Y. K . (1987). Three - dimensional analysis of pile groups. Journ. Geotechnical Engineering, Div., ASCE, v. 113, n.6, Junho, p.637-651 
DO VAL, E. C.; DE MELLO, L. G. F. S. (1986). Estimativa da contribuição do bloco na capacidade de carga de grupo de estacas. In: VIII CONGRESSO BRASILEIRO DE MECÂNICA DOS SOLOS E ENGENHARIA DE FUNDAÇÕES, 12-16 de Outubro, Porto Alegre, p.297-307.

FERREIRA, C. V. (1991). Caracterização geotécnico do solo de uma área da cidade de Bauru - SP. São Carlos. Dissertação (Mestrado). Escola de Engenharia de São Carlos - Universidade de São Paulo.

FERRO, N. C. P.; VENTURINI, W. S. (1995). Estudos de efeitos de segunda ordem em estruturas de edifícios considerando-se a ligação elástica com o semi - espaço infinito. In: XXVII JORNADAS SUDAMERICANAS DE ENGENIERIA ESTRUCTURAL, Tucumán, Argentina.

FONTE, A. O. C.; JUCÁ, J. F. T.; PONTES FILHO, J. D. S (1994). Interação soloestrutura em edificios altos. XCOBRAMSEF / $1^{\circ} \mathrm{SBMR}$

FONTE, A. O. C.; JUCÁ, J. F. T.; PONTES FILHO, J. D. S. (1994). Building perfomance founded on an improved sand in Recife, Brazil, Geotecnical Special Publication no. 40, ASCE, v.2, p.1202-1213.

GOMES, R. C. (1986). Análise do comportamento carga - recalque e metodologias de controle na implantação de estacas cravadas. Dissertação de Mestrado. COPPE UFRJ.

GOSCHY, B. (1978). Soil - foundation - structure interaction. Journ. Strusctural Division ASCE, v.104, ST-5, p. 749-761 .

GUSMÃO, A. D.; LOPES, F. R. (1990). Um método simplificado para consideração da interação solo - estrutura em edificações. In: $6^{\circ} \mathrm{CBGE} / \mathrm{IX}$ COBRAMSEF Salvador.

GUSMÃO, A. D.; LOPES, F. R. (1991). On the influence of soil - structure interaction in the distribution of foundation loads and settlements. X ECSMFE Deformation of Soil and Displacements of Structures, Vol II. Firenze - Itália. 
GUSMÃO, A. D.; GUSMÃO FILHO, J. A. (1994). Avaliação da influência da interação solo - estrutura. In. X COBRAMSEF, Foz de Iguaçu, PR, ABMS. Anais, Vol.1, p. 68-74.

GUSMÃO, A. D. (1994). Aspectos relevantes da interação solo - estrutura em edificações . Solos e Rochas, São Paulo, v.17, n.1, p.47- 55.

GUSMÃO FILHO, J. A. (1995). Contribuição à prática de fundações: a experiência do Recife. Tese para concurso de Professor Titular. Escola de Engenharia de Pernambuco / Universidade Federal de Pernambuco.

GWIZDALA, K. (1997). Polish design methods for single axially loaded piles. Design of Axially Loadede Piles- European Practice, Balkema, Rotterdam.

HOLANDA JÚNIOR, O. G. (1998). Interação solo - estrutura para edificios de concreto armado sobre fundações diretas. São Carlos. Dissertação (Mestrado) - Escola de Engenharia de São Carlos, Universidade de São Paulo.

KUSAKABE, O. et al. (1989). Report on questionnaire: Prediction of bearing capacity and driveability of piles. In: PROCEEDINGS OF THE TWELFTH INTERNATIONAL CONFERENCE ON SOIL MECAHNICS ANDA FOUNDATION ENGINEERING., Rio de Janeiro, 13 - 18 Agosto. p.2957-2962.

LEE, C. Y. ; POULOS , H. G. (1990). Axial response analysis of piles in vertically and horizontally non - homogeneous soils . Computers and Geotechnics n.9, p.133-148.

LOBO, A. S.; FERREIRA, C. V.; ALBIERO, J. H. (1994). Comportamento de tubulões através da medida de recalques de um edifício no interior de São Paulo. In:. COBRAMSEF, 10, v.1, p. 135-142, Foz do Iguaçu.

LOBO, A. S.; FERREIRA, C. V.; ALBIERO, J. H. (1996). Recalques de tubulões na cidade de Bauru. Revista de Engenharia e Ciências Aplicadas. Vol. 3, Editora da UNESP. 
LOBO, A. S.; FERREIRA, C. V.; ALBIERO, J. H. (1997). Redistribuição de carga entre pilares de edificios durante a construção. In: JORNADAS SUL AMERICANAS DE ENGENHARIA ESTRUTURAL, XXVIII, São Carlos, 1997. Anais, São Carlos, p.1545-1554.

MARTINS, C. H. (1998). Contribuição da rigidez à flexão das lajes, na distribuição dos esforços em estruturas de edifícios de andares múltiplos, em teoria de segunda ordem. São Carlos. Dissertação (Mestrado). Escola de Engenharia São Carlos, Universidade de São Paulo.

MENDONÇA, A. V. (1997). Análise da interação placa - estaca - solo via combinação do método dos elementos finitos com elementos de contorno. São Carlos. Dissertação (Mestrado). Escola de Engenharia São Carlos, Universidade de São Paulo.

MENDONÇA, A. V.; PAIVA, J. B. (2000). A boundary element method for the static analysis of raft foundations on piles. Engng. Boundary Elements, Vol. 24, pp. 237 247.

MEYERHOF, G. G. (1953). Some Recent foundation research and its application to design. The Structural Engineering, v.31, p.151-167, Londres.

MEYERHOF, G. G. (1959). Compaction of sands and bearing capacity of piles. Journal of the Soil Mechanics and Foundation Division, v.85, SM6, p. 1-29

MINDLIN, R. D. (1936). Force at a point in the interior of a semi-infinite solid. Physics, 7, p. 195-202.

MORI, D. D. (1992). Os núcleos estruturais e a não linearidade geométrica na análise de estruturas tridimensionais de edificios altos. Tese (Doutorado) - Escola de Engenharia de São Carlos, Universidade de São Paulo.

MOURA, A. R. L. U. (1995). Interação solo - estrutura em edifícios. Recife. Dissertação (Mestrado). Centro de Tecnologia e Geociências / Universidade Federal de Pernambuco. 
MOURA, A. R. L. U. (1999). Análise tridimensional de interação solo - estrutura em edificios. SOLOS E ROCHAS, v.22, n.2, Agosto 1999.

MUQDADIR, A.; DESAI, C. S. (1986). Three - dimensional analysis of a pile - group foundation. Int. Journ. for Num. and Analiytical Methods in Geomechanics. v.10, p. 41-58.

O’ NEILL, M. W.; GHAZZALY, O I.; HA, H. B. (1977). Analysis of threedimensional pile groups with non linear response and pile - soil - pile interaction. Proc. 9 th Annual Offshore Tech. Conf., paper n. OTC 2838. (apud POLO \& CLEMENTE (1998)).

PAIVA, J. B. (1993). Formulação do método dos elementos de contorno para análise da interação solo - estrutura. Tese de Livre - docência. Escola de Engenharia São Carlos, Universidade de São Paulo.

POULOS, H. G. (1968). Analysis of the settlement of pile groups. Géotechnique, London, England, 18 (4), pp.449-471.

POULOS, H. G. (1988). Modified Calculation of Pile-Group Settlement Interaction . Journ. Geotechnical Engineering. v.114, n. 6, Junho.

POULOS, H. G. (1989). Pile behaviour - theory and application. Géotechnique, 39, n.3, p. 365-415.

POLO, J. M.; CLEMENTE, J. L. M. (1988). Pile group settlement using independent shaft and point loads. Journal of Geothecnical Engeneering Division,ASCE, v.114, n. GT4, p. 469-487.

PRUDENTE, M. (1983). Análise de estruturas tridimensionais usuais de edifícios altos. São Carlos. Dissertação (Mestrado) - Escola de Engenharia São Carlos, Universidade de São Paulo. 
RAMALHO, M. A .; CORRÊA, M. R. S. (1991). Interação solo - estrutura para edificios sobre fundação direta. In: JORNADAS SUL-AMERICANAS DE ENGENHARIA ESTRUTURAL, 25, Porto Alegre, 1991. Anais. Porto Alegre, UFRGS. v.2, p.433444.

RANDOLPH, M. F. (1994). Design methods for pile groups anda pile rafts. In: XIII ICSMFE, New Delhi, Índia, v.5, p.61-81

REIS, J. H. C. (2000). Interação solo - estrutura de grupo de edificios em fundações superficiais em argila mole. São Carlos. Dissertação (Mestrado). Escola de Engenharia de São Carlos, Universidade de São Paulo.

REZENDE, M. E. B. (1995). Análise de recalques de grupos de estacas escavadas de pequeno diâmetro através de provas de carga in situ e em modelos centrifugados. São Carlos, 257 p. Tese (Doutorado). Escola de Engenharia de São Carlos, Universidade de São Paulo.

RIOS, B. M. C. (1991). Análise tridimensional e envoltória de esforços em edificios altos sujeitos à ações verticais e horizontais. São Carlos. Dissertação (Mestrado). Escola de Engenharia São Carlos, Universidade de São Paulo.

ROSEN, R.; RUBINSTEIN, M. F. (1970). Substructure analysis by matrix decomposition. Journal of the Structural Division, ASCE, v.3, p. 663-670.

SAYEGH, A. F.; TSO, F. K. (1988). Analysis of linear on nonlinear pile foundation. Computers \& Structures, v. 29, n. 4, p. 633-643.

SCHIEL, F. (1957). Estática de estaqueamento. Publicação n n 10, Escola de Engenharia de São Carlos, Universidade de São Paulo. 142p.

SKEMPTON, A. W. (1953). Discussion: Piles and pile foundation settlement of pile foundation. In: III ICSMFE, Zurich, p. 172. 
SOUSA JUNIOR, E. (1996). Um aplicativo para o ambiente Windows para aquisição de dados para a análise de pavimentos de edifícios via método dos elementos finitos. São Carlos. Dissertação (Mestrado). Escola de Engenharia São Carlos, Universidade de São Paulo.

SOWERS, G. F.; MARTIN, C. B.; WILSON, L. L. (1961). The bearing capacity of friction pile groups in homogeneous clay from model studies. In: V ICSMFE, Paris, p.155159.

STAMATO, M. C. (1971). Cálculo elástico de estaqueamento. Publicação no 70, Escola de Engenharia de São Carlos, Universidade de São Paulo. 86p.

TERZAGHI, K.; PECK, R. B. (1967). Soil Mechanics in Engineering Practice, 2ª Ed., John Wiley and Sons, New York.

TOMLINSON, M. J. (1986). Foundation Design and Construction. 5 th. Ed. Harlow: Longman Scientifc and Technical.

VARGAS, M.; SILVA, F. P. (1973). O problema das fundações de edifícios altos Experiência de São Paulo e Santos. Conferência Regional Sul Americana Sobre Edifícios Altos. Porto Alegre.

VESIC, A. S. (1969). Experiments with instrumented pile groups in sand. In: SYMPOSIUN ON PERFOMANCE OF DEEP FOUNDATIONS, Proc. ASTM, Spec. Tech. Pub. n. 444, p.171-222.

VESIC, A. S. (1975). Principles of pile foundation design. SM n. 38, Duke University.

VESIC, A. S. (1977). Problems of development of a mathematical model to predict perfomance of a pile group. Working paper preparede for the Federal Highway Administration Research Review Conference. Atlanta, George.

YAMASHITA, K.; TOMONO, M.; KAKURAI, M. (1987). Method for estimating immediate settlement of piles and pile groups. Soil and Foundations . Vol. 27, No.1, 61-76. Março. 
WHITAKER, T. C. (1957). Experiments with model piles in groups. Géocechnique, v.7, n.4, p.147-167.

\section{BIBLIOGRAFIA CONSULTADA}

ALONSO, U. R. (1989). Dimensionamento de fundações profundas, Editora Edgard Blücher LTDA .

ANTUNES, H. M. C. C.; SOUZA, J. C. A. O. (1976). Estática das estruturas (temas complementares). São Carlos. Publicação 045/92. Escola de Engenharia de São Carlos, Universidade de São Paulo.

ANTUNES, H. M. C. C.; IWAMOTO, R. K. (2000). A importância da consideração da interação solo - estrutura para edifícios de múltiplos andares. [CD-ROM]. In: CONGRESSO BRASILEIRO DO CONCRETO, 42., Fortaleza, 13-18 agosto 2000. São Paulo, IBRACON, 2000. 11p.

ANTUNES, H. M. C. C.; IWAMOTO, R. K. (2000). Considerações sobre a interação soloestrutura em edifícios de múltiplos andares com fundação profunda. [CD-ROM]. In: JORNADAS SUDAMERICANAS DE ENGENIERÍA ESTRUCTURAL, 29. / JUBILEO PROF. JULIO RICALDONI, Punta Del Este, Uruguay, 13-17 noveimbre, 2000. Memorias Montevideo, Instituto de Estructuras y Transportes / ASAIE, 2000. 21p. ( a ser publicado).

ANTUNES, H. M. C. C.; IWAMOTO, R. K. (2000). Comparação entre resultados observados in situ e modelos numéricos para a interação estrutura - solo. [CDROM]. In: SIMPÓSIO INTERAÇÃO ESTRUTURA -SOLO EM EDIFÍCIOS, São Carlos, 27-28 nov.2000. Artigos completos. São Carlos, EESC - Programa de PósGraduação em Geotecnia e Engenharia de Estruturas, 2000. 19p. 
ANTUNES, H. M. C. C.; IWAMOTO, R. K. (2000). Um modelo numéricos de interação solo - estrutura em edifícios de múltiplos andares com fundação profunda [CDROM]. In: IBERIAN LATIN-AMERICAN CONGRESS ON COMPUTATIONAL METHODS IN ENGINEERING, 21. (CILAMCE 2000), Rio de Janeiro, December 6-8, 2000. Rio de Janeiro, PUC-Rio, 2000. 17p.

ASSOCIAÇÃO BRASILEIRA DE NORMAS TÉCNICAS (1984). NBR-8681 - Ações e segurança nas estruturas. Rio de Janeiro.

ASSOCIAÇÃO BRASILEIRA DE NORMAS TÉCNICAS (1996). NBR-6122. Projeto e execução de Fundações. Rio de Janeiro.

BUTERFIELD, R.; BANERJEE, P. K. (1971). The problem of pile group-pile cap interaction. Geotechnique, vol. 21, n.2, p.135-142.

CAPUTO, H. P. (1988). Mecânica dos solos e suas aplicações. Vol. 2, 6a edição. Livros Técnicos e Científicos Editora S.A. Rio de Janeiro.

CAPUTO, H. P. (1987). Mecânica dos solos e suas aplicações. V. 3, 4ª edição. Livros Técnicos e Científicos Editora S.A. Rio de Janeiro.

CLEMENTE, J. L. M. (1988). Analysis of Pile groups with variable shaft - load point - load ratios. Journ. Geotechnical Engineering. v. 116, n. 4, Abril.

CLEMENTE, J.L. M. (1989). Nonlinear analysis of settlement and load distribution in pile groups. Computers \& Strusctures. v. 36, n.2, p. 203-210.

CLEMENTE, J. L. M.; POLO, J. M. (1988). Micro - computer analysis of pile groups settlement using independent point and shaft loads. Computers \& Structures. v.29, n.2, p. 241-255.

CLEMENTE, J. L. M.; POLO, J. M. (1988). Pile - group settlement using independent shaft and point loads. Journ. Geotechnical Engineering. v.114, n.4, Abril. 
CHOW, Y. K. (1991). Pile - cap - pile - group interaction in nonhomogeneous soil. Journal of Geotecnical Engineering, v.117, n.11, p.1655-1668.

DULÁCSKA, E. (1992). Soil settlement effects on buildings. Developments in Geotechnical Engineering, 69. Elsevier.

GERE, J. M.; WEAVER Jr., W. (1981). Análise de estruturas reticuladas. Ed. Guanabara Dois, Rio de Janeiro.

KOERNER, R. M. \& PARTOS,A. (1974). Settlement of building on pile foundation in sand. Journ. Geotechnical Engineering Division. v. 100, n. GT3, Março.

LEE, I. K.; BROWN, P. T. (1972). Structure - foundation interaction analysis. Journ. Structural Division. v.98, n. ST11, Novembro.

LEE,C.Y. (1993). Settlement of pile groups - pratical approach. Journal of Geotechnical Engineering. v.119, n.9, Setembro.

LEE,C.Y. (1993). Pile group settlement analysis by hybrid layer approach. v .119, n.6, Junho.

MAJIMA, M.; ENAMI, A.; NAGAO, T.; WAKAME, Y. (1995a). Settlement behavior of a tall building supported by friction piles. Part -1 , Observation results and its consideration.. Journ. Struct. Constr. Eng., AIJ, n.467, p.83-92, Jan. (in japanese)

MAJIMA, M.; ENAMI, A.; NAGAO, T.; WAKAME, Y. (1995b). Settlement behavior of a tall building supported by friction piles. Part - 2, Analysis of ground and foundation settlement. Journ. Struct. Constr. Eng., AIJ, n.474, p.97-105, Aug.. (in japanese)

MENDONÇA, J. C. (2000). Um modelo computacional de análise da interação estrutura maciço de solos em edifícios. São Carlos. Dissertação (Mestrado). Escola de Engenharia de São Carlos, Universidade de São Paulo.

MEYERHOF, G. G. (1947). The settlement analysis of buildng frames. The Structural Engineering, v. 25, p. 369. 
MIYAHARA, F.; ERGATOUDIS, J. G. (1976). Matrix analysis of structure - foundation interaction. Journ. Structural Division . v. 102. n. ST1, Janeiro.

O'NEILL, M. W.; MAHAR, L. J. (1982). Load transfer mechanisms in pile and pile groups. Journ. Geotechnical Engineering Division. v. 108, n. GT12, Dezembro.

OTTAVIANI, M. (1975). Three - dimensional finite element analysis of vertically loaded pile groups. Géotechnique 25, n.2, 159-174.

PINHO, C. R. A ; DE BRITO, P. S. V. (1986). TREFIC-86 Interação estrutura - solo. Trabalho Especial de Fim de Curso, IME.

POULOS, H. G. (1975). Soil-structure interaction . In: X ICSMFE, Estocolmo, ISSMFE. Proceedings. v. IV, p. 307-334.

POULOS, H. G.; PRESSLEY, J. S. (1986). Finite element analysis of mechanisms of pile group behaviour. Inter. Journ. Num. and Analytical Methods in Geomechanics. vl.10, p. 213-221

PRZEMIENIECKI, J. S. (1963). Matrix structural analysis of subestructures. AIAA Journal, v.1, n.1, p.138-147.

RANDOLPH, M. F.; WROTH, C. P. (1979). An analysis of vertical deformation of pile groups. Géotechnique, London, England, 29 (4) ,423-439

RUBINSTAIN, M. F. (1966). Matrix computer analysis of structures. Englewood Cliffs, New Jersey, Prentice-Hall. 402p.

SORIANO, H. L. (1987). Análise de estruturas reticuladas em computadores de pequeno porte. Escola de Engenharia da Universidade Federal do Rio de Janeiro. 104p.

TSUCHIYA, T.; TANIOKA, Y. (1996). A practical approach for settlement of building with friction piles. Journ. Struct. Constr. Eng., AIJ, n.489, p.33-39, Nov. (in japanese) 
VARGAS, M. (1977). Fundações de edificios. Escola Politécnica da Universidade de São Paulo.

ZAMBROZUSKI, N. J. M.; BASSIL, A. P.; GRACIO, A. M.; SALES, R. J.M.(1985). Estudo da interação estrutura - solo. Trabalho Especial de Fim de Curso, IME. 